\title{
Optimization of Mud Hammer Drilling Performance - A Program to Benchmark the Viability of Advanced Mud Hammer Drilling
}

Final Report

Reporting Period Start Date - October 1, 2000

Reporting Period End Date - September 30, 2005

Authors; $\quad$ Arnis Judzis, TerraTek

Report Date - March, 2006

DOE Award Number - DE-FC26-00NT40918

TerraTek, Inc.

1935 South Fremont Drive

Salt Lake City, UT 84104 


\section{DISCLAIMER}

This report was prepared an as account of work sponsored by an agency of the United States Government. Neither the United States Government nor any agency thereof, nor any of their employees, makes any warranty, express or implied, or assumes any legal liability or responsibility for the accuracy, completeness, or usefulness of any information, apparatus, product, or process disclosed, or represents that its use would not infringe privately owned rights. Reference herein to any specific commercial product, process, or service by trade name, trademark, manufacturer, or otherwise does not necessarily constitute or imply its endorsement, recommendation, or favoring by the United States Government or any agency thereof. The views and opinions of authors expressed herein do not necessarily state or reflect those of the United States Government or any agency thereof. 


\begin{abstract}
This document details the program results on the OPTIMIZATION OF MUD HAMMER DRILLING PERFORMANCE - A PROGRAM TO BENCHMARK THE VIABILITY OF ADVANCED MUD HAMMER DRILLING contract for the period starting October 2000 through September 2005.
\end{abstract}

\title{
Review of 2000 \\ Q4 2000
}

- Contract negotiations with Ms. Dona Sheehan were conducted and the cooperative agreement was signed. A kick-off meeting in Morgantown was scheduled with the project manager Roy Long. No other activities were conducted, as the technical portion of the project did not start.

\section{Review of 2001}

\section{Q1 2001}

- On January $9^{\text {th }}$ of 2001, details of the Mud Hammer Drilling Performance Testing Project were presented at a "kick off" meeting held in Morgantown.

- A preliminary test program was formulated and prepared for presentation at a meeting of the advisory board in Houston on the $8^{\text {th }}$ of February.

- The meeting was held with the advisory board reviewing the test program in detail.

- Consensus was achieved and the approved test program was initiated after thorough discussion.

- This new program outlined the details of the drilling tests as well as scheduling the test program for the weeks of the $14^{\text {th }}$ and $21^{\text {st }}$ of May 2001.

- All the tasks were initiated for a completion to coincide with the test schedule.

- By the end of March the hardware had been designed and the majority was either being fabricated or completed.

- The rock was received and cored into cylinders.

Q2 2001

- DOE's National Energy Technology Laboratory highlighted the Mud Hammer Project at an exhibit at the Offshore Technology Conference April 30 through May 3. TerraTek assisted NETL personnel with presentation materials appropriate for the project and a demonstration sample of 'hard rock' drilled in TerraTek's wellbore simulator.

- TerraTek has completed 13 drilling tests in Carthage Marble and hard Crab Orchard Sandstone with the SDS Digger Tool, Novatek tool, and a conventional rock bit. After some initial mud pump and flow line problems at TerraTek, we completed the testing matrix for the SDS Digger Tool and the Novatek hammer on 27 June 2001. Overall the hammers functioned properly at 'borehole' pressures up to 3,000 psi with weighted water based mud. The Department of Energy goals to determine hammer benchmark rates of penetration and ability to function at depth are being met. Additionally data on drilling intervals and rates of penetration specific to flow rates, pressure drops, rotary speed, and weights-on-bit have been given to the Industry 
Partners for detailed analysis. SDS and Novatek have gained considerable experience on the operation of their tools at simulated depth conditions. Some optimization has already started and has been identified as a result of these first tests.

Q3 2001

- TerraTek highlighted DOE's National Energy Technology Laboratory effort on Mud Hammer Optimization at the recent Annual Conference and Exhibition for the Society of Petroleum Engineers. The original exhibit scheduled by NETL was cancelled due to events surrounding the September tragedies in the US.

- TerraTek has completed analysis of drilling performance (rates of penetration, hydraulics, etc.) for the Phase One testing which was completed at the beginning of July.

- TerraTek jointly with the Industry Advisory Board for this project and DOE/NETL conducted a lessons learned meeting to transfer technology vital for the next series of performance tests. Both hammer suppliers benefited from the testing program and are committed to pursue equipment improvements and 'optimization' in accordance with the scope of work.

- An abstract for a proposed publication by the society of Petroleum Engineers/International Association of Drilling Contractors jointly sponsored Drilling Conference was accepted as an alternate paper. Technology transfer is encouraged by the DOE in this program, thus plans are underway to prepare the paper for this prestigious venue.

\section{Q4 2001}

- TerraTek provided information and a drilled hard rock sample to highlight DOE's National Energy Technology Laboratory effort on Mud Hammer Optimization at the October 2001 Annual Conference and Exhibition for the Society of Petroleum Engineers. The original exhibit scheduled by NETL was however cancelled due to events surrounding the September tragedies in the US and the rock sample was returned to TerraTek for future use by NETL.

- In accordance to Task 7.0 (D. \#2 Technical Presentations) TerraTek successfully completed the manuscript detailing phase 1 testing results for the February 2002 IADC/SPE Drilling Conference, a prestigious venue for presenting DOE and private sector drilling technology advances. The full reference is as follows:

IADC/SPE 74540 "World's First Benchmarking of Drilling Mud Hammer Performance at Depth Conditions" authored by Gordon A. Tibbitts, TerraTek; Roy C. Long, US Department of Energy, Brian E. Miller, BP America, Inc.; Arnis Judzis, TerraTek; and Alan D. Black, TerraTek. Gordon Tibbitts, TerraTek, will present the paper in February of 2002.

- PDVSA has joined the advisory board to this DOE mud hammer project and has formally committed funds (cost sharing) for the upcoming effort in testing at TerraTek.

\section{Review of 2002 Q1 2002}


- In accordance to Task 7.0 (D. \#2 Technical Publications) TerraTek, NETL, and the Industry Contributors successfully presented a paper detailing Phase 1 testing results at the February 2002 IADC/SPE Drilling Conference, a prestigious venue for presenting DOE and private sector drilling technology advances. The full reference is as follows:

IADC/SPE 74540 "World's First Benchmarking of Drilling Mud Hammer Performance at Depth Conditions" authored by Gordon A. Tibbitts, TerraTek; Roy C. Long, US Department of Energy, Brian E. Miller, BP America, Inc.; Arnis Judzis, TerraTek; and Alan D. Black, TerraTek. Gordon Tibbitts, TerraTek, will presented the well-attended paper in February of 2002. The full text of the Mud Hammer paper was included in the last quarterly report.

- The Phase 2 project planning meeting (Task 6) was held at ExxonMobil's Houston Greenspoint offices on February 22, 2002. In attendance were representatives from TerraTek, DOE, BP, ExxonMobil, PDVSA, Novatek, and SDS Digger Tools.

- PDVSA has joined the advisory board to this DOE mud hammer project. PDVSA's commitment of cash and in-kind contributions were reported during the last quarter.

- Strong Industry support remains for the DOE project. Both Andergauge and Smith Tools have expressed an interest in participating in the 'optimization' phase of the program. The potential for increased testing with additional Industry cash support was discussed at the planning meeting in February 2002.

\section{Q2 2002}

- Presentation material was provided to the DOE/NETL project manager (Dr. John Rogers) for the DOE exhibit at the 2002 Offshore Technology Conference.

- Two meeting at Smith International and one at Andergauge in Houston were held to investigate their interest in joining the Mud Hammer Performance study.

- SDS Digger Tools (Task 3 Benchmarking participant) apparently has not negotiated a commercial deal with Halliburton on the supply of fluid hammers to the oil and gas business.

- TerraTek is awaiting progress by Novatek (a DOE contractor) on the redesign and development of their next hammer tool. Their delay will require an extension to TerraTek's contracted program.

- Smith International has sufficient interest in the program to start engineering and chroming of collars for testing at TerraTek.

- Shell's Brian Tarr has agreed to join the Industry Advisory Group for the DOE project. The addition of Brian Tarr is welcomed as he has numerous years of experience with the Novatek tool and was involved in the early tests in Europe while with Mobil Oil.

- Conoco's field trial of the Smith fluid hammer for an application in Vietnam was organized and has contributed to the increased interest in their tool.

\section{Q3 2002}

- Smith International agreed to participate in the DOE Mud Hammer program.

- Smith International chromed collars for upcoming benchmark tests at TerraTek, now scheduled for 4Q 2002. 
- ConocoPhillips had a field trial of the Smith fluid hammer offshore Vietnam. The hammer functioned properly, though the well encountered hole conditions and reaming problems. ConocoPhillips plan another field trial as a result.

- DOE/NETL extended the contract for the fluid hammer program to allow Novatek to 'optimize' their much delayed tool to 2003 and to allow Smith International to add 'benchmarking' tests in light of SDS Digger Tools' current financial inability to participate.

- ConocoPhillips joined the Industry Advisors for the mud hammer program.

\section{Q4 2002}

- Smith International participated in the DOE Mud Hammer program through full scale benchmarking testing during the week of 4 November 2003.

- TerraTek acknowledges Smith International, BP America, PDVSA, and ConocoPhillips for cost-sharing the Smith benchmarking tests allowing extension of the contract to add to the benchmarking testing program.

- Following the benchmark testing of the Smith International hammer, representatives from DOE/NETL, TerraTek, Smith International and PDVSA met at TerraTek in Salt Lake City to review observations, performance and views on the optimization step for 2003.

- The December 2002 issue of Journal of Petroleum Technology (Society of Petroleum Engineers) highlighted the DOE fluid hammer testing program and reviewed last years paper on the benchmark performance of the SDS Digger and Novatek hammers.

- TerraTek's Sid Green presented a technical review for DOE / NETL personnel in Morgantown on 'Impact Rock Breakage' and its importance on improving fluid hammer performance. Much discussion has taken place on the issues surrounding mud hammer performance at depth conditions.

\section{Review of 2003}

Q1 2003

- ExxonMobil has expressed interest in the possibility of a program to examine cutter impact testing, which would be useful in answering how hammers break rock and ultimately how to improve their performance.

- The March 2003 issue of Drilling (American Association of Drilling Engineers) highlighted the DOE fluid hammer testing program. Information from Smith International, TerraTek and PDVSA (one of the Industry partners) provided interesting insights for the future of hammer technology.

- Novatek (cost sharing supplier of tools) has informed the DOE project manager that their tool may be ready for 'optimization' testing late summer 2003 (August September timeframe).

- Tasks for an addendum to the hammer project related to cutter impact studies will be written during 2Q 2003.

\section{Q2 2003}

- Hughes Christensen has recently expressed interest in the possibility of a program to examine cutter impact testing, which would be useful in a better understanding of the 
physics of rock impact. Their interest however is not necessarily fluid hammers, but to use the information for drilling bit development.

- Novatek (cost sharing supplier of tools) has informed the DOE project manager that their tool may not be ready for 'optimization' testing late summer 2003 (August September timeframe) as originally anticipated. During 3Q Novatek plans to meet with TerraTek to discuss progress with their tool for 4Q 2003 testing.

- A task for an addendum to the hammer project related to cutter impact studies was written during 2Q 2003.

- Smith International internally is upgrading their hammer for the optimization testing phase. One currently known area of improvement is their development program to significantly increase the hammer blow energy.

\section{Q3 2003}

- Task 8 'Cutter Impact Testing' was added to the Mud Hammer Optimization program. During $4^{\text {th }}$ quarter 2003, tasks related to both the retesting of the Smith and Novatek hammers and 'cutter impact' testing in TerraTek's high rate 2-post machine will be conducted.

- Hughes Christensen confirmed interest in the program to examine cutter impact testing. Their interest however is not necessarily fluid hammers, but to use the information for drilling bit development. Shell E\&P is also interested in this program and are now part of the Industry Team.

- Novatek personnel (4 of them) met with TerraTek on August 14, 2003 to discuss progress with their tool for 4Q 2003 testing. The tool has been redesigned as part of another DOE program and will not be ready until end of 2003.

- A review of studies conducted at Clausthal University was undertaken and summarized by TerraTek. The PhD dissertation and accompanying post-doctorate work in German was performed on hard impermeable rocks and concluded that pressure rapidly diminishes rock breakage with cutter impact.

\section{Q4 2003}

- Task 8 'Cutter Impact Testing' was contractually added to the Mud Hammer Optimization program. During $4^{\text {th }}$ quarter 2003, TerraTek prepared the equipment for testing now scheduled to begin 1Q 2004.

- TerraTek met with Smith International on November 18, 2003 in Houston to prepare 'optimization' testing plans for the DOE program aimed at assessing the performance of their completely re-designed tool. Its longer collar necessitated revision of breakout procedures and placement of the hammer in TerraTek's wellbore simulator.

- A revised program for testing the smith tool was developed to address inclusion of an aggressive bit and the performance of the 'optimized' tool under a variety of conditions, both considered by the Industry Advisory Board to be important.

- At the request of the DOE project manager, TerraTek prepared a paper for publication in conjunction with an upcoming peer review at the GTI Natural Gas Technologies Conference in February. Manuscripts and associated presentation material were delivered during 4Q 2003 on schedule.

\section{Review of 2004}




\section{Q1 2004}

- TerraTek presented a paper for publication in conjunction with a peer review at the GTI Natural Gas Technologies Conference February 10, 2004. Manuscripts and associated presentation material were delivered on schedule. The paper was entitled "Mud Hammer Performance Optimization".

- Shell Exploration and Production continued to express high interest in the "cutter impact' testing program Task 8. Hughes Christensen supplied inserts for this testing program.

- TerraTek hosted an Industry / DOE planning meeting to finalize a testing program for 'Cutter Impact Testing - Understanding Rock Breakage with Bits' on February 13, 2004.

- Formal dialogue with Terralog was initiated. Terralog has recently been awarded a DOE contract to model hammer mechanics with TerraTek as a sub-contractor.

\section{Q2 2004}

- TerraTek re-tested the 'optimized' fluid hammer provided by Smith International during April 2004. Many improvements in mud hammer rates of penetration were noted over Phase 1 benchmark testing from November 2002.

- Shell Exploration and Production in The Hague was briefed on various drilling performance projects including Task 8 'Cutter Impact Testing'. Shell interest and willingness to assist in the test matrix as an Industry Advisor is appreciated.

- TerraTek participated in a DOE/NETL Review meeting at Morgantown on April 15, 2004.

- Terralog's Dr. Gang Han witnessed some of the full-scale optimization testing of the Smith International hammer in order to familiarize him with downhole tools. TerraTek recommends that modeling first start with single cutters / inserts and progress in complexity.

- The final equipment problem on the impact testing task was resolved through the acquisition of a high data rate laser based displacement instrument.

- TerraTek provided Novatek much engineering support for the future re-testing of their optimized tool. Work was conducted on slip ring [electrical] specifications and tool collar sealing in the testing vessel with a reconfigured flow system on Novatek's collar.

\section{Q3 2004}

- TerraTek continued the analysis of the full-scale testing of the 'optimized' fluid hammer provided by Smith International during April 2004. Many improvements in mud hammer rates of penetration were noted over Phase 1 benchmark testing from November 2002 and initial results were reported in the 2Q 2004 report to the DOE.

- Novatek's inability to provide an optimized mud hammer to the DOE and TerraTek on schedule mandated a no cost extension for this project. Engineering work to test the new tool at simulated depth conditions however continued with Novatek.

- The majority of the tests for Task 8 'Impact Testing' were conducted during 3Q 2004 with preliminary results reviewed with Industry Advisors. Fuller data sets will be reported 4Q 2004. 
- ReedHycalog personnel visited TerraTek and reviewed the 'Impact Testing' program with great interest on August 10, 2004.

- Hughes Christensen visited TerraTek to review the 'Impact Testing' program on September 22, 2004. Roy Ledgerwood viewed the Task 8 experiments as a significant step forward.

TerraTek commenced the analysis of the impact testing program with assistance by Lawrence Berkeley's Dr. Seiji Nakagawa. Early analysis has confirmed the robustness of the experimental work and validity of the data sets.

\section{Q4 2004}

- The majority of the tests for Task 8 'Impact Testing' were conducted during 3Q 2004 with preliminary results reviewed with Industry Advisors. More data sets were analyzed during 4Q 2004.

- During 4Q 2004, TerraTek assisted the DOE in preparing a review and workshop of the Terralog 'Fundamentals of Percussion Drilling' program.

\section{Review $0 f 2005$}

Q1

- A proposal submitted for a paper in the Society of Petroleum Engineers' 2005 Annual Technical Conference and Exhibition was accepted. "Single Cutter Testing Improves Understanding of Deep-Well Hammer Drilling Performance" was co-authored by Sid Green/Arnis Judzis/Alan Black (TerraTek), John Rogers (DOE-NETL and Project Manager for the work), and David Curry/Umesh Prasad (Hughes Christensen).

- TerraTek continues to work with Novatek as requested to ensure progress in testing their updated mud hammer. Specifically engineering continued on a Novatek hammer fluid flow shroud and control systems via slip rings at TerraTek.

\section{Q2}

- A proposal paper (formal manuscript) was submitted for the Society of Petroleum Engineers' 2005 Annual Technical Conference and Exhibition. "Single Cutter Impact Tests Investigate Deep-Well Hammer Drilling Performance" was co-authored by Sid Green/Arnis Judzis/Alan Black (TerraTek), John Rogers (DOE-NETL and Project Manager for the work), and David Curry/Umesh Prasad (Hughes Christensen).

- DOE's Project Manager requested that TerraTek complete another series of 'impact tests' in lieu of testing the Novatek mudhammer.

\section{Q3}

- Plans were made to prepare the final project report as well as the financial and other required reports.

- TerraTek conducted mud hammer tests for Terralog's DOE project using the Smith International tool. The tests were successfully conducted (some with pore pressure control) and are to be reported by Terralog separately. 


\section{TABLE OF CONTENTS}

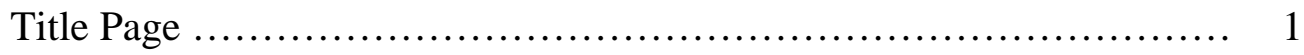

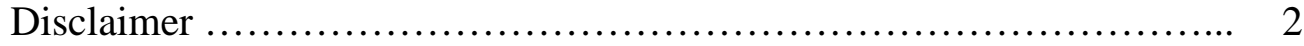

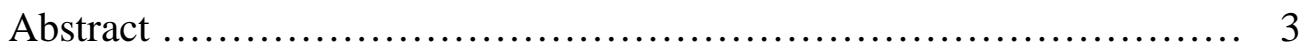

Table of Contents .................................................. 10

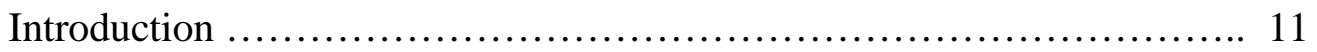

Executive Summary ............................................. 16

Experimental ................................................... 21

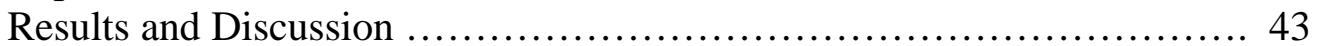

Conclusions .......................................................... 174

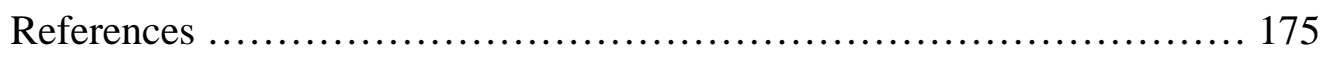




\title{
INTRODUCTION
}

The focus for the Introduction is on the relevant publications and information transferred as a result of the successful large scale testing with mud hammers, augmented of course by the advanced studies of 'impact testing'.

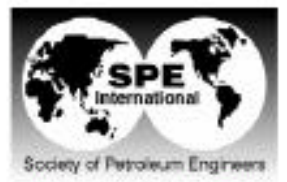

IADC/SPE 74540

World's First Benchmarking of Drilling Mud Hammer Performance at Depth Conditions Gordon A. Tibbints, TerraTek; Roy C. Long, US Department of Energy, Brian E. Miller, BP America, Inc; Arnis Judzis, TerraTek; Alan D. Black, TerraTek

\begin{abstract}
Operators continue to look for ways to improve hard rock drilling performance through emerging technologies. A consortium of Department of Energy, operator and industry participants put together an effort to test and optimize mud driven fluid hammers as one emerging technology that has shown promise to increase penetration rates in hard rock. The thrust of this program has been to test and record the performance of fluid hammers in full scale test conditions including, hard formations at simulated depth, high density / high solids drilling muds, and realistic fluid power levels. This paper details the testing and results of testing two $7 \frac{3 / 4}{4}$ diameter mud hammers with $81 / 2$ " hammer bits. A Novatek MHN5 and an SDS Digger FH185 mud hammer were tested with several bit types, with performance being compared to a conventional (IADC Code 537) tricone bit. These tools functionally operated in all of the simulated downhole environments. The performance was in the range of the baseline ticone or better at lower borehole pressures, but at higher borehole pressures the performance was in the lower range or below that of the baseline tricone bit. A new drilling mode was observed, while operating the MHN5 mud hammer. This mode was noticed as the weight on bit (WOB) was in transition from low to high applied load. During this new "transition drilling mode", performance was substantially improved and in some cases outperformed the tricone bit. Improvements were noted for the SDS tool while drilling with a more aggressive bit design. Future work includes the optimization of these or the next generation tools for operating in higher density and higher borehole pressure conditions and improving bit design and technology based on the knowledge gained from this test program.
\end{abstract}


By Wajilid Rasheed, Latin American editor, Hart's E\&P

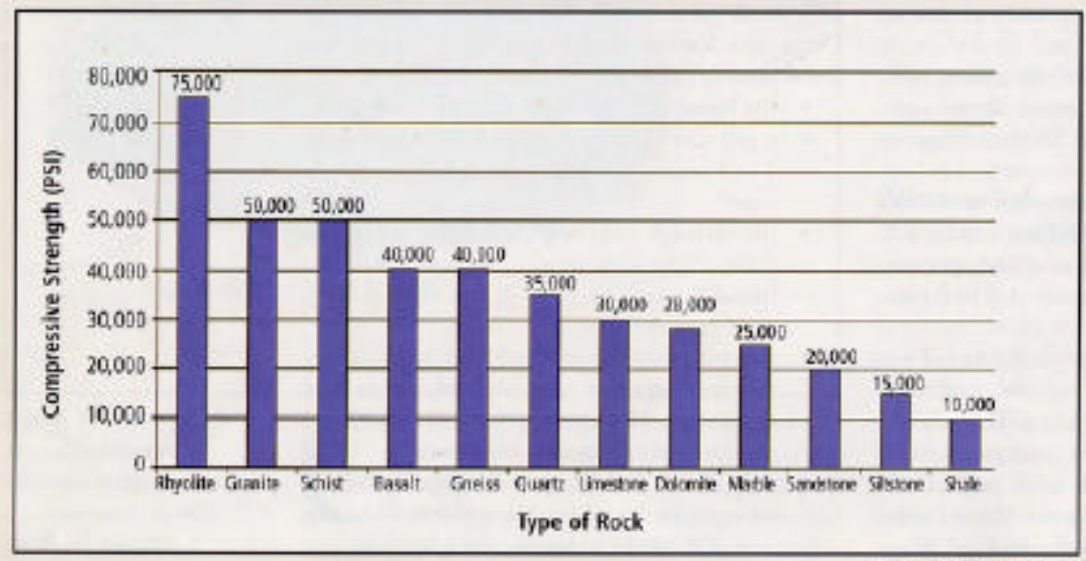

experts eye hammers for seis micwhile-drilling application to better identify fommations and refine the bakmeing of pore prossies and fricture gradients.

Investigating hammer technologies encompass two industry initiatives One is the US. Departunent of Energy? (DOE) ongoing mud ham mer benchmarking program. The other is a worldwide band rock drilling joint industr? project (JIP) completed in 2002. The driver is clear reduce expense and impreve performance, Calculations

Figure 1. Compressive rock strength table

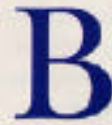

it companics are offering a diverse drill bit selection ranging from tumgstra carbicte buttons, diamond impregnated cutters. min abrasive dises and some bits cven incorporating explosive charges and lasers.

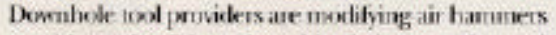
to widhstand solicls and emable their tasage beyond mining. Other companies are introducing muddrisen hammers designed specifically for the oil indusiry

The latest mud hammers tako referred to as fluir and hydraulic) promise unprecedented longevity. higher penetration rates, and compatibility with convenuional drill bis and muds. Previously, a short life and the inevitable pullout of thole before the section end outweighed the value hammers ofven added to operations. Also, penetration rate gain. havi to $\mathrm{t} x$ : weighed against performance limitations imposed by specialixed drill bits and muds. The difference is the fluid hammers are not only imprening hard rock penetration rates, but also are on the verge of clocking up economically viable mean time bewren failure (M1BF). More excitement is being creatcd as formation craluation khow that seriose driling time, alning with the mimber of trips and bits, can potentially be haked. For Operators with hard rock assets, the importance of such gamechanging technology speaks for itself: resaves and production can be increased from an ahility to chill hand rock oust effeccisely:

What is hand roche Ask a geologis and the answer probably will be arw rock with a compressive srength exceeding 40,000 psi. Yet from a drilling engineer's perspective, this seems too narrow a definition. Perhaps the term bardtordrill rock bettex explains the challenge, as it lowers the compressive strength threshold to about 20,000psi and also cosers formations where penetration rates fall below $16.4 \mathrm{ft} / \mathrm{hr}(\mathrm{mm} / \mathrm{hr})$.

\section{Air hammers and hammer bits}

For many years, air hammers and hammer bits have been used extensively in the mining industry. But they have made relatively little impart in the oil industry except in areas such as West Texas, the Northeast United States and the Rockies. Usage beyond these scenarios has heen restricted because of three factors. 
Firstly, gauge holes are more important in oil field applications than in mining. Secondly, conventional oil fleld muds and even brines are not encountered in mining, Finally, oil ficld drilling exhibits harsher conditions. Typically, bottomhole temperatures and pressures are higher than those of mining wells. Additionally, space is a preminm on affshore rigs, and the extra room beeded for air pumps, comprestors and separators may not be readily available on an offshore installation.

Smith's Percussion Drilling Manager Lance Underwood said the company introduced the first diamond-enhaneed hammer his in the late 1980s. The importance of these inserts in oil field drilling is holding gauge and eliminating trips by increac ing bit/insert life. Unlike mining, where a single bit drills multiple shorinterval wetk, in the oil field multiple bits are typically used in a single well. If a given bit becomes undergauge, the next bit has to ream. Or, as is the case in some arcas, a smallersize bit is run to follow the undergange bit. This practice is called telescoping. The advanage of diamondenhanced bits is that they almost ahways drill full-gauge holes, so a sulwequent full gange bit can be run without reaming An example of what can be achieved was shown by a recent run in Val Verde County, Texas, where an 8 3/4-in. bammer bit drilled a world rocond nun of $10,650 f$ ( $3,248.25 m)$ in 148 hours.

"As a rule, hamuner his typucally out-drill tri-cone bits by a farcor of Iwo, in terms of footage and ROP [rate of penerration]. So, if you're air drilling there's a pretty good chance you should be nunning hammer bits. However, water influx limits ltammer usage. When water influx gets too higb, the result ing pressure drop in the anmulus causes hammer to shut down. For insunce, it is not uncomnon for an operatar is trip iffer a $3,000 \mathrm{ft}[915 \mathrm{~m}]$ hamme rum and tese a tricone bit to drill the remainder $A$ s a solution, Smith is dencloping an air hammer with increased water tolerance," Underwood said.

"Another factor that differentiates oil field drilling from mining applications is botombole temperature. In decper wells, high temperature: can cause failure of the foot value (a plastic valve which is pressed into the bit). Our new hammer eliminates the possibility of footnalve failure by designing the value into the hammer itself, which allons the value to he made of steel.

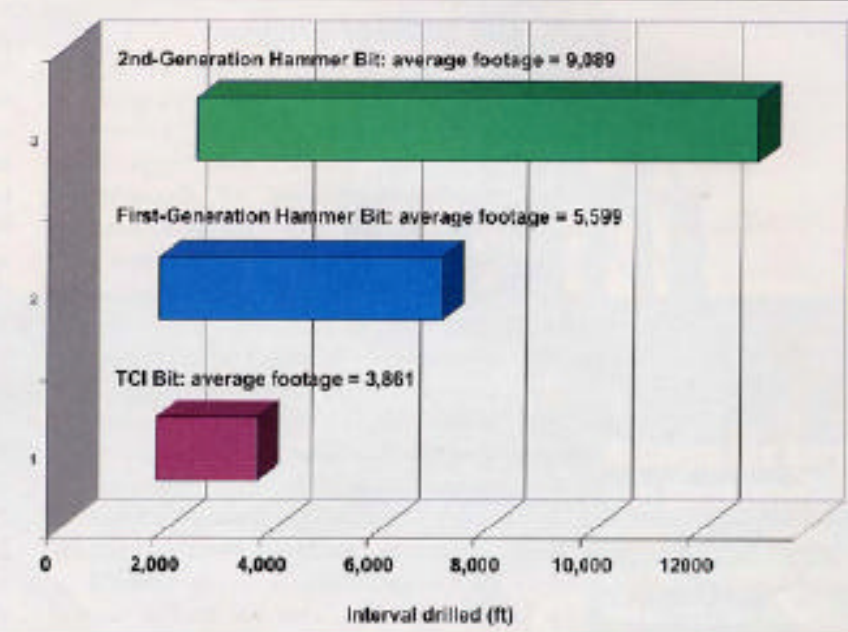

\section{Mud hammers}

"Regarding fluid hammers, we're still in the development stage. Our approach is somewhat different than that of some oxher compranies in that we'te using lixed head bis, which can handle higher hammer energy levets than tri-cone bits We've solved some really fundamental problems, such as getting a piston to survive the abrasive effects of the drilling fluid that drines it. Now that we re past some of the major hurdles, it seenus thet we're finding other relatively minor reak links such als scal tailures and insent breakange. We've done field tests and seen good rates of penetration in britule and friable formations (granites and sandstones, in particular).

"We're continuing to field test, generally target. ing applications with hard/britile/friable formettions staying away from intervals with a lot of soit, plasuic stringers. Many hand rock applications are drilled with clear brines, which is what we'd prefer from a drilling fluid/formation interaction standpoint. The striking thing about this project is the interest from operators.

Many of our customers operate in fields that have ar least one hard-todril interval that is just not drilled eflextively with existing technologies, In many of these applications, air drilling is not an option duc to formation considerations (i.e. either massive vater influx or insufficiently compctent formation), yet the formation is britle or friable and percussive drilling would serent to be the best way to break the rock," Underwood said 


\section{DOE mud hammer program}

Established to optimixe meid hammer dilling per. formance, the DOE has set up a program to benchmark the viability of this technology: Contrarting company Terra Tek, SIXS Digger Tools. Nowatek, Smith International, BP, ExxonMobil, Conceophillips, PDVSA and Pajarito Enterprises intend $w$ address the commencialization of prototype mud hammers by benchmark testing and optimixing drilling performance. Tena Tek is worling elooty with suppliens of nud hammers to demonstrate their performance limis and facilitate conmencialization.

"Misel hammer performance and endurance have not been tested sufficiently for hammen to be viable in the marketplace. Hammer drilling, particwlarly in high borehole pressure conditions, is prone to peiformance problems. Both rates of penetration and longevity are adversely affected by mudk coniaining solick. This can kad to varying degrees of staccess owing to lower efficiencies or $\$ 0-$ called uming problems. Also, modes of hammer impact can be changed by hydrodynamic condtions and wellbore pressures. Nonetheless, the markets for mud haunmers, including directional mud hammers, are sufficiently large to make the development of a fieleterable device compelling. If rates of drilling rutes of penetration can be increased substantially, the deeper bard rock basins in the Unitod States would see more efficient operations and an increase in well construction activities resulting from enhanced economics, Example basins include Anadarko, Appolachian, Arkomna, Fast Texas, Permian and San Juan," said Terratek Vice President Amis fudris.

TerraTek has completed benchmarking two of the harnmers. The program is now tuming its attention to deternining hammer rates of penetration and their ability to function at depth. Tois alreasly have started, and some design improwements inci performance optimization have been reporteri.

PDVSA also is participating in the benchmarking program

"New tochnology suecesses are ofien slow to materáalize and not wery well understood because direa comparsons are made with conventional drilling processes. Hammers do not escape frum this reality. Furthermore, hytraulic hammers requise a new form of thinking, not just regarding the opxerator or the drilling teran, but also in terms of the rig itselt. Toulay's hammens nequiure a pressure drop and hence pump capacity, which often exceeds standard pump sperifications. This potentially limits the sce naries in which hammers can be used. Also, the design and performance of conventional PDC or tricone bits are very different from the ideal hammer bit. Therefore, a system approach encompassing bit. hammer, drillstring and rig parametens is requived. Howeser, as there is nosingle technology that ean be applied universilly, Interep (PDVSA's research and deselopment arm) is participating in other iniuartives too, such as the laser drilling program with the Gas Technolosy Instinue," said PDVSA drilling torhnology manager Alcjandro Lagreca.

\section{Hard rock drilling JIP}

"The IIP imvolved Petrobras, Amerada Hess, ExxonMokil and Boland. We finishod testing earlier this year and showed that several developmental technologies, stuch as mini-bit discs and highpressure bit nozzles, exist and although these are unazilable commercially, they offer the potential to increase ROP. These types of technolugies and hydraulic hammers still need to prove themselvea

In contrast, pneumatic harnmers have prowen themw-lwes, bet tyydraulic hammers are still lighting to owercome some problems. For example, many tools work perfectly well with elean liquids, surh as water, but with conmercial drilling fluick, hammer MTBF is still uncoonomic and per formance hesves a lot to be desired," said Joas Garlen Placido, croordinator of the Hard Rock Drilliag project. "Nthongh not part of the projec, the Andergange hammer presents some different characteristics. Because it generates lower impact forees, it may not increase ROP as much as other hammers, but it inspires more confidence regarding MTBE, It ako bes the advantage of being coupatible with any type of joumal bearing bit. 1 think it will enter the market mone quickly than other tyxdranlic hammers"

\section{Future of hammer technology}

Recent adsanocs are accelerating hammer commereialization, but several key areas still require further research. Future research should optimis: existing (or next-generation) fools for higher bore hole pressure atul densily conditions. Greater design work needs to be done to match hammer and bis acconding to geophyxical formation propervies. More consideration also should be given to understanding the unique effects hammer drilling bas on cuttings size and clistribution, hole cleaning. wellbore stability and ultimately ROP. 


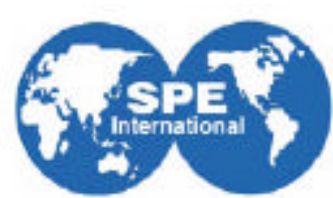

SPE 97173

Single Cutter Impact Tests Investigate Deep-Well Hammer-Drilling Performance

S. Green, SPE, TerraTek, A Judzis, SPE; TerraTek. D. Curry, SPE. Hughes Christersen, A. Black, SPE; TerraTek, U Prasad, SPE, Hughes Christensen, J. Rogers, SPE, U.S. Department of Energy

\section{Abstract}

The use of a percussion hammer can provide high penetration rates through hard rocks when air drilling. The work of this paper was partly sponsored by the US Department of Energy to develop hammer drilling techniques for drilling deep hard rocks, using real drilling muds. Unfortunately, development is complicated because understanding rock breakage and cuttings removal under the dynamic loading conditions of hammer drilling is difficult. Historically, empirical relations have been used to relate hammer blow energy and blow rate with drilling.

This paper presents results of carefully measured single cutter impact-as well as high rate and 'static'-rock indentation tests under high borehole pressure conditions, using real drilling muds. The results include cutter forcedisplacement and crater volumes for both first stress wave (initial impact) and long time (quasi static) rock indentations. From this, specific energy for rock breakage (i.e. the energy to excavate a unit volume of rock) can be calculated.

The specific energy values measured in these single cutter impact tests show the rock destruction efficiency that can be achieved by impact loading. They are compared with specific energies measured during full scale hammer and rotary drilling experiments, under relatively similar conditions.

For a given rock type, impact stress, cutter configuration, wellbore pressure, and mud type are shown to be critical parameters. A key observation is that most of the rock breakage occurs during the first stress-wave, and for higher impact stresses above the dynamic confined indentation strength, relatively little additional rock breakage seems to occur. 


\section{EXECUTIVE SUMMARY}

Progress on the testing of fluid driven drilling hammers;

On January $9^{\text {th }}$ of 2001, details of the Mud Hammer Drilling Performance Testing Project were presented at a "kick off" meeting held in Morgantown. Industry support is high and the importance to the drilling industry, as the business challenge of "hard rock drilling", was presented by John Shaughnssy of BP Amoco. The Industry Partners for this program are SDS Digger Tools, Novatek, BP Amoco, and ExxonMobil. A test program was formulated and prepared for presentation at a meeting of the Industry Advisory Board in Houston on the $8^{\text {th }}$ of February. The meeting was held and the DOE approved a test program was after thorough discussion.

DOE's National Energy Technology Laboratory highlighted the Mud Hammer Project at an exhibit at the Offshore Technology Conference April 30 through May 3, 2001. TerraTek assisted NETL personnel with presentation materials appropriate for the project and a demonstration sample of 'hard rock' drilled in TerraTek's wellbore simulator.

TerraTek completed 13 drilling tests by beginning July in Carthage Marble and hard Crab Orchard Sandstone with the SDS Digger Tool, Novatek tool, and a conventional rock bit. Overall the hammers are functioned properly at 'borehole' pressures up to 3,000 psi with weighted water based mud. Clearly the Department of Energy goals to determine hammer benchmark rates of penetration and ability to function at depth are being met. Additionally data on drilling intervals and rates of penetration specific to flow rates, pressure drops, rotary speed, and weights-on-bit have been given to the Industry Partners for detailed analysis. SDS and Novatek have gained considerable experience on the operation of their tools at simulated depth conditions. Some optimization has already started and has been identified as a result of these first tests.

TerraTek completed analysis of drilling performance (rates of penetration, hydraulics, etc.) for the Phase One testing which was completed at the beginning of July. TerraTek also convened jointly with the Industry Advisory Board for this project and DOE/NETL a 'lessons learned meeting' to transfer technology vital for the next series of performance tests. Both hammer suppliers benefited from the testing program and are committed to pursue equipment improvements and 'optimization' in accordance with the scope of work.

PDVSA joined the advisory board to this DOE mud hammer project end 2001 and formally committed funds (cost sharing) for the upcoming effort in testing at TerraTek. Additionally, TerraTek, DOE, and BP America (one of the industry contributing partners) has completed a publication entitled "World's First Benchmarking of Drilling Mud Hammer Performance at Depth Conditions".

In accordance to Task 7.0 (D. \#2 Technical Publications) TerraTek, NETL, and the Industry Contributors successfully presented a paper detailing Phase 1 testing results at 
the February 2002 IADC/SPE Drilling Conference, a prestigious venue for presenting DOE and private sector drilling technology advances. The full reference is as follows:

IADC/SPE 74540 "World's First Benchmarking of Drilling Mud Hammer Performance at Depth Conditions" authored by Gordon A. Tibbitts, TerraTek; Roy C. Long, US Department of Energy, Brian E. Miller, BP America, Inc.; Arnis Judzis, TerraTek; and Alan D. Black, TerraTek. Gordon Tibbitts, TerraTek, presented the well-attended paper in February of 2002. The full text of the Mud Hammer paper was included in the last quarterly report.

The Phase 2 project planning meeting (Task 6) was held at ExxonMobil's Houston Greenspoint offices on February 22, 2002. In attendance were representatives from TerraTek, DOE, BP, ExxonMobil, PDVSA, Novatek, and SDS Digger Tools. PDVSA has joined the advisory board to this DOE mud hammer project. PDVSA's commitment of cash and in-kind contributions were reported during the last quarter. Strong Industry support remains for the DOE project. Both Andergauge and Smith Tools have expressed an interest in participating in the 'optimization' phase of the program. The potential for increased testing with additional Industry cash support was discussed at the planning meeting in February 2002.

Presentation material was provided to the DOE/NETL project manager (Dr. John Rogers) for the DOE exhibit at the 2002 Offshore Technology Conference. Two meeting at Smith International and one at Andergauge in Houston were held to investigate their interest in joining the Mud Hammer Performance study.

SDS Digger Tools (Task 3 Benchmarking participant) apparently had not negotiated a commercial deal with Halliburton on the supply of fluid hammers to the oil and gas business. TerraTek is awaiting progress by Novatek (a DOE contractor) on the redesign and development of their next hammer tool. Their delay will require an extension to TerraTek's contracted program. Smith International has sufficient interest in the program to start engineering and chroming of collars for testing at TerraTek.

Shell's Brian Tarr then agreed to join the Industry Advisory Group for the DOE project. The addition of Brian Tarr was welcomed as he has numerous years of experience with the Novatek tool and was involved in the early tests in Europe while with Mobil Oil. Finally, Conoco's field trial of the Smith fluid hammer for an application in Vietnam was organized and has contributed to the increased interest in their tool.

Smith International agreed to participate in the DOE Mud Hammer program mid 2002 and chromed collars for upcoming benchmark tests at TerraTek, scheduled for 4Q 2002. ConocoPhillips had a field trial of the Smith fluid hammer offshore Vietnam. The hammer functioned properly, though the well encountered hole conditions and reaming problems. ConocoPhillips planned another field trial as a result.

DOE/NETL extended the contract for the fluid hammer program to allow Novatek to 'optimize' their much delayed tool to 2003 and to allow Smith International to add 'benchmarking' tests in light of SDS Digger Tools' current financial inability to participate. ConocoPhillips joined the Industry Advisors for the mud hammer program 
and TerraTek acknowledges Smith International, BP America, PDVSA, and ConocoPhillips for cost-sharing the Smith benchmarking tests allowing extension of the contract to complete the optimizations tests.

During 4Q 2002, Smith International participated in the DOE Mud Hammer program through full scale benchmarking testing (5 tests) during the week of 4 November 2003. TerraTek acknowledges Smith International, BP America, PDVSA, and ConocoPhillips for cost-sharing the Smith benchmarking tests allowing extension of the contract to add to the benchmarking testing program. Following the benchmark testing of the Smith International hammer, representatives from DOE/NETL, TerraTek, Smith International and PDVSA met at TerraTek in Salt Lake City to review observations, performance and views on the optimization steps for 2003. The December 2002 issue of Journal of Petroleum Technology (Society of Petroleum Engineers) highlighted the DOE fluid hammer testing program and reviewed last years paper on the benchmark performance of the SDS Digger and Novatek hammers. TerraTek's Sid Green presented a technical review for DOE / NETL personnel in Morgantown on 'Impact Rock Breakage' and its importance on improving fluid hammer performance. Much discussion has taken place on the issues surrounding mud hammer performance at depth conditions.

At the start of 2003 the DOE and TerraTek continued to wait for Novatek on the optimization portion of the testing program (they are completely rebuilding their fluid hammer). ExxonMobil expressed interest in the possibility of a program to examine cutter impact testing, which would be useful in answering how hammers break rock and ultimately how to improve their performance. Additionally, The March 2003 issue of Drilling (American Association of Drilling Engineers) highlighted the DOE fluid hammer testing program. Information from Smith International, TerraTek and PDVSA (one of the Industry partners) provided interesting insights for the future of hammer technology. Finally, Novatek (cost sharing supplier of tools) informed the DOE project manager that their tool may be ready for 'optimization' testing late summer 2003 (August - September timeframe).

Hughes Christensen had expressed during 2Q 2003 interest in the possibility of a program to examine cutter impact testing, which would be useful in a better understanding of the physics of rock impact. Their interest however is not necessarily fluid hammers, but to use the information for drilling bit development. Novatek (cost sharing supplier of tools) informed the DOE project manager that their tool may not be ready for 'optimization' testing late summer 2003 (August - September timeframe) as originally anticipated. A task for an addendum to the hammer project related to cutter impact studies was written during 2Q 2003 and submitted to the DOE project manager. Finally, Smith International internally was busy upgrading their hammer for the optimization testing phase. One currently known area of improvement is their development program to significantly increase the hammer blow energy.

During 3Q 2003, Task 8 'Cutter Impact Testing' was added to the Mud Hammer Optimization program. Hughes Christensen confirmed interest in the program to examine cutter impact testing. Shell E\&P is also highly interested in this program and they are 
now part of the Industry Team. Novatek personnel (4 of them) met with TerraTek on August 14, 2003 to discuss progress with their tool for 4Q 2003 testing. The tool has been redesigned as part of another DOE program and will not be ready until 2004. And finally, a review of studies conducted at Clausthal University was undertaken and summarized by TerraTek. The PhD dissertation and accompanying post-doctorate work in German was performed on hard impermeable rocks and concluded that pressure rapidly diminishes rock breakage with cutter impact.

During 4Q 2003 'Cutter Impact Testing' was contractually added to the Mud Hammer Optimization program and TerraTek prepared the equipment for testing now scheduled to begin 1Q 2004. TerraTek also met with Smith International on November 18, 2003 in Houston to prepare 'optimization' testing plans for the DOE program aimed at assessing the performance of their completely re-designed tool. Its longer collar necessitated revision of breakout procedures and placement of the hammer in TerraTek's wellbore simulator. A revised program for testing the smith tool was subsequently developed to address inclusion of an aggressive bit and the performance of the 'optimized' tool under a variety of conditions, both considered by the Industry Advisory Board to be important. And finally at the request of the DOE project manager, TerraTek prepared a paper for publication in conjunction with a peer review session at the GTI Natural Gas Technologies Conference in February. Manuscripts and associated presentation material were delivered during 4Q 2003 on schedule.

During 1Q 2004, TerraTek presented a paper for publication in conjunction with a peer review at the GTI Natural Gas Technologies Conference (February 10, 2004). Manuscripts and associated presentation material were delivered on schedule. The paper was entitled "Mud Hammer Performance Optimization". Shell Exploration and Production continued to express high interest in the 'cutter impact' testing program Task 8. Hughes Christensen supplied inserts for this testing program. TerraTek hosted an Industry / DOE planning meeting to finalize a testing program for 'Cutter Impact Testing - Understanding Rock Breakage with Bits' on February 13, 2004. Finally two items Formal dialogue with Terralog was initiated. Terralog has recently been awarded a DOE contract to model hammer mechanics with TerraTek as a sub-contractor and Novatek provided the DOE with a schedule to complete their new fluid hammer and test it at TerraTek.

During 2Q 2004 TerraTek re-tested the 'optimized' fluid hammer provided by Smith International during April 2004. Many improvements in mud hammer rates of penetration were noted over Phase 1 benchmark testing from November 2002. Shell Exploration and Production in The Hague was briefed on various drilling performance projects including Task 8 'Cutter Impact Testing'. Shell interest and willingness to assist in the test matrix as an Industry Advisor is appreciated. TerraTek participated in a DOE/NETL Review meeting at Morgantown on April 15, 2004. The discussions were very helpful and a program related to the Mud Hammer optimization project was noted - Terralog modeling work on percussion tools. Terralog's Dr. Gang Han witnessed some of the full-scale optimization testing of the Smith International hammer in order to familiarize him with downhole tools. TerraTek recommends that modeling first start with single cutters / 
inserts and progress in complexity. The final equipment problem on the impact testing task was resolved through the acquisition of a high data rate laser based displacement instrument. And finally TerraTek provided Novatek much engineering support for the future re-testing of their optimized tool. Work was conducted on slip ring [electrical] specifications and tool collar sealing in the testing vessel with a reconfigured flow system on Novatek's collar.

During 3Q 2004 TerraTek continued the analysis of the full-scale testing of the 'optimized' fluid hammer provided by Smith International during April 2004. Many improvements in mud hammer rates of penetration were noted over Phase 1 benchmark testing from November 2002 and initial results were reported in the 2Q 2004 report to the DOE. Novatek's inability to provide an optimized mud hammer to the DOE and TerraTek on schedule mandated a no cost extension for this project. Engineering work to test the new tool at simulated depth conditions however continued with Novatek. The majority of the tests for Task 8 'Impact Testing' were conducted during 3Q 2004 with preliminary results reviewed with Industry Advisors. ReedHycalog personnel visited TerraTek and reviewed the 'Impact Testing' program with great interest on August 10, 2004 and Hughes Christensen visited TerraTek to review the 'Impact Testing' program on September 22, 2004. Roy Ledgerwood viewed the Task 8 experiments as a significant step forward. TerraTek commenced the analysis of the impact testing program with assistance by Lawrence Berkeley's Dr. Seiji Nakagawa. Early analysis has confirmed the robustness of the experimental work and validity of the data sets.

During 4Q 2004 the majority of the tests for Task 8 'Impact Testing' were conducted during 3Q 2004 with preliminary results reviewed with Industry Advisors. More data sets were analyzed during 4Q 2004. Also, TerraTek assisted the DOE in preparing a review and workshop of the Terralog 'Fundamentals of Percussion Drilling' program.

During 1Q 2005 the abstract for the paper entitled "Single Cutter Testing Improves Understanding of Deep-Well Hammer Drilling Performance" (co-authored by Sid Green / Arnis Judzis / Alan Black, TerraTek; John Rogers, DOE-NETL and Project Manager for the work; and David Curry / Umesh Prasad, Hughes Christensen) was prepared and subsequently accepted by the Society of Petroleum Engineers. TerraTek continued engineering work with Novatek's John Fernandez on testing equipment related to a fluid flow shroud and control systems tied in to the TerraTek slip rings on the rig. During 2Q 2005 discussions with John Rogers to evaluate the options of testing the Novatek tool versus more impact testing will be held.

During 2Q 2005 John Rogers, DOE/NETL Project Manager, requested that TerraTek expand Task 8 ('Impact Testing') in lieu of a second round of optimization tests with the yet to be delivered Novatek mudhammer. The equipment was readied and tested successfully during 2Q 2005. A significant achievement was the submittal of a manuscript for the upcoming 2005 Society of Petroleum Engineers Annual Technical Conference and Exhibition. "Single Cutter Impact Tests Investigate Deep-Well Hammer Drilling Performance" was co-authored by Sid Green/Arnis Judzis/Alan Black 
(TerraTek), John Rogers (DOE-NETL and Project Manager for the work), and David Curry/Umesh Prasad (Hughes Christensen).

And finally during 3Q 2005 plans were made to prepare the final project report as well as the financial and other required reports. TerraTek conducted mud hammer tests for Terralog's DOE project using the smith International tool. The tests were successfully conducted (some with pore pressure control) and are to be reported by Terralog separately.

\section{EXPERIMENTAL}

2001

\section{Task 2.0 Characterization of Applications}

Published and unpublished documentation of mud hammer performance was gathered and analyzed. Dr. John Rowley, of Pajarito Enterprises, supplied documentation from searches and discussions. There were several papers and articles from Russia in regards to hammer drilling and experimentation but little information of use for these experiments. Two SPE papers (referenced in this document) were identified and reviewed for applicability. These papers proved to have the most merit in setting up the parameters and conditions for the test program. The proposed test program was based on these papers and reviewed at the Advisory Board meeting in Houston.

The key operational parameters, rock types, final tools, bits, and conventional bit test parameters were reviewed by the Advisory panel during the Houston meeting on the $8^{\text {th }}$ of February. Participants were as follows:

- Roy Long

- Peter Whitehead

- David Pixton

- John and Mary Rowley

- Darrell Howard

- John Shaughnessy

- Brian Tarr

- Tim Travis

- Alan Black

- Gordon Tibbitts
Gov't. NETL

SDS Digger Tools

Novatech

Pajarito Enterprises

BP Amoco

BP Amoco

ExxonMobil

ExxonMobil

TerraTek

TerraTek

Consensus was reached on all the points brought up in the meeting and are reflected in the following information detailing the results of the meeting. This information was distributed to Dona Sheehan and Roy Long a week after the meeting. 


\section{TEST SEQUENCE}

$\begin{array}{lllr}\text { TEST } & \text { HAMMER/BIT } & \text { ROCK } & \text { MUD DENSITY } \\ 1 & \text { SDS } & \text { Carthage Marble } & 10 \mathrm{ppg} \\ 2 & \text { SDS } & \text { Crab Orchard S.S. } & 10 \mathrm{ppg} \\ 3 & \text { Novatek } & \text { Carthage Marble } & 10 \mathrm{ppg} \\ 4 & \text { Novatek } & \text { Crab Orchard S.S. } & 10 \mathrm{ppg} \\ 5 & \text { Conventional } & \text { Carthage Marble } & 15 \mathrm{ppg} \\ 6 & \text { Conventional } & \text { Crab Orchard S.S. } & 15 \mathrm{ppg} \\ 7 & \text { SDS } & \text { Carthage Marble } & 15 \mathrm{ppg} \\ 8 & \text { SDS } & \text { Crab Orchard S.S. } & 15 \mathrm{ppg} \\ 9 & \text { Novatek } & \text { Carthage Marble } & 15 \mathrm{ppg} \\ 10 & \text { Novatek } & \text { Crab Orchard S.S. } & 15 \mathrm{ppg} \\ 11^{* *} & \text { SDS } & \text { Carthage Marble } & 15 \mathrm{ppg} \\ 12^{* *} & \text { SDS } & \text { Crab Orchard S.S. } & 15 \mathrm{ppg} \\ 13^{* *} & \text { Novatek } & \text { Carthage Marble } & 15 \mathrm{ppg} \\ 14^{* *} & \text { Novatek } & \text { Crab Orchard S.S. } & 15 \mathrm{ppg} \\ * \text { Use the data from SPE paper No. } & \text { 15620 for conventional bit performance (HPSM } \\ \text { rollercone bit) in 10ppg mud. } & \end{array}$

\section{SDS DIGGER MUD HAMMER TEST CONFIGURATION}

- Spud 3" into the rock sample at 1000 psi borehole pressure conditions, 1900 psi pressure drop through the tool, rotary speed of 20 RPM, WOB high enough to start the tool and ending at $2000 \mathrm{lbs}$ at 3" depth into the rock

- At 3" start test condition 1 - 1000 psi borehole conditions, 2000 lbs WOB, 20 RPM and a 1900 psi pressure drop through the tool. 4" of rock have been allocated for this test condition. If possible obtain data points at 15 RPM and 25 RPM if rock is available.

- At 7" pull off bottom and establish borehole conditions at 3000 psi maintaining the 1900 psi pressure drop through the tool.

- Engage the bottom hole at these conditions and drill $2 \frac{1 / 2 "}{}$ of rock in transition as the tool function becomes steady state.

- At $91 / 2$ " start test condition 2 - 3000 psi borehole conditions, 2000 lbs WOB, 20 RPM, and 1900 psi pressure drop through the tool. 6" of rock has been allocated for this test condition. If rock exists get data points at 15 RPM and 25 RPM.

- At $15 \frac{1}{2}$ " pull off bottom and change the pressure drop through the tool to $1600 \mathrm{psi}$.

- Engage the bottom hole at this new condition and drill $2 \frac{1 / 2}{2}$ " of rock in transition as the tool function becomes steady state.

- At 18" start test condition 3-3000 psi borehole conditions, 2000 lbs WOB, 20 RPM and 1600 psi pressure drop through the tool. 6" of rock has been allocated for this test condition. If rock is available obtain data points at 15 RPM and 25 RPM.

- At 24" pull off bottom and change the pressure drop through the tool to 2200 psi.

- Engage the bottom hole at this new condition and drill $2 \frac{1 / 2}{2}$ of rock in transition as the tool function becomes steady state. 
- At 26 1/2" start test condition $4-3000$ psi borehole conditions, 2000 lbs WOB, 20 RPM, and 2200 psi pressure drop through the tool. $6 \frac{1}{1} 2$ " of rock has been allocated for this test condition. If rock is available obtain data points at 15 RPM and 25 RPM.

- At 33" pull off bottom and end test.

\section{NOVATEK MUD HAMMER TEST CONFIGURATION}

- Spud 3" into the rock sample at 1000 psi borehole pressure conditions, 1000 psi pressure drop through the tool, 30 RPM, and WOB to10,000 lbs at 3" depth into the rock

- At 3" start test condition 1-1000 psi borehole conditions, 30 RPM, 10,000 WOB and 1000 psi pressure drop through the tool. 4"'of rock have been allocated for this test condition. If rock is available, get data points at $10 \mathrm{RPM}$ and $60 \mathrm{RPM}$.

- At 7" pull off bottom and establish 3000 psi borehole conditions while maintaining the 1000 psi pressure drop through the tool.

- Engage the bottom hole and bring WOB up to $10,000 \mathrm{lbs}$ at the $3000 \mathrm{psi}$ borehole conditions and 30 RPM. 1/2" of rock has been allowed for this transition to WOB. 4" of rock has been allocated for this test condition (2). If rock exists, obtain data points for 10 RPM and 60 RPM.

- At $11 \frac{1}{12}$ " increase WOB to 20,000 lbs (test condition 3) at 30 RPM and $1000 \mathrm{psi}$ pressure drop through the tool. 4" of rock has been allocated for this test condition. If rock exists obtain data points at 10 RPM and 60 RPM.

- At $15 \frac{1 / 2 "}{2}$ pull off bottom and increase the pressure drop through the tool up to 1500 psi.

- Engage the bottom hole at this new condition and bring WOB up to $10,000 \mathrm{lbs}$ in the $1 / 2$ " of transition rock. Start test condition $4-3000$ psi borehole pressure, 30 RPM, and 10,000 lbs WOB. 4" of rock has been allocated for this test condition. If rock exists obtain data points at 10 RPM and 60 RPM.

- At 20" increase the WOB to 20,000 lbs to establish test condition 5-3000 psi borehole conditions, $30 \mathrm{RPM}, 20,000 \mathrm{lbs}$ WOB, and 1500 psi pressure drop through the tool. 4" of rock has been allocated for this test condition. If rock exists obtain data points at 10 RPM and 60 RPM.

- At 24" pull off bottom and decrease the pressure drop through the tool to $750 \mathrm{psi}$.

- Engage the bottom hole at this new condition and bring WOB up to 10,000 lbs in the $1 / 2$ " of transition rock. Establish test condition $6-3000$ psi borehole conditions, 30 RPM, 10,000 lbs WOB, and 750 psi pressure drop through the tool. 4" of rock has been allocated for this test condition. If rock exists, obtain data points at 10 RPM and $60 \mathrm{RPM}$.

- At $281 / 2$ " increase the WOB to 20,000 lbs (test condition 7) and get data point at 30 RPM, 3000 psi borehole conditions, and 750 psi pressure drop through the tool. If rock exists, obtain data points for 10 RPM and 60 RPM.

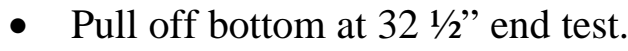


Owing to the early equipment problems experienced by Novatek (nozzles, bit washout) and to a lesser extent SDS, some of the experiments were started and stopped numerous times, thus adding to set-up, changeover, and waiting on equipment times. Nonetheless, the test matrix was completed under DOE's guidance as follows (multiple tests with letter designations indicate performance interval data was taken at different times and on separate files due to interruptions, hammer modifications, etc. The exception is test \#3 where a change out to a different bit was made):

1. DOE 1 ( plus $1 \mathrm{~A} \& 1 \mathrm{~B})$

2. DOE 2 (plus 2A \& 2B)

3. DOE 3, Novatek bit

4. DOE 3A, roller cone bit

5. DOE 4

6. DOE 5

7. DOE 6 (plus 6A)

8. DOE 7

9. DOE 8 (plus 8A \& 8B)

10. DOE 9

11. DOE 10

12. DOE 11 (plus 11A)

13. DOE 12
SDS

SDS

Novatek

Novatek

Conventional

Conventional

SDS

SDS

SDS

SDS

Novatek

Novatek

Novatek

Summary data and charts for these tests were published in the quarterly reports. In this report, the archived photos of the bottomhole patterns are presented (DOE Test \#3 had no bottomhole pattern since the entire sample was drilled through to the lower steel plate): 


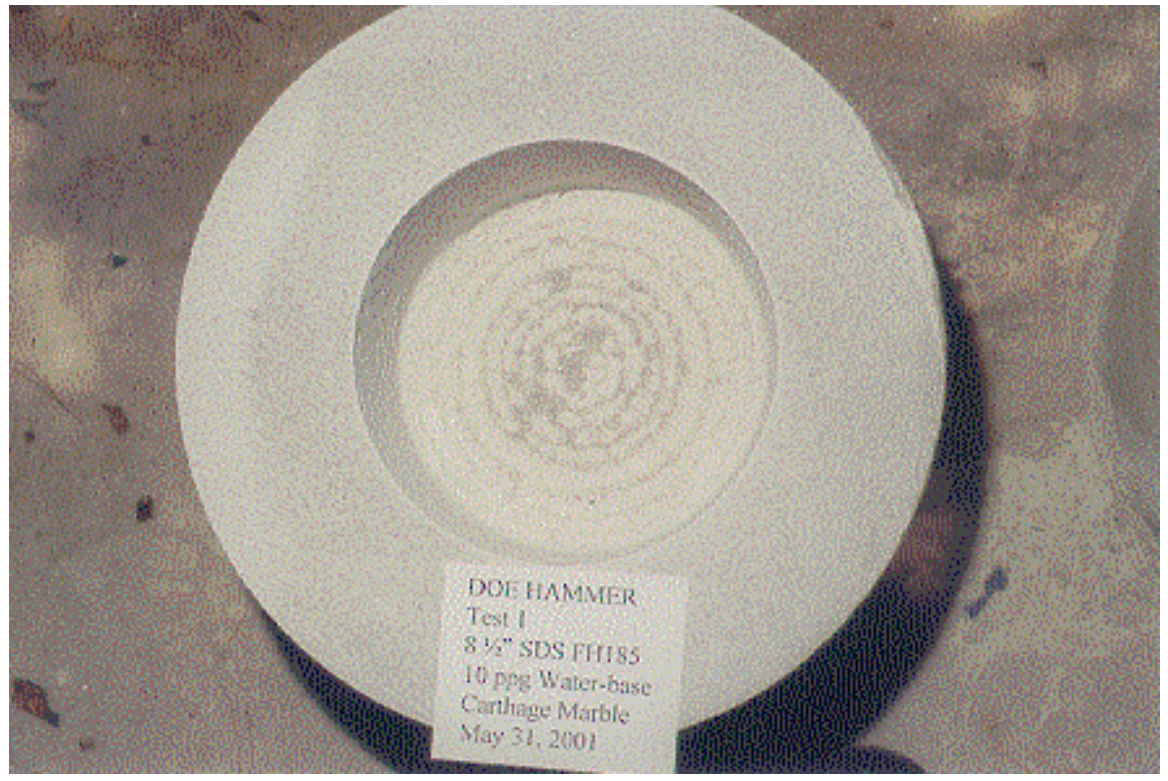

DOE 1

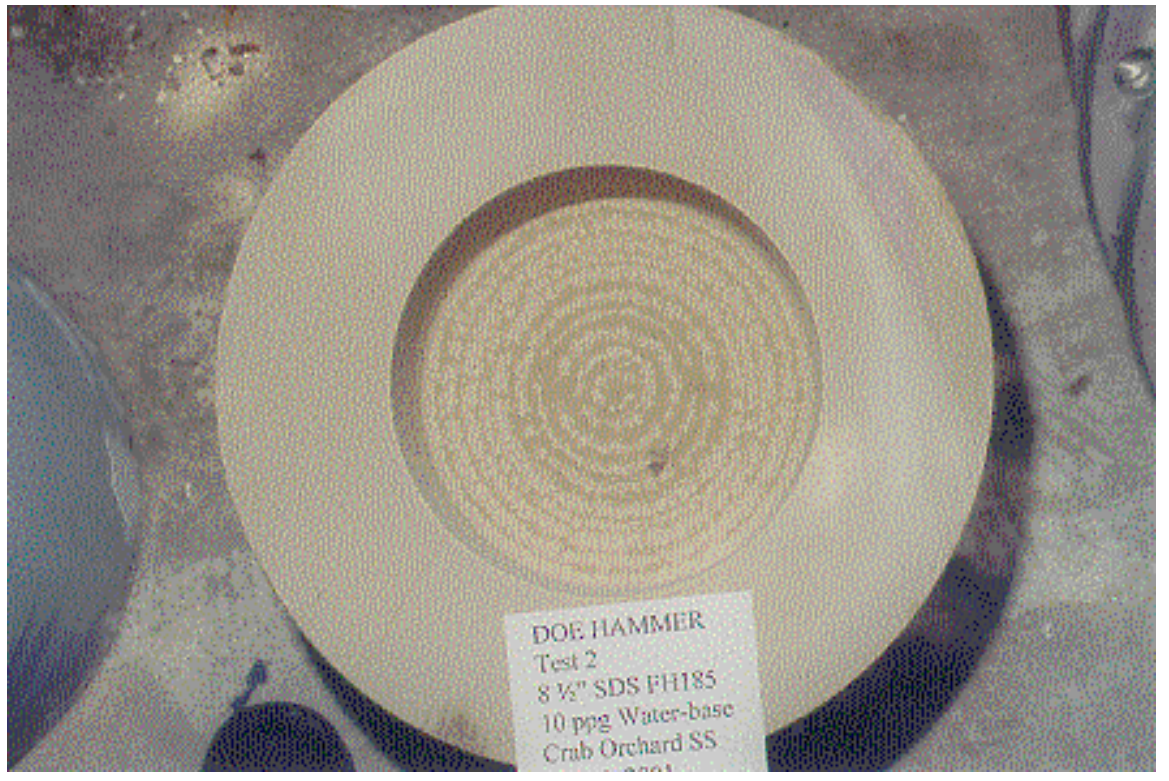

DOE 2 


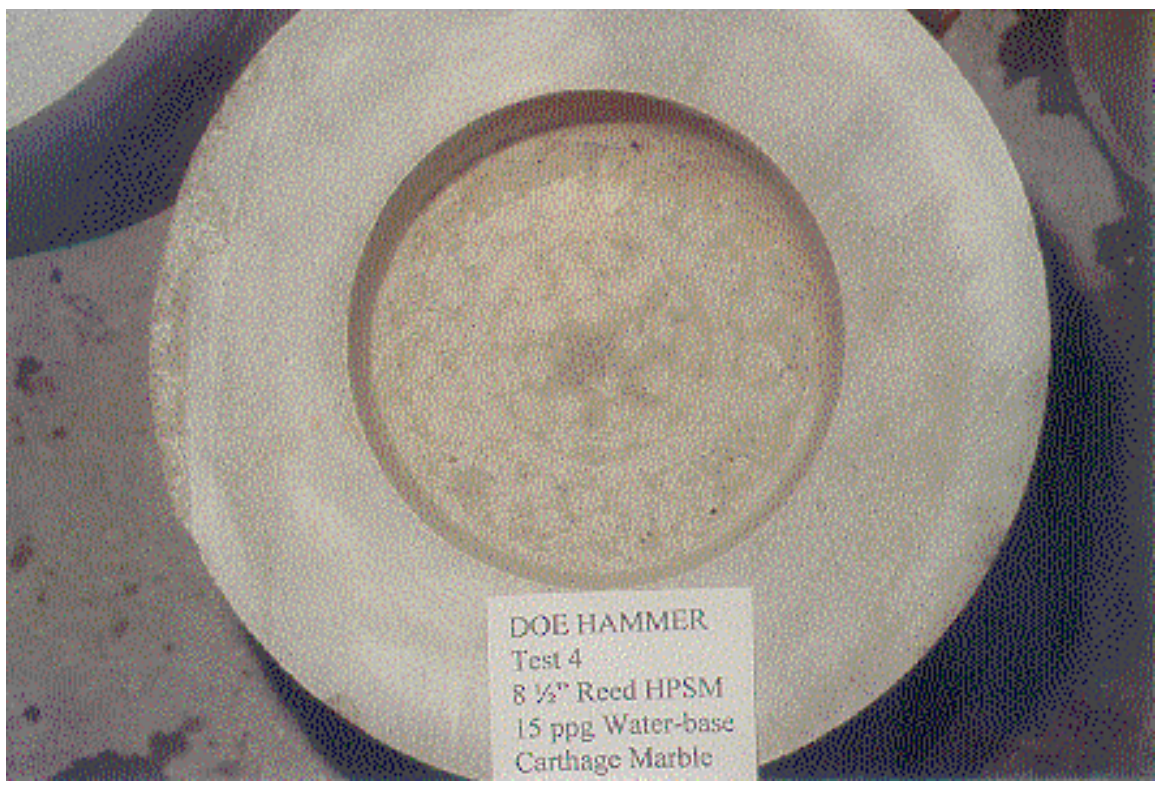

DOE 4

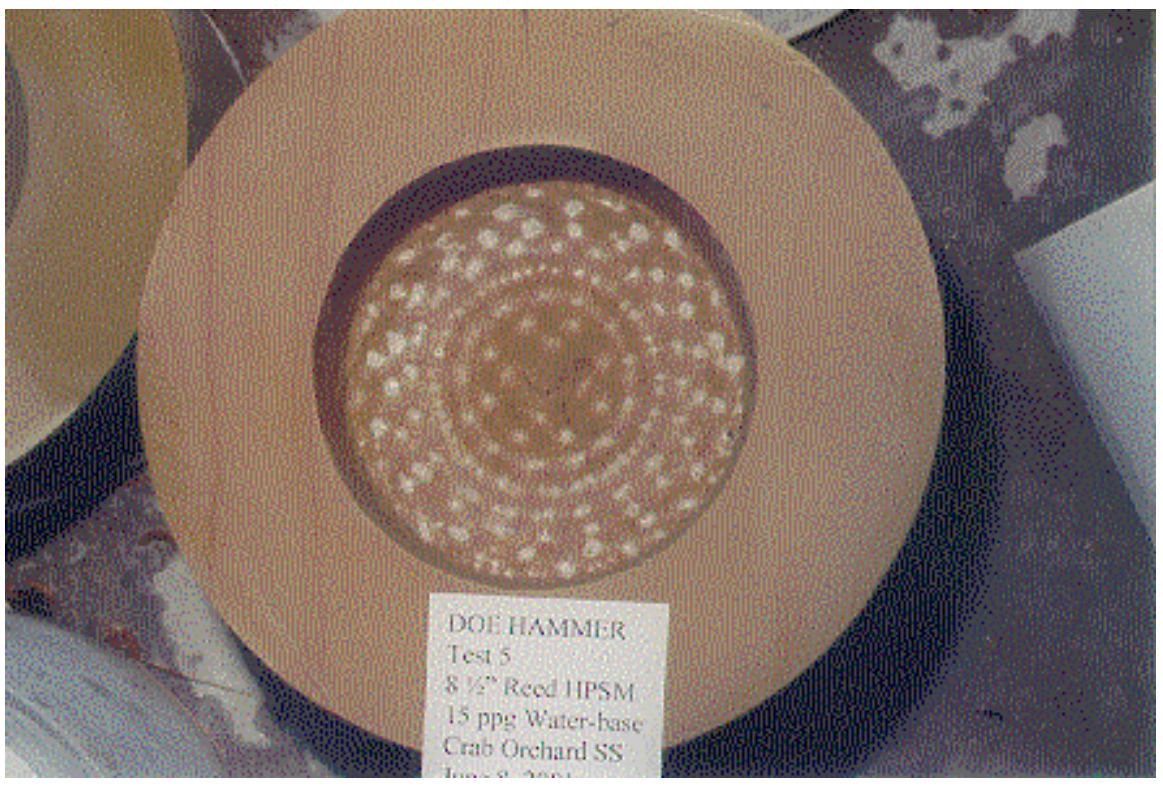

DOE 5 


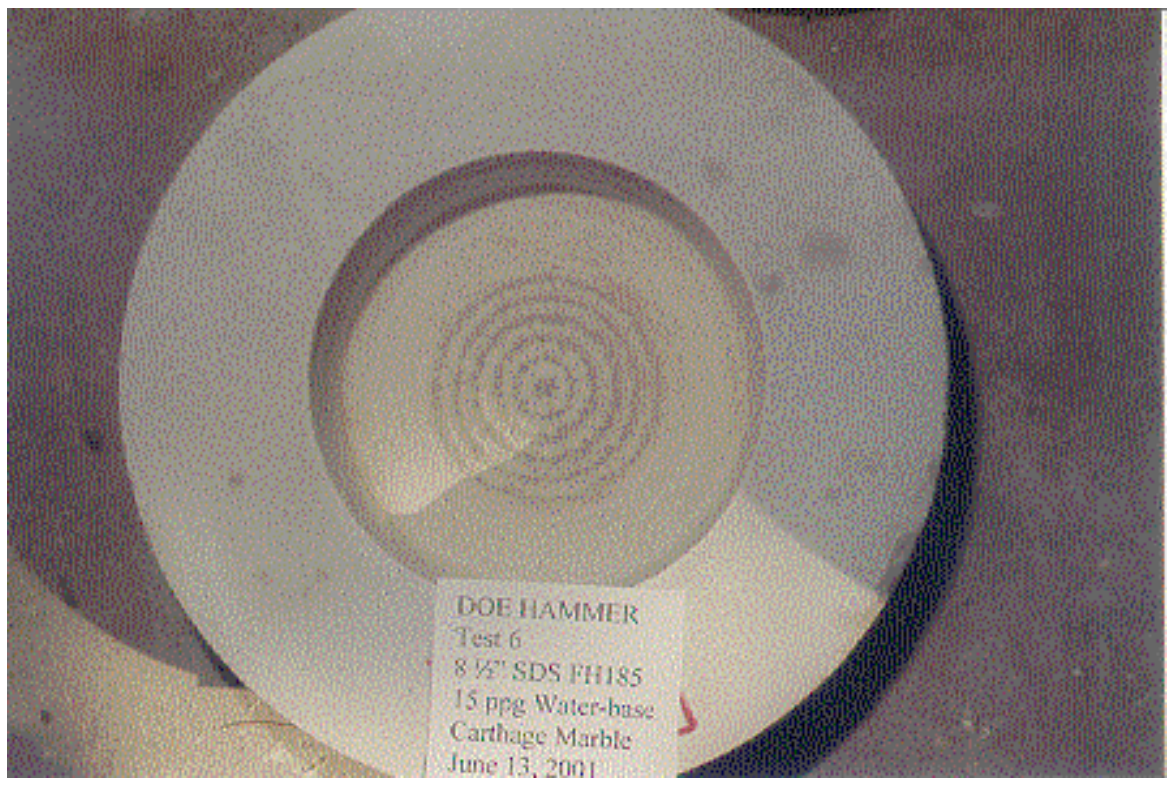

DOE 6

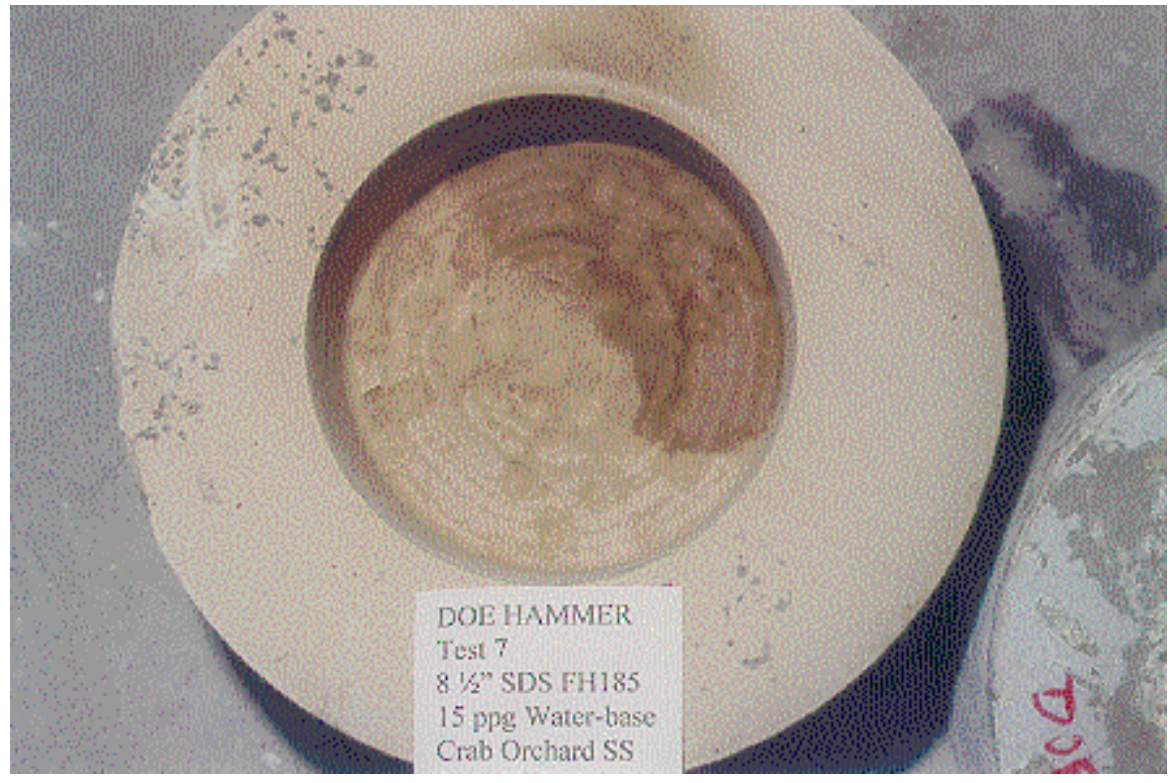

DOE 7 


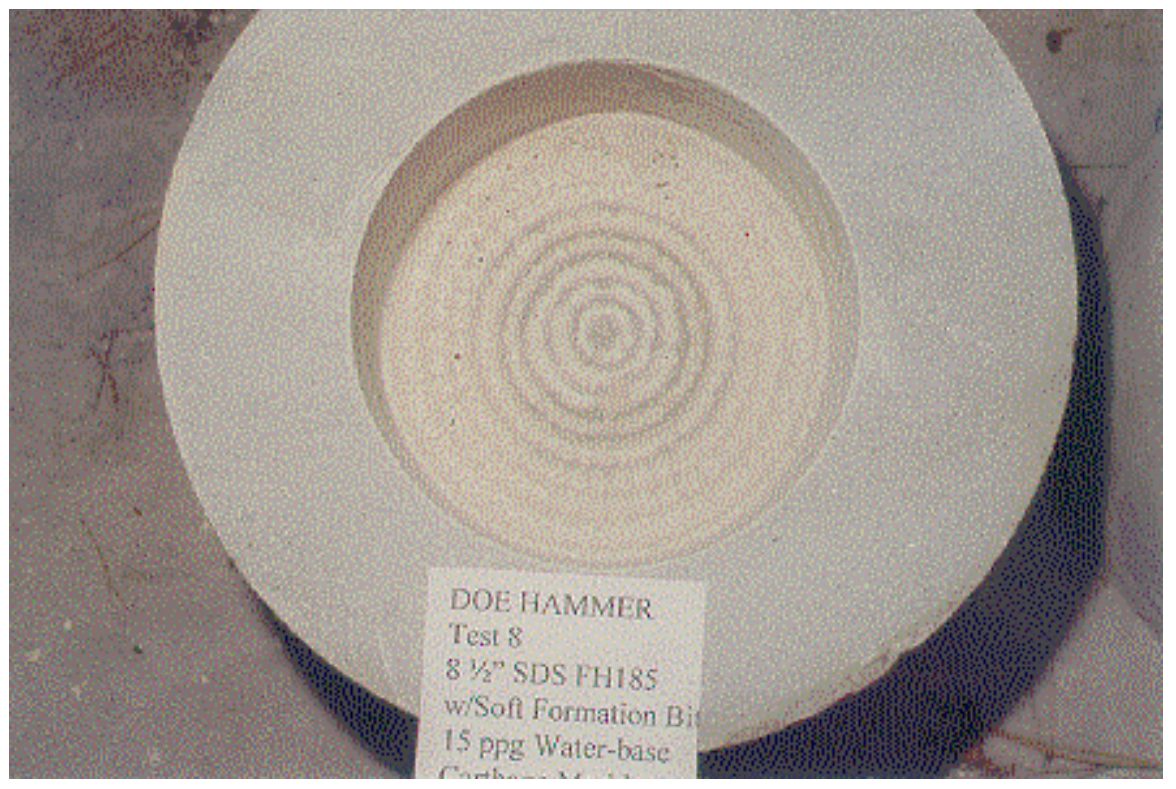

DOE 8

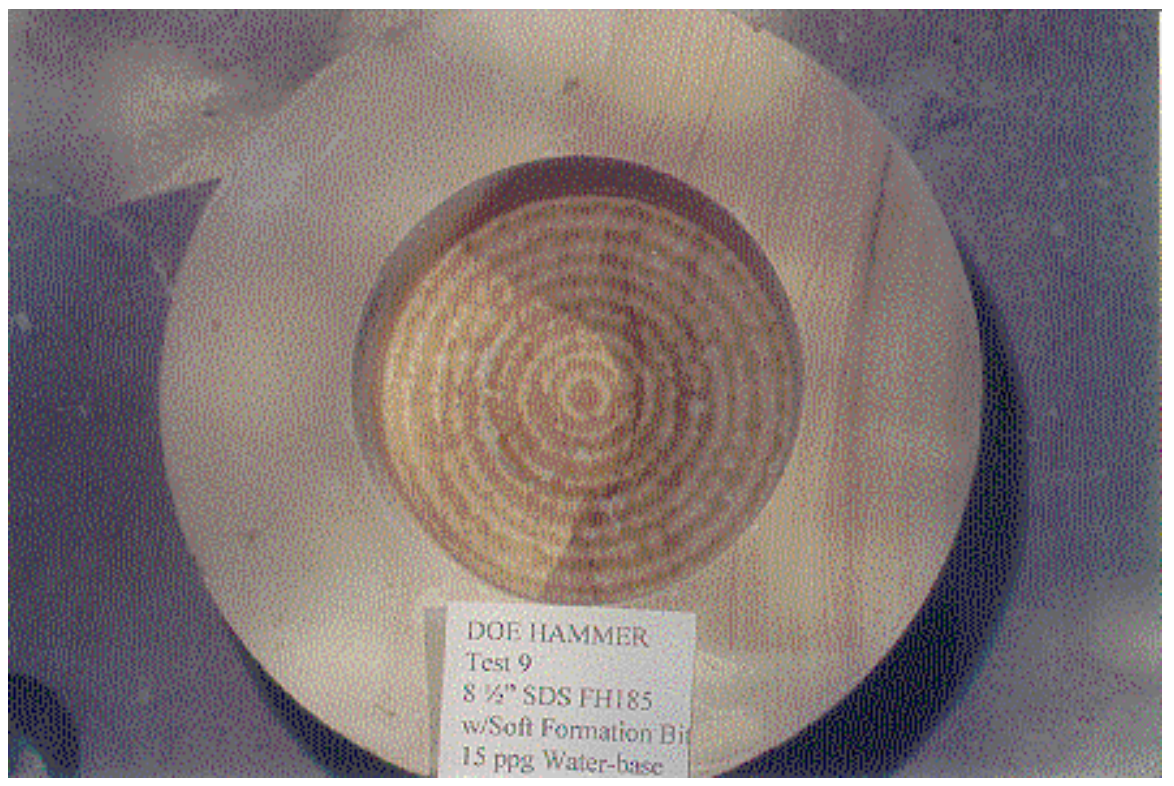

DOE 9 


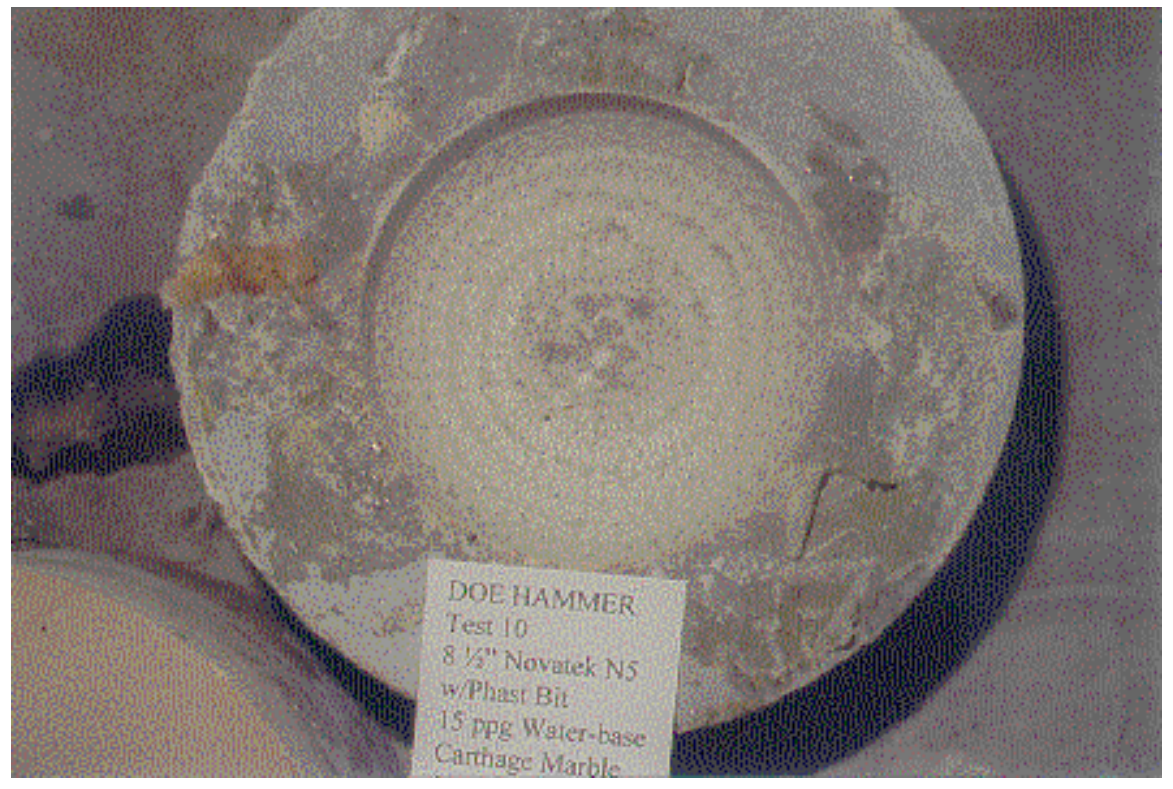

DOE 10

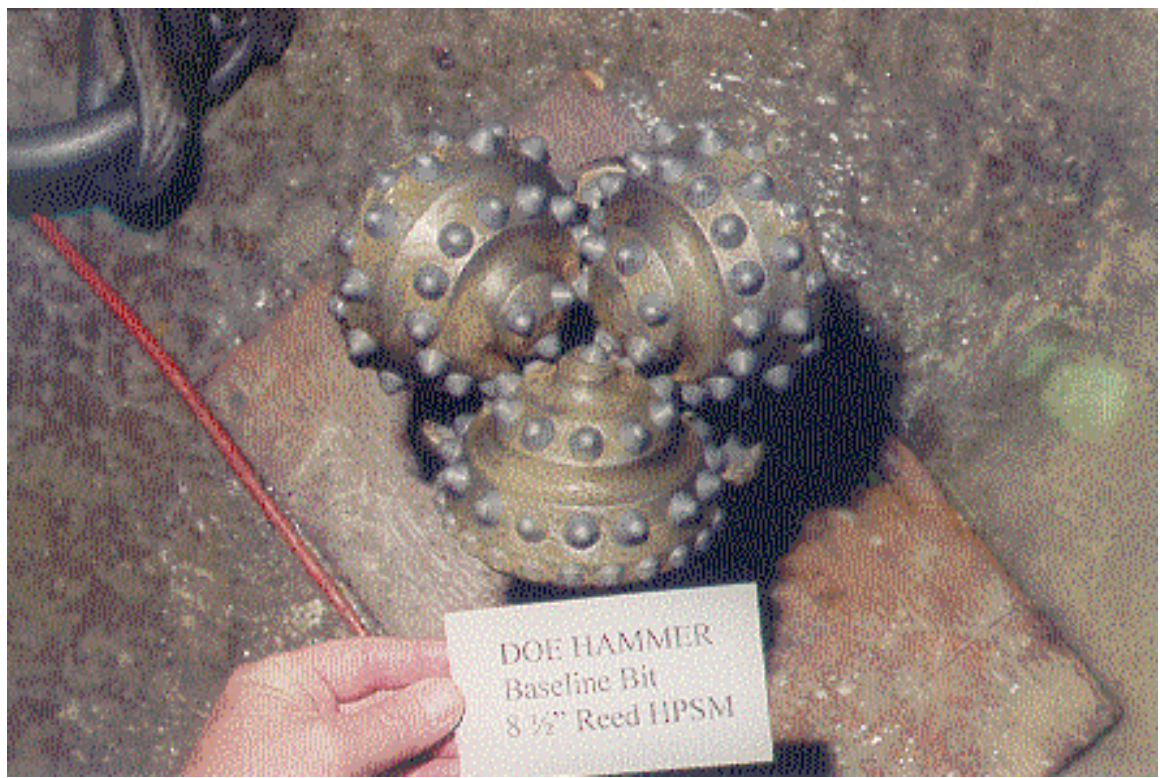

Baseline Bit 


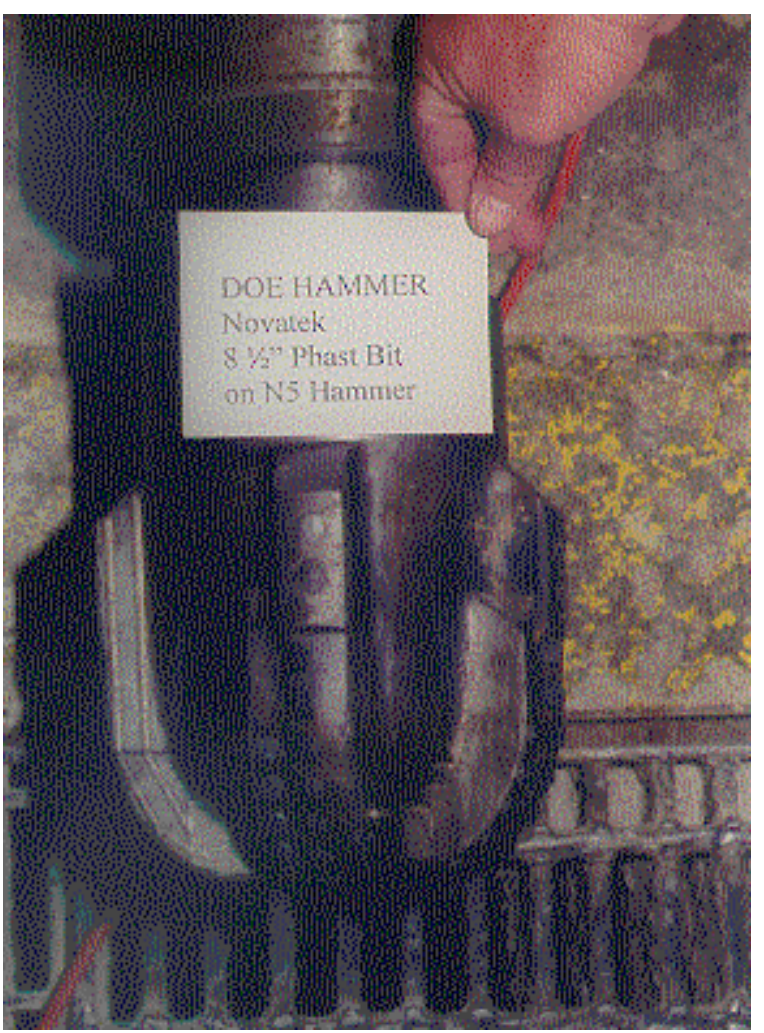

Novatek Bit

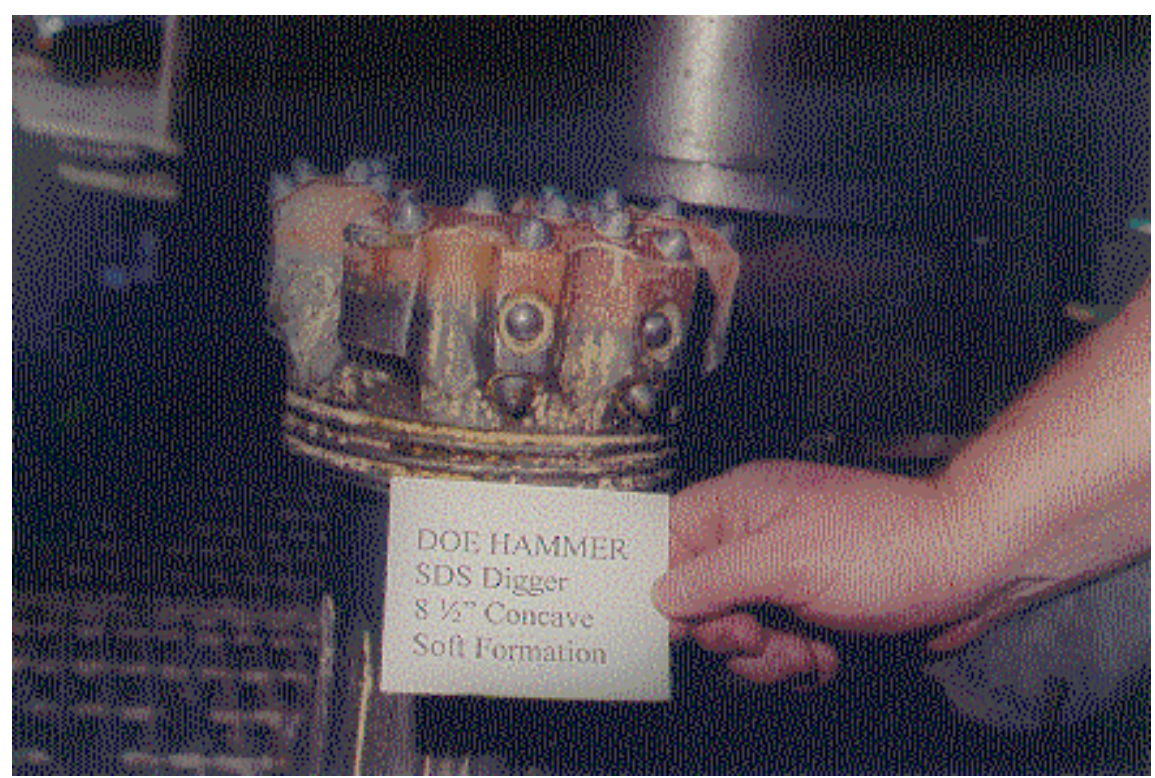

SDS Digger Bit 


\section{Performance data for these tests follow:}

Comparison of DOE Test 1 SDS FH185 Hammer/Hard Formation Bit and 8 1/2" Reed HPSM Bit Rotary Drilling for 10 ppg Water-base Mud and Carthage Marble

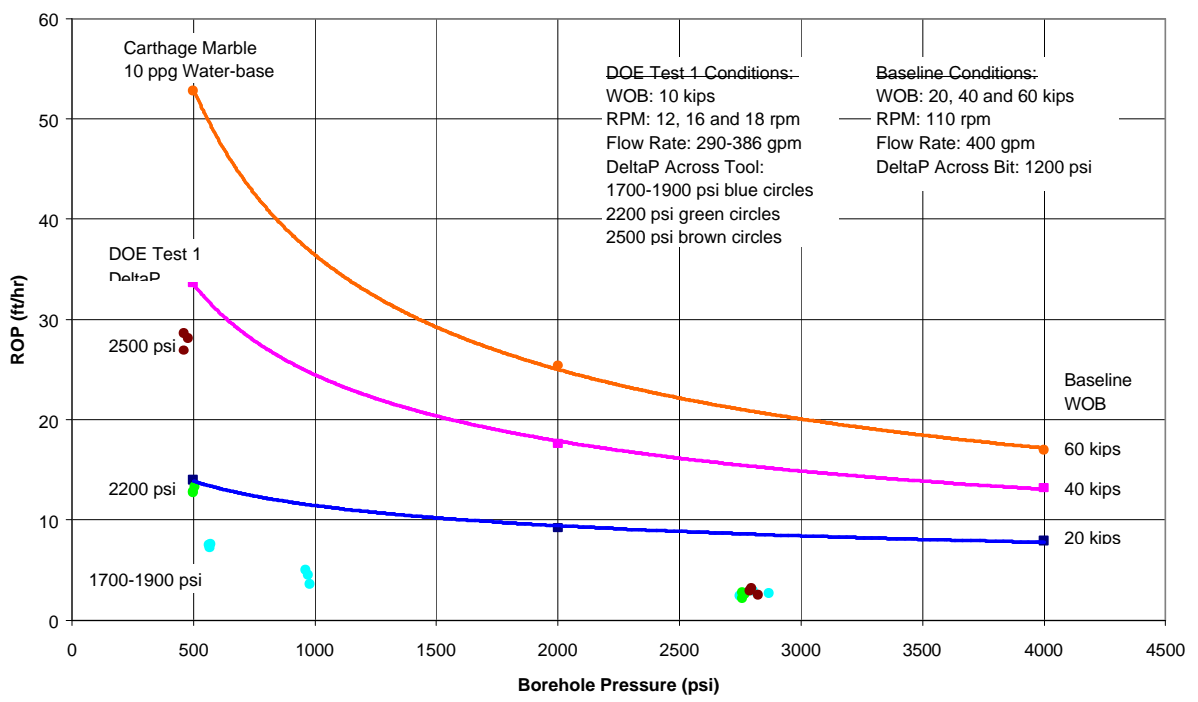

Comparison of DOE Test 2 SDS FH185 Hammer/Hard Formation Bit and 8 1/2" Reed HPSM Bit Rotary Drilling for 10 ppg Water-base Mud and Crab Orchard Sandstone

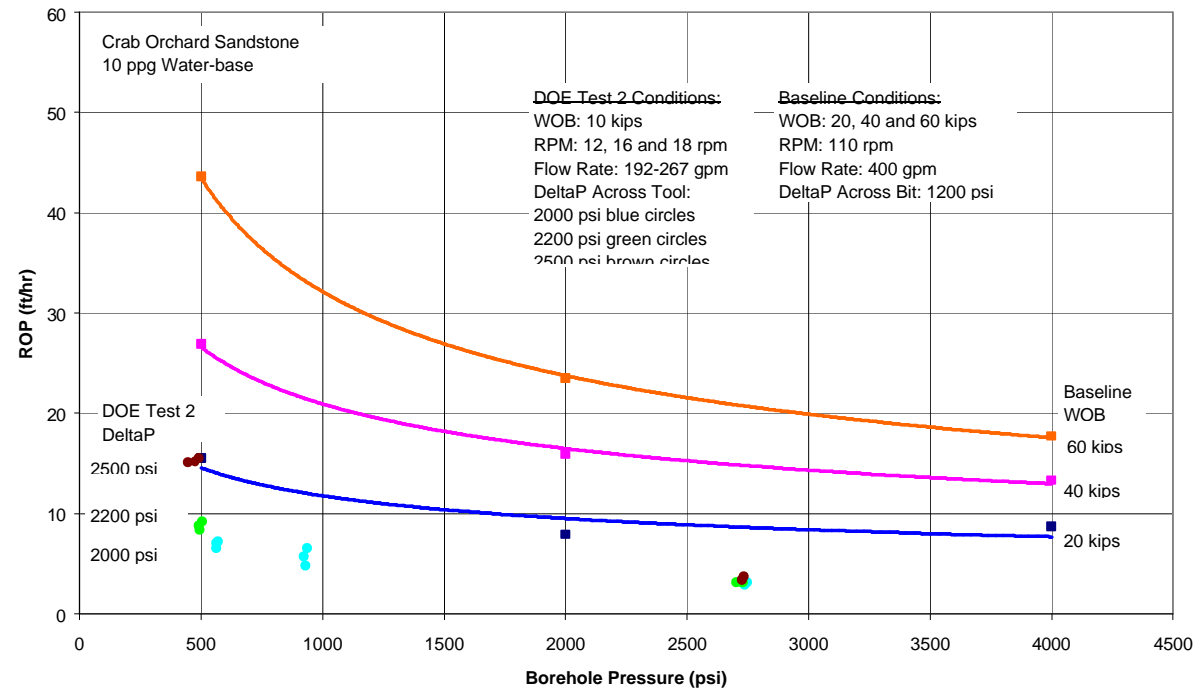


Comparison of DOE 3 Novatek N5 Hammer/Phast Bit and 8 1/2" Reed HPSM Bit Rotary Drilling for $10 \mathrm{ppg}$ Water-base Mud and Carthage Marble

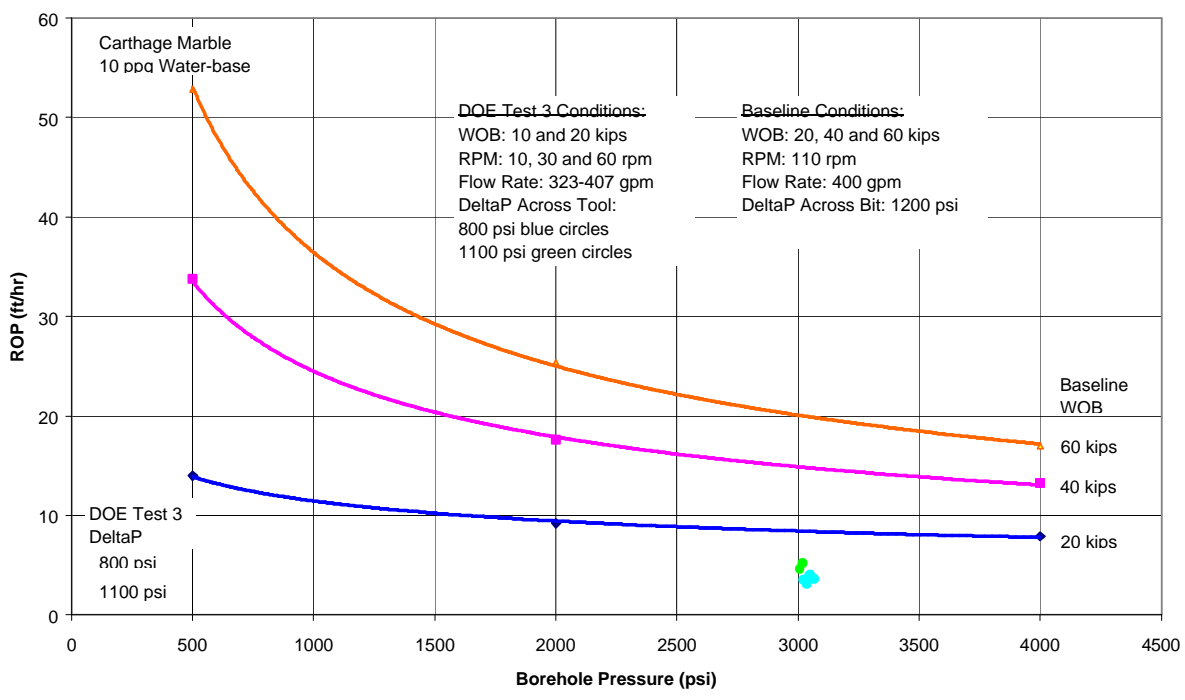

Comparison of DOE 3A Novatek N5 Hammer/Reed HPSM Bit and 8 1/2" Reed HPSM Bit Rotary Drilling for $10 \mathrm{ppg}$ Water-base Mud and Carthage Marble

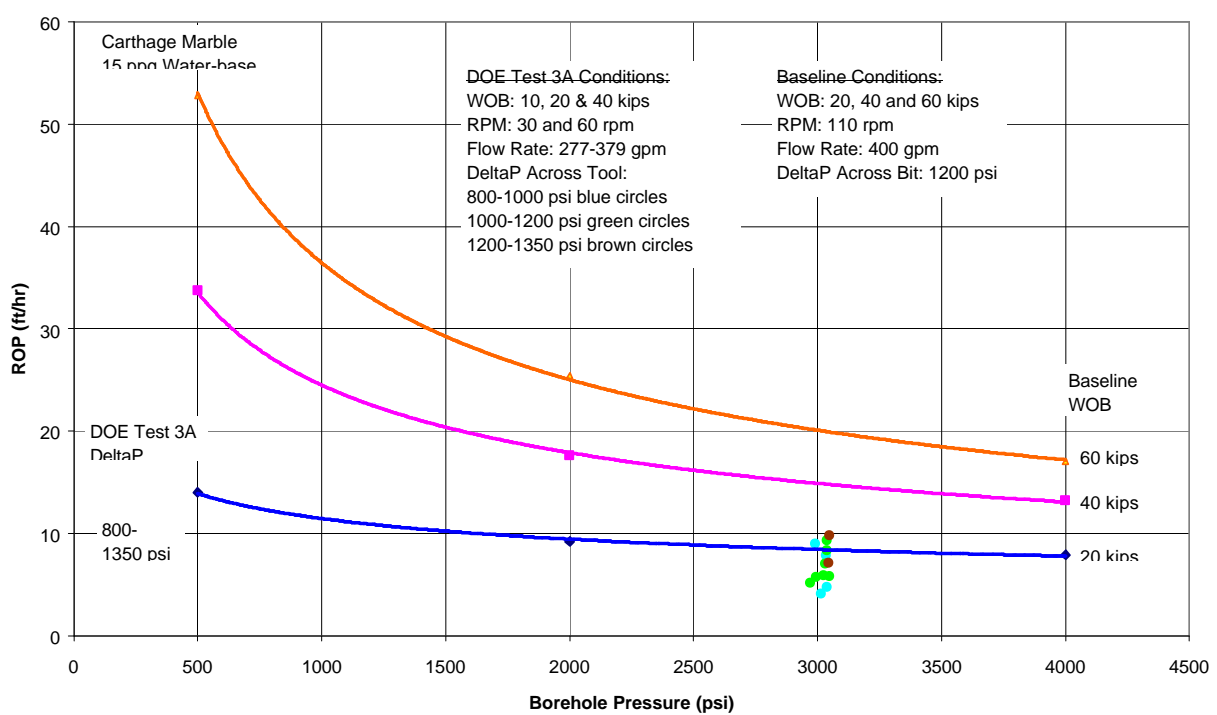




\section{DOE 4}

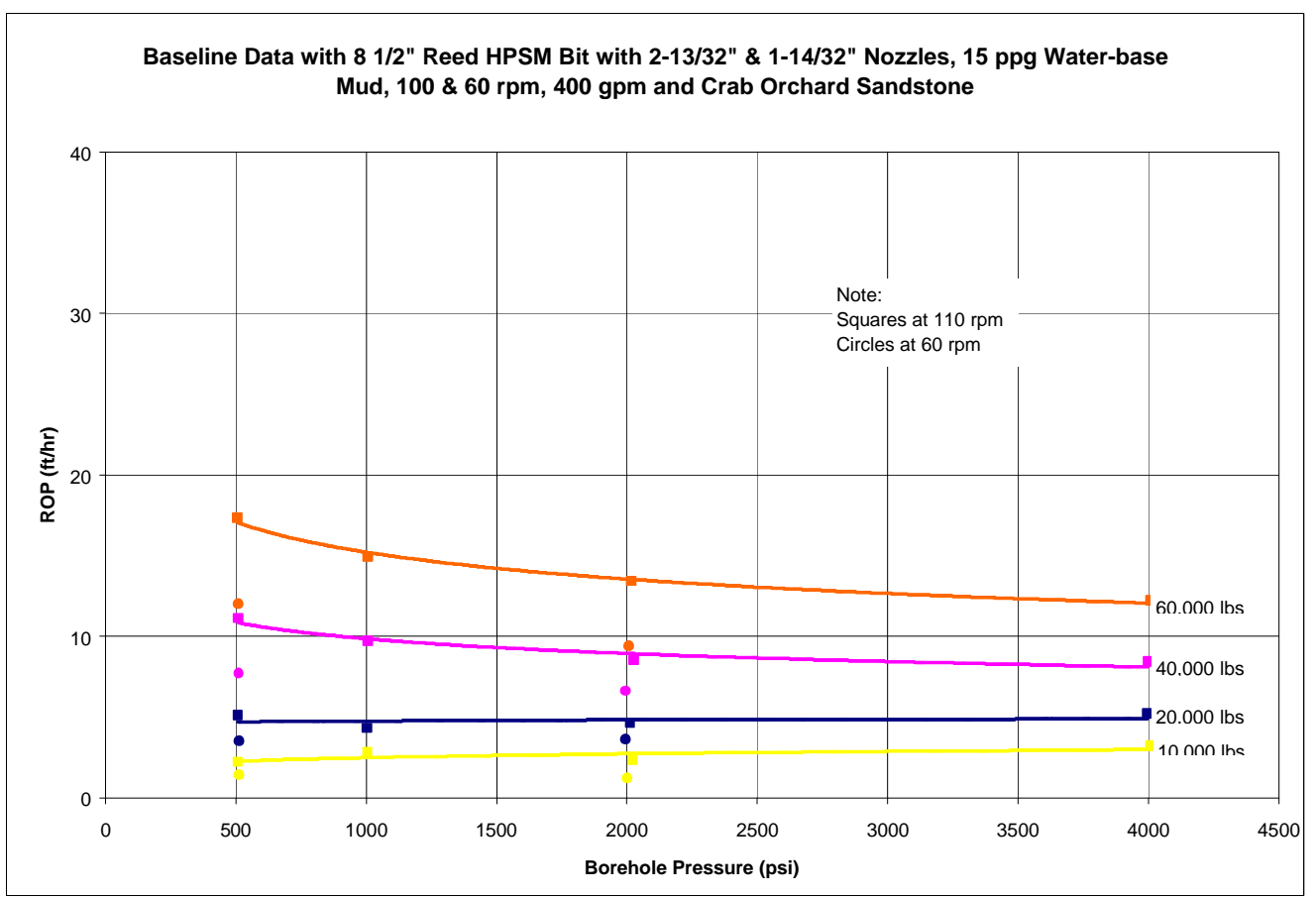

\section{DOE 5}

Baseline Data with 8 1/2" Reed HPSM Bit with 2-13/32" \& 1-14/32",

$15 \mathrm{ppg}$ Water-base Mud, $110 \& 60 \mathrm{rpm}, 400 \mathrm{gpm}$ and Carthage Marble

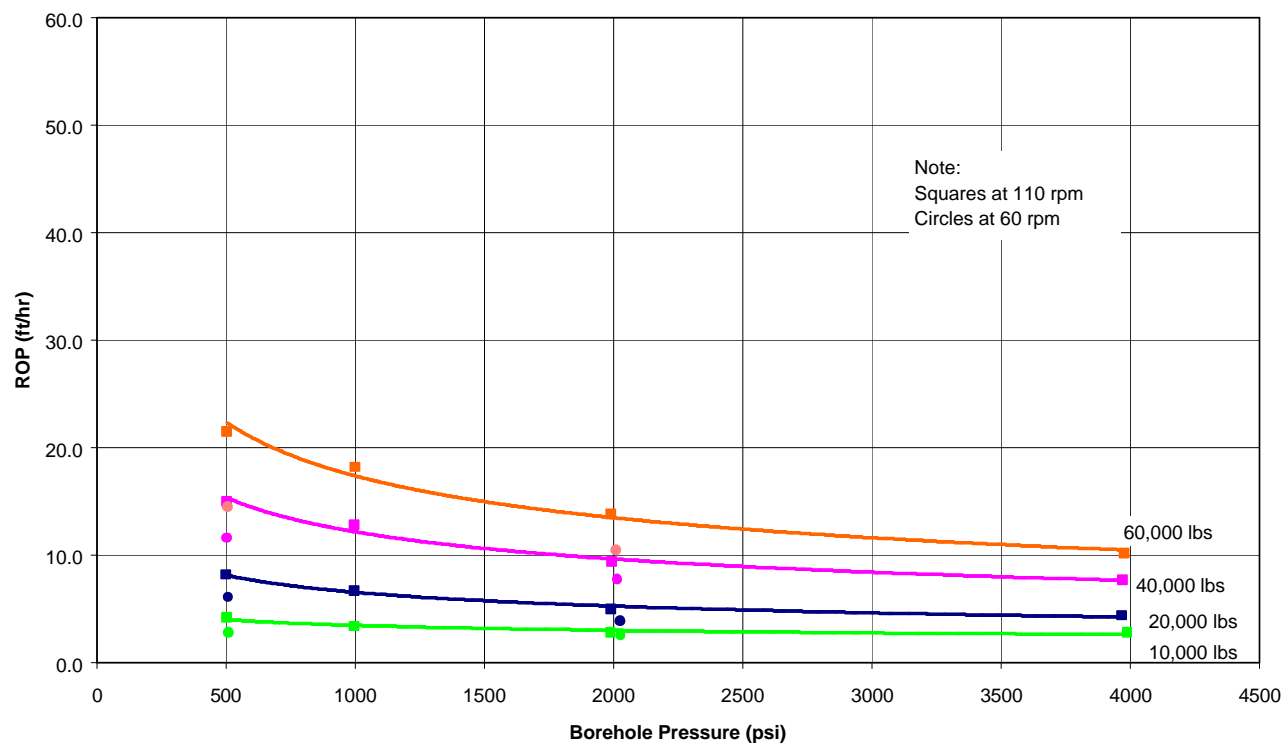




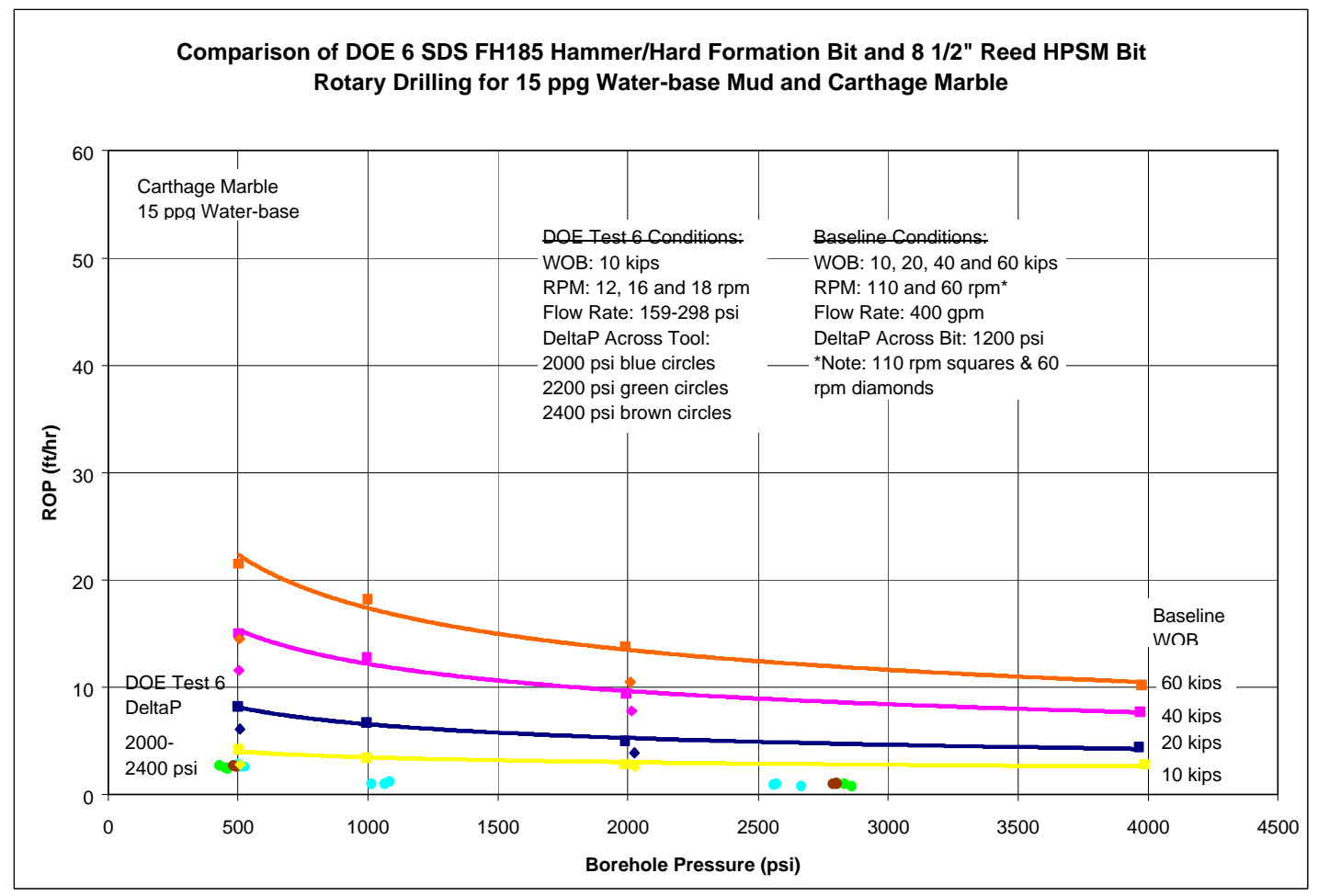

Comparison of DOE 7 SDS FH185 Hammer/Hard Formation Bit and 8 1/2" Reed HPSM Bit Rotary Drilling for 15 ppg Water-base Mud and Crab Orchard Sandstone

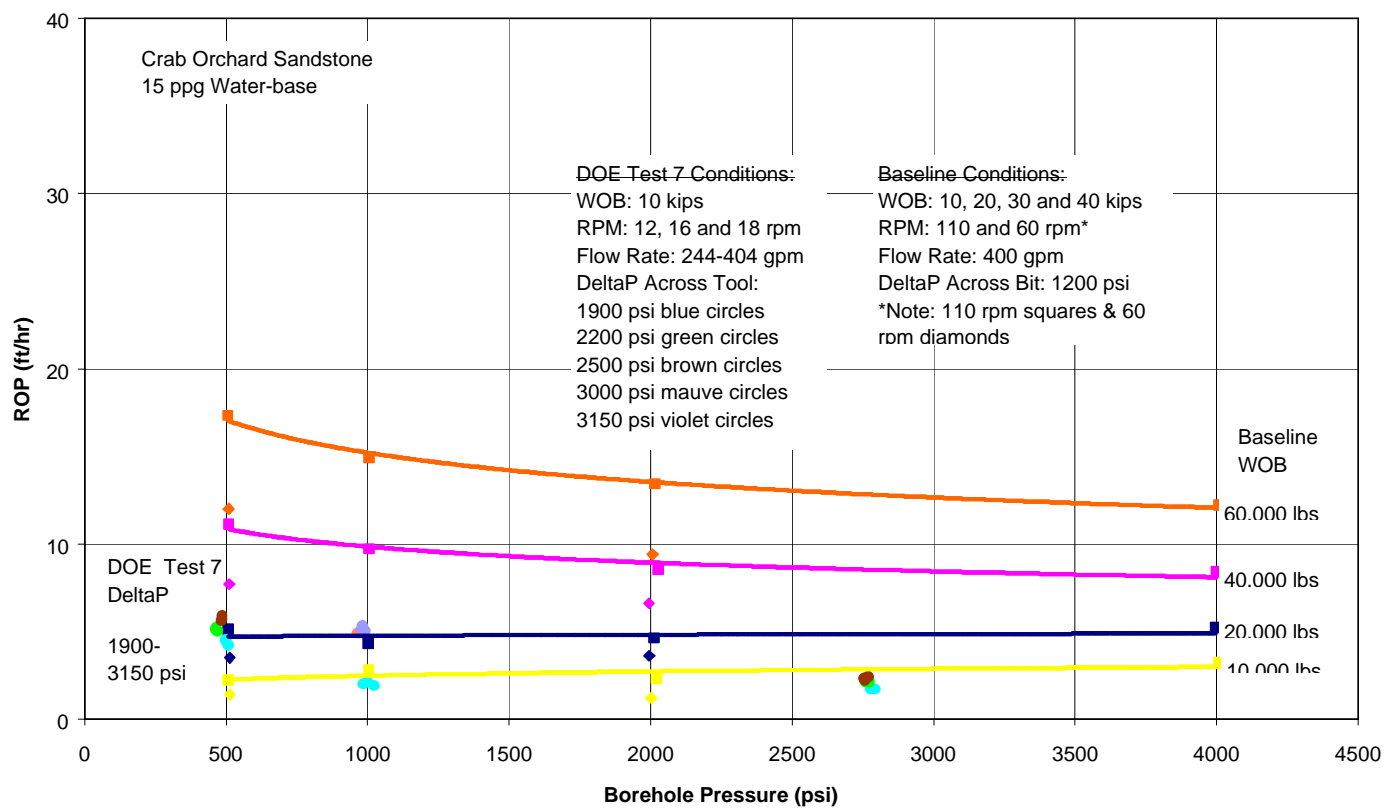




\section{Comparison of DOE 8 SDS FH185 Hammer/Soft Formation Bit and 8 1/2" Reed HPSM Bit} Rotary Drilling for 15 ppg Water-base Mud and Carthage Marble

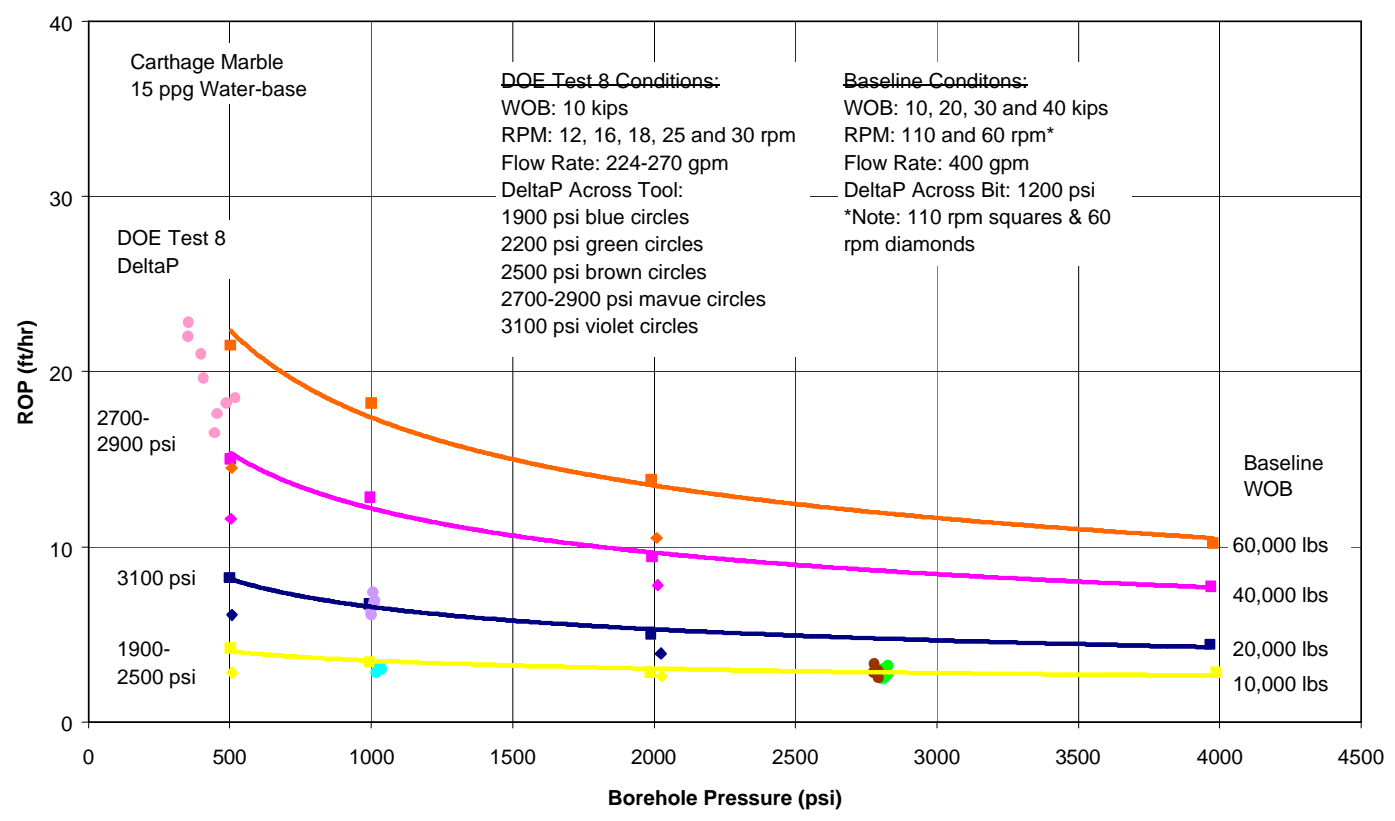

Comparison of DOE 9 SDS FH185 Hammer/Soft Formation Bit and 8 1/2" Reed HPSM Bit Rotary Drilling for 15 ppg Water-base Mud and Crab Orchard Sandstone

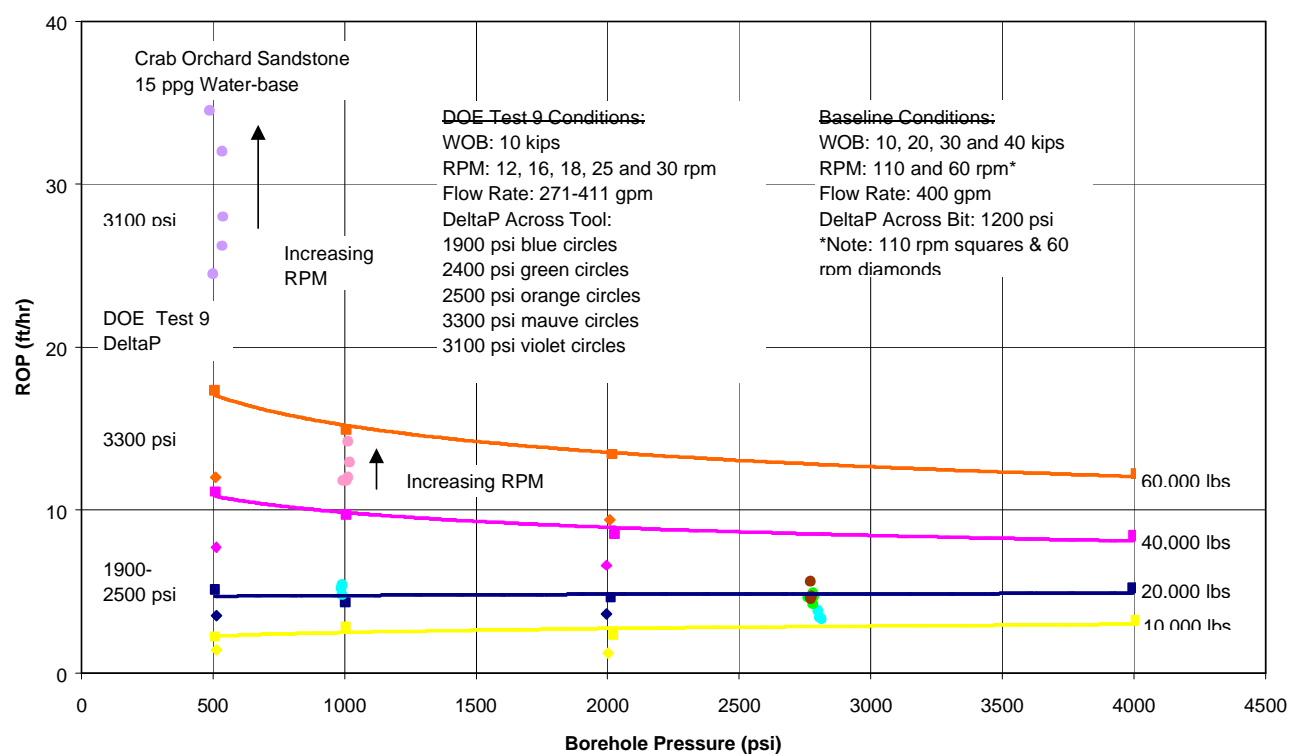


Comparison of DOE 10 Novatek N5 Hammer/Phast Bit and 8 1/2" Reed HPSM Bit Rotary Drilling for 15 ppg Water-base Mud and Carthage Marble
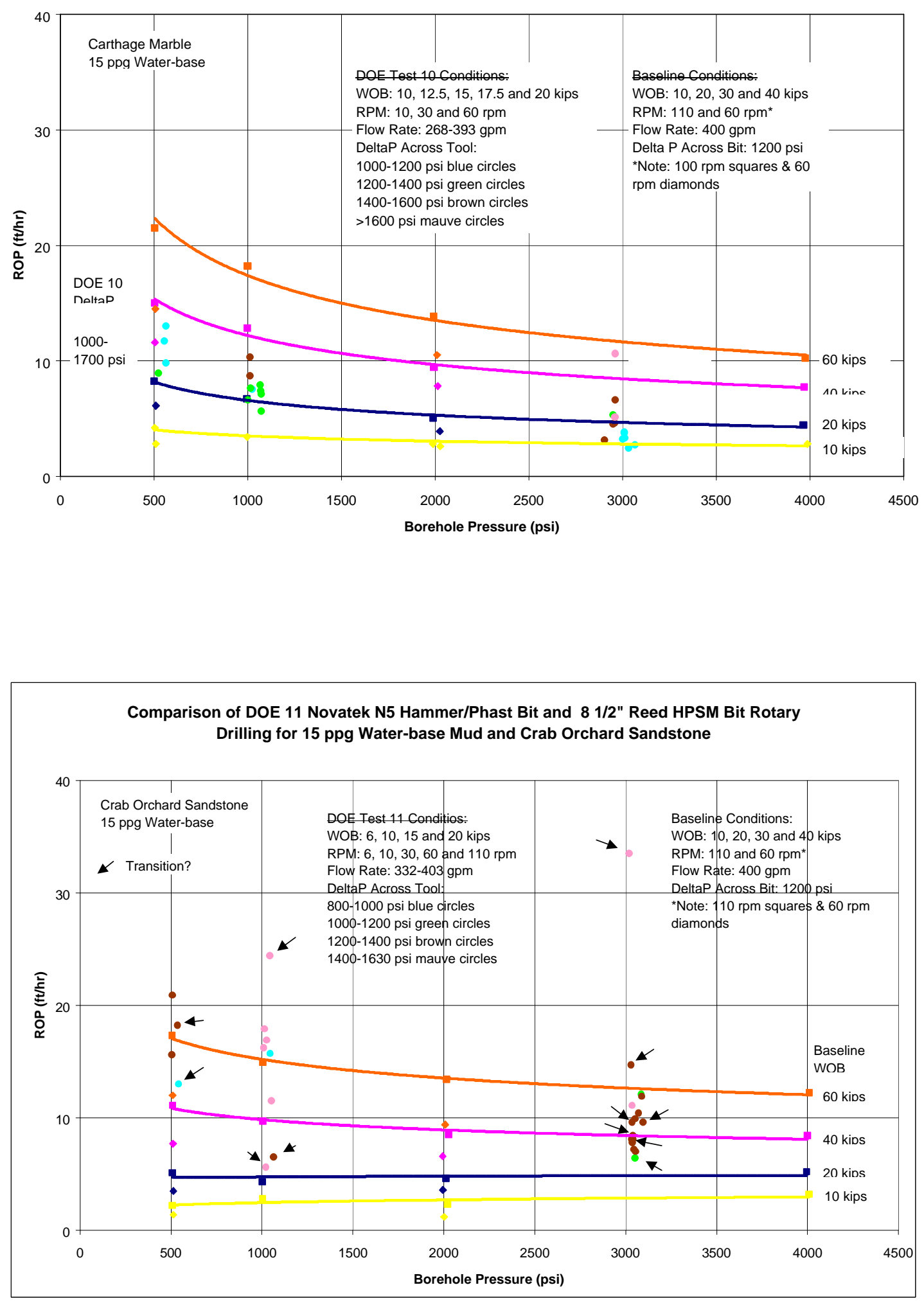


\section{Comparison of DOE 12 Novatek N5 Hammer/Phast Bit and 8 1/2" Reed HPSM Bit Rotary Drilling for 15 ppg Water-base Mud and Carthage Marble}

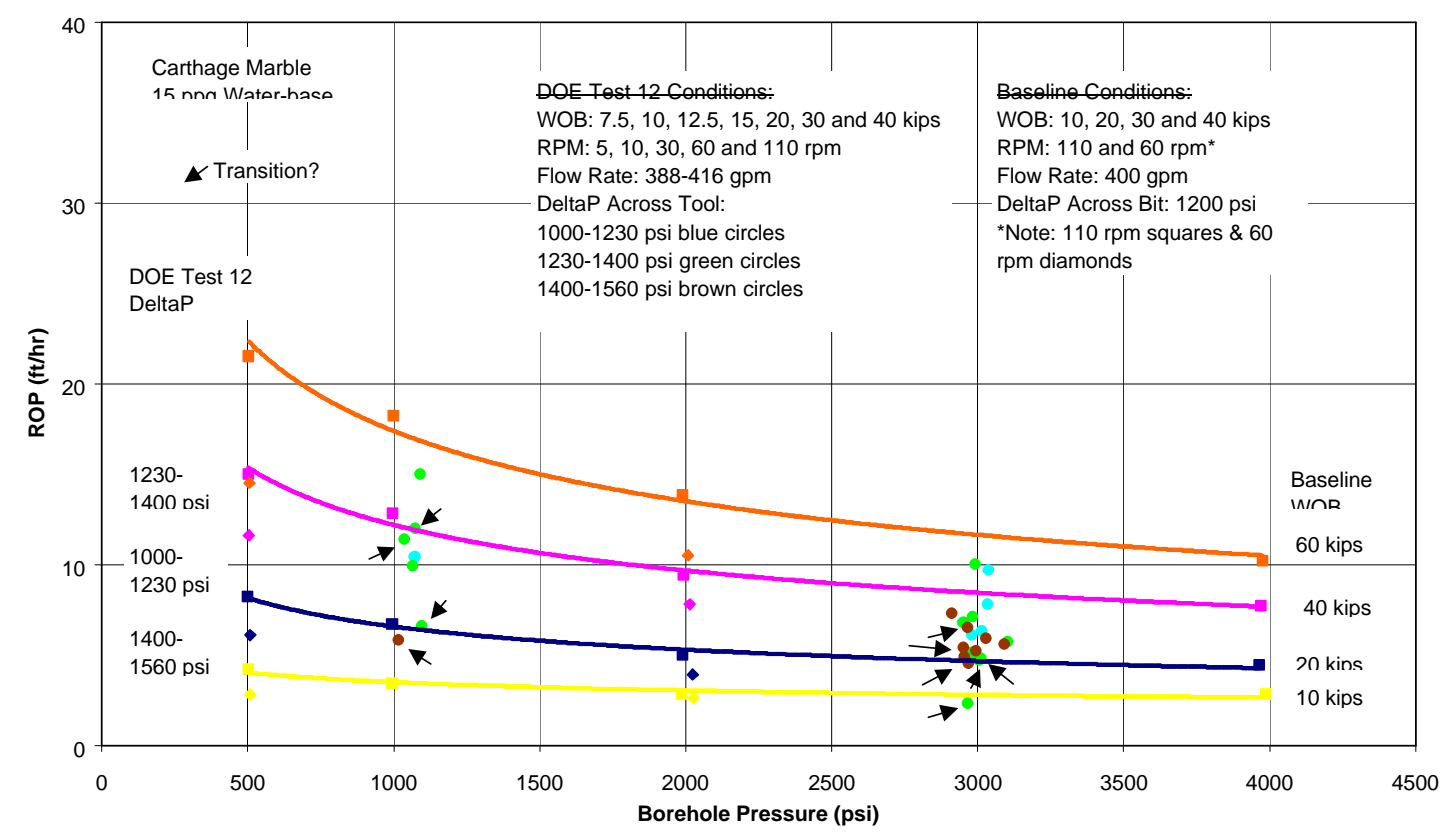

2002

Q1 and Q2; All experimental work for Phase 1 testing has been completed and reported. Discussions and planning for Task 6 are underway with addition experimental work commencing after the February 22, 2002 planning meeting.

Experimental work for 'Benchmark' testing has been completed with the introduction of the Smith International hammer tests during the week of 4 November 2002.

Q3 and Q4; The following test matrix was followed (13 tests were previously done):

\begin{tabular}{|l|l|l|l|}
\hline DOE Number* & Hammer/Bit & Rock & Mud Density, ppg \\
\hline 13 Test \#14 & 3 cone IADC Code 537 & Carthage & 9 ppg brine \\
\hline 14 Test \#15 & Smith & Carthage & 9 ppg brine \\
\hline 15 Test \#16 & Smith & Carthage & 10 ppg water-based \\
\hline 16 Test \#17 & Smith & Crab Orchard & 10 ppg water-based \\
\hline 17 Test \#18 & Smith & Carthage & 15 ppg water-based \\
\hline
\end{tabular}

*Prior reports reviewed Tests 1 through 13 using DOE \#s to 12

From previous testing, the comparison to 'conventional drilling' is available for 10 and 15 ppg fluids. Industry input at the February '02 planning meeting (particularly BP, PDVSA) prompted plans to use a lighter weight brine as extra data points. 
2003

Experimental work for 'Benchmark' testing was completed with the introduction of the Smith International hammer tests during the week of 4 November 2002. Experimental work completing Task 6 is awaiting Smith's tool for February 2004 and Novatek's tool mid 2004.

\section{4}

Experimental work for 'Benchmark' testing has been completed with the introduction of the Smith International hammer tests during the week of 4 November 2002.

Experimental work during 2Q 2004 for 'Optimization' testing was completed with the Smith International hammer tests during the weeks of April 19 and 26, 2004. Experimental work completing Task 6 is awaiting Novatek's tool mid 2005.

The following test matrix was followed (17 tests were previously done):

\begin{tabular}{|l|l|l|l|}
\hline DOE Number & Hammer/Bit & Rock & Mud Density, ppg \\
\hline 18 Baseline & 3 cone IADC Code 537 & Crab Orchard / Carthage & 10 ppg water-based \\
\hline 19 & Smith, standard bit & Crab Orchard / Carthage & 9 ppg brine \\
\hline 20 & $\begin{array}{l}\text { Smith, standard bit, but } \\
\text { with torque 'feed-back' }\end{array}$ & Crab Orchard / Carthage & 10 ppg water-based \\
\hline 21 & Smith, standard bit & Crab Orchard & 10 ppg water-based \\
\hline 22 & $\begin{array}{l}\text { Smith, aggressive bit } \\
\text { with chisel cutters }\end{array}$ & Carthage & $\begin{array}{l}10 \text { ppg WBM followed } \\
\text { by 15 ppg water-based }\end{array}$ \\
\hline
\end{tabular}

Industry input at the February '02 planning meeting (particularly BP, PDVSA) prompted plans to use a lighter weight brine as extra data points. Test \#22 was interrupted before weighting up to $15 \mathrm{ppg}$ due to some hammer tool problems.

Details $-8-1 / 2$ " bits (including aggressive chisel shaped)

Addition of internal 'accumulator' system to hammer 350 to 400 gpm flow rate. Pressure drops $\sim 2500$ psi

Servo control on torque signal - Many data points at 600 to $800 \mathrm{ft}-\mathrm{lb}$

\section{DOE - Smith Hammer Drilling Test Plan Updated April 7, 2004}

1. Number of Tests: 5 plus torque checkout test

2. Type Tests: 1 baseline, 10 ppg water-base, roller-cone, Crab Orchard/Carthage composite 1 torque control checkout, 10 ppg water-base, roller-cone, Carthage 1 hammer, 9 ppg $\mathrm{NaCl}$ brine, standard bit, Crab Orchard/Carthage composite 1 hammer, 10 ppg water-base, standard bit, Crab Orchard/Carthage composite 1 hammer, 10 ppg water-base, standard bit, Crab Orchard ss with pore pressure $1 / 2$ hammer, 10 ppg water-base, aggressive bit, Carthage marble $1 / 2$ drilled $1 / 2$ hammer, 15 ppg water-base, aggressive bit, Carthage marble 1/2 drilled *Composite: Spud 1", drill CO 17", drill Carthage 16", leave 3" at bottom 
3. Test Control:

TerraTek will attempt to set up the torque signal as feed back to the servocontroller and will check out this torque feed back mode prior to the DOE tests. If successful, torque feed back will be used to control the four hammer tests in the 500 to $1000 \mathrm{ft}$ lbs torque range.

4. Test 18 Baseline Test: Using the standard 8 1/2" diameter Reed HPSM baseline bit, drill a composite sample of Crab Orchard ss/Carthage marble using a 10 ppg water-base mud and limit WOB 40,000 lbs and RPM $60 \mathrm{rpm}$. Run 10, 40 and 60 kips WOB, 60 rpm and borehole pressures of 500, 1000, 2000 and 4000 psi.

5. Test 19 Hammer Test: Using Smith hammer with 8 1/2” standard bit, drill a composite sample of Crab Orchard ss/Carthage marble using 9 ppg $\mathrm{NaCl}$ brine in torque feed back between 500-1000 ft lbs with 500, 1000, 2000 and 3000 psi borehole pressures and flow rates $400 \mathrm{gpm}$ or less as specified by Smith. RPM will be specified by Smith. Near the end of the test, drill a short distance at 0 psi borehole pressure by directly flowing back to the mud tank.

6. Test 20 Hammer Test: Using Smith hammer with 8 1/2” standard bit, drill a composite sample of Crab Orchard ss/Carthage marble using 10 ppg water-base mud in torque feed back between 500-1000 ft lbs with 500, 1000, 2000 and 3000 psi borehole pressures and flow rates $400 \mathrm{gpm}$ or less as specified by Smith. RPM will be specified by Smith. Three times during the test (after 500 and 3000 psi borehole pressure in the Crab Orchard sandstone and 500 psi borehole in the Carthage marble) the test will be stopped and the cuttings screen emptied and the vessel opened up and sample removed to photograph the bottom hole pattern. After test, collect cuttings from 3000 psi in the Carthage marble and photograph bottom hole pattern. Near the end of the test, drill a short distance at 0 psi borehole pressure by directly flowing back to the mud tank.

7. Test 21 Hammer Test: Using Smith hammer with 8 1/2" standard bit, drill a full saturated sample of Crab Orchard ss using 10 ppg water-base mud in torque feed back between 500$1000 \mathrm{ft}$ lbs with differential pressure across the filter-cake from underbalanced to balanced to 3000 psi overbalanced. Initially pump fluid at a known rate into the bottom of the sample and through the borehole to create an underbalanced drilling condition. After drilling a short distance, stop pumping and with a borehole pressure and pore pressure equal at 3000 psi ( 0 psi differential) begin drilling and then open the pore pressure valve and begin bleeding off pore pressure at a reasonably controlled rate from 3000 to 0 psi. As differential pressure across the filter-cake increases, then ROP should decrease. With flow rate 400 gpm or less as specified by Smith, RPM as specified by Smith, drill the entire sample. During the drilling test, continuously monitor borehole and pore pressure and the amount of pore fluid volume expelled versus time. Knowing the permeability of the Crab Orchard sandstone, back calculate the pressure drop across the rock and the resulting differential pressure across the filter-cake as (Borehole Pressure minus Pore Pressure) - (Calculated Pressure Drop Across the Rock).

8. Test 22 Hammer Test Using Smith hammer with 8 1/2" an aggressive bit, drill $1 / 2$ of a full Carthage marble sample using a $10 \mathrm{ppg}$ water-base mud in torque feed back between 500-1000 ft lbs with 500, 1000, 2000 and 3000 psi borehole pressures and flow rates $400 \mathrm{gpm}$ or less as specified by Smith. RPM will be specified by Smith. Stop the test and increase mud density to $15 \mathrm{ppg}$ and drill the remaining $1 / 2$ of the Carthage marble sample at the same conditions. Three times during the test (after 500 and 3000 psi borehole pressure with 10 ppg mud and at 500 psi borehole with $15 \mathrm{ppg}$ mud, the test will be stopped and the cuttings screen emptied and the vessel opened up and sample removed to photograph the bottom 
9. Data Acquisition:

10. Accumulators:

11. Make up/breakout:

12. Cuttings collection:

13. Bottomhole Photos: hole pattern. After test, collect cuttings from the 15 ppg and 3000 psi condition and photograph bottom hole pattern. Near the end of the test, drill a short distance at 0 psi borehole pressure by directly flowing back to the mud tank.

Smith will bring their own data recording equipment to record the dynamic WOB and torque signals at 500 to $1000 \mathrm{~Hz}$ continuously. TerraTek will provide the cables to direct the signals to the Smith data acquisition system in the form of $+/-10$ volt DC signals.

Set up and tie down two 10 gallon accumulators if available or one only and set gas pressure to $600-800$ psi.

TerraTek will provide a Scorpion make up/breakout unit with up to 30,000 $\mathrm{ft}$ lbs capacity to assist Smith in disassembling a section of the hammer, modifying the tool for the next mud weight and then assembling it again.

During Tests 20 and 22, the test will be stoppedthree times (at 500 and 3000 psi in the Crab Orchard ss and at 500 psi in the Carthage marble) to empty the cutting collection screen in an attempt distinguish the differences in cuttings size and shape for these conditions. Also, after the test the cuttings from the 3000 psi borehole pressure in the Carthage marble will be collected. Therefore, a comparison can be made between cuttings generated at 500 and 3000 psi borehole pressure in both rock types.

During Tests 20 and 22, the sample will be removed three times during the test (at the same time the cuttings are recovered as noted above) and the mud from the bottomhole will be cleaned out and the bottom hole pattern photographed. It will be necessary to mount the camera on an extension rod and to provide lighting to get the camera close enough to the bottom hole to distinguish the bottom hole pattern clearly.

14. Test 21 Pore Pressure: Prior to Test 21, a 15.5" diameter by 35.5" long Crab Orchard sandstone sample will be evacuated and saturated with water. After placing the sample inside the pressure vessel and applying confining pressure, water will be pumped into the bottom of the sample via a flow distributor plate to flow through the sample. A 100 psi back pressure will be maintained on the water flowing out of the sample to help distribute the water throughout the sample and to absorb any residual gas into the pressurized water. Since the Crab Orchard sandstone has a relatively low permeability, this process will likely take at least 24 hours to complete the saturation. After the saturation is complete and just prior to the drilling test, the borehole pressure will be raised to 3000 psi and the pore pressure will be increased to $3000 \mathrm{psi}$ by pumping water into the bottom of the sample to elevate the pore pressure to $3000 \mathrm{psi}$. As drilling commences, water will be pumped at a know rate to create an underbalanced drilling condition and then the pumping will be stopped and the pore pressure stabilized again at 3000 psi. At this balanced condition, drilling with the hammer at a fixed RPM and torque will again commence. A valve will then be opened on the pore pressure outlet to allow the pore pressure to be reduced (hopefully in a controlled manner) from 3000 psi to zero while the sample of Crab Orchard sandstone is being drilled up with the Smith hammer. The objective is to determine the effect of overbalance (borehole minus pore) on penetration rate. As noted, it will be necessary to measure the pore fluid volume with time to determine a filtration rate in order to calculate the pressure drop across the rock as the hole is deepened. The resulting differential pressure across the filter-cake as (Borehole Pressure minus Pore Pressure) - (Calculated Pressure Drop Across the Rock). 
16. Test Schedule: $\quad$ Baseline and torque check out week of April $12^{\text {th }}$ and hammer testing week of April $19^{\text {th }}$.

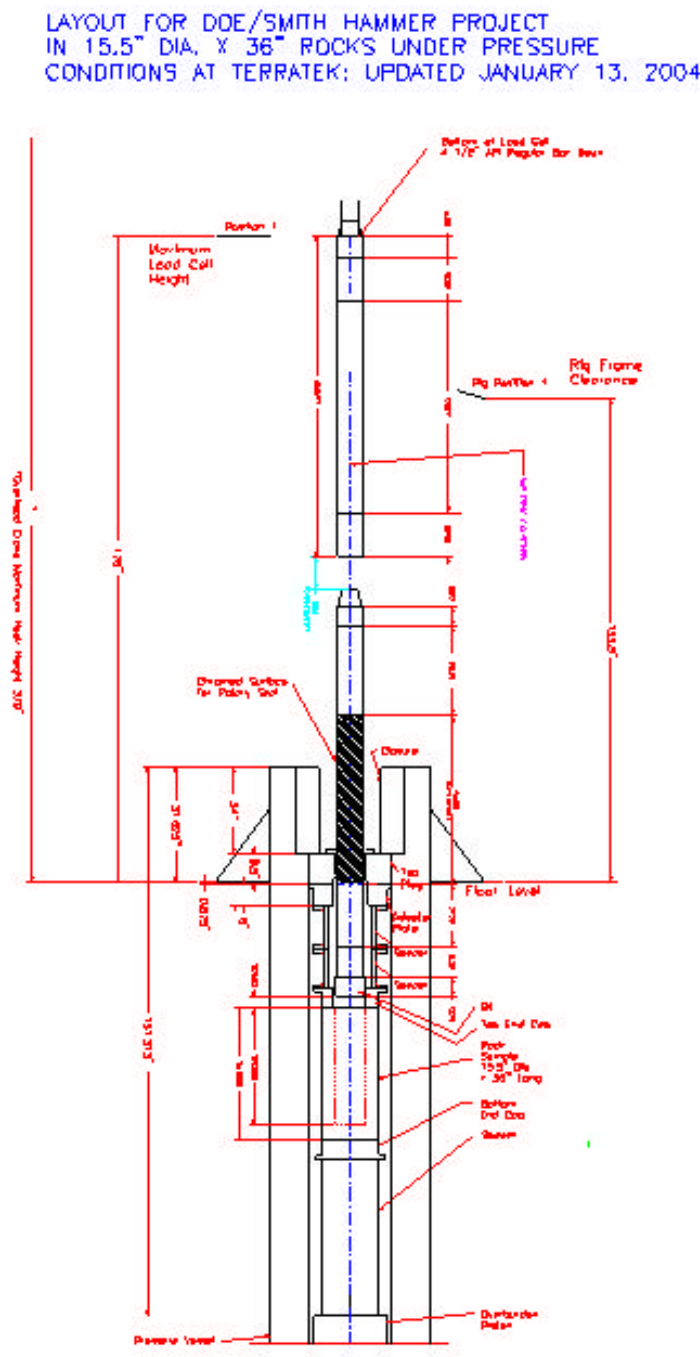

LAVOUT FOR DOE/SMTH HAMMER PROJECT IN $15.5^{\circ}$ DIA, $X 36^{\circ}$ ROCKS LNNDER PRESSLRE CONDITIONS AT TERRATEK: UPDATED JANUARY 13, 2004

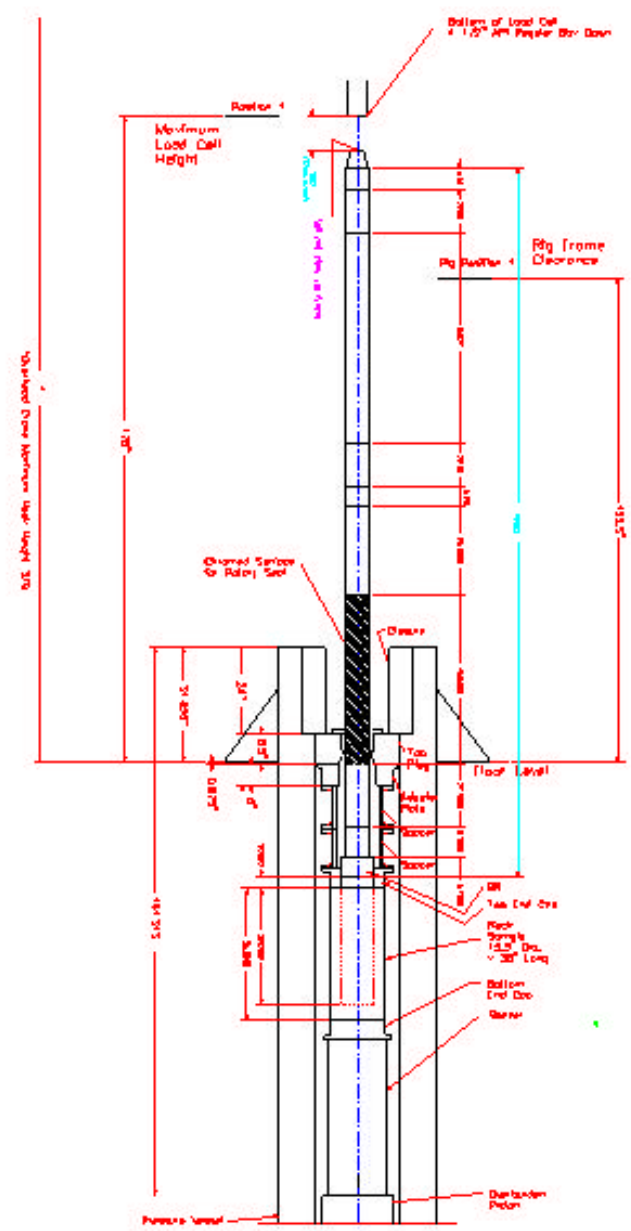

A comprehensive program for Task 8 'Impact Testing' was developed and executed during 3Q 2004 in conjunction with the DOE and Industry Advisors. 


\begin{tabular}{|c|c|c|c|c|c|c|c|c|c|}
\hline \multicolumn{4}{|c|}{ DOE Impact Project Test Matrix } & Borehole & H-Gas & Max. Static Load & Gap & Travel & Input Vel \\
\hline Test \# & Cutter & Rock & Fluid & psi & psi & lbs & in. & in. & in/sec \\
\hline Ind1a & Conical & Carth1 & $10 \mathrm{ppg}$ & 3000 & 442 & 4948 & $0.03^{\prime \prime}$ & $0.25^{\prime \prime}$ & 352 \\
\hline Ind2a & Conical & Carth1 & $10 \mathrm{ppg}$ & 3000 & 449 & 4948 & $0.03^{\prime \prime}$ & $0.50^{\prime \prime}$ & 495 \\
\hline Ind4a & Conical & Carth1 & $10 \mathrm{ppg}$ & 3000 & 451 & 4948 & $0.03^{\prime \prime}$ & $0.75^{\prime \prime}$ & 610 \\
\hline Ind5 & Conical & Crab1 & $10 \mathrm{ppg}$ & 3000 & 478 & 4948 & $0.03^{\prime \prime}$ & $0.25^{\prime \prime}$ & 357 \\
\hline Ind6 & Conical & Crab1 & $10 \mathrm{ppg}$ & 3000 & 449 & 4948 & $0.03^{\prime \prime}$ & $0.50^{\prime \prime}$ & 495 \\
\hline Ind7 & Conical & Crab1 & $10 \mathrm{ppg}$ & 3000 & 451 & 4948 & $0.03^{\prime \prime}$ & $0.50^{\prime \prime}$ & 495 \\
\hline Ind8 & Conical & Crab1 & $10 \mathrm{ppg}$ & 3000 & 425 & 4948 & $0.03^{\prime \prime}$ & $0.75^{\prime \prime}$ & 590 \\
\hline Ind9 & Conical & Man1 & $10 \mathrm{ppg}$ & 3000 & 451 & 4948 & $0.03^{\prime \prime}$ & $0.25^{\prime \prime}$ & 355 \\
\hline Ind10 & Conical & Man1 & $10 \mathrm{ppg}$ & 3000 & 448 & 4948 & $0.03^{\prime \prime}$ & $0.50^{\prime \prime}$ & 494 \\
\hline Ind11 & Conical & Man1 & $10 \mathrm{ppg}$ & 3000 & 451 & 4948 & $0.03^{\prime \prime}$ & $0.50^{\prime \prime}$ & 495 \\
\hline Ind12 & Conical & Man1 & $10 \mathrm{ppg}$ & 3000 & 450 & 4948 & $0.03^{\prime \prime}$ & $0.75^{\prime \prime}$ & 610 \\
\hline Ind13 & Spherical & Carth2 & $10 \mathrm{ppg}$ & 3000 & 445 & 4948 & $0.03^{\prime \prime}$ & $0.25^{\prime \prime}$ & 353 \\
\hline Ind14 & Spherical & Carth2 & $10 \mathrm{ppg}$ & 3000 & 455 & 4948 & $0.03^{\prime \prime}$ & $0.50^{\prime \prime}$ & 498 \\
\hline Ind15 & Spherical & Carth2 & $10 \mathrm{ppg}$ & 3000 & 450 & 4948 & $0.03^{\prime \prime}$ & $0.50^{\prime \prime}$ & 495 \\
\hline Ind16 & Spherical & Carth2 & $10 \mathrm{ppg}$ & 3000 & 449 & 4948 & $0.03^{\prime \prime}$ & $0.75^{\prime \prime}$ & 610 \\
\hline Ind17 & Spherical & Crab2 & $10 \mathrm{ppg}$ & 3000 & 452 & 4948 & $0.03^{\prime \prime}$ & $0.25^{\prime \prime}$ & 356 \\
\hline Ind18 & Spherical & Crab2 & $10 \mathrm{ppg}$ & 3000 & 449 & 4948 & $0.03^{\prime \prime}$ & $0.50^{\prime \prime}$ & 495 \\
\hline Ind19 & \begin{tabular}{|l} 
Spherical \\
\end{tabular} & Crab2 & $10 \mathrm{ppg}$ & 3000 & 455 & 4948 & $0.03^{\prime \prime}$ & $0.50^{\prime \prime}$ & 498 \\
\hline Ind20 & Spherical & Crab2 & $10 \mathrm{ppg}$ & 3000 & 449 & 4948 & $0.03^{\prime \prime}$ & $0.75^{\prime \prime}$ & 610 \\
\hline Ind21 & Spherical & Man2 & $10 \mathrm{ppg}$ & 3000 & 449 & 4948 & $0.03^{\prime \prime}$ & $0.25^{\prime \prime}$ & 355 \\
\hline Ind22a & Spherical & Man2 & $10 \mathrm{ppg}$ & 3000 & 448 & 4948 & $0.03^{\prime \prime}$ & $0.50^{\prime \prime}$ & 495 \\
\hline Ind23 & Spherical & Man2 & $10 \mathrm{ppg}$ & 3000 & 450 & 4948 & $0.03^{\prime \prime}$ & $0.50^{\prime \prime}$ & 495 \\
\hline Ind24a & Spherical & Man2 & $10 \mathrm{ppg}$ & 3000 & 450 & 4948 & $0.03^{\prime \prime}$ & $0.75^{\prime \prime}$ & 610 \\
\hline Ind25 & Conical & Carth3 & $15 \mathrm{ppg}$ & 3000 & 454 & 4948 & $0.03^{\prime \prime}$ & 0.25 & 357 \\
\hline Ind26 & Conical & Carth3 & $15 \mathrm{ppg}$ & 3000 & 451 & 4948 & $0.03^{\prime \prime}$ & 0.5 & 495 \\
\hline Ind27 & Conical & Carth3 & $15 \mathrm{ppg}$ & 3000 & 449 & 4948 & $0.03^{\prime \prime}$ & 0.5 & 495 \\
\hline Ind28 & Conical & Carth3 & $15 \mathrm{ppg}$ & 3000 & 451 & 4948 & $0.03^{\prime \prime}$ & 0.75 & 610 \\
\hline Ind29 & Conical & Crab3 & $15 \mathrm{ppg}$ & 3000 & 460 & 4948 & $0.03^{\prime \prime}$ & 0.25 & 359 \\
\hline Ind30 & Conical & Crab3 & $15 \mathrm{ppg}$ & 3000 & 452 & 4948 & $0.03^{\prime \prime}$ & 0.5 & 496 \\
\hline Ind31 & Conical & Crab3 & $15 \mathrm{ppg}$ & 3000 & 452 & 4948 & $0.03^{\prime \prime}$ & 0.5 & 496 \\
\hline Ind32 & Conical & Crab3 & $15 \mathrm{ppg}$ & 3000 & 452 & 4948 & $0.03^{\prime \prime}$ & 0.75 & 611 \\
\hline Ind33 & Conical & Man3 & $15 \mathrm{ppg}$ & 3000 & 452 & 4948 & $0.03^{\prime \prime}$ & 0.25 & 356 \\
\hline Ind34 & Conical & Man3 & $15 \mathrm{ppg}$ & 3000 & 453 & 4948 & $0.03^{\prime \prime}$ & 0.5 & 497 \\
\hline Ind35 & Conical & Man3 & $15 \mathrm{ppg}$ & 3000 & 453 & 4948 & $0.03^{\prime \prime}$ & 0.5 & 497 \\
\hline Ind36 & Conical & Man3 & $15 \mathrm{ppg}$ & 3000 & 453 & 4948 & $0.03^{\prime \prime}$ & 0.75 & 612 \\
\hline Ind37 & Conical & Carth4 & $10 \mathrm{ppg}$ & 3000 & 453 & 4948 & $0.03^{\prime \prime}$ & 0.75 & 611 \\
\hline Ind38 & Conical & Carth4 & $10 \mathrm{ppg}$ & 1500 & 453 & 4948 & $0.03^{\prime \prime}$ & 0.75 & 611 \\
\hline Ind39 & Conical & Carth4 & $10 \mathrm{ppg}$ & 500 & 453 & 4948 & $0.03^{\prime \prime}$ & 0.75 & 611 \\
\hline Ind40a & Conical & Carth 4 & $10 \mathrm{ppg}$ & 0 & 453 & 4948 & $0.03^{\prime \prime}$ & 0.75 & 611 \\
\hline Ind41 & Conical & Crab4 & $10 \mathrm{ppg}$ & 3000 & 449 & 4948 & $0.03^{\prime \prime}$ & 0.75 & 610 \\
\hline Ind42 & Conical & Crab4 & $10 \mathrm{ppg}$ & 1500 & 452 & 4948 & $0.03^{\prime \prime}$ & 0.75 & 611 \\
\hline Ind43 & Conical & Crab4 & $10 \mathrm{ppg}$ & 500 & 451 & 4948 & $0.03^{\prime \prime}$ & 0.75 & 610 \\
\hline Ind44 & Conical & Crab4 & $10 \mathrm{ppg}$ & 0 & 453 & 4948 & $0.03^{\prime \prime}$ & 0.75 & 611 \\
\hline Ind45 & Conical & Man4 & $10 \mathrm{ppg}$ & 3000 & 450 & 4948 & $0.03^{\prime \prime}$ & 0.75 & 610 \\
\hline Ind46 & Conical & Man4 & $10 \mathrm{ppg}$ & 1500 & 451 & 4948 & $0.03^{\prime \prime}$ & 0.75 & 610 \\
\hline Ind47 & Conical & Man4 & $10 \mathrm{ppg}$ & 500 & 452 & 4948 & $0.03^{\prime \prime}$ & 0.75 & 611 \\
\hline Ind48 & Conical & Man4 & $10 \mathrm{ppg}$ & 0 & 452 & 4948 & $0.03^{\prime \prime}$ & 0.75 & 611 \\
\hline
\end{tabular}

\begin{tabular}{|c|c|c|c|c|c|c|c|c|c|}
\hline \multicolumn{4}{|c|}{ Rapid and Static Loading Tests } & Borehole & H-Gas & Max. Static Load & Gap & Travel & Loading \\
\hline Test \# & Cutter & Rock & Fluid & psi & psi & psi & in. & in. & Static/Rapid \\
\hline $\operatorname{Ind} 449$ & Conical & Carth5 & $10 \mathrm{ppg}$ & 3000 & 452 & 4948 & $0.03^{\prime \prime}$ & 0 & Rapid \\
\hline Ind50 & Conical & Carth5 & $10 \mathrm{ppg}$ & 3000 & 787 & 8100 & $0.50^{\prime \prime}$ & 0 & Static \\
\hline Ind51 & Conical & Carth5 & $10 \mathrm{ppg}$ & 3000 & 787 & 10000 & $0.50^{\prime \prime}$ & 0 & Static \\
\hline Ind52 & Conical & Carth5 & $10 \mathrm{ppg}$ & 3000 & 787 & 10000 & $0.50^{\prime \prime}$ & 0 & Static \\
\hline Ind53 & Conical & Crab5 & $10 \mathrm{ppg}$ & 3000 & 453 & 4948 & $0.03^{\prime \prime}$ & 0 & Rapid \\
\hline Ind54 & Conical & Crab5 & $10 \mathrm{ppg}$ & 3000 & 787 & 10000 & $0.50^{\prime \prime}$ & 0 & Static \\
\hline Ind55 & Conical & Crab5 & $10 \mathrm{ppg}$ & 3000 & 787 & 10000 & $0.50^{\prime \prime}$ & 0 & Static \\
\hline Ind56 & Conical & Crab5 & $10 \mathrm{ppg}$ & 3000 & 787 & 10000 & $0.50^{\prime \prime}$ & 0 & Static \\
\hline Ind57 & Conical & Man5 & $10 \mathrm{ppg}$ & 3000 & 452 & 4948 & $0.03^{\prime \prime}$ & 0 & Rapid \\
\hline Ind58 & Conical & Man5 & $10 \mathrm{ppg}$ & 3000 & 787 & 10000 & $0.50^{\prime \prime}$ & 0 & Static \\
\hline Ind59 & Conical & Man5 & $10 \mathrm{ppg}$ & 3000 & 787 & 10000 & $0.50^{\prime \prime}$ & 0 & Static \\
\hline Ind 60 & Conical & Man5 & $10 \mathrm{ppg}$ & 3000 & 787 & 10000 & $0.50^{\prime \prime}$ & 0 & Static \\
\hline
\end{tabular}




\title{
RESULTS AND DISCUSSION
}

\section{1}

After kicking off the project beginning January, 2001 progress has been made according to the schedule and scope of work proposed. Tasks 1, 2, 3, 4, and 5 have been completed, with progress now being made on Task 6 (convene planning meeting on February 22, 2002 with Industry Sponsors prior to next phase of testing) and Task 7 Reporting of Results through publication.

Review of January 2001 through March 2001 -

Task 1 - As confirmed by Roy Long, COR at NETL, the information required for the National Environmental Policy Act was submitted in calendar year 2000.

Task 2 - Completed and described in previous quarterly report.

Task 3 - Prepared rock samples and finalized tool logistics with hammer suppliers.

Review of April 2001 through June 2001 -

Task 3 - Set-up of large scale experiments completed. The test program was completed on June 27, 2001 after 13 full-scale tests were completed. Initial flow line and mud pump problems were resolved at TerraTek. The Novatek bit experienced both washouts and nozzle failures at first. The bit was repaired and testing continued after some delay and extra set-up time. SDS Digger hammer experienced fewer problems.

Review of July through September 2001 -

Task 4 - Benchmarking of mud hammer performance was completed. Interval data from all tests has been transmitted to the DOE project manager and Industry Sponsors.

Task 5 - A Peer Review ('Lessons Learned' meeting) was held with members of the Industry Advisory Board and the DOE. The suppliers and operators reviewed their own learnings and progress in addressing performance problems. The summary notes are made a part of the quarterly report below.

$* * * * * * * * * * * * * * * * * *$

\author{
MINUTES AND NOTES \\ OPTIMIZATIONOF MUD HAMMER DRILLING PERFORMANCE \\ LESSONS LEARNED MEETING \\ HOUSTON \\ 27 SEPTEMBER, 2001
}




\section{PARTICIPANTS}

Tim Travis (EXXONMOBIL), John Rogers (DOE NETL), Jim Powers (EXXONMOBIL), Brian Miller (BP), David Pixton (NOVATEK), Arnis Judzis (TERRATEK), Gordon Tibbitts (TERRATEK)

\section{GENERAL DISCUSSION}

- An abstract was submitted to the spring IADC/SPE conference that details the mud hammer testing in this first phase. The abstract was accepted as an alternate paper. It was decided to proceed with this paper and present it at this conference.

- Approval was obtained to open this program to additional industry cost sharing.

- If other industry cost sharers join the program, testing will be performed at TerraTek in the USA and be within the scope of the DOE program.

- A second phase planning meeting will be held prior to the next testing program. Test conditions and procedures will be determined at that meeting. It is hoped the information from the lessons learned meeting will be used to help define the next test program.

- Concurrent field testing by the operators is welcomed and would add another dimension to this program.

\section{PRESENTATIONS}

NOVATEK David Pixton

- Key to Novatek design philosophy to design and operate a tool which could function on typical oil field capabilities ( pump pressure and flow rates )

- Designed a bit to operate using the unique functions of a rotary percussive tool.

- $\quad$ Bit designated as the PHAST bit.

PDC bit containing both high back rake PDC cutters and pressure intensified nozzles in front of the cutters

Cutters had large chamfers as well as diamond well into the cylindrical portion of the cutter substrate

- This was a prototype bit and as such several issues in the construction and the operation of the bit need to be addressed in the future for this system to perform effectively.

A more robust design might be required to house the internal porting to the nozzles.

A different mounting system for the nozzles should be looked at.

- The tool did not exhibit optimal operation in the heavier than water mud systems. The tools will need to be "retuned" for these types of fluids. Possibly the stroke length and other parameters could be altered through design.

- Letting the tool stand for any period of time, which allows the drilling mud to dry, can foul the present hammer valve. This condition was experienced even though the tool was flushed with clear water. Modification of the valve can relieve this issue.

- The same performance was obtained with their hammers and tricone bits as convent ional rotary drilling. Hammers with roller cone bits do not provide increased penetration rates.

- During these tests, increased performance was noted at two distinct areas. One was at higher bit horsepower (rpm $\times$ WOB). The other was observed at lower bit horsepower and was unexpected.

The new drilling mode was observed in the transition of low WOB to higher WOB. At these lower WOB levels, elevated penetration rates were observed in spite of lower horsepower being applied.

The mode was observed at a variety of conditions and is believed to be real.

- This new drilling mode needs to be explored and better understood.

\section{NEXT STEPS}

- Explore this new drilling mode and expand the transition zone

- Test both with jet augmentation as well as without

- Look at bit design and tool design

- Retune tool to operate in these drilling fluids 
Test both the next generation tool and bit. The next generation bit will be tested first to help answer fundamental rotary percussion drilling questions. Based on these results, the next generation tool will be designed and built (the redesign would mainly provide operational and robustness benefits, not answer fundamental questions).

SDS Malcom Mclnnis (was not able to attend due to flight issues after the incidents of 11 September)

- A report was sent to the meeting

The SDS tool performed in the mud systems used in the program

The tool did not run in an optimized manner while using these muds as a drilling fluid

- Additional information on the next steps to make this tool more viable commercially will be requested from SDS.

\section{OPEN DISCUSSION}

\section{OPERATORS}

Brian Miller BP

- One of the major issues in drilling hard rock is the inability of drilling tools to penetrate "soft" intervals or stringers at appreciable penetration rates. Brian suggested that some shale should be included in the next phase to demonstrate the feasibility of drilling these materials with hammer systems. Note: It is possible to build samples for the Wellbore Simulator that embodies a shale lens sandwiched between the host material. It is also possible to drill into whole shale samples.

- It appears that a quick opportunity for these tools is the underbalanced drilling applications and low weight on bit applications.

- There would be benefit in running baseline bit tests of the Novatek bit in a straight rotary drilling scenario. Should allow the measure of performance increase when used in the hammer system compared to conventional rotary systems.

- A question exists as to whether the Phast bit should be compared to a PDC bit rather than a roller cone bit.

- It appears that there is no advantage to drilling with a system utilizing both hammers and roller cone bits in terms of Rate of Penetration.

- The higher ROP data points in the Novatek system (transition points) need to be investigated and better understood.

- A question exists as to whether these tools will work on multi phase fluid.

- Would like to see more analysis of the high-speed data.

Tim Travis ExxonMobil

- Rate of Penetration is king particularly in gas well drilling. Would like to focus on $25 \mathrm{ksi}$ formations (pore pressures in the range of 8 to $10 \mathrm{ppg}$ ).

- Would like to see the program expanded to include more tool suppliers (Smith mentioned as well as a German program at Claustal) as well as bit companies. The thought is to get more expertise being applied to the bit portions of these systems.

- The bits are a huge and critical component of these drilling systems.

- Value is a key driving force in the success of this technology. The systems must provide value in the field in order to be utilized. These systems must be "user friendly " to the rig hands that run them. They appear to be quite complex in getting the optimum pressure drops, weight on bit, and rotary speed for performance it this time.

- Underbalanced drilling applications are there. Currently drilling with air hammers. Also straight hole low weight on bit applications are potential applications.

- The performance of these tools must be proven at realistic rig capabilities.

For $77 / 8$ " to $83 / 4$ " hole sizes 400GPM max. 2700 psi for on shore rigs. 500 GPM 2500 to 3000psi (max 3500psi) for others

For $121 / 4 "$ hole size 800 GPM max same pressure constraints.

Tim will supply current rig operating constraints. 


\section{PLANS LOOKING FORWARD}

- Judzis to request more details of Phase 1 "lessons learned" from SDS. (Completed 9 October and will augment the next quarterly report.)

- Judzis to invite PDVSA and Halliburton to join the DOE program. (Completed)

- TerraTek to schedule Phase II planning meeting for the Advisory Board. This meeting is tentatively planned to be in the late November early December time frame.

$* * * \star * * * * * * * * * * * * * *$ end lessons learned summary

Review of October through December 2002 -

Task 6 - Plans are underway to identify the testing for the Optimization task. A planning meeting was attempted at the end of 2001 however some of the Industry Partners had scheduling difficulties dung the holiday season. That meeting is now set for February 22, 2002 and will be reported on the next quarterly report. PDVSA has joined the hammer program through cost sharing, thus will sit with the other Industry Partners in recommending tests appropriate for the overarching objective of the program - to accelerate the commercialization and availability of fluid hammers which operate at depth conditions and with weighted drilling muds.

Task 7 - TerraTek has completed the publication for the 2002 SPE/IADC Drilling Conference entitled "World's First Benchmarking of Drilling Mud Hammer Performance at Depth Conditions".

The full text of the SPE/IADC publication written as part of the DOE award follows:

$* * * * * * * * * * * * * * * * * * * * * * * * * * * * * * * * * * * *$ publication below $* * * * * * * * * * * * * * * *$ 


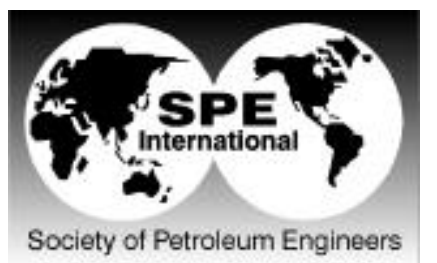

IADC/SPE 74540

\title{
World's First Benchmarking of Drilling Mud Hammer Performance at Depth Conditions \\ Gordon A. Tibbitts, TerraTek; Roy C. Long, US Department of Energy, Brian E. Miller, BP America, Inc.; Arnis Judzis, TerraTek; Alan D. Black, TerraTek
}

SPE Members

\begin{abstract}
Operators continue to look for ways to improve hard rock drilling performance through emerging technologies. A consortium of Department of Energy, operator and industry participants put together an effort to test and optimize mud driven fluid hammers as one emerging technology that has shown promise to increase penetration rates in hard rock. The thrust of this program has been to test and record the performance of fluid hammers in full scale test conditions including, hard formations at simulated depth, high density / high solids drilling muds, and realistic fluid power levels. This paper details the testing and

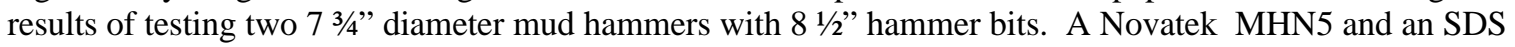
Digger FH185 mud hammer were tested with several bit types, with performance being compared to a conventional (IADC Code 537) tricone bit. These tools functionally operated in all of the simulated downhole environments. The performance was in the range of the baseline ticone or better at lower borehole pressures, but at higher borehole pressures the performance was in the lower range or below that of the baseline tricone bit. A new drilling mode was observed, while operating the MHN5 mud hammer. This mode was noticed as the weight on bit (WOB) was in transition from low to high applied load. During this new "transition drilling mode", performance was substantially improved and in some cases outperformed the tricone bit. Improvements were noted for the SDS tool while drilling with a more aggressive bit design. Future work includes the optimization of these or the next generation tools for operating in higher density and higher borehole pressure conditions and improving bit design and technology based on the knowledge gained from this test program.
\end{abstract}

\section{Introduction}

The majority of drilling related costs occur in harder rock drilling. Improvement in the penetration rates in hard rock drilling is an opportunity to reduce overall well costs and in some cases drastically reduce drilling program costs in hard rock country and particularly in drilling for gas. Hard rock regions in the U.S. include but are not limited to the Rockies, Tuscaloosa trend, Anadarko basin, Cretaceous limestones, and 
several areas in Texas as well as deep Gulf of Mexico formations. Worldwide interest would include Bolivia, Colombia, Egypt, Argentina, Kazakhstan, South East Asia, and Oman. The estimated yearly cost to drill hard rock in the United States is $\$ 1,200 \mathrm{MM}$. Potential savings of $\$ 200 \mathrm{MM}$ to $\$ 600 \mathrm{MM}$ are possible if the penetration rate in hard rock is doubled with the assumption that bit life is reasonable. Several new technology schemes are currently being developed to reach this goal including mud hammers.

Mud hammer development has been going on for some time ${ }^{1-4}$, but performance and endurance have not been adequately tested for them to be a viable commercial tool in the deep oil and gas applications. Hammer performance had been sketchy at best and reported to have performance problems when operated at high borehole pressures and in muds containing a high percent of solids. A clear picture of mud hammer performance was near impossible to determine although many operators have supported efforts to accelerate development of these tools through several separate programs. Notable efforts include those of Amoco (Pan American), Gulf, Shell as well as a Hughes Tool Company effort involving Humble Oil, Shell, Sinclair, and Sun Oil. Operators such as BP see the potential and have targeted applications. Large scale testing under simulated drilling conditions offered an economical alternative to high day rate field testing as well as providing clear performance comparison of different power levels, rotary speed, weight on bit, bit type, mud density, and rock type.

A program providing the answers to performance in high borehole pressure and high solids mud conditions was initiated. Funding for the effort was obtained through the Department of Energy and cost shared by ExxonMobil, BP, Novatek, SDS Digger Tools, and Pajarito Enterprises. The testing was performed at TerraTek's Drilling and Completions Laboratory in Salt Lake City, Utah.

\section{Background}

The Department of Energy (DOE) implements its Office of Fossil Energy upstream natural gas technology development program predominantly by cost shared research projects with industry, academia, and the national laboratories. These projects are initiated and managed by DOE's National Energy Technology Laboratory (NETL) in Morgantown, West Virginia. In response to the Energy Information Administration's current forecast that gas consumption will increase by $60 \%$ by 2020 , NETL is cost sharing various technology development projects to enhance development of deep gas resources, a key element of supply that will help in meeting the expected increase in demand.

NETL's focus on mud hammers is a direct result of its attempt to reduce drilling cost and, thus, make deep gas exploration economics more attractive to industry. The mud hammer was considered to be one of the technologies with potential to reduce deep gas drilling cost because of the demonstrated capabilities of existing industrial air and water hammers in hard rock drilling applications and ease of incorporation of hammers into existing drilling systems. As noted above, however, no detailed studies have previously been performed to thoroughly investigate hammer performance in drilling mud environments; and, no studies have been performed to evaluate the effectiveness of next generation hammer bit technologies, such as the hydraulic assist system developed by Novatek in partnership with NETL.

Another benefit recognized in the project is TerraTek's ability to aid in market penetration of mud hammer technology for deep drilling. The current environment within the petroleum industry can be characterized as extremely risk averse. As a condition to utilizing a new mud hammer system in a 20,000 foot well, the operator must be assured that the system will operate once on bottom and will have at least significant promise of exceeding the penetration rate and cost per foot established with conventional systems. The full scale testing and downhole data gathering capabilities at simulated downhole conditions offered by the TerraTek facility provided what was considered to be one of the best methods to establish the required confidence level for further testing in actual field conditions.

\section{Operator Needs}

One of the performance measures operators often use to evaluate drilling performance, when comparing alternative drilling systems for use in a given hole section, is overall cost per foot. Reducing cost per foot generally requires achieving a higher average rate of penetration (ROP) and/or increasing the useful drilling time $\left(\mathrm{D}_{\text {time }}\right)$ between trips, as indicated by the following cost per foot formula: 


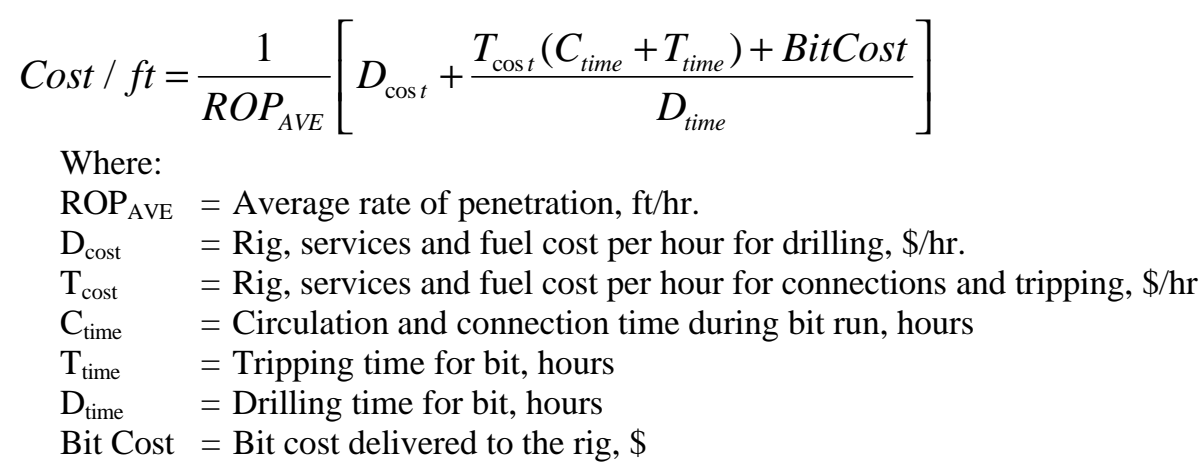

To date for hard and abrasive drilling conditions, in deep wells drilled with mud, tricone bits have consistently offered the highest ROP potential but their susceptibility to wear and bearing failure limits the usable drilling time. In deeper hole sections, when tripping times are longer, TSP or natural diamond bits have been the tricone bit's chief competitor in hard rock drilling, especially in smaller hole sizes. This is because TSP and natural diamond bits can provide a much longer bit life (drilling time) to offset their generally lower ROP to achieve a reduction in overall cost per foot compared with tricone bits.

However, hammer drilling with simple percussion drill bits has been proven as an economic alternative for a range of hard rock drilling applications including when air or clear water can be used as the drilling fluid. Air drilling results in the highest possible ROPs and air hammer drilling is now a widely used alternative for many air drilled hole sections. Hammer drilling with percussion bits in clear water is still a relatively new alternative for the oil and gas drilling industry and has been limited to relatively shallow hole depth applications, i.e. less than $3,000 \mathrm{ft}$.

Based on the competitive performance of hammer drilling with percussion bits in clear water applications, operators are interested in learning if these drilling systems can provide an economic alternative in hard rock drilling applications with weighted muds, especially for deeper hole depths. Limited field testing of these fluid driven hammer systems in weighted mud systems has shown promise but the ROP response of these systems to variables such as mud density, rock type and hydrostatic pressure (which increases with hole depth) have not been rigorously explored. The controlled drilling tests reported in this study provide key insights not available from random field tests.

As a first step to determining economic viability of hammer drilling with percussion bits in deep hole sections drilled with weighted mud, the test program was designed to explore only the ROP response of available fluid driven hammer tools compared with a tricone bit (IADC Code 537) ROP performance baseline. If these results were sufficiently encouraging, further work to determine hammer and bit life expectancy could then be justified. Ultimately, operators are only interested in the further development of drilling systems that can provide reductions in the overall cost per foot of drilling

\section{Test Program Description}

An Advisory Board was assembled to formulate and direct the test program. Representatives from the Department of Energy (DOE)/National Energy Technology Laboratory (NETL), ExxonMobil, BP, TerraTek, Novatek, SDS Digger Tools and Pajarito Enterprises sat on the Advisory Board. The test program consisted of full-scale tests simulating downhole conditions while drilling into rocks that were selected to represent hard rock drilling. Carthage marble was selected to represent a moderately hard limestone. Crab Orchard sandstone was selected as the representative for hard sandstone. Table 1 provides the salient rock properties of these materials. A 10.0 and a $15.0 \mathrm{ppg}$ water based mud systems were selected as drilling fluids which would have high solids contents and provide realistic comparisons to field muds used in conventional drilling.

Performance of an $81 / 2$ " tricone drill bit (IADC Code 537 tungsten carbide insert bit) was documented in SPE paper $\# 15620^{5}$. These tests were run using a $10.0 \mathrm{ppg}$ water based mud system while drilling into 
Carthage Marble and Crab Orchard Sandstone at various weight on bit (WOB) conditions and constant rotary speed. It was decided to use this data as the comparison to conventional rotary drilling. Additional tests were performed in which the same bit was run in a $15.0 \mathrm{ppg}$ water based mud. By running in the highly weighted mud, a comparison of tricone bit performance and the mud hammers could be ascertained.

Table 2 shows the number and type of test run for the program. The borehole pressure usually is the key to penetration rate reduction. As if the borehole pressure is increased, penetration rate decreases. The largest incremental changes take place before a borehole pressure of $3000 \mathrm{psi}$ is reached. For these tests the highest borehole pressure was $3000 \mathrm{psi}$. Additional data was obtained at $2000 \mathrm{psi}, 1000 \mathrm{psi}$, and in some cases 500 psi. At all of these borehole pressures, the confining stress and the overburden stress were held at $4000 \mathrm{psi}$ and $5000 \mathrm{psi}$ respectively. Although the main thrust of the program was to look at the performance at elevated borehole pressure near $3000 \mathrm{psi}$, the lower borehole pressure data provides a glimpse of how the performance transition occurs from low to higher bore hole pressure.

All of the mud hammer tests and the conventional drilling tests were run in the TerraTek Drilling and Completions Laboratory's Wellbore Simulator (WBS) (Figure 1). This simulator has the capability of performing drilling experiments with full-scale bits, high flow volume and fluid pressure with a variety of drilling muds, and rock samples from natural occurring formations stressed to in situ conditions. The laboratory also has extensive instrumentation and data collection equipment to extract the needed information from drilling experiments.

In a typical test, the 15.5 " diameter jacketed rock sample was connected to the top vessel plug, which sealed the appropriate mud hammer and bit combination. The assembly was then lowered into the WBS. The upper closure of the WBS would be inserted and the drillstring made up to the drill rig. Because these rock samples are relatively strong, the confining stress and the overburden stress were applied to the rock prior to flowing the pressurized mud into the borehole. This also prevented the tools from being cycled without load for appreciable amounts of time while the stresses on the rock samples were being established. When the rock stresses and desired borehole pressure were established, the sample was drilled following a protocol outlining the appropriate tool pressure drop, rotary speed, and weight on bit. The data was recorded as shown by example in Figure 2. Each reduced data point is an average of many individual data points taken at that particular set of drilling parameters. The performance data such as rate of penetration is calculated from this reduced data.

\section{Results}

The performance of the tricone bit run in the $15 \mathrm{ppg}$ waterbase mud system compared to the $10 \mathrm{ppg}$ water based mud was significantly reduced. Figures 3 and 4 shows the penetration rates for the bit in the two mud weights and two rock types. The performance of the ticone bit in $10 \mathrm{ppg}$ mud was obtained using a constant $110 \mathrm{RPM}$ and $400 \mathrm{gpm}$ flow rate. The $15 \mathrm{ppg}$ performance was obtained at $110 \mathrm{RPM}$ also but includes some 60 RPM data as well (shown only in the hammer performance plots). The hydraulic horsepower per square inch (HSI) for the $15 \mathrm{ppg}$ mud was maintained by running different nozzle diameters in the bit at the same flow rate.

The results of these tests comprise the baseline and comparison data for the mud hammer performance. The appropriate portions of the baseline data are shown on all of the specific performance graphs of the mud hammers and bit combinations.

\section{SDS PERFORMANCE}

The SDS tool operates (cycles) only after a prescribed amount of WOB has been applied to the tool, although full flow may have already been established. The tool cycles very smoothly. During these tests, the bypass nozzles were blocked off, although in field applications they are directed up hole and may be fitted with different diameter nozzles to match drill rig hydraulic requirements.

Figure 5 shows the performance of the SDS mud hammer and a hard formation percussion type bit (Figure 6) in Carthage Marble at a variety of rotary speeds, pressure drops across the tool (at flow rates to provide those different pressure drops), borehole pressures, and constant WOB (10,000 lbs). These performance points are compared directly to the ticone bit performance obtained for the same weight drilling mud (10 
ppg). It is notable that the performance is best at low borehole pressures. As the borehole pressure increases to the 3000psi level the performance drops off significantly. The performance at $3000 \mathrm{psi}$ borehole pressure appears to be about the same in terms of ROP at all pressure drops and rotary speeds. The rate of penetration (ROP) is in the range of 2 to 4 feet per hour (FPH).

Figure 7 shows a similar suite of performance data in Crab Orchard Sandstone again in 10 ppg mud. In this hard sandstone, the performance of the mud hammer is reduced through all borehole pressure ranges tested. The performance at various pressure drops and rotary speeds is lower than the conventional bit especially at borehole pressure above 1000psi. The ROP range appears to be in the 2 to 4 FPH range.

Figures $8 \& 9$ shows the performance of the mud hammer with the same bit in the 15 ppg mud in the two rock types. Similar results were obtained although the overall penetration rates are lower in the higher weight mud system. This echoes the reduction of performance as seen in the tricone bit in the heavier mud system. The ROPs for these tests ranged from 1 to $3 \mathrm{FPH}$.

Figures $10 \& 11$ show performance improvement when a more aggressive precussion type bit was run with the mud hammer. Significant improvement can be seen at lower borehole pressures and in some cases is better than the tricone performance. As the borehole pressure increases, the performance is moderately improved. The penetration rates at 3000 psi borehole pressure are in the 3 to $7 \mathrm{FPH}$ range.

\section{NOVATEK PERFORMANCE}

The Novatek tool operates (cycles) when a minimum amount of fluid is pumped through the tool. It will cycle with no WOB. As WOB is added, the tool closes until the anvil is loaded and then transfers the impacts to the cutting structure.

Figure 12 shows the performance results of the Novatek N5 mud hammer run with the IADC Code 537 tricone bit compared to the IADC Code 537 tricone rotary drilled in $10 \mathrm{ppg}$ mud. The rates of penetration of the hammer and tricone combination are clustered around the performance of the stand-alone tricone bit at its lowest WOB and 110 RPM. This test was run at the 3000 psi borehole conditions only. The penetration rates range from 4 to $10 \mathrm{FPH}$.

Although performance levels for the Novatek tool and the polycrystalline diamond cutter (PHAST) bit (Figure 13), were in the lower range or below the comparison bit in early tests, a couple of points were observed that showed moderate performance increases. Additional tests were run to try and duplicate the conditions where these points were observed.

Figures $14 \& 15$ shows the performance of the N5 tool and the PHAST bit in both rock types and a $15 \mathrm{ppg}$ mud system. The most salient feature of these graphs are the data points which have performance levels above or close to the rock bit ROP's. These points are highlighted with an arrow. These points were observed in the "transition zone" as the tool had WOB being applied but had not been "bottomed out". Some tool elasticity or compliance was still present at these points. As the tool was loaded completely, the performance was degraded. It should be noted that similar tests were run on the other rock type and although the performance levels were elevated the overall effect was somewhat diminished. The performance level of this tool and bit combination exceeded that of the rotary drilled tricone in Crab Orchard sandstone and came close to the best case performance curve when drilling into the Carthage marble.

\section{Way Forward}

The following steps will be necessary in optimizing the performance of these hammers before they will be broadly accepted as commercially viable tools for deep oil and gas applications. The next phase of the program will employ these points in the development of mud hammers and their optimization.

- Explore and understand the phenomenon, which allows the Novatek mud hammer to successfully perform in the "transition zone".

- Improve the Novatek tool performance by redesign to operate in the "transition zone" at optimum performance levels in weighted mud systems and at depth. 
- Research and design bits for both tools that are compatible and perform utilizing the complex dynamics created underneath these tools.

- Design both tools to be able to operate at optimum levels of performance at realistic rig capabilities.

- Optimize the SDS tool to operate in weighted mud and at depth conditions.

- Through design, improve the overall hydraulic efficiency of both of these tools.

\section{Conclusions}

- These new generation mud hammers have the ability to operate in 10 to 15 ppg water base mud systems.

- $\quad$ Competitive ROP performance demonstrated at hydrostatic pressures at or below 1,000 psi.

- Further work required to achieve competitive ROP performance at higher borehole pressure.

- They have the ability of drilling medium to hard rock although they need optimization.

- There appears to be no advantage in the use of conventional IADC Code 537 tricone bits in conjunction with these tools.

- A new drilling mode has been identified for the Novatek mud hammer while transitioning from low WOB to higher WOB. Performance improvement while drilling in this mode appears to be of significance.

- Drill bits designed to exploit both the rotary and impact components of the applied load, appears to provide better performance.

\section{Acknowledgements}

The authors wish to thank the Department of Energy and BP for their permission to publish this paper and for their support of this project. In addition to the aforementioned, the authors also wish to thank all those who cost shared in this phase of the project including Dr. J. Rowley of Pajarito Enerprises, ExxonMobil, SDS Digger Tools, and Novatek. A special thanks to SDS Digger Tools and Novatek for supplying tools and bits and their expertise and knowledge in analyzing the results of the testing.

\section{References}

1. Pixton, D., Sianguang, Y., Fryer, B., Payne, S., Hall, D., “A New Generation Mud Driven Rotary Percussion Tool:, Third Edition, February 15, 1995, Novatek, Provo, Utah.

2. Melamed, Y., Kiselev, A., Gelfgat, M., Dreesen, D., Blacic, J., "Hydraulic Hammer Drilling Technology: Development and Capabilities", Presented at Energy Week Conference \& Exhibition, ASME, January 2830, 1997, Houston, Texas.

3. Deutsch, U., Marx, C., Rischmuller, "Evaluation of Hammerdrill - Potential for KTB in Super-Deep Continental Drilling and Deep Geophysical Sounding," K. Fuchs, Ed. Springer-Verlad, Berlin, pp. 310-321.

4. Ramirez, J., Geraud, M., Saldzar, V., Algate, G., "Fluid Percussion Drilling in Deep Hard Rock in Eastern Venezuela" SPE 69520 presented at the SPE Latin America and Caribbean Petroleum Engineering Conference held in Buenos Aires, Argentina, March 25-28, 2001.

5. Walker, B.H., Black, A.D., Klauber, W.P., Little, T., Khadverdian, M., "Roller-Bit Penetration Rate Response as a Function of Rock Properties and Well Depth" SPE 15620 presented at SPE Annual Conference in New Orleans, October 5-8, 1986.

Table 1

\begin{tabular}{|l|c|c|}
\hline \multicolumn{2}{|c|}{ ROCK PROPERTIES } \\
\hline & $\begin{array}{c}\text { CARTHAGE } \\
\text { MARBLE }\end{array}$ & $\begin{array}{c}\text { CRAB ORCHARD } \\
\text { SANDSTONE }\end{array}$ \\
\hline $\begin{array}{l}\text { Unconfined Compressive } \\
\text { Strength (psi) }\end{array}$ & 16,000 & 23,000 \\
\hline Porosity (\%) & 1.4 & 7.0 \\
\hline
\end{tabular}




\begin{tabular}{|l|c|c|}
\hline Permability (md) & 0.00005 & 0.1 \\
\hline Bulk Density (gm/cc) & 2.65 & 2.47 \\
\hline Grain Density (gm/cc) & 2.69 & 2.64 \\
\hline Friction Angle (degrees) & 30 & 42 \\
\hline
\end{tabular}

Table 2

\begin{tabular}{|c|c|c|c|}
\hline \multicolumn{4}{|c|}{ IEST SEQUENCE } \\
\hline TEST & HAMMER/BIT & ROCK & $\begin{array}{c}\text { MUD DENSITY } \\
\text { (PPG) }\end{array}$ \\
\hline 1 & SDS/IMPACT HARD & Carthage Marble & 10 \\
\hline 2 & SDS/IMPACT HARD & Crab Orchard S.S. & 10 \\
\hline 3 & Novatek PDC PHAST & Carthage Marble & 10 \\
\hline 3 A & Novatek IADC 537 & Carthage Marble & 10 \\
\hline 4 & Rotary IADC 537 & Carthage Marble & 15 \\
\hline 5 & Rotary IADC 537 & Crab Orchard S.S. & 15 \\
\hline 6 & SDS/IMPACT HARD & Carthage Marble & 15 \\
\hline 7 & SDS/IMPACT HARD & Crab Orchard S.S. & 15 \\
\hline 8 & SDS/IMPACT SOFT & Carthage Marble & 15 \\
\hline 9 & SDS/IMPACT SOFT & Crab Orchard S.S. & 15 \\
\hline 10 & Novatek PDC PHAST & Carthage Marble & 15 \\
\hline 11 & Novatek PDC PHAST & Crab Orchard S.S. & 15 \\
\hline 12 & Novatek PDC PHAST & Carthage Marble & 15 \\
\hline
\end{tabular}

Figure 1 Wellbore Simulator

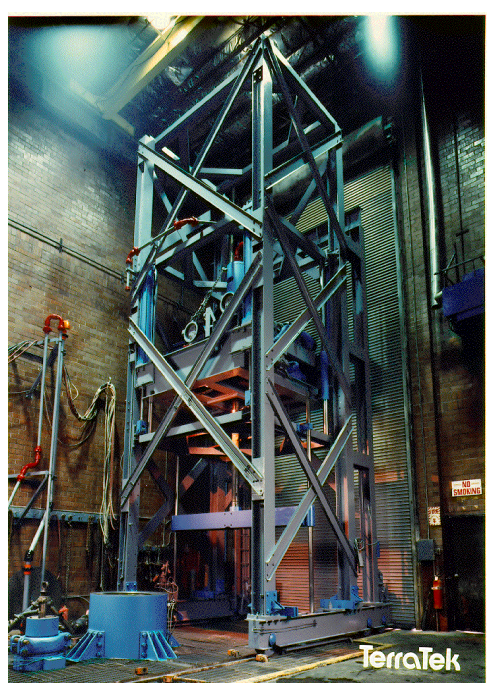


Figure 2 Tvpical Performance

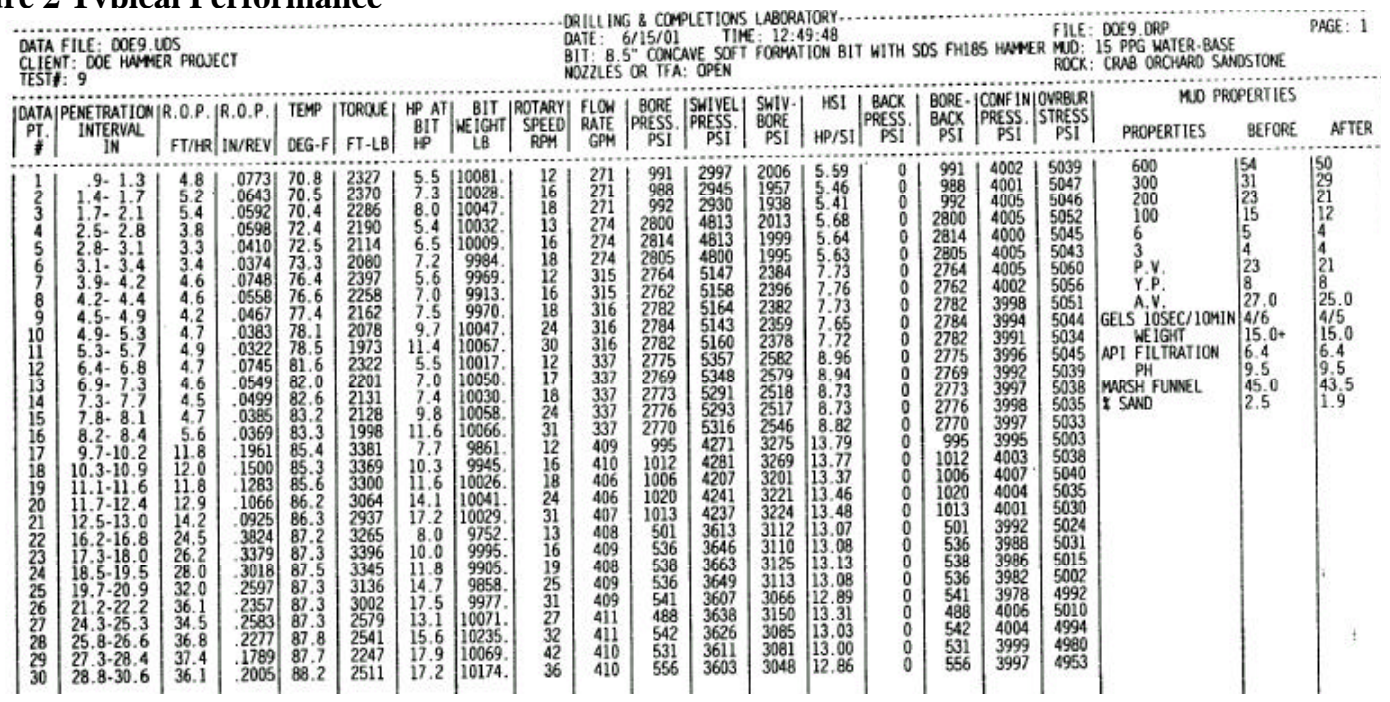

Baseline Data with 8 1/2" IADC 537 Bit with 10 ppg and 15 ppg Water-base Mud for Carthage Marble

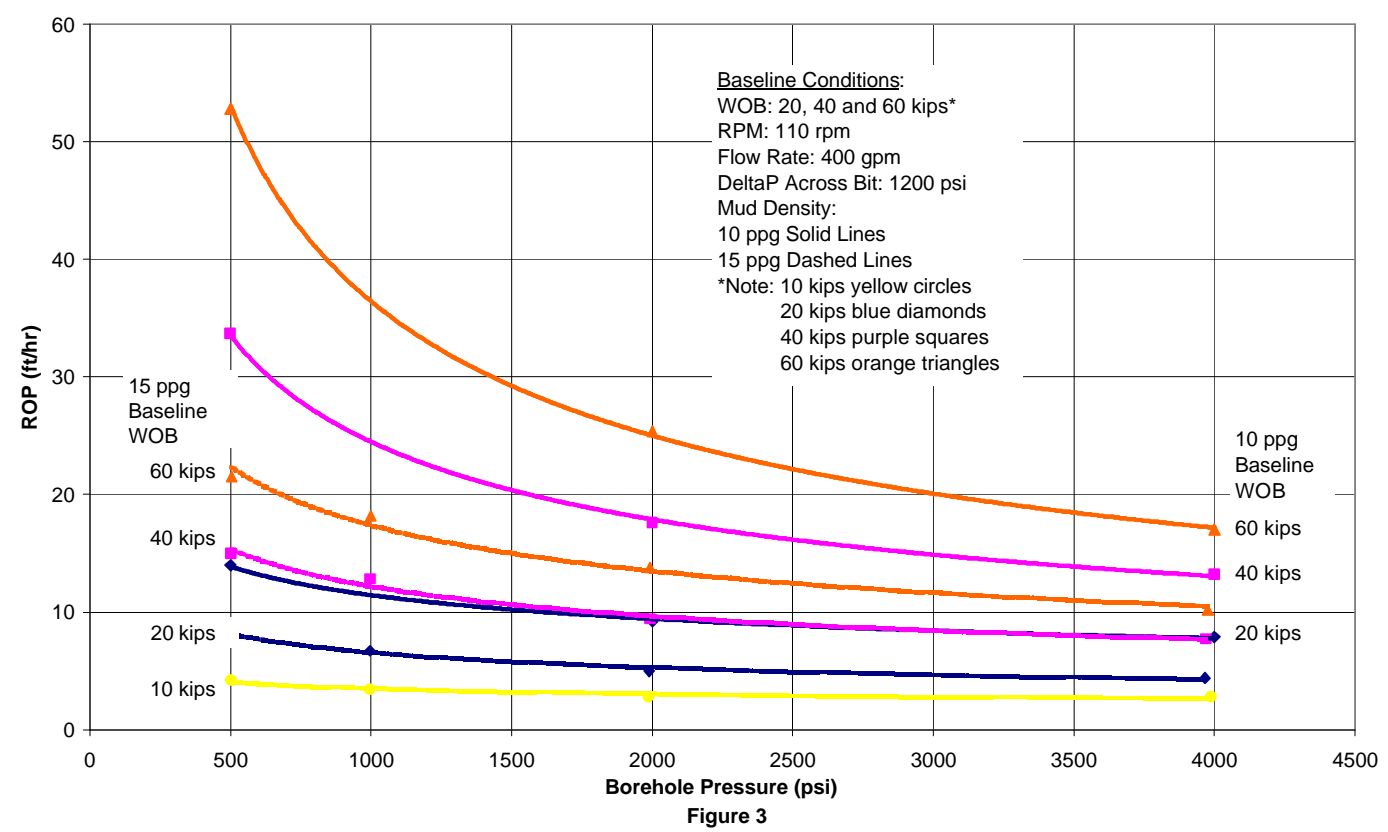


Baseline Data with 8 1/2" IADC 537 Bit with 10 ppg and 15 ppg Water-base Mud for Crab Orchard Sandstone

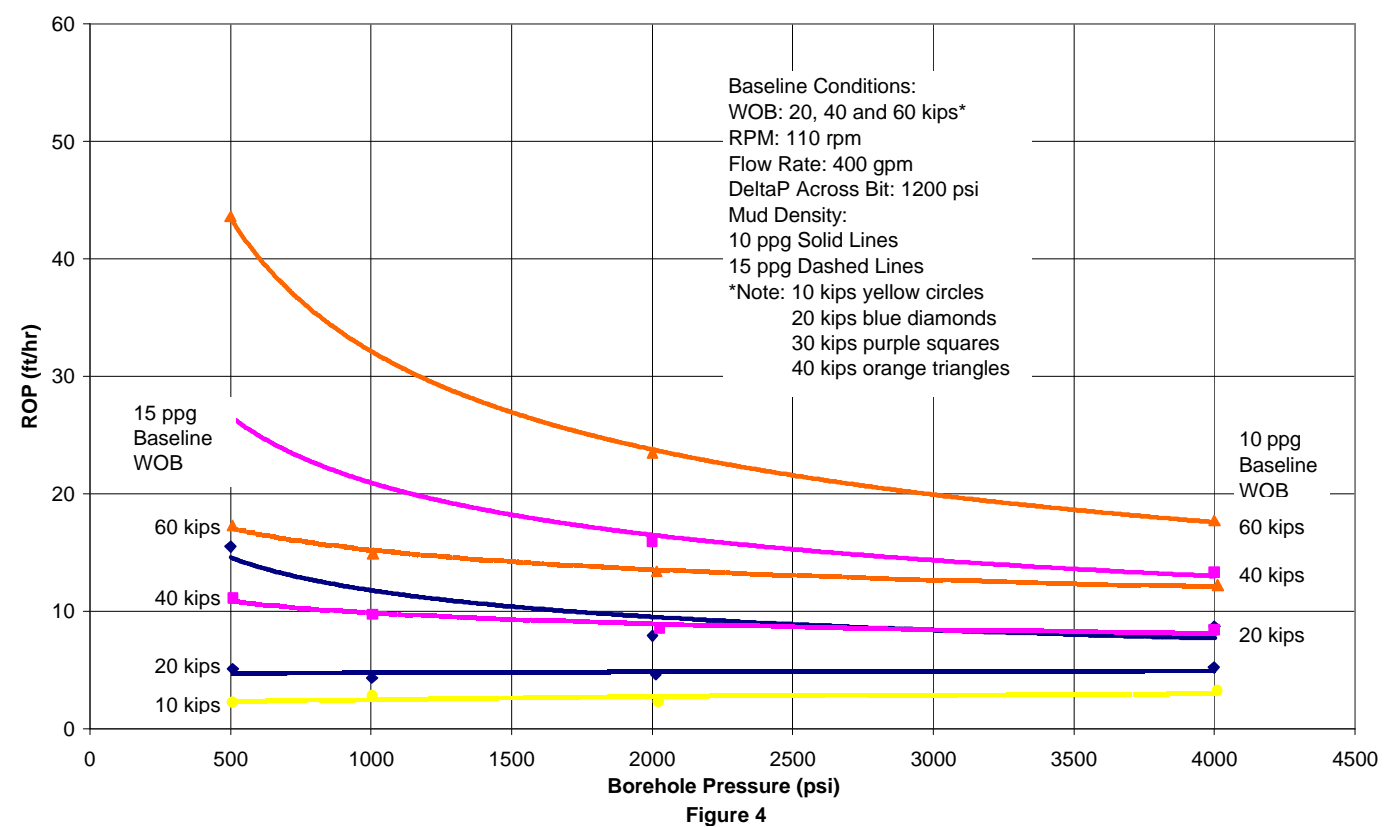

Comparison of DOE Test 1 SDS FH185 Hammer/Hard Formation Bit and 8 1/2" IADC 537 Bit Rotary Drilling for 10 ppg Water-base Mud and Carthage Marble

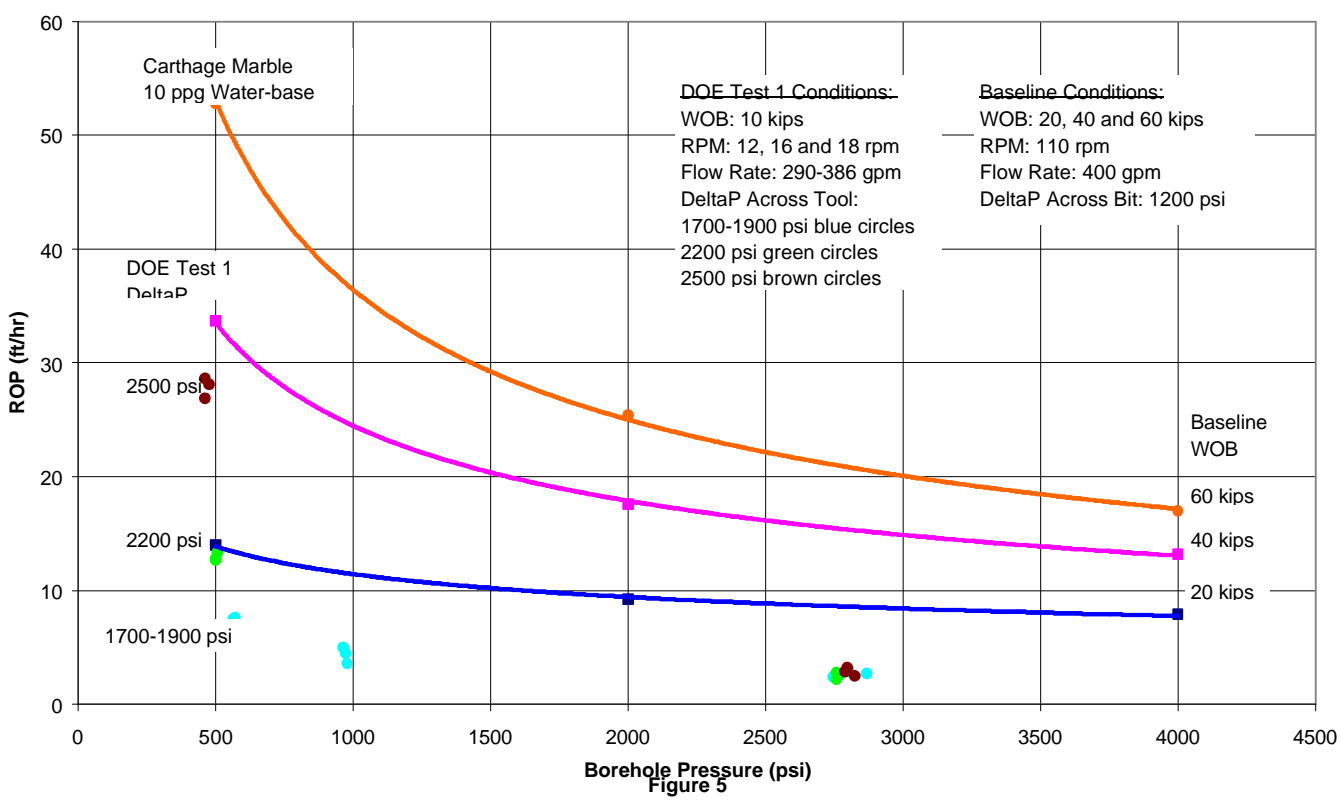


Figure 6 SDS Impact Bit

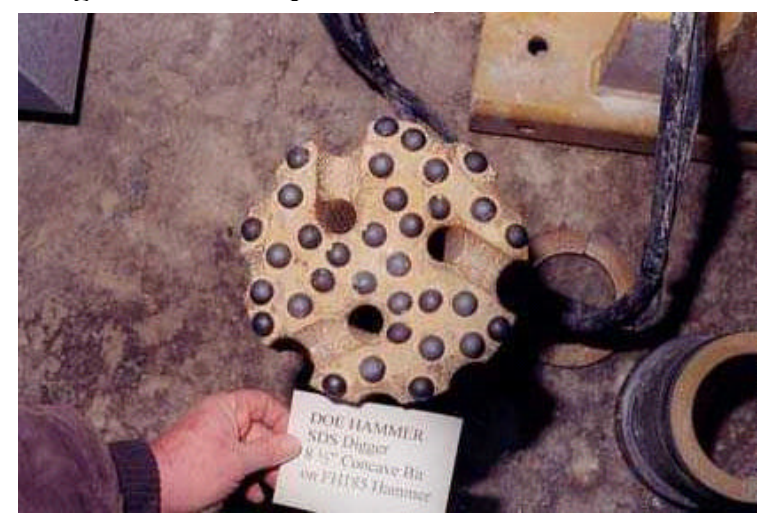

Comparison of DOE Test 2 SDS FH185 Hammer/Hard Formation Bit and 8 1/2" IADC 537 Bit Rotary Drilling for 10 ppg Water-base Mud and Crab Orchard Sandstone

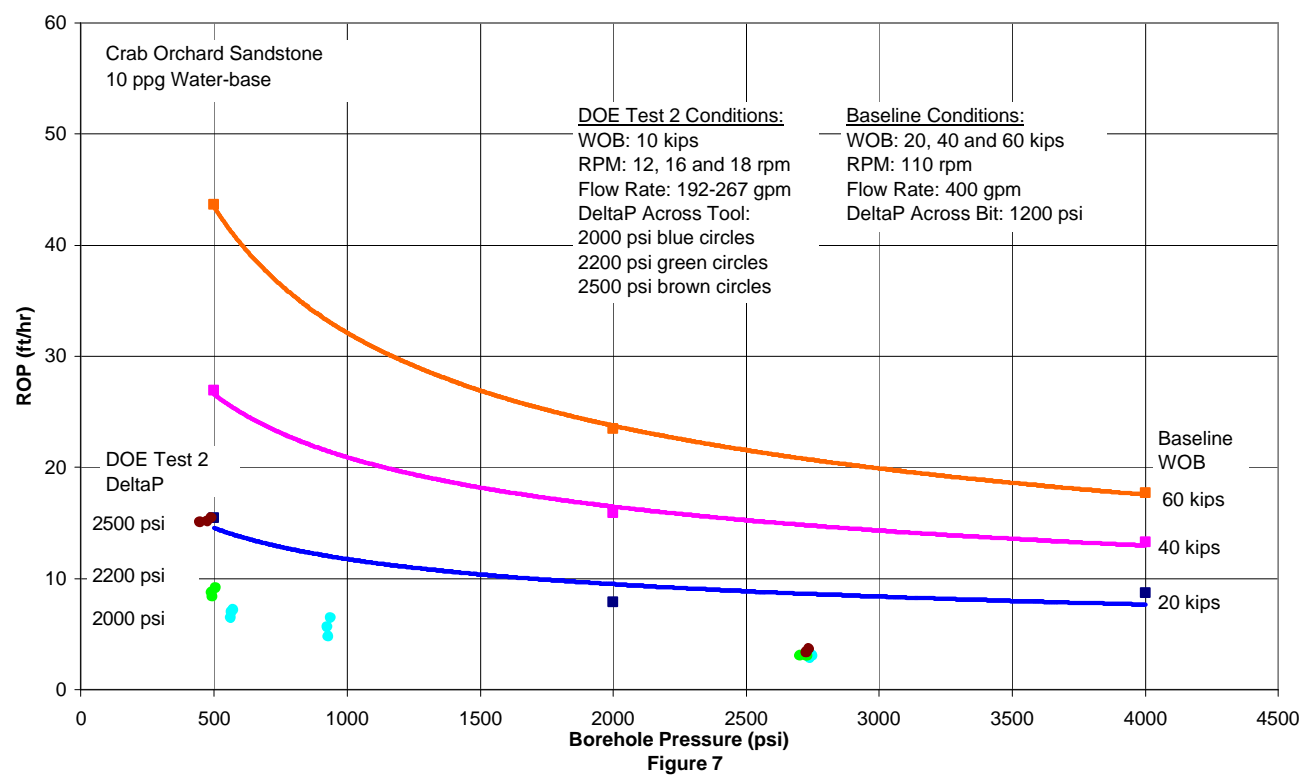


Comparison of DOE 6 SDS FH185 Hammer/Hard Formation Bit and 8 1/2" IADC 537 Bit Rotary Drilling for 15 ppg Water-base Mud and Carthage Marble

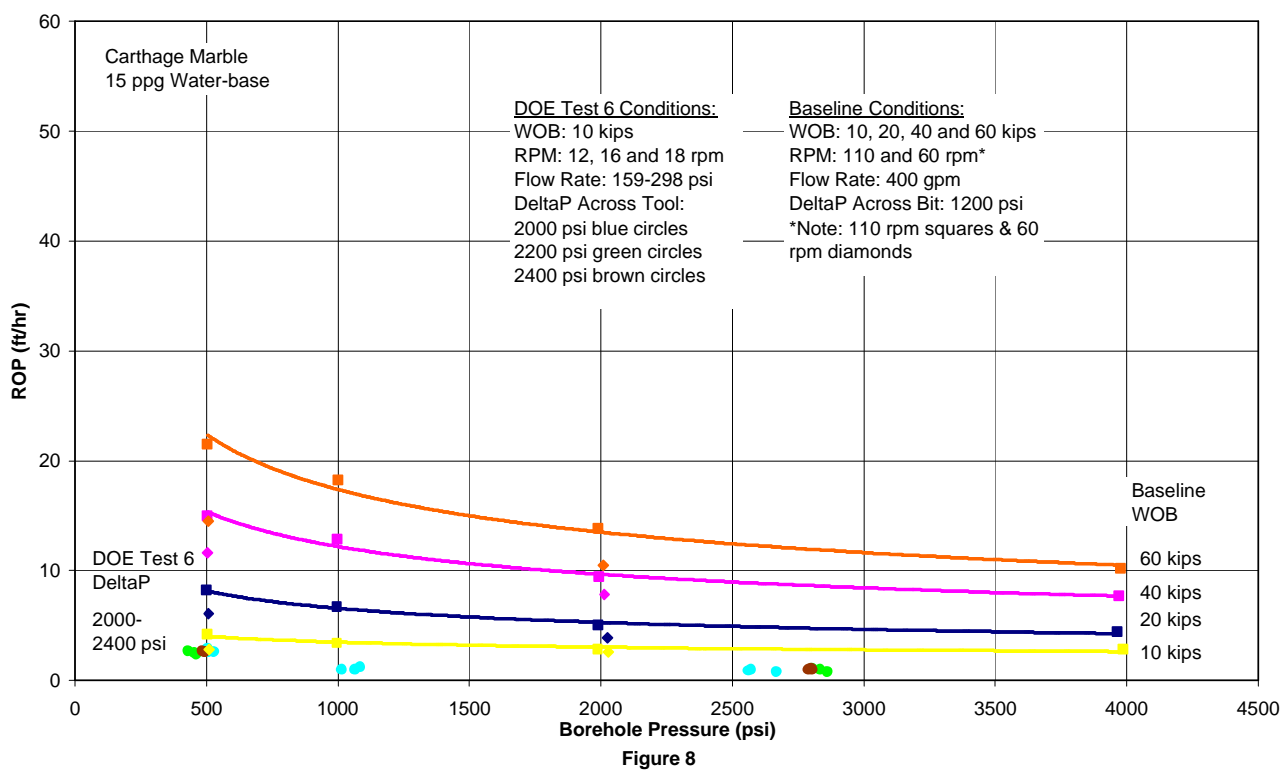

Comparison of DOE 7 SDS FH185 Hammer/Hard Formation Bit and 8 1/2" IADC 537 Bit Rotary Drilling for 15 ppg Water-base Mud and Crab Orchard Sandstone

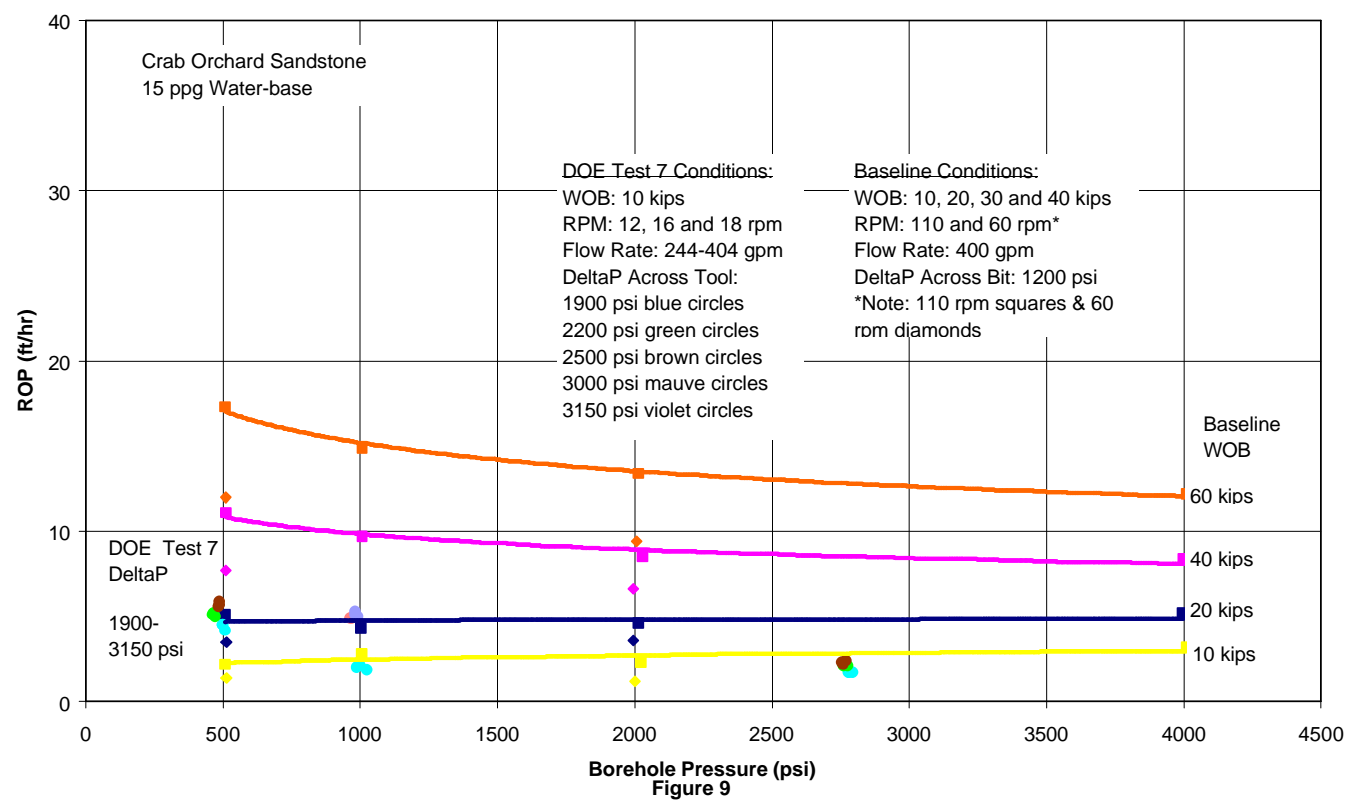


Comparison of DOE 8 SDS FH185 Hammer/Soft Formation Bit and 81/2" IADC 537 Bit Rotary Drilling for 15 ppg Water-base Mud and Carthage Marble

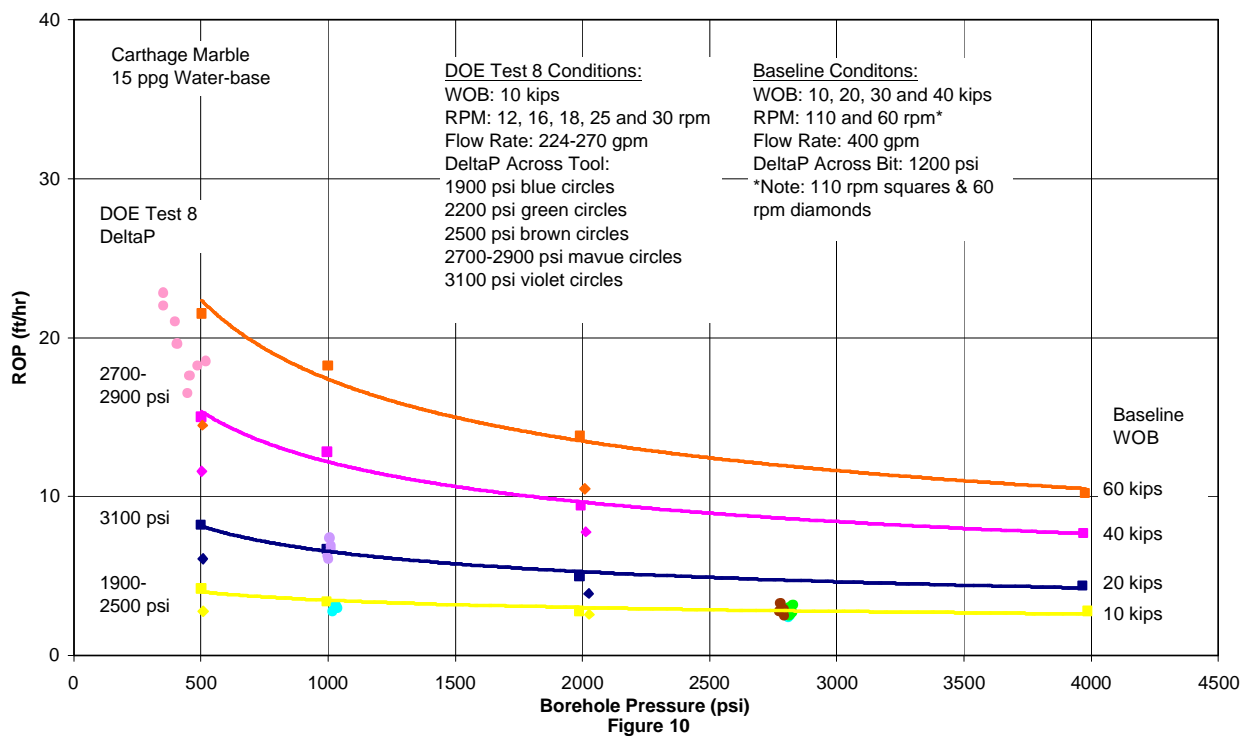

Comparison of DOE 9 SDS FH185 Hammer/Soft Formation Bit and 8 1/2" IADC 537 Bit Rotary Drilling for 15 ppg Water-base Mud and Crab Orchard Sandstone

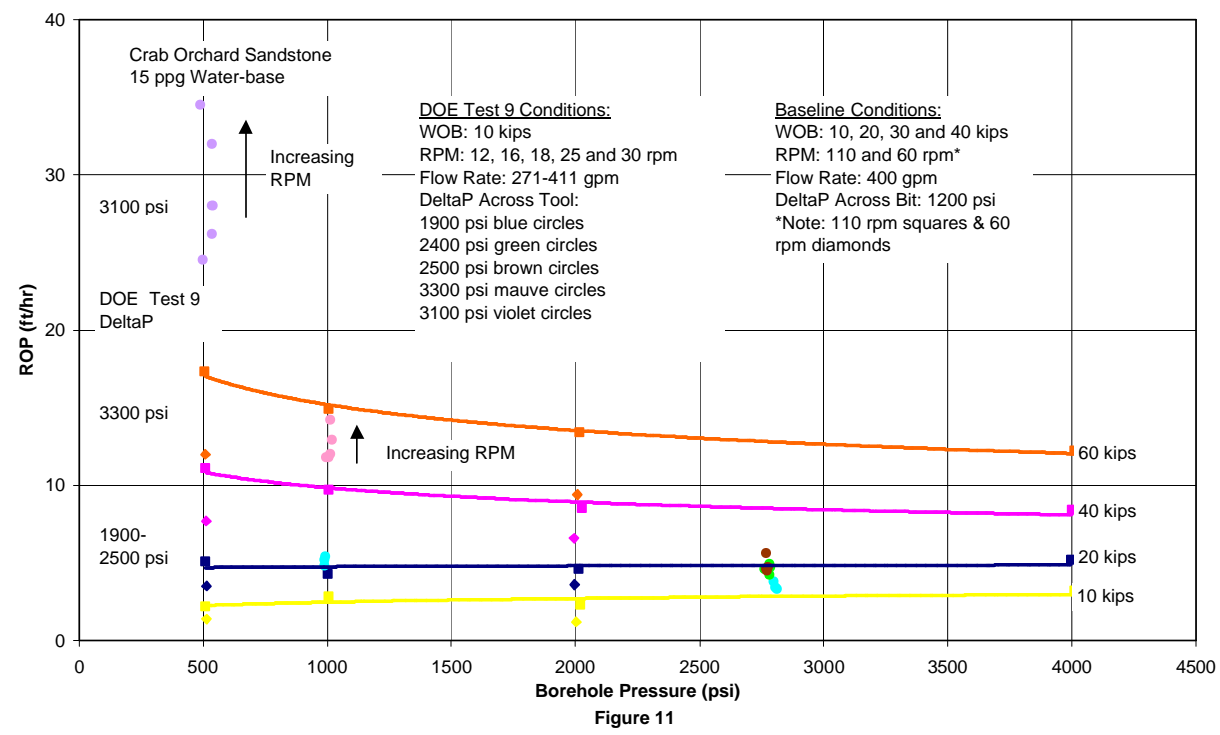




\section{Comparison of DOE 3A Novatek N5 Hammer/IADC 537 Bit and 8 1/2" IADC 537 Bit Rotary Drilling for $10 \mathrm{ppg}$ Water-base Mud and Carthage Marble}

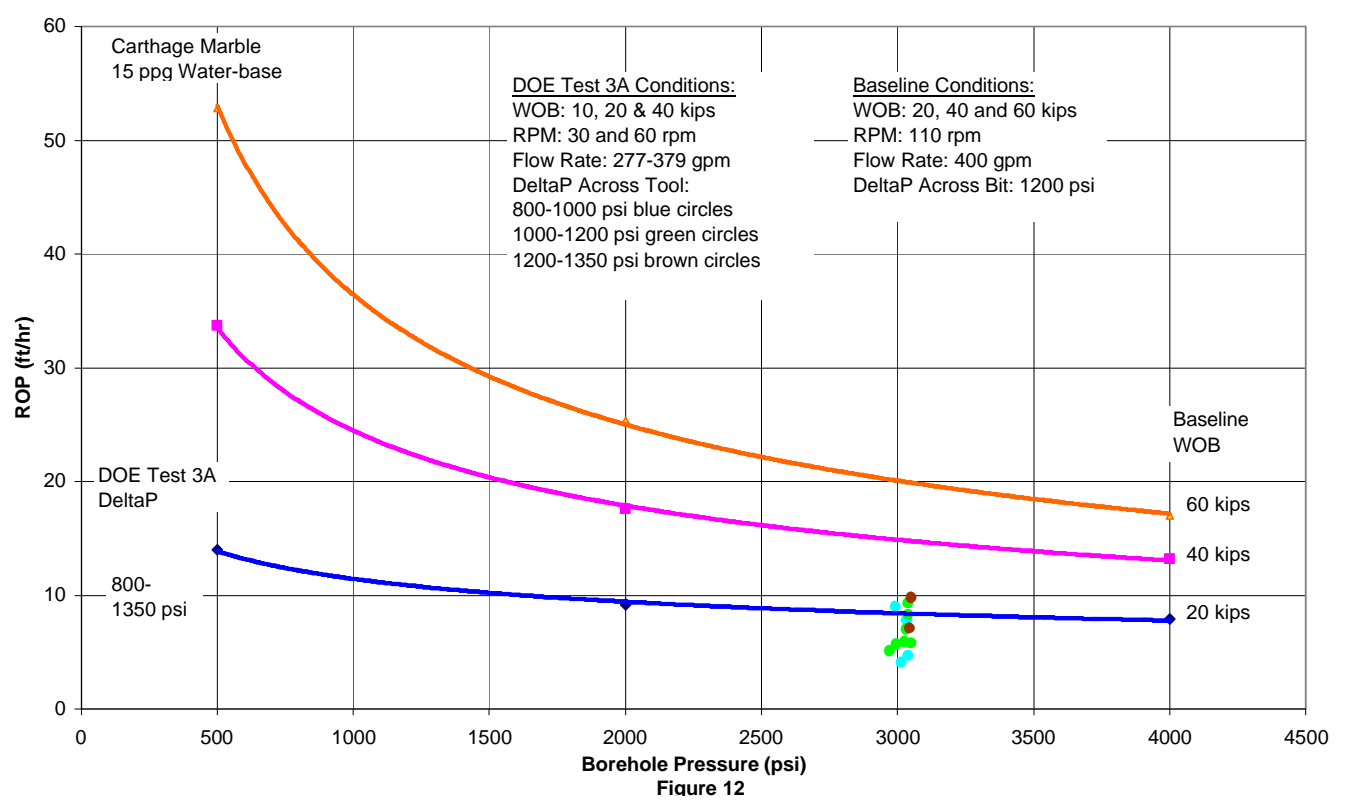

Figure 13 Novatek Bit (Patent

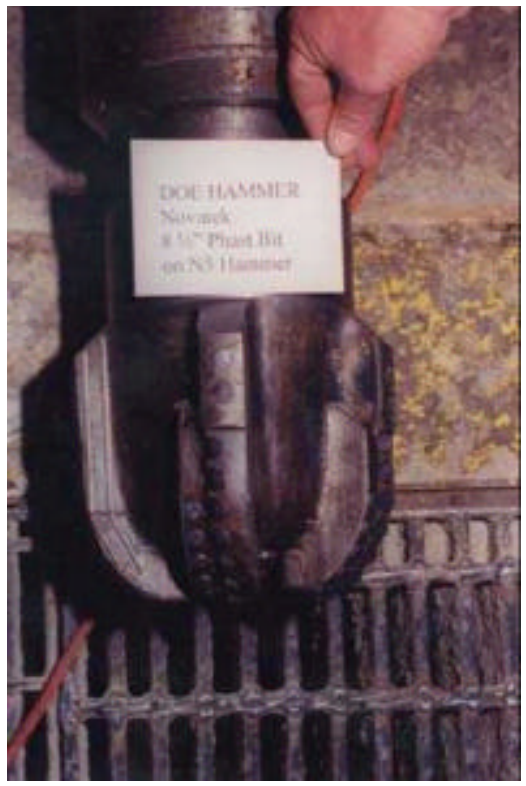


Comparison of DOE 12 Novatek N5 Hammer/Phast Bit and 8 1/2" IADC 537 Bit Rotary Drilling for 15 ppg Water-base Mud and Carthage Marble

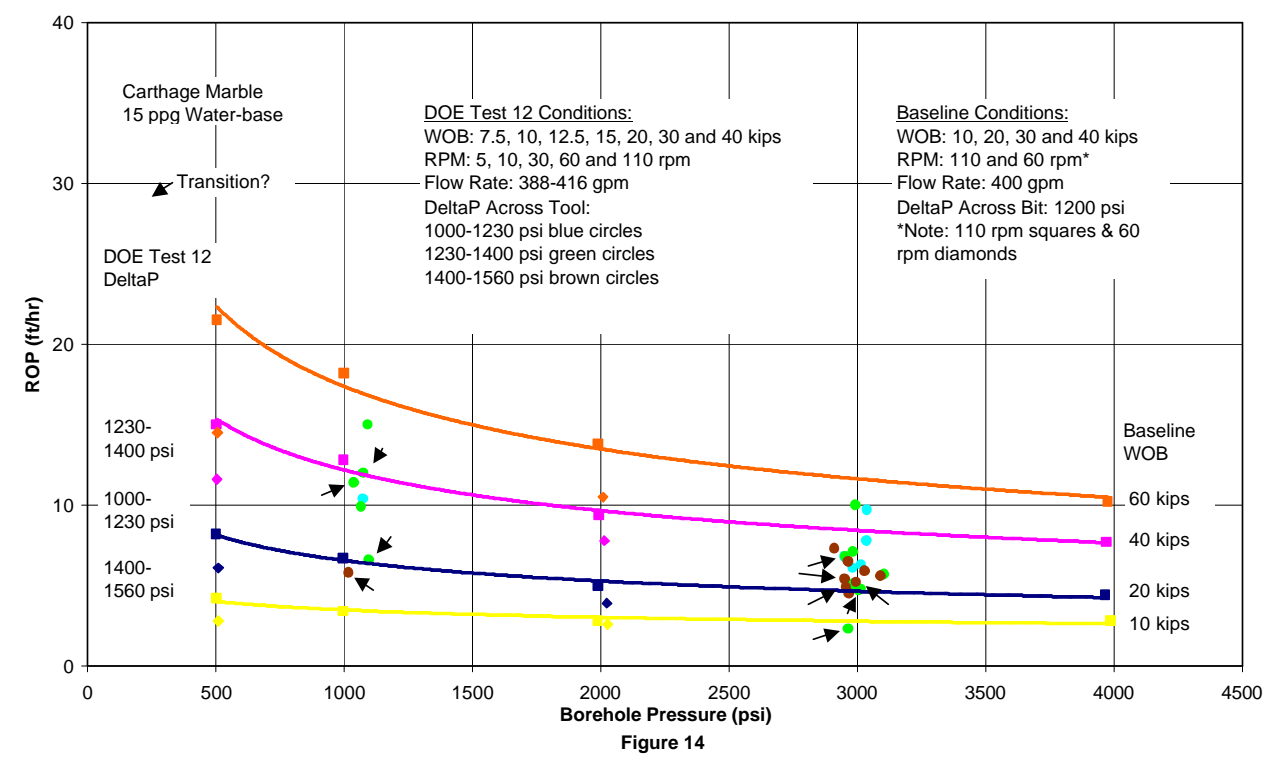

Comparison of DOE 11 Novatek N5 Hammer/Phast Bit and 8 1/2" IADC 537 Bit Rotary Drilling for 15 ppg Water-base Mud and Crab Orchard Sandstone

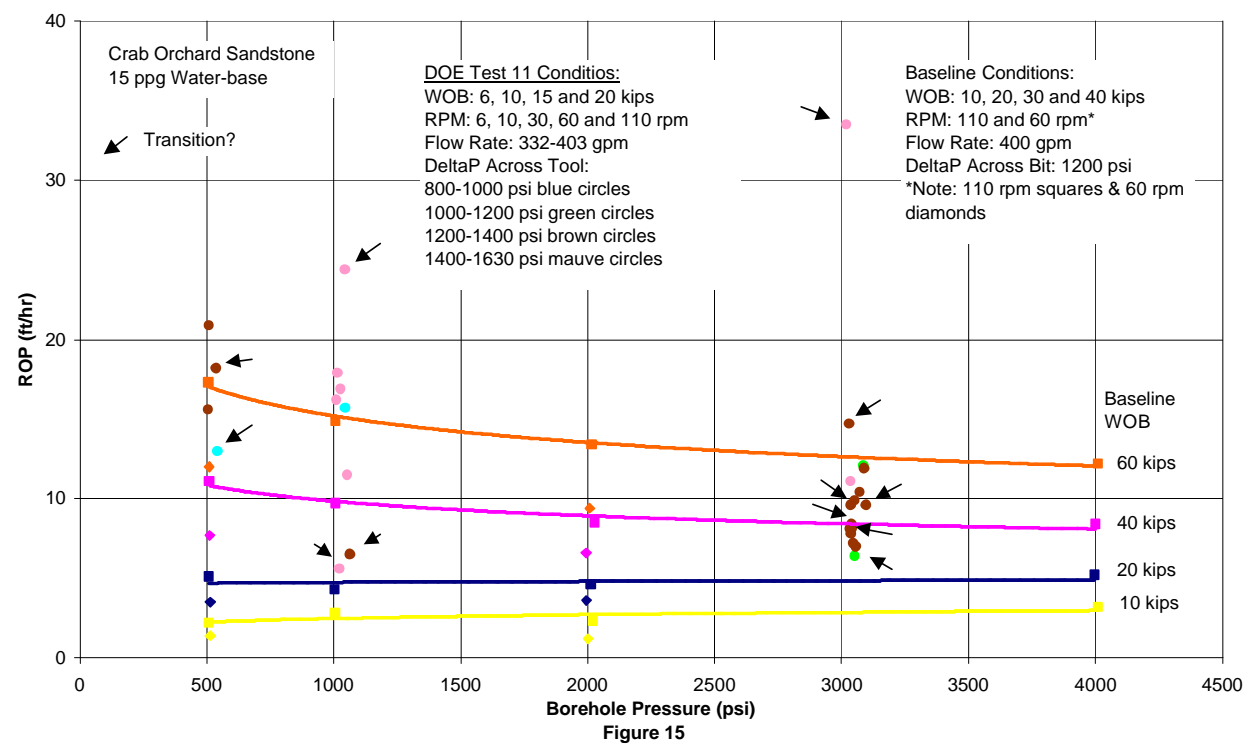


************************** end of publication $* * * * * * * * * * * * * * * * * * * *$

Q1

Planning meeting notes:

\section{MINUTES AND NOTES \\ OPTIMIZATION OF MUD HAMMER DRILLING PERFORMANCE \\ PHASE II PLANNING MEETING HOUSTON \\ $22^{\mathrm{ND}}$ FEBRUARY 2002 \\ PARTICIPANTS}

John Rogers (DOE NETL), Tim Travis (EXXONMOBIL), David Pixton (NOVATEK), Malcolm McInnes (SDS Digger Tools), Richard Reiley (BP America), Adam Aylor (EXXONMOBIL), Alejandro Lagrecea (PDVSA), Jesse Holster (EXXONMOBIL), Arnis Judzis (TERRATEK), Gordon Tibbitts (TERRATEK)

\section{GENERAL DISCUSSION}

- A paper detailing the work and results from Phase I has been completed -SPE74540

- A presentation of this paper will be made at the SPE/IADC meeting in Dallas on the $28^{\text {th }}$ of February (Completed)

- PDVSA has joined the program and has contributed to funding more testing for the program. Their representative at this meeting is Alejandro Legracea

- Meeting to proceed as outlined in the approved meeting agenda

\section{PHASE I AND WAY FORWARD REVIEW}

A brief review of the phase I test program was given. Emphasis was placed on what issues need to be addressed to move the hammer technology towards commercialization. For the Novatek tool the primary issues was learning about the "transition zone" improved performance mode of drilling that was observed in the latter part of phase I. For the SDS tool it was adapting the internal configuration to retain performance when the tool is used with denser, overbalanced drilling fluids, within recognized oil field pump pressure restraints.

\section{SDS TOOL IMPROVEMENTS BASED ON THE RESULTS OF PHASE I}

Malcolm McInnes SDS thanked the program sponsors and TerraTek for the valuable test data, which had closed some $R \& D$ loops and provided additional insight into tool characteristics. An appropriate design response was established early. The new 
knowledge also contributed to the achievement of an ROP of 5.5 times the offset rotary rate, at 5,000 feet in a subsequent Venezuelan hard formation drilling trial. The tool operates within a window of low WOB and good control is required. The tool cannot be considered in isolation from the deployment system because of dynamic interactions.

The presentation included graphs and charts of the data collected at TerraTek, which demonstrated the general characteristics of the tool, including strong relationships between key parameters such as ROP relative to offset and impact frequency. It appeared that bore hole pressure and formation were less important. There was also significant scope for the optimization of rotational speed, bit design, WOB and impact power. Extrapolations of fitted curves indicated the potential performance of the SDS tool if the target impact frequency had been achieved, without pressure constraints.

The next generation tool would be redesigned to reduce operating differential pressure. Phase II developments were only constrained by funding availability. The tool design originated in the hard, metalliferous mining industry where it was powered by a low flow rate of clean water, at high pressure. The typical operating differential pressure is 2,000 psi to 2,500 psi although a hole opening job has been done successfully at $850 \mathrm{psi}$, in Norway.

Tim Travis had suggested measuring tool performance in terms of total mechanical and hydraulic energy used to break a volume of rock. SDS had done this using units of Joules/litre of rock, but was concerned that the ultimate performance measuring scale was the $\$$ /litre. Different drilling technologies could have different mixes of ROP, life, operating cost and energy efficiency. Life testing is outside the scope of the current program.

A lively discussion ensued on the maximum pump pressure at which current contractors and TerraTek would allow their pumps to be run. This pump pressure determines the available hydraulic horsepower available to tools in the drill string after parasitic losses are addressed and the bottoms up pressure drop is added to the equation. At issue are the current operator needs for their applications and future requirements for these new tools in order to have performances above expectations. In the TerraTek facility, the bore hole pressure is achieved with the aid of a choke acting against the flow rate.

The levels suggested by EXXONMOBIL were 1500 to 1700 psi pressure drop through the tool as surface pump delivery systems are limited to operate at 3000 psi.

The SDS percussion tool would be required to perform on hydraulic power, against rotary and hybrid rotary tools, which could use similar amounts of hydraulic power supported by additional mechanical power. SDS has had little experience with Fluid Hammer commercial projects where pump pressure limited tool performance or where mud specific gravity was as high as that used in the TerraTek tests.

The SDS tool does not need any significant hydraulic HP at the bit face and does not need a heavy, narrow bore, BHA. In many cases, the SDS tool can operate at a lower flow rate. 


\section{NOVATEK TOOL IMPROVEMENTS BASED ON THE RESULTS OF PHASE I}

David Pixton Novatek will be pursuing rotary percussive bits as the cutting structure for their tools. The mud hammer valve timing is affected by the mud weight and will need to be redesigned to operate optimally.

Novatek presented a graph comparing the rate of penetration of the tool/bit to the horsepower at the bit. For the most part the horsepower at the bit increase nominally with an increase in ROP. In the transition area of interest the horsepower at the bit remains the same for a drastic increase in ROP. This will be their focus moving forward. They will try to define the following:

- Operational factors leading to the high rate drilling

- The influence of jet assisted drilling on performance

- Influence of rock type on high rate drilling

- Understand the energy output of the hammer in heavier muds

Novatek believes the needed improvements for their hammer and bit system will encompass the following areas:

- Less influence of mud characteristics on the hammer operation

- Improve the robustness of the tool

- Gain more control over the applied WOB

- Improve the reliability of the jet assisted hammer bit

David thinks the redesign for the next generation hammer and bit to be completed in the summer of 2002. They are planning to build a complete new tool with a preliminary qualification of the tool in 90 days.

David suggested that testing for the optimization of their tool should be done at only one borehole pressure and that pressure should be as high as possible.

\section{OPERATOR REQUIREMENTS}

EXXONMOBIL

- Would like to see an "accounting" of hydraulic energy through the tool systems. How much energy is expended at each stage of the tool function and rock destruction? It would be helpful in establishing rig operating conditions.

- Would like to understand the mechanics of the "transition zone" drilling and ascertain whether or not we can drill at those conditions.

- Would like to see an expansion of the project to include other mud hammers

NOTE: Arnis Judzis mentioned that the prime way to get other mud hammer companies involved in the program was to have either a sponsor fund their participation or the companies that represent the hammers fund the testing directly. Arnis Judzis will report on progress as appropriate.

PDVSA

- Their applications require rock in the 25 to $30 \mathrm{KPa}$ strength range. 
- Suggested possibly performing the testing of the tools by performing "drill off" tests. Set the WOB and then drill off to establish the ROP data.

- Their applications to date are run with low weight mud systems.

- They have interest in the hammer/bit as a system.

\section{BP AMERICA}

- Current and near future applications are aimed at near balanced or under balanced directional drilling conditions or low WOB slide applications in the reservoir sections of the hole

- They would like to see Multi phase fluid tests to verify these tools can operate in such an environment

- Mentioned Oil/Water, Nitrogen/Diesel

- Needs to establish the performance of these tools in Shale sequences. Need to exhibit reasonable rates in shale as well as hard rock

- Would like to know the directional characteristics of mud hammers

- Concerned about Axial stick/slip vibration. Anything we can do in the testing to look at this?

\section{PHASE II TEST PLAN}

A test plan was presented that outlined the 15 tests now available to the program with PDVSA's sponsorship. Originally there were 12 tests planned for phase II. The suggested plan is shown below.

\section{TEST SCENARIO \\ PHASE II \\ MUD HAMMER OPTIMIZATION PROGRAM}

\section{$\underline{\text { TEST }} \quad \underline{\text { DESCRIPTION }}$}

1

2

3

4

5

6
EXPLORE THE TRANSITION ZONE

OF THE NOVATEK TOOL

EXPLORE THE TRANSITION ZONE OR THE NOVATEK TOOL

SDS TOOL OPTIMIZATION

NOVATEK TOOL OPTIMIZATION

SDS TOOL OPTIMIZATION

NOVATEK TOOL OPTIMIZATION

SDS TOOL OPTIMIZATION

NOVATEK TOOL OPTIMIZATION
ROCK SAMPLE

CRAB ORCHARD S.S. OR CARTHAGE MARBLE

CRAB ORCHARD S.S. OR CARTHAGE MARBLE

COMBINATION SAMPLE

COMBINATION SAMPLE

COMBINATION SAMPLE

COMBINATION SAMPLE

COMBINATION SAMPLE

COMBINATION SAMPLE 
9
SDS BIT OPTIMIZATION

NOVATEK BIT OPTIMIZATION

SDS BIT OPTIMIZATION

NOVATEK BIT OPTIMIZATION

SDS SHALE DRILLABILITY

NOVATEK SHALE DRILLABILITY

SDS BEST PRACTICE
COMBINATION SAMPLE

COMBINATION SAMPLE

COMBINATION SAMPLE

COMBINATION SAMPLE

SANDWICH SAMPLE

SANDWICH SAMPLE

to be determined

The test plan includes two tests using combination samples to test the Transition zone of the Novatek tool. It shows six tests for tool optimization, splitting the tests equally between the two tool manufactures. Additionally four tests are allocated for bit optimization work. Two tests have been included to test the response of these tools to shale stringers by employing samples that have a shale interval sandwiched between harder rock. The final test is available to test the best practice of the SDS configuration.

Consensus was reached on performing the tests at one borehole condition of 3000psi. Discussion on running just one mud weight was left open. Although that mud weight was tentatively agreed upon at $15 \mathrm{ppg}$ because of the data already in hand, it was left open to get additional feed back from PDVSA and BP.

The timing of the tests could not be detailed, as both the mud hammer manufactures needed to analyze the time necessary to redesign and build prototype tools. It was suggested however that if the tools could re ready for testing in late spring or the early summer it would accommodate the contract and the laboratory schedule well. It appears that SDS has a faster turn around time for the redesign and fabrication of their tool and might be the logical first tool to be tested.

\section{ATTENDENCE LIST \\ Phase II Mud Hammer Planning Meeting Houston \\ 22 February, 2002}

NAME

ARNIS JUDZIS

ALEJANDRO LAGRECA

JESSE HOLSTER

TIM TRAVIS

DAVID PIXTON

TELEPHONE NUMBER E-MAIL

8015842483

582129086734

7134314044

2816544267

8013742755 judzis@terratek.com

lagrecaa@pdvsa.com

jesse.holster@exxonmobil.com

tim.travis@exxonmobil.com

dpixton@novatekonline.com 


RICHARD REILEY
JOHN ROGERS
MALCOLM McINNES
ADAM AYLOR
GORDON TIBBITTS

2813665189
3042854880
61883380877
7134317649
8015842429

reileyr@bp.com

john.rogers@ netl.doe.gov

cymac@ozemail.com.au

adam.w.aylor@exxonmobil.sprint.com

gtibbitts@terratek.com

*********** End of February 22, 2002 planning meeting minutes $* * * * * * * * * * * *$

After kicking off the project beginning January 2001 progress has been made according to the schedule and scope of work proposed. Tasks 1, 2, 3, 4, and 5 have been completed, with progress now being made on Task 6 (completed planning meeting on February 22, 2002 with Industry Sponsors prior for next phase of testing) and Task 7 Reporting of Results through publication.

Review of January 2001 through March 2001 -

Task 1 - As confirmed by Roy Long, COR at NETL, the information required for the National Environmental Policy Act was submitted in calendar year 2000.

Task 2 - Completed and described in previous quarterly report.

Task 3 - Prepared rock samples and finalized tool logistics with hammer suppliers.

Review of April 2001 through June 2001 -

Task 3 - Set-up of large scale experiments completed. The test program was completed on June 27, 2001 after 13 full-scale tests were completed. Initial flow line and mud pump problems were resolved at TerraTek. The Novatek bit experienced both washouts and nozzle failures at first. The bit was repaired and testing continued after some delay and extra set-up time. SDS Digger hammer experienced fewer problems.

Review of July through September 2001 -

Task 4 - Benchmarking of mud hammer performance was completed. Interval data from all tests has been transmitted to the DOE project manager and Industry Sponsors.

Task 5 - A Peer Review ('Lessons Learned' meeting) was held with members of the Industry Advisory Board and the DOE. The suppliers and operators reviewed their own learnings and progress in addressing performance problems. The summary notes are made a part of the quarterly report below.

Review of October through December 2001 -

Task 6 - Plans are underway to identify the testing for the Optimization task. A planning meeting was attempted at the end of 2001 however some of the Industry Partners had scheduling difficulties dung the holiday season. That meeting was set for February 22, 
2002 and will be reported in the next quarterly report. PDVSA has joined the hammer program through cost sharing, thus will sit with the other Industry Partners in recommending tests appropriate for the overarching objective of the program - to accelerate the commercialization and availability of fluid hammers which operate at depth conditions and with weighted drilling muds.

Task 7 - TerraTek has completed the publication for the 2002 SPE/IADC Drilling Conference entitled "World's First Benchmarking of Drilling Mud Hammer Performance at Depth Conditions".

Review of January through March 2002 -

Task 6 - The planning meeting for Phase 2 testing was conducted on February 22, 2002 (minutes in results section of this report). NETL's new Contracting Officer's Representative, Dr. John Rogers, was in attendance

Task 7 - TerraTek presented IADC/SPE 74540 described above.

\section{Q2}

This section of the report will expand upon some of the major issues progressed during the three month time period.

\section{Meetings with Smith International}

\begin{tabular}{|c|c|c|c|c|}
\hline \multicolumn{5}{|c|}{ Dimensions of Smith's Mud Hammer } \\
\hline & \multirow{2}{*}{\multicolumn{4}{|c|}{ Length (inches) }} \\
\hline & & & & \\
\hline & Start* & End & Diameter & Section \\
\hline \multirow{3}{*}{ Top Sub } & 0.0 & 22.2 & 6.75 & 22.2 \\
\hline & 22.2 & 26.2 & 6.50 & 4.0 \\
\hline & 26.2 & 36.2 & 7.00 & 10.0 \\
\hline \multirow{3}{*}{ Casing } & 36.2 & 61.2 & 7.00 & 25.0 \\
\hline & 61.2 & 107.7 & 7.13 & 46.5 \\
\hline & 107.7 & 124.8 & 7.25 & 17.1 \\
\hline Retainer & 124.8 & 133.1 & 7.63 & 8.3 \\
\hline Bit & 133.1 & 136.8 & $8.75^{\star *}$ & 3.7 \\
\hline \multicolumn{5}{|c|}{ * Length is measured from the top of the tool (uphole side) } \\
\hline \multicolumn{5}{|c|}{ " Bit diameter (range 7.875 to $8.75 "$ ) } \\
\hline \multicolumn{5}{|c|}{ *Te top sub and casing each are beveled $.08 \times 45$ degrees } \\
\hline \multirow{2}{*}{\multicolumn{2}{|c|}{ Overall Length }} & & & \\
\hline & & 136.8 & inches & \\
\hline
\end{tabular}

Memo June, 2002 to "Mr. Swadi [Smith International], 
It was a pleasure to meet you and discuss this project over the phone this morning.

After our discussion on the appropriate placement of the chrome on your tool, I took a more detailed look at the test scenario. I believe the optimum placement of the chrome on the 7.13 " diameter $x 46.5$ " would be the following:

Start the chrome 4" from the top of the sub and end the chrome $31 / 2$ " from the bottom of the sub. This will provide for a limited tong area on both the top and bottom just in case we have to break the tool down while it is here at the drilling laboratory. The top 4" should be undercut to allow burrs from "tonging" to not contact the seal surfaces during installation throughout the test program. The diameter might be the same as the adjacent sub.

This placement of the chrome will provide a total drilled depth of 28 " into the test sample. The 28 " will provide ample rock to gather the needed operational parameters for the tool. $81 / 2$ " diameter bits were used in the previous testing programs and as such will most likely be the choice for these tests also. The chrome specification that we have used in the past is as follows:

.006" to .008" Hard chrome Mil spec. QQC-320A Type II Class 2A. Grind to a 16 finish. Diametrical tolerance is $+000-002 "$.

Gordon Tibbitts, TerraTek"

Industry Partner (PDVSA) and SDS Digger Tools)

Mamo June 2002 to "Alejandro [PDVSA],

Gordon is on well deserved holiday, thus I will answer your questions.

First of all, I have attached the 1Q '02 progress report as delivered to the US Department of Energy. The second quarter report will be written end July '02.

Progress on the 'optimization' of the two tools has been slow, though here is my assessment of the situation. Novatek is building a completely new tool with a redesigned valve. The DOE is funding another project at Novatek (telemetry) thus they have put their resources on that project. The DOE and TerraTek expect a September schedule of tests at TerraTek.

SDS Digger has been difficult to reach. Gary Algate again informed me this week Malcolm in Australia needs money to ship the tool here plus personnel. I have 
not yet been contacted by him directly, though this indicates that their 'cost sharing' commitment is difficult to meet. If the amount is small, perhaps SDS can ask BP or ExxonMobil for some direct costs (?). TerraTek must certify Industry Cost sharing as we spend/invoice the DOE - that is mandatory per contract. I do not have a clear schedule for them, however Gary said that September is likely. SDS are also sending a tool to Vietnam for the Conoco application, thus that may be occupying their time. Have you contacted Malcolm since our planning meeting?

TerraTek has approached other suppliers with good success. Smith is willing to provide their hammer and test at TerraTek sometime in August. We are seriously considering this new opportunity given the fact that TerraTek's contract with the DOE will now need time extension and the DOE has approved the option of 'benchmarking' the Smith hammer "immediately". The DOE acknowledges that delays by Novatek (also a DOE contractor) and SDS Digger are commercially unacceptable to TerraTek.

Andergauge is also willing to test their 'hammer'(longer tool though) at TerraTek. They do not have funds to cover testing costs on their own.

Other operators are indeed interested too, though getting money has been difficult. Most prominent is Shell however there has been silence since May '02 from them. Any further operator interest and cost sharing could result in immediate testing of the Smith and possibly Andergauge tools, followed by a September re-test of the delayed Novatek and SDS tools.

I hope this helps. If you have better contacts with SDS or other operators, please let me know.

Arnis Judzis

TerraTek

judzis@ terratek.com

$+1(801)$ 584-2483

\section{Q3}

This section of the report will expand upon some of the major issues progressed during the three month time period.

Plans were underway to add the Smith collar to the testing program. Various experimental programs and layouts to fit TerraTek's Wellbore Simulator were discussed and drawn up. 


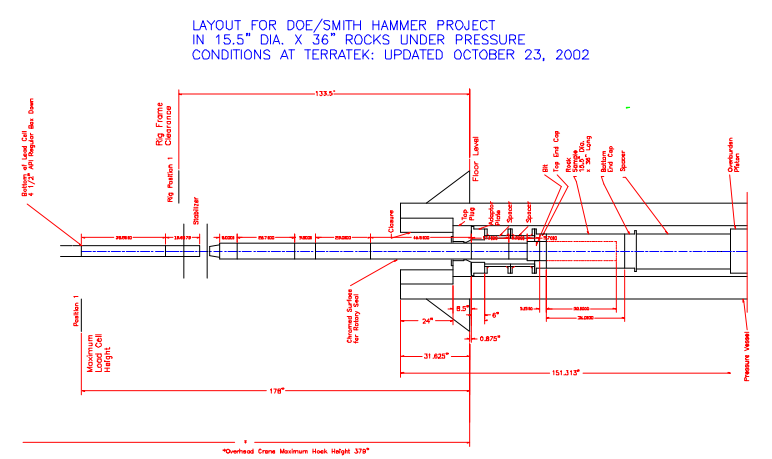

\section{$\underline{\text { Scope of Work Changes }}$}

\section{Task 3.1.1 Addition}

The following table will be inserted or added to the agreement in order to test Smith international mud hammer tool in Subtask 3.1.1 Test program under test sequence. All other testing specifications will remain as in the original agreement

\begin{tabular}{|l|l|l|l|}
\hline Test & Hammer/Bit & Rock & Mud Density, ppg \\
\hline 13 & Smith & Carthage & 10 \\
\hline 14 & Smith & Crab Orchard & 10 \\
\hline 15 & Smith & Carthage & 15 \\
\hline 16 & Smith & Crab Orchard & 15 \\
\hline 17 & Conventional & Carthage or Crab & $*$ \\
\hline 18 & Smith & $*$ & $*$ \\
\hline
\end{tabular}

* From previous testing, the comparison to 'conventional drilling' is available for 10 and 15 ppg fluids. Industry input at the February '02 planning meeting (particularly BP, PDVSA) prompted plans to use a lighter weight brine as extra data points.

Task 5.1: Promoting Industry Development and Experience with Fluid Hammers The task will seek out other hammer suppliers (e.g. Andergauge) and operators not currently in the program and determine if mud hammers could increase significantly hard rock drilling performance in their operations

Subtask 5.1.1: TerraTek and its Industry partners will implement the recommendations from the Industry Advisory Board planning meeting and reassess the capabilities of the early developers of Mud Hammers. 
Subtask 5.1.2 TerraTek will evaluate information available from field trials available from its contacts within the industry (e.g. PDVSA in Venezuela, Conoco's hard rock drilling program, and BP's domestic hard rock drilling areas).

Subtask 6.3.1 The difficulties experience by both Novatek and SDS Digger are attributed in part to the challenge imposed by the DOE - that is ensure the satisfactory 'performance of mud hammers at depth and with actual drilling fluids'. TerraTek's tests under Task 4 provided the Industry partners with learnings perhaps exceeding what was originally expected - tools would require greater development times to optimize and could require different testing methods; e.g. SDS Digger is considering the use of a combination pressure balanced stroke sub - hammer system to deliver weights-on-bit independent of drill string extensions. Testing of these tools will require more extensive set-ups and time at TerraTek.

The Industry suppliers have already been working on Tasks 6.1, 6.2, and 6.4 as part of the preparation for Large-Scale testing.

\section{Schedule and Milestones}

Original portion of Task 3 has already been completed. The addendum to Task 3.1.1. (above) will be conducted during September and October 2002. Milestone will be the test results of the Smith tool benchmark performance

Original portion of Task 5.0 has already been completed. Proposed Tasks under 5.1 would commence immediately and continue through completion of Task 6.3 July 2003. An interim project meeting with Industry Advisors is now planned subsequent to benchmarking the Smith Tool (ca. November 2002).

Task 6.3 will commence end 2002 pending resources allocated by another DOE contractor Novatek. Testing is projected to commence November 2003 and end May 2003, assuming that SDS will continue to have prototype development deficiencies and scheduling problems identified in the completed 'benchmark' testing.

\section{End of Scope of Work Changes section}

\section{Q4}

This section of the report presents performance results of the Smith Hammer during the three month time period. 
DOE Test 14 with Smith Hammer Compared with 8 1/2" Reed HPSM Baseline Bit for $9.0 \mathrm{ppg} \mathrm{NaCl}$ Brine and Carthage Marble

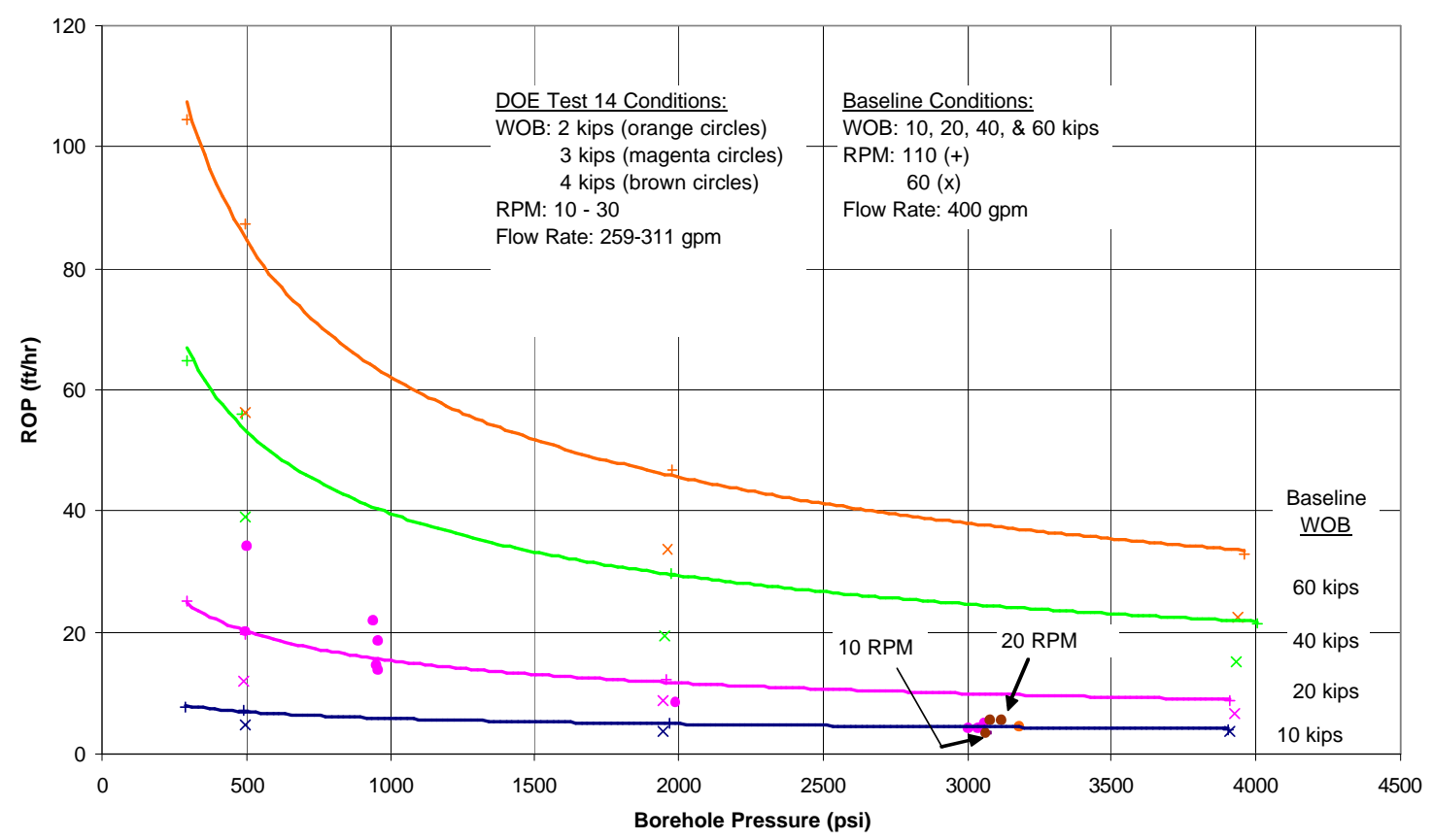

DOE Test 15 with Smith Hammer Compared with 8 1/2" Reed HPSM Baseline Bit for 10 ppg Water-Base Mud and Carthage Marble

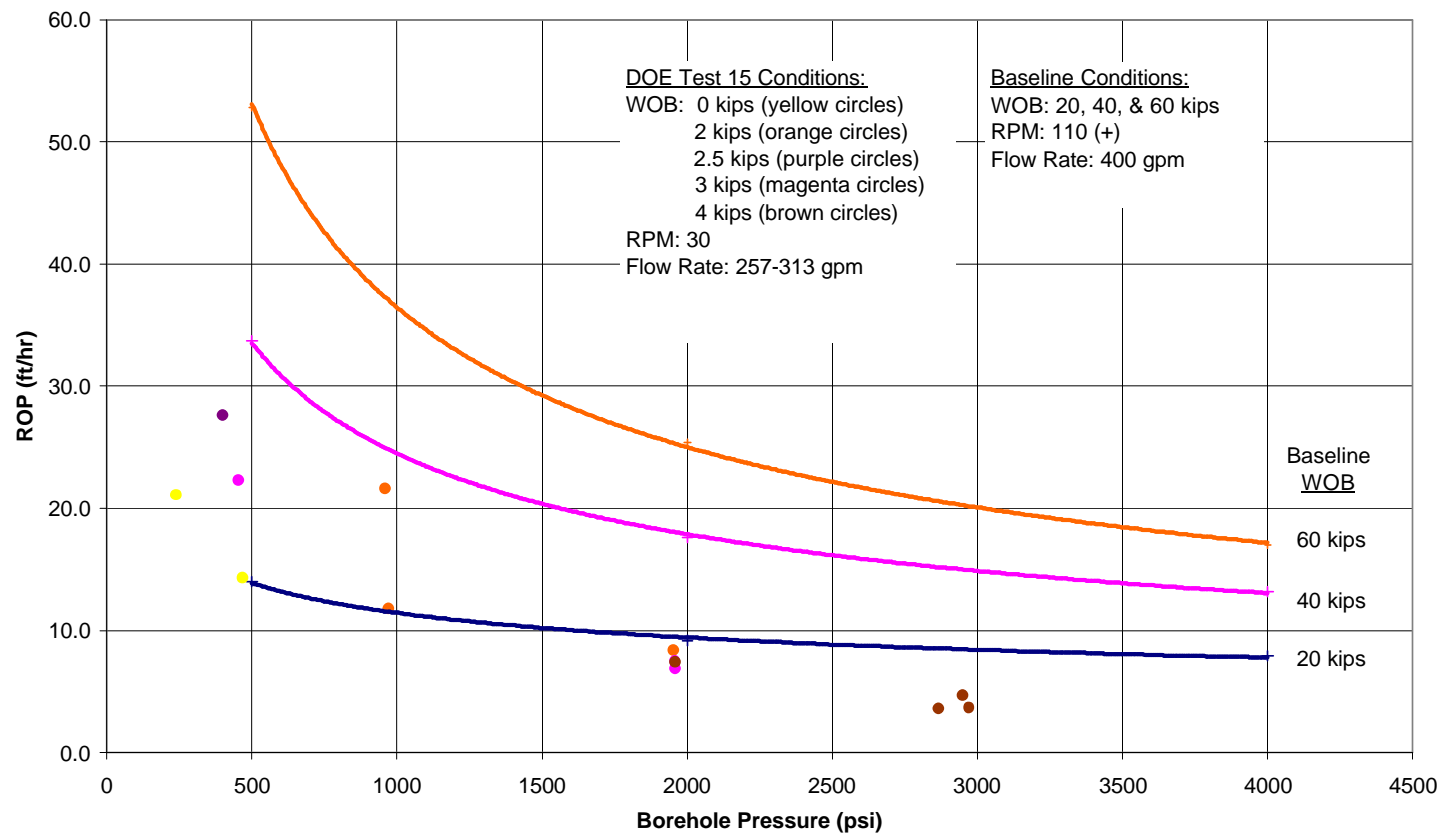


DOE Test 16 with Smith Hammer Compared with 8 1/2" Reed HPSM Baseline Bit for 10 ppg Water-Base Mud and Crab Orchard Sandstone

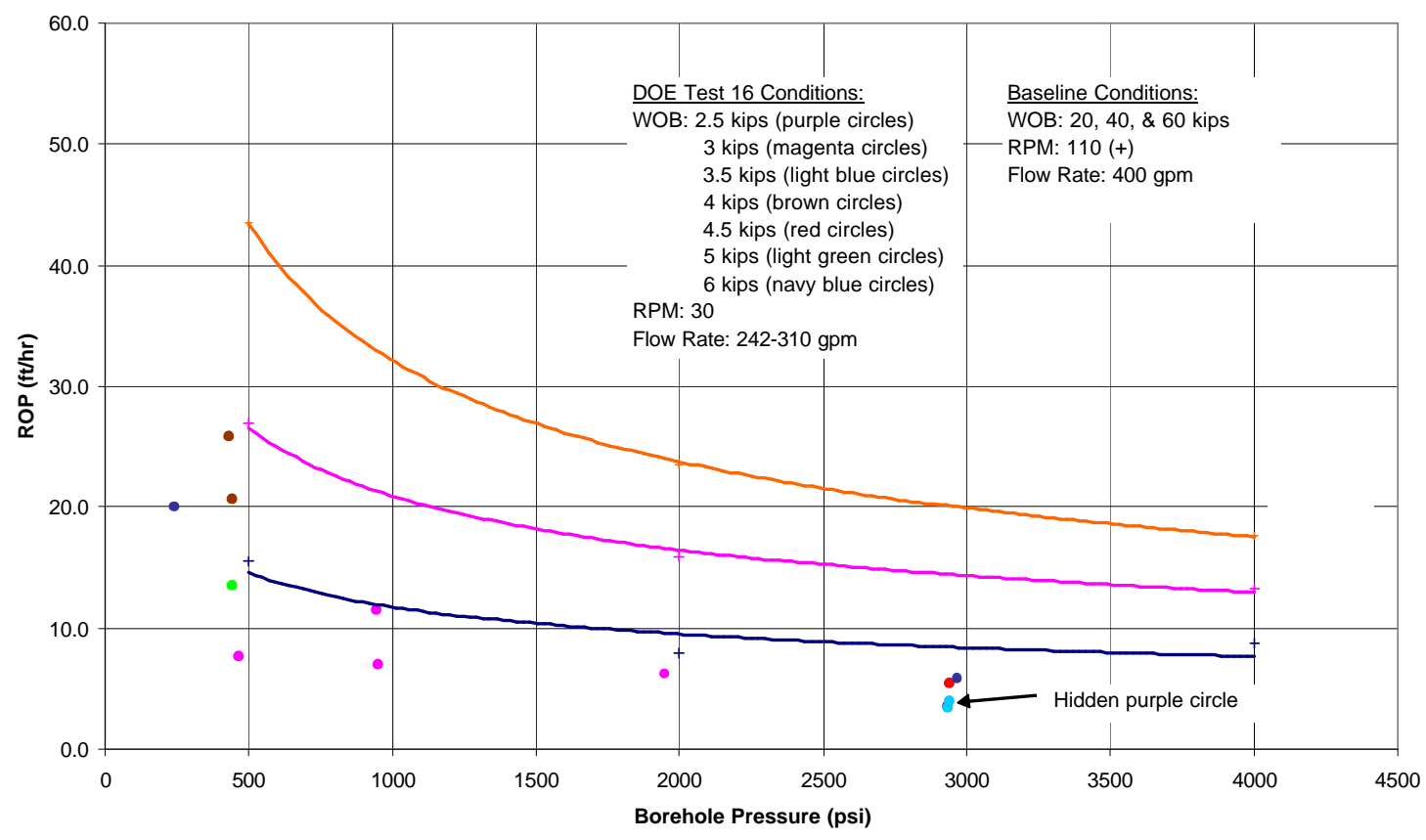

DOE Test 17 with Smith Hammer Compared with 8 1/2" Reed HPSM Baseline Bit for 15 ppg Water-Base Mud and Carthage Marble

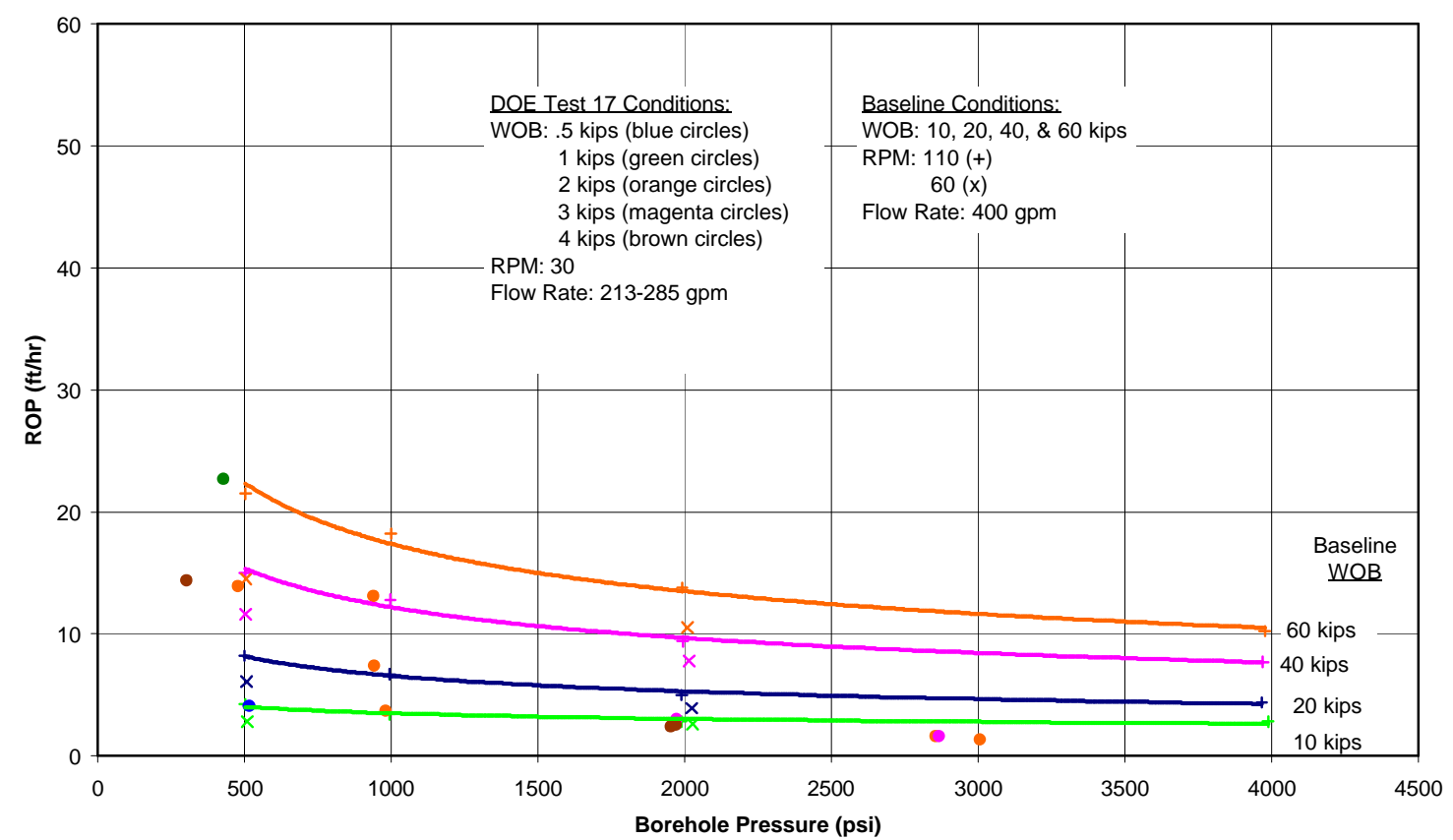


Bottomhole patterns were also photographed;
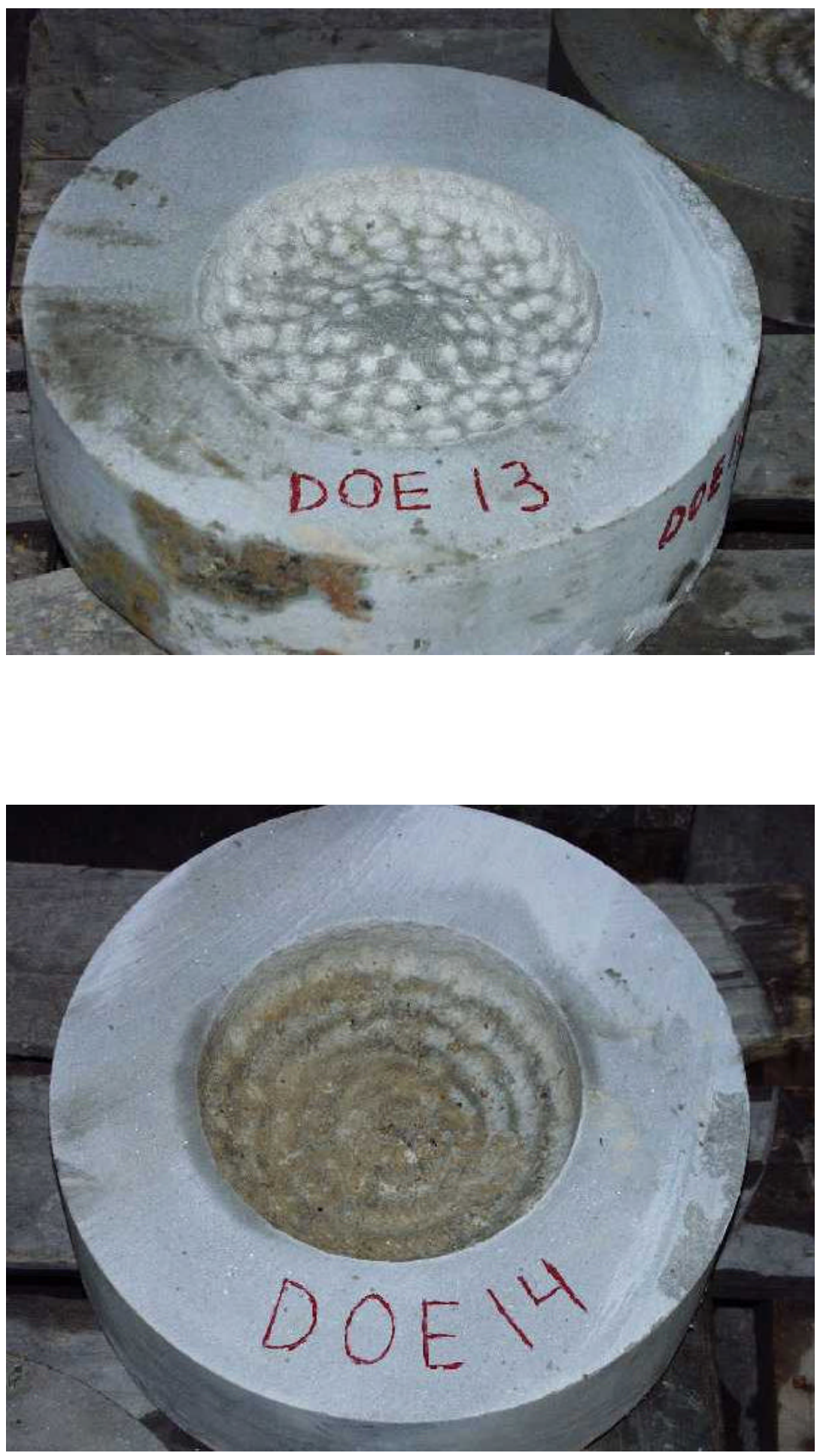

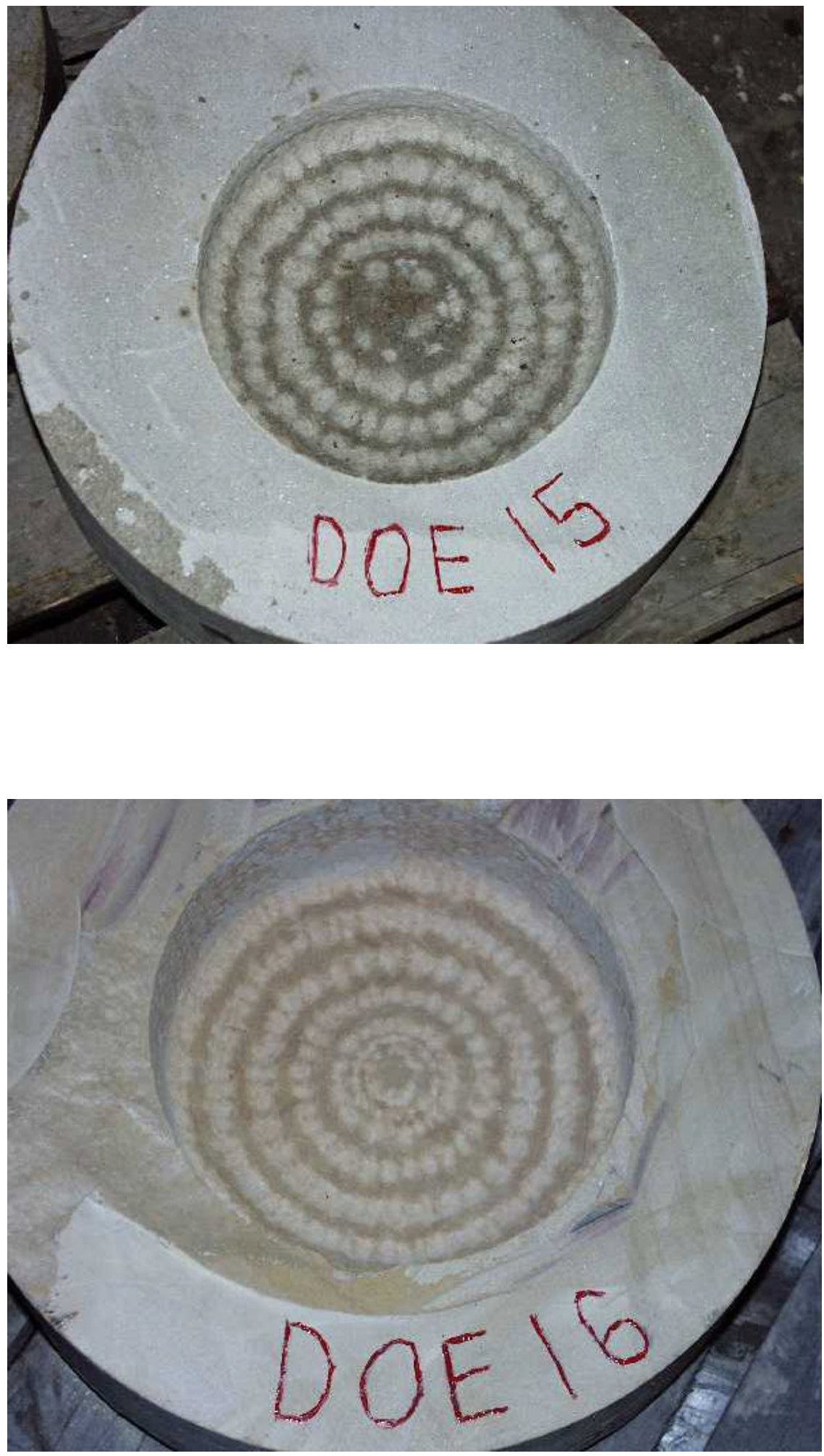


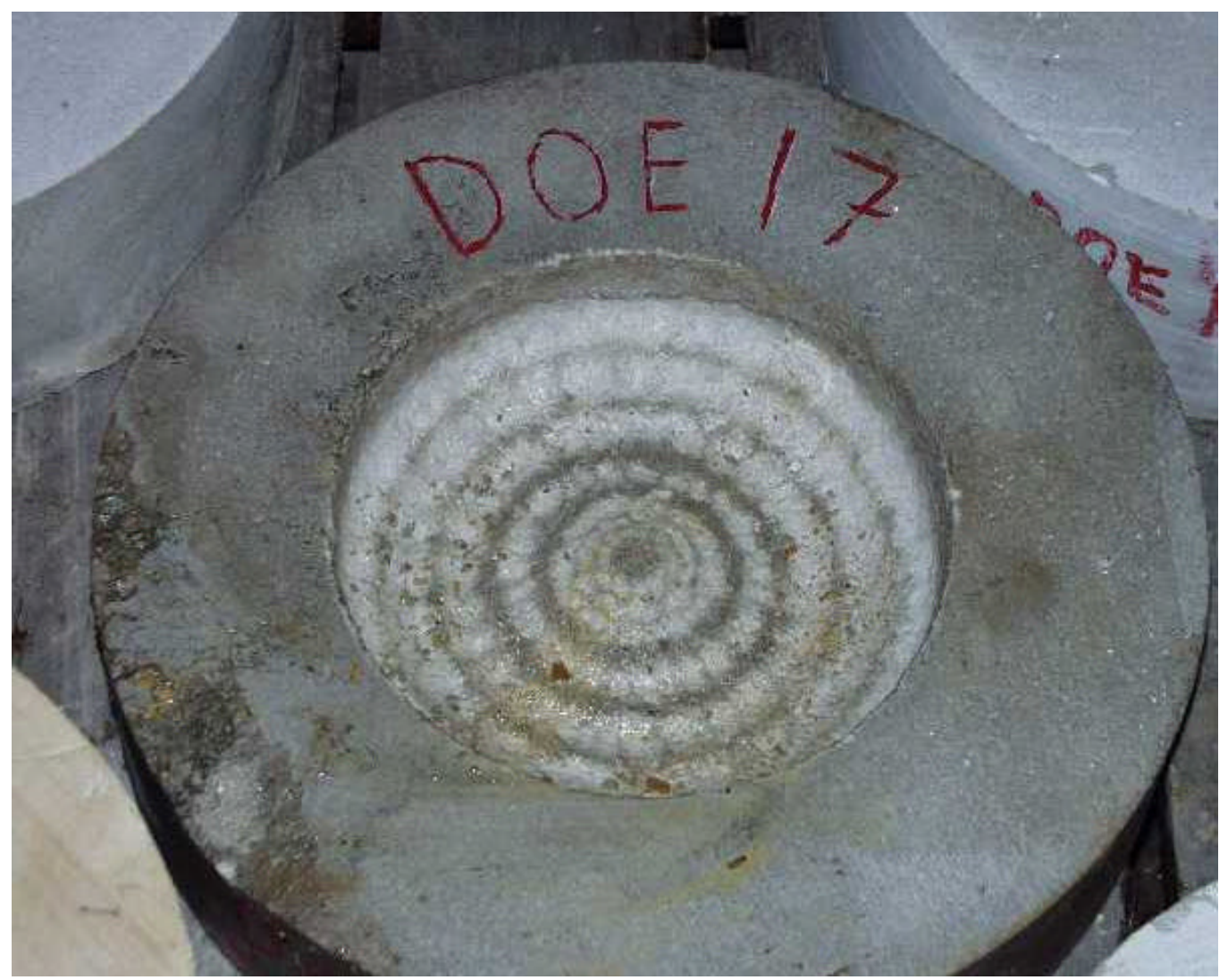

\section{Lesson Learned Meeting Summary November 7, 2002}

Attendees; John Rogers (DOE / NETL), Lance Underwood and Shantanu Swadi (Smith International), Alejando Lagreca and Delcio de Santana (PDVSA), and Arnis Judzis (TerraTek). Regrets from Rich Reiley (BP) and Gary Collins (ConocoPhillips).

Discussion;

Lance Underwood (Smith) - Some field experience [data] better than observed at TerraTek; performance did not beat 3 cone bit especially with high borehole pressures. $80 \%$ of their forecasted market is at 10 ppg or less. Smith views energy input and bit design important for optimization. Check into higher rate data collection for optimization tests. Smith potential markets for mud hammer - Brazil, Travis Peak and Cotton Valley sandstones, cherts in W. Texas, carbonates various locations. Lance is also interested in rock destruction by looking at impact testing of single cutters, etc. Need to quantify effects and energy requirements at high borehole pressures among other things.

Shantanu Swadi (Smith) - Also views energy input as being crucial. 
Alejandro Lagreca (PDVSA) - Need to understand fundamental relationships such as energy input. ROP can be studied .. will have to also look at longevity. 9 or 10 ppg fluid seen as biggest current use for hammers.

John Rogers (NETL) - Parameters such as mud weight can be suggested by operators and service companies. 15 ppg mud weight could be representative of Tuscaloosa or deep Anadarko. DOE's aim is to improve gas productivity in the domestic market and fluid hammers should make a difference. What do we need to change for upcoming optimization tests? . . . energy level, hammer/bit system, etc. Make ROP good and reliable.

\section{December 2002 Issue 'Journal of Petroleum Technology}

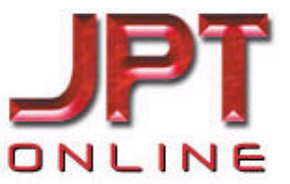

\section{Mud-Hammer Drilling Performance}

This article, written by Assistant Technology Editor Karen Bybee, contains highlights of paper SPE 74540, "World's First Benchmarking of Drilling Mud-Hammer Performance at Depth Conditions," by Gordon A. Tibbits, TerraTek; Roy C. Long, SPE, U.S. Dept. of Energy; Brian E. Miller, SPE, BP; and Arnis Judzis, SPE, and Alan D. Black, SPE, TerraTek, originally presented at the 2002 IADC/SPE Drilling Conference, Dallas, 26-28 February.

Operators continue to look for ways to improve hard-rock drilling performance. A consortium of Dept. of Energy (DOE), operator, and industry participants assembled an effort to test and optimize mud-driven fluid hammers as an emerging technology that shows promise to increase penetration rates in hard rock. The full-length paper details the results of full-scale testing of two 7 3/4-in.-diameter mud hammers with 8 1/2-in. hammer bits and compares their performance with a conventional tricone bit.

\section{Introduction}

The majority of drilling-related costs are incurred drilling harder rock. Improved rate of penetration (ROP) in hard rock has the potential to reduce overall well costs. Estimated costs to drill hard rock in the U.S. is U.S. \$1,200 million. Potential savings of U.S. \$200 million to $\$ 600$ million are possible if ROP in hard rock is doubled with reasonable bit life. Mud-hammer development has been going on for some time, but performance and endurance have not been tested adequately for mud hammers to be a viable commercial tool in deep drilling applications. Hammer performance had been sketchy at best, and mud hammers are reported to have performance problems at high borehole pressures and in muds containing high solids percentages. Full-scale testing under simulated drilling conditions offered an economical alternative to high-day-rate field testing as well as a clear performance comparison of different power levels, rotary speeds, weight on bit (WOB), bit types, mud densities, and rock types. 


\section{Background}

The DOE implements its Office of Fossil Energy upstream natural-gas technology development program by cost-shared research projects. These projects are initiated and managed by DOE's Natl. Energy Technology Laboratory (NETL). In response to the Energy Information Admin. forecast that gas consumption will increase $60 \%$ by 2020 , NETL is cost-sharing various technology-development projects to enhance deep-gas development. NETL's focus on mud hammers is a direct result of its attempt to reduce drilling costs and make deep-gas exploration economics more attractive to industry. The mud hammer was considered to be a technology with potential to reduce deep-gas drilling costs because of demonstrated capabilities of existing air and water hammers in hard-rock drilling applications and ease of incorporating mud hammers into existing drilling systems.

\section{Operator Needs}

For hard and abrasive drilling conditions in deep wells drilled with mud, tricone bits have the highest ROP, but their susceptibility to wear and bearing failure limits their drilling time. In deeper hole sections, where tripping times are longer, thermally stable polycrystalline or natural diamond bits are chief competitors of the tricone bit, especially in smaller hole sizes. Thermally stable polycrystalline and natural diamond bits have a much longer bit life to offset their lower ROP and reduce overall cost per foot compared with tricone bits. Hammer drilling with simple percussion drill bits has proved to be an economical alternative for a range of hard-rock drilling applications including drilling with air or clear water as drilling fluid. Air drilling results in the highest ROPs, and airhammer drilling is a widely used alternative for many air-drilled hole sections. Hammer drilling with percussion bits in clear water is a relatively new alternative that has been limited to relatively shallow holes (i.e., less than 3,000 ft). Because of hammer drilling performance in clear-water applications, operators are interested in learning if these drilling systems can provide an economic alternative in hard-rock drilling applications with weighted muds at deeper hole depths. The controlled drilling tests reported in the full-length paper provide key insights into mud-hammer drilling not available from random field tests.

\section{Test Program}

To determine economic viability of hammer drilling with percussion bits in deep hole sections drilled with weighted mud, the test program was designed to explore only the ROP performance of available fluid-driven hammer tools. An advisory board composed of representatives from the DOE/NETL, ExxonMobil, BP, TerraTek, Novatek, SDS Digger Tools, and Pajarito Enterprises directed the test program. Carthage marble was selected to represent a moderately hard limestone. Crab Orchard sandstone was selected to represent hard sandstone. Two water-based muds (WBMs), 10.0 and $15.0 \mathrm{lbm} / \mathrm{gal}$, were used for high-solids-content drilling fluids to provide realistic comparisons to field muds used in conventional drilling. Performance of an 8 1/2-in. tricone bit [Intl. Assn. of Drilling Contractors (IADC) 537 tungsten carbide insert bit] was documented in paper SPE 15620, "Roller-Bit Penetration Rate Response as a Function of Rock Properties and Well Depth." The tests described were run using a 10.0-lbm/gal WBM while drilling Carthage marble and Crab Orchard sandstone at various WOB conditions and constant rotary speed. Additional tests were performed with the same bit with $15.0-1 \mathrm{bm} / \mathrm{gal}$ WBM. 
As borehole pressure increases, ROP decreases. The highest borehole pressure was 3,000 psi. Data also were obtained at 2,000, 1,000, and 500 psi. Confining stress and overburden stress were held constant at 4,000 psi and 5,000 psi, respectively. Although the main goal of the program was to examine drilling performance at the 3,000-psi borehole pressure, the lower-borehole-pressure data provided information about the performance transition from low to higher borehole pressure. All mud-hammer and conventional drilling tests were run in a wellbore simulator that can perform drilling experiments with full-scale bits, high flow volumes, and high fluid pressure with a variety of drilling muds and rock samples stressed to in-situ conditions. The laboratory has extensive instrumentation and data collection equipment to measure and record information from drilling experiments. In a typical test, the 15 1/2-in. jacketed rock sample was connected to the top vessel plug that sealed the mud hammer and bit combination. The assembly then was lowered into the wellbore simulator. The upper closure of the wellbore simulator would be inserted and the drillstring made up to the drilling rig. Because the rock samples were relatively strong, confining and overburden stresses were applied to the rock before flowing the pressurized mud into the borehole. When rock stresses and borehole pressure were established, the sample was drilled following a procedure that outlined tool pressure drop, rotary speed, and WOB.

\section{Results}

The tricone bit did not perform as well in the $15-1 \mathrm{bm} / \mathrm{gal} \mathrm{WBM}$ as in the $10-\mathrm{lbm} / \mathrm{gal}$ WBM. Rotary speed for both mud weights was $110 \mathrm{rev} / \mathrm{min}$, but the data for the 15$\mathrm{lbm} / \mathrm{gal} \mathrm{WBM}$ contains some data taken at $60 \mathrm{rev} / \mathrm{min}$. Hydraulic horsepower per square inch for the $15-\mathrm{lbm} / \mathrm{gal}$ mud was maintained by running different nozzle diameters in the bit at the same flow rate. Results of the tricone bit tests comprise the baseline and comparison data for mud-hammer performance.

SDS Tool Performance. The SDS tool operates (cycles) only after a predetermined weight is applied to the tool. The tool cycles very smoothly. The bypass nozzles were blocked off during these tests, although in field operation they are directed uphole and may be fitted with different diameter nozzles to match drilling rig hydraulic requirements. Fig. 1 shows the impact bit used with the SDS mud hammer. In Carthage marble, ROP performance at 3,000-psi borehole pressure appears to be approximately the same at all pressure drops and rotary speeds. ROP is 2 to $4 \mathrm{ft} / \mathrm{hr}$. WOB was a constant $10,000 \mathrm{lbf}$. 


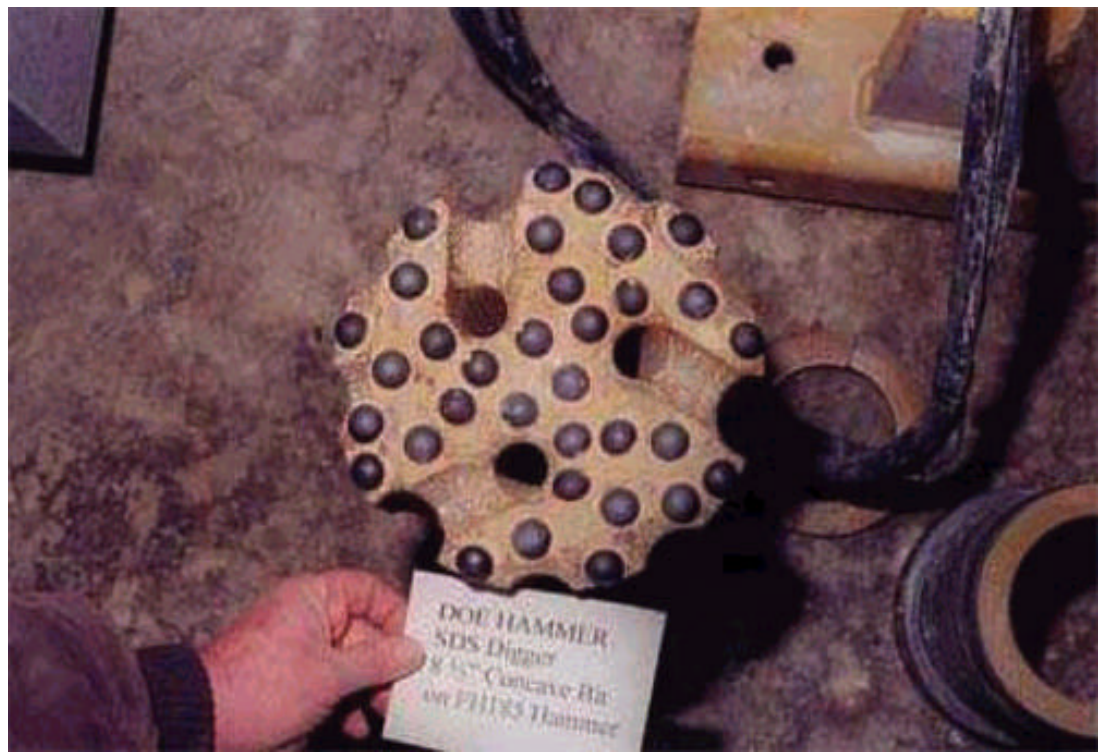

Fig. 1-Impact bit used with the SDS mud hammer.

Performance was similar in Crab Orchard sandstone with 10-1bm/gal WBM. Performance at various pressure drops and rotary speeds is lower than with a conventional bit, especially at borehole pressures greater than 1,000 psi. ROP was 2 to $4 \mathrm{ft} / \mathrm{hr}$. Similar results were obtained in the two rock types when mud weight was increased to 15 $\mathrm{lbm} / \mathrm{gal}$, although ROP was lower in the higher-weight mud system. ROP ranged from 1 to $3 \mathrm{ft} / \mathrm{hr}$. When a more aggressive percussion-type bit was run with the mud hammer, significant improvement was seen at lower borehole pressures, and, in some cases, performance was better than the tricone performance. As the borehole pressure was increased, performance improved moderately. ROP at 3,000-psi borehole pressure ranged from 3 to $7 \mathrm{ft} / \mathrm{hr}$.

Novatek Performance. The Novatek tool operates (cycles) when a minimum amount of fluid is pumped through the tool, and it will cycle with no WOB. As WOB is applied, the tool closes until the anvil is loaded and then transfers the impacts to the cutting structure. When a Novatek N5 mud hammer was run with an IADC 537 tricone bit in 10- $1 \mathrm{bm} / \mathrm{gal}$ mud, the resulting ROPs clustered around the performance of the standard IADC 537 tricone rotary drilling results at its lowest WOB and $110 \mathrm{rev} / \mathrm{min}$. ROP ranged from 4 to $10 \mathrm{ft} / \mathrm{hr}$. Although performance levels for the Novatek tool and the polycrystalline diamond cutter bit (Fig. 2) were in the lower range or below the comparison bit in early tests, a couple of points were observed that showed moderate performance increases over the IADC 537 bit. The performance level of the Novatek tool and polycrystalline diamond cutter bit exceeded that of the rotary-drilled tricone bit in Crab Orchard sandstone and came close to the best-case performance curve when drilling the Carthage marble. 


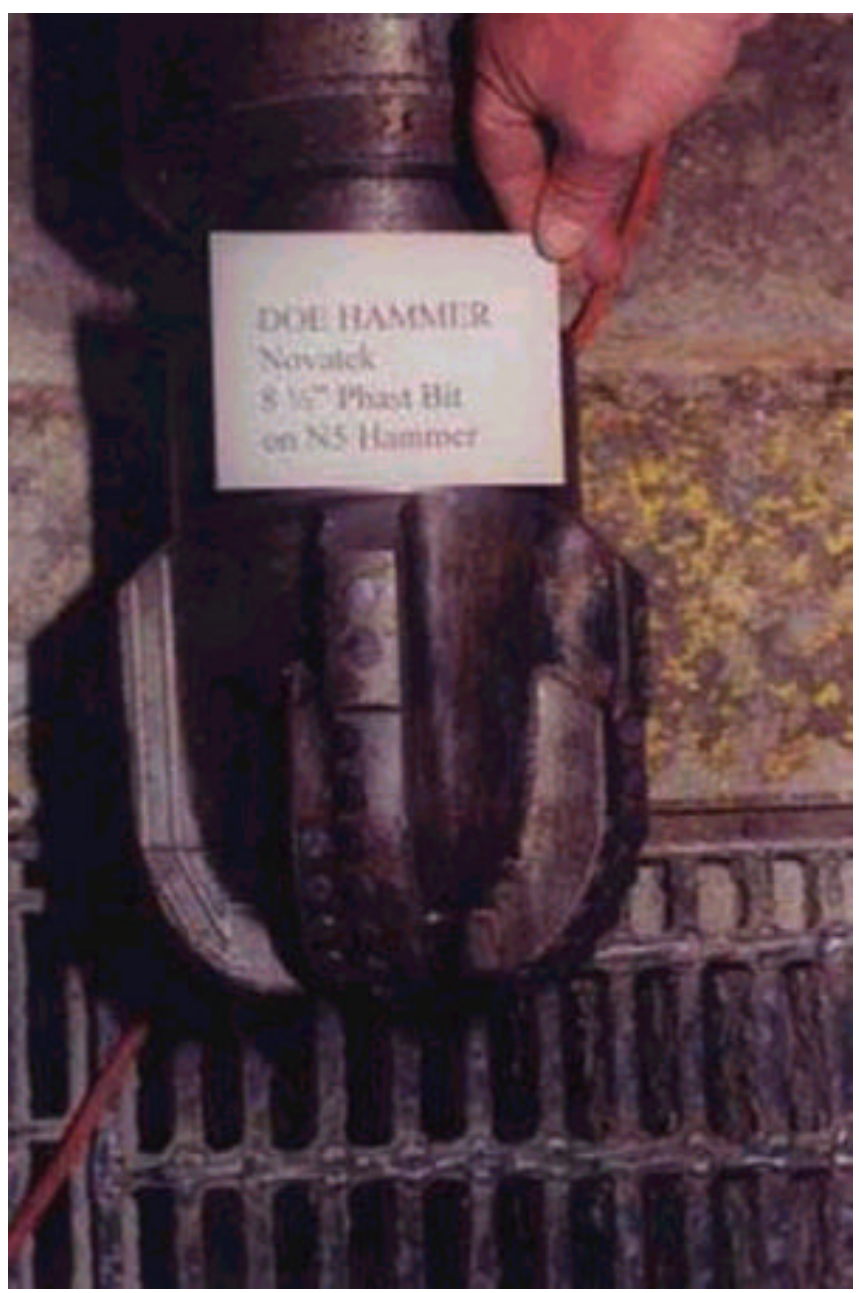

Fig. 2-Novatek bit.

\section{Conclusions}

1. New generation mud hammers have the ability to operate in 10 - to $15-1 \mathrm{bm} / \mathrm{gal}$ WBM.

2. There is no advantage in using mud hammers with conventional IADC 537 tricone bits.

3. Drill bits designed to exploit both rotary and impact-applied loads provide better performance used with mud hammers.

4. Performance improvement is significant for the Novatek mud hammer in the transition region between low and high WOB. 


\section{3}

\section{Q1}

The March 2003 issue of Drilling (American Association of Drilling Engineers) highlighted the DOE fluid hammer testing program. Information from Smith International, TerraTek and PDVSA (one of the Industry partners) provided interesting insights for the future of hammer technology.

\section{Mud Hammers Changing the Game}

"Arguably, mud hammers are the industry's Holy Grail. With the prospect of drilling times being halved and operators keen to cut costs, competition is heating up between rival technologies."

\section{By Wajid Rasheed, Latin American Editor, Hart's E\&P}

Bit companies are offering a diverse drill-bit selection ranging from tungsten carbide buttons, diamond impregnated cutters, mini abrasive discs and some bits even incorporating explosive charges and lasers. Downhole tool providers are modifying air hammers to withstand solids and enable their usage beyond mining. Yet other companies are introducing mud-driven hammers designed specifically for the oil industry.

The latest mud hammers (also referred to as fluid and hydraulic) promise unprecedented longevity, higher penetration rates, and compatibility with conventional drill-bits and muds. Previously, a short life and the inevitable pull-out-of-hole before section end outweighed the value that hammers added to operations often. Also, penetration rate gains had to be weighed against performance limitations imposed by specialized drill bits and muds. What is different this time is that fluid hammers are not only improving hard rock penetration rates but are on the verge of clocking up economically viable mean time between failure (MTBF). More excitement is being created as formation evaluation experts eye hammers for seismic-while-drilling applications to better identify formations and refine the balancing of pore pressures and fracture gradients.

Investigating hammer technologies are two industry initiatives. One is the U.S. Department of Energy's (DOE) ongoing mud hammer benchmarking program. The other is a worldwide hard rock drilling joint industry project (JIP) completed this year. The driver is clear - reduce expense and improve performance. Calculations show that section-drilling time, along with the number of trips and bits, can potentially be halved. For operators with hard rock assets, the importance of such game-changing technology speaks for itself: an inability to drill hard rock cost effectively are more marginal fields, and reduced recoverable reserves and production.

What is and what isn't hard rock? Ask a geologist and he or she will probably reply any rock with a compressive strength exceeding 40,000psi is hard. Yet from a drilling engineer's perspective, this seems too narrow a definition. Perhaps the term hard-to-drill rock better explains the challenge, as it lowers the compressive strength threshold, to 
about 20,000psi and also covers formations where penetration rates fall below $16.4 \mathrm{ft} / \mathrm{hr}$ $(5 \mathrm{~m} / \mathrm{hr})$.

\section{Air hammers and hammer bits}

For many years, air hammers and hammer bits have been used extensively in the mining industry. But they have made relatively little impact in the oil industry except in areas such as the Rockies. Usage beyond these scenarios has been restricted because of three factors. Firstly, gauge holes are more important in oil field applications than in mining. Secondly, conventional oil field muds and even brines are not encountered in mining. Finally, oil field drilling exhibits much harsher conditions. Typically, bottomhole temperatures and pressures are higher than those of mining wells. Additionally, space is a premium on offshore rigs, and the extra room needed for air pumps, compressors and separators may not be readily available on an offshore installation.

Smith Percussion Drilling Manager Lance Underwood said they introduced the first diamond-enhanced hammer bits in the late 1980s. The importance of these inserts in oil field drilling is holding gauge. Unlike mining, where a single bit drills multiple shortinterval wells, in the oil field, multiple bits are typically used in a single well. If a given bit becomes under-gauge, the next bit has to ream. Or, as is the case in some areas, a smaller-size bit is run to follow the under-gauge bit. This practice is called "telescoping." The advantage of diamond-enhanced bits is they almost always drill full-gauge hole so a subsequent full-gauge bit can be run without reaming. An example of what can be achieved was shown by a recent run in Val Verde County, Texas, where an 8 3/4-in. hammer bit drilled a world record run of $10,650 \mathrm{ft}(3,248.25 \mathrm{~m})$ in 148 hours.

"As a rule, hammer bits typically out-drill tri-cone bits by a factor of 2 , in terms of footage and ROP [rate of penetration]. So, if you're air drilling, there's a pretty good chance you should be running hammer bits. However, water influx limits hammer usage. When water influx gets too high, the resulting pressure drop in the annulus causes hammers to shut down. For instance, it is common for an operator to trip after a 3,000ft [915m] hammer run and use a tri-cone bit to drill the remainder. As a solution, Smith is developing a hammer with increased water tolerance," Underwood said. "Another factor that differentiates oil field drilling from mining applications is bottomhole temperature. In deeper wells, high temperatures can cause failure of the foot valve (a plastic valve which is pressed into the bit). Our new hammer eliminates the possibility of foot valve failure by designing the valve into the hammer itself, which allows the valve to be made of steel. As with improved water tolerance, I think this feature will expand the applications in which air hammers can be successfully used," he said. Underwood said, "We're still in the development stage. Our approach is somewhat different than that of some other companies in that we're using fixed head bits, which can handle higher hammer energy levels than tri-cone bits. We've solved some really fundamental problems, such as getting a piston to survive the abrasive effects of the drilling fluid that drives it. Now that we're past some of the major hurdles it seems that we're finding other relatively minor weak links, such as seal failures and insert breakage. We've done field tests and seen good rates of penetration in brittle and friable formations (granites and sandstones, in particular)," Underwood said. "We're continuing to field test, generally targeting applications with hard/brittle/friable formations staying away from 
intervals with a lot of soft stringers. Many such applications are drilled with clear brines, which is what we'd prefer from a drilling fluid/formation interaction standpoint. The striking thing about this project is the interest from operators. Many of our customers operate in fields that have at least one hard-to-drill interval that is just not drilled effectively with existing technologies. In many of these applications air drilling is not an option due to formation considerations (i.e. either massive water influx or insufficiently competent formation), yet the formation is brittle or friable and percussive drilling would seem to be the best way to break the rock."

\section{DOE mud hammer program}

Established to optimize mud hammer drilling performance, the DOE has set up a program to benchmark the viability of this technology. Contractor TerraTek, SDS Digger Tools, Novatek, Smith International, BP, ExxonMobil, ConocoPhillips, PDVSA and Pajarito Enterprises intend to address the commercialization of prototype mud hammers by benchmark testing and optimizing drilling performance. TerraTek is working closely with suppliers of mud hammers to demonstrate their performance limits and to facilitate commercialization.

"Mud hammer performance and endurance have not been tested sufficiently for hammers to be viable in the marketplace. Hammer drilling, particularly in high borehole pressure conditions, is prone to performance problems. Both rates of penetration and longevity are adversely affected by muds containing solids. This can lead to varying degrees of success owing to lower efficiencies or so-called tuning problems. Also, modes of hammer impact can be changed by hydrodynamic conditions and wellbore pressures. Nonetheless, the markets for mud hammers, including directional mud hammers, are sufficiently large to make the development of a field usable device compelling. If rates of drilling rates of penetration can be increased substantially the deeper hard rock basins in the United States would see more efficient operations and an increase in well construction activities resulting from enhanced economics; example basins include Anadarko, Appalachian, Arkoma, East Texas, Permian and San Juan," said TerraTek's Vice President Arnis Judzis.

Objectives of the DOE program

- Large-scale hammer drilling tests to determine the viability of advanced mud hammer drilling in reservoir conditions;

- benchmarking of hammer performance to assess performance of mud hammer rates of penetration at high wellbore pressures relative to conventional drilling;

- optimization of hammer performance to improve the performance of fluid hammers to a level acceptable to operators and develop best practices (scheduled for 2003); and

- commercialization and field deployment to accelerate the manufacture of field-ready tools and ensure commercial availability in the marketplace.

TerraTek has completed benchmarking two of the hammers. The program is now turning its attention to determining hammer rates of penetration and their ability to function at depth. Tests already have started, and some design improvements and performance optimization have been reported. 
"Certainly the greatest challenges for fluid hammers involve drilling applications at depth with drilling fluids containing solids. At elevated borehole pressures (greater than 3,000psi), hammer effectiveness diminishes, thus efforts to optimize or 'tune' hammer tool performance as well as consider the hammer - bit as a system is vital. During the course of the DOE program, operators have also identified hard rock applications for fluid hammers that can be drilled with moderately weighted brines. Fluid hammers should drill these formations readily," Judzis said.

Also participating in the benchmarking program is PDVSA. Drilling Technology Manager Alejandro Lagreca said "New technology successes are often slow to materialize and not very well understood because direct comparisons are made with conventional drilling processes, Hammers do not escape from this reality. Furthermore, hydraulic hammers require a new form of thinking not just regarding the operator or the drilling team but also in terms of the rig itself. Today's hammers require a pressure drop and hence pump capacity which often exceeds standard pump specifications. This potentially limits the scenarios in which hammers can be used. Also the design and performance of conventional PDC or tri-cone bits are very different from the 'ideal' hammer bit. Therefore a system approach encompassing bit, hammer, drill-string and rig parameters is required. However, as there is no single technology that can be applied universally Intevep (Pdvsa's R \& D arm) is participating in other initiatives too such as the laser drilling program with the Gas Technology Institute.

\section{Hard rock drilling JIP}

"The JIP involved Petrobras, Amerada Hess, Exxon-Mobil and Boland. We finished testing earlier this year and showed that several developmental technologies, such as mini bit discs and high pressure bit nozzles, exist and although these are unavailable commercially, they offer the potential to increase ROP. These types of technologies and hydraulic hammers still need to prove themselves. In contrast, pneumatic hammers have proven themselves, but hydraulic hammers are still fighting to overcome some problems. For example, many tools work perfectly well with clean liquids such as water but with commercial drilling fluids, hammer MTBF is still uneconomic and performance leaves a lot to be desired," said Joao Carlos Placido, coordinator of the Hard Rock Drilling project. "Although not part of the project, the Andergauge hammer presents some different characteristics. Because it generates lower impact forces, it may not increase ROP as much as other hammers, but it inspires more confidence regarding MTBF. It also has the advantage of being compatible with any type of journal bearing bit. I think it will enter the market more quickly than other hydraulic hammers."

The AnderHammer uses a proven rotating valve mechanism from the AG-itator tool to generate pressure pulses. Using these pulses to drive a steel mass, the AnderHammer impacts the bit eight times a second resulting in 80,000 $\mathrm{lb}$ of bit strike force. With more than 250 runs, some lasting 200 circulating hours, the Agitator has demonstrated this mechanism can withstand harsh downhole conditions. The impact improves penetration rates, but is of a sufficiently low magnitude to avoid damaging bit journals. Endurance testing in granite field trials has shown the AnderHammer significantly improves ROP, is compatible with standard rock bits and has a circulating life of $60+$ hours. 


\section{Future of hammer technology}

Recent advances are accelerating hammer commercialization, but several key areas still require further research. Future research should optimize existing (or next generation) tools for higher borehole pressure and density conditions. Greater design work needs to be done to match hammer and bits according to geophysical formation properties. More consideration also should be given to understanding the unique effects hammer drilling has on cuttings size and distribution, hole cleaning, wellbore stability and ultimately ROP.

*********** End of publication $* * * * * * * * * * *$

ExxonMobil has expressed interest in the possibility of a program to examine cutter impact testing, which would be useful in answering how hammers break rock and ultimately how to improve their performance.

$* * * * * * * * * * * * * * * * * * *$

To: Arnis Judzis

CC: Arnis Judzis, INTERNET:judzis@terratek.com

CC: Jesse Holster, INTERNET:jesse.holster@exxonmobil.com

From: INTERNET:tim.travis@exxonmobil.com,

INTERNET:tim.travis@exxonmobil.com

Date: 5/1/03, 6:42 AM

Re: Re: 1Q 2003 In Kind Mud Hammer Costs

Arnis,

I spent no in kind costs for this past quarter. Looks to me that the cutter impact testing is heading us in a direction that I feel very useful in answering how does a hammer fail rock and what methods.

Regards,

Tim Travis

EMDC Drilling Technical

281-654-4267

CC: Tim Travis, INTERNET:tim.travis@exxonmobil.com

CC: Arnis Judzis, INTERNET:judzis@terratek.com

From: INTERNET:jesse.holster@exxonmobil.com,

INTERNET:jesse.holster@exxonmobil.com

Date: 4/24/03, 2:51 PM

I'm glad that it has been recognized that some fundamental work needs to be done on single cutter impact. I fully expect that the failure mechanics will be significantly different when the rock is under hydrostatic 
pressure.

Regards,

Jesse Holster

ExxonMobil Upstream Research Company

Telephone: 713-431-4044

$* * * * * * * * * * * * * * *$

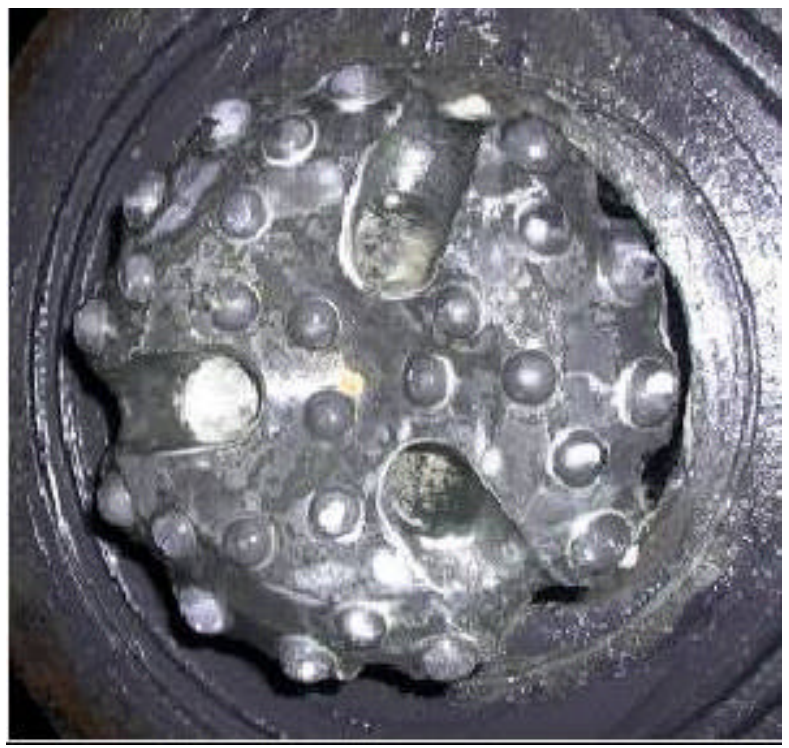

Smith Hammer Bit

Q2

May 2003 Addendum proposal:

$* * * * * * * * * * * * * * * * * * * * * * * * * * * * *$

Mud Hammer Drilling - 'Understanding Rock Breakage'

CUTTER IMPACT STUDY

Addition of Task 8

Objective 
Based on benchmark testing of fluid hammers to date, drilling performance (rates of penetration) has been determined to be satisfactory with respect to short term operation in weighted drilling muds containing solids and modest wellbore pressures. However at elevated wellbore pressures (ca. > 1500 psi), rate of penetration performance has not yet been optimized.

This addendum to the program proposes to study single cutter impact breaking of rock under various simulated borehole conditions. A literature survey of work performed to date and presented to NETL on December 17, 2002 by Sid Green, CEO TerraTek, showed that only little has been documented and understood in this area. Quantitative information is needed for single cutter tests to better understand stress effects, bit/cutter load and 'rpm' effect, fluid effects, rock effects, and cutter design.

\section{Background Context and Industry Support}

Industry players are also concerned that rapid commercialization of fluid hammers may be hindered by the lack of this fundamental information. The scope of the single cutter impact tests can help answer some of the basic questions pertaining to percussion drilling.

Shantanu Swadi, Senior Project Engineer with Smith International has stated the following:

"... . the fundamental questions that we are trying to answer are the following:

1. Is there a significant difference in the way the rock breaks in air vs. fluid?

2. How does the energy required to break rock change with depth, hydrostatic pressure?

3. What, if any, threshold levels of blow energy exist for a given formation?

4. What is the best way to deliver percussive energy to rock as related to the intensity and duration of the stress wave?"

Input by operators (e.g. BP, ExxonMobil, PDVSA) has brought up similar needs for such a study. Jesse Holster, Drilling Advisor for ExxonMobil R\&D, stated the following:

"The following items are important things to learn from single cutter impact tests for mud hammer applications.

1. As wellbore pressure increases, what will physically happen to the rock upon impact? Will there be fractures or simple ductile indentations into the rock?

2. The above effect of wellbore pressure needs to be established in several rock types, most important of which are sandstones, siltstones, carbonates and shales. I'm sure things like granite and metamorphosed rocks are important to some folks, but we rarely drill them. I expect they are important for geothermal applications and hence could be included.

3. What is the transition pressure from brittle failure to ductile indentations in each rock type (assuming there is a transition)?

4. Do rock permeability and pore pressure play a role in establishing the failure mechanics and if so, how?

5. I would expect failure to be a function of impulse loading (mass x velocity of impact). This parameter should be varied in the experiments.

6. What role does indexing play? First establish results for clean, single impacts. Then determine what results from a second adjacent impact and its spacing relative to the first. What happens if there is overlap? Is there some optimal overlap? What happens with zero overlap (repeat blows in the same spot)?

7. In those rocks at the wellbore pressures where simple indentations result, does a "glancing blow" help remove rock. In other words, if the impact occurs at some value of rotary speed of a bit such that there is translational motion in addition to the downward impact, will it assist in rock failure?"

\section{Forward Plan}

The first part of Task 8 is aimed to understand the effects of rock properties on impact cutting (or breaking). TerraTek proposes to conduct impact experiments using single cutters and different rock 
samples under downhole conditions. Two loading systems are planned in order to simulate impact loading over a wide range of impact conditions. A split Hopkinson pressure bar system will be modified to include a pressure vessel to simulate downhole conditions, up to about 5000 psi borehole pressures (see Figure 1 showing a picture of the system without pressure vessel attached). And, the TerraTek high strain rate loading system-with loading capability in the milliseconds-will use the same pressure vessel to provide a lower impact range of experiments, again under downhole conditions (see Figure 2 of the TerraTek high strain rate machine).

The test matrix will include variations in:

1. rock (formation) types-with expected rocks of Carthage marble, crab orchard sandstone (previously studied in various programs), Berea sandstone, and nugget sandstone,

2. borehole pressures - with maximum pressures up to about 5000 psi and with drilling muds as well as clean water,

3. confining pressure and pore pressure - to simulate different reservoir conditions including where possible underbalanced drilling and overbalanced drilling,

4. impact-including impact velocity (i.e. magnitude of the impact stress), wave frequency (i.e. rise time of the impact wave), impact duration (i.e. length of the impact pulse), and possibly novel wave loadings (i.e. varying the rise time, decay time, multiple waves, wave step loading, and the like), and

5. if possible several single cutters will be investigated.

The number of tests that can be undertaken is uncertain, though may exceed fifty in number depending on the complexity. The test matrix is critical in order to discover 'first order' effects with minimal number of tests. This will be the priority for the limited tests that can be conducted.

The second part of Task 8 will be to assess the cutter-rock interaction-based on the experimental dataunder the impact conditions with high borehole pressures. TerraTek will seek to define rock breakage and rock removal in terms of quantifiable impact and borehole pressure for a given rock type and for a given cutter. Some analysis will be performed to consider an 'energy' model (considering energy into the rock) versus an 'impact' model (considering impact stress magnitude) for rock removal.

These data would then be the basis for industry design of improved cutters and bit designs to allow optimum rock removal from mud hammers. TerraTek will seek to disseminate the program results through open publication, direct meetings with appropriate industry players, and most importantly through direct industry participation in the program during the program performance.

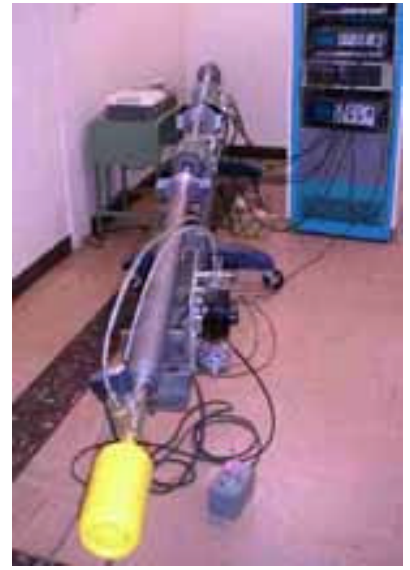

Figure 1. Hopkinson Bar Equipment

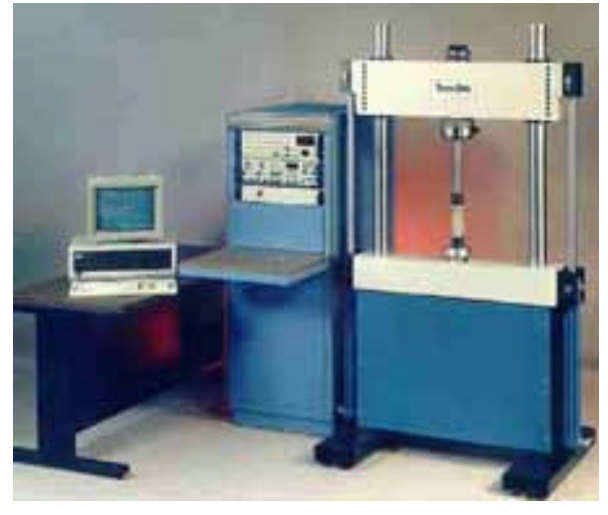

Figure 2. High Rate Test Machine 
$\underline{\text { Schedule and Milestones }}$

Task 8 can be done concurrently with Task 6 'Optimization Testing'. On approval, the addendum work could start July 1, 2003 with an expected duration of six (6) months. Milestones will include the following: Ready equipment for impact testing end August 2003

Incorporate pressure vessel capability

Test data on various rock samples and single cutters

end September 2003

Analysis of cutter-rock data

end December, 2003

Report for Task 8

end February, 2004

end March, 2004

\section{Supporting Cost Detail}

\section{Direct Labor Rates}

Where identifiable we have used the actual direct labor rates of the employees proposed for use on this program, otherwise composite rates have been used.

\section{$\underline{\text { Indirect Rates }}$}

The indirect rate at TerraTek for booking, billing and forward pricing are all the same. Costs are segregated into pools. The rates and methods of computation are as follows:

$\begin{array}{lll}\text { Category } & \underline{\text { Rate }} & \\ \text { Fringe } & 30 \% & \text { Direct Labor Dollars } \\ \text { Overhead } & 122 \% & \\ \text { G\&A } & \text { N/A (0) }\end{array}$

Travel Summary

One two-person trip for 3 days to NETL

One one-person trip for 2 days SLC to Houston

Consultant travel 5 days to Salt Lake City from Boston

$\$ 2000.00$


DETAII DESCRIPTION OF COST ELEMENTS

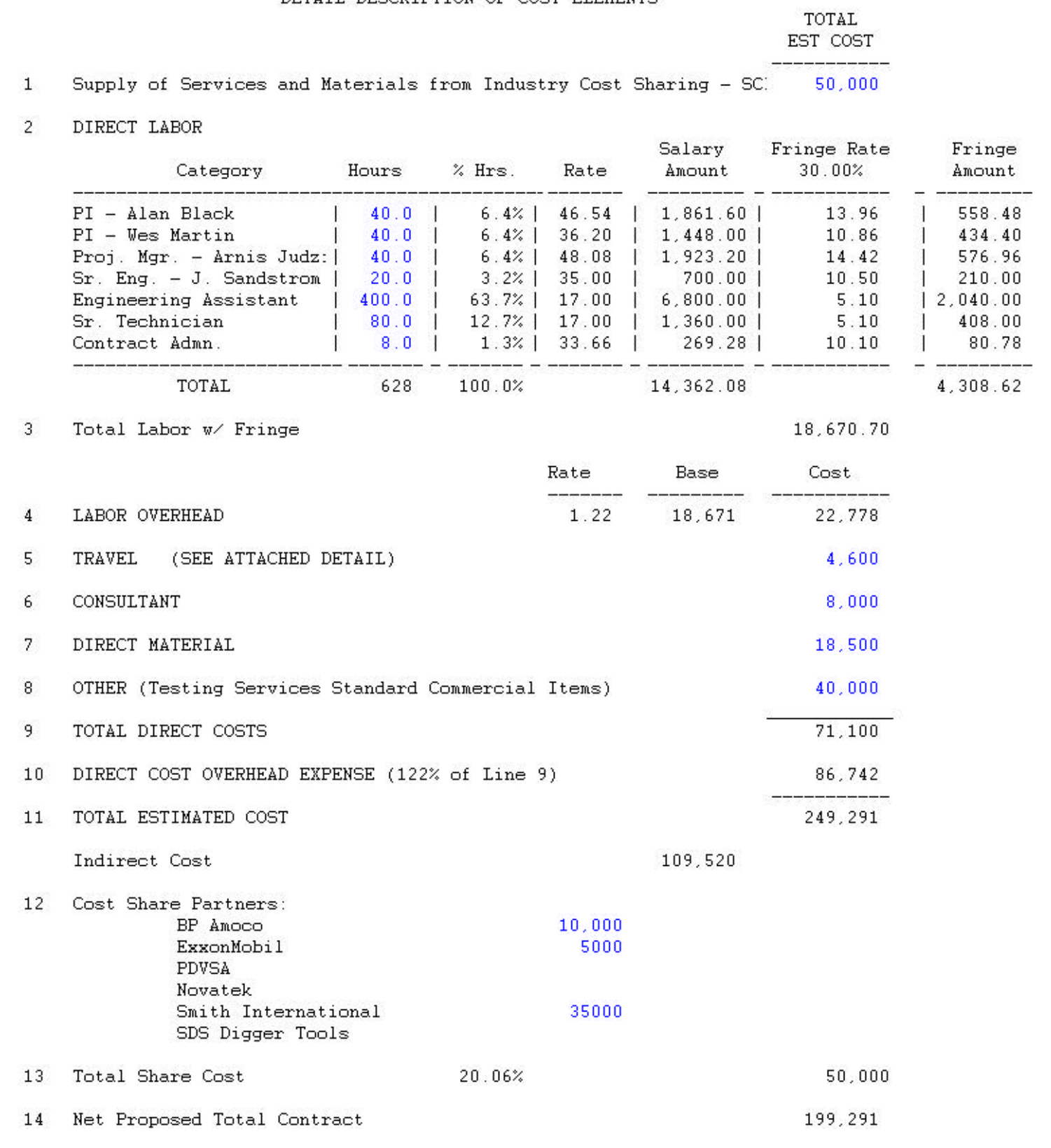

$* * * * * * * * * * * * * * * * * * * * * * * * * * * * *$

\section{Q3}

Review of Claustal information by Craig Wengel, University of Utah graduate student employed by TerraTek: 


\section{Mud Hammer Drilling at Depth}

\section{Introduction}

Mud hammer drilling is attractive because of the success it has enjoyed in shallow holes. Rotary percussion drills require only about one-tenth the bit weight of a rotary drill, resulting in straighter holes.

However, testing to date has not shown the same advantages in deeper holes. The reasons for the poor performance of mud hammers at depth are not completely understood. Some research has been done to evaluate performance, but more is required if mud hammers are to be optimized for deep-hole conditions.

The research that has been already done, however, is very enlightening. Two groups have studied percussion drilling at depth. First, in the late 80's and early 90's at the Technical University Clausthal, in Clausthal Germany. Currently, research is underway at TerraTek, in Salt Lake City, Utah. The results of these studies will be briefly summarized in this paper.

\section{Clausthal Work}

The work at TU Clausthal is presented in two dissertations, by Dr. Josef Weltermann in 1990 and Dr. Ralf Luy in 1992. The later builds upon the former and is more applicable to the problem at hand. As such, this review will give a brief summary of Dr. Luy's dissertation.

Dr. Luy's dissertation is entitled "Untersuchung zur Wirksamkeit des Bohrprozesses beim drehschlagenden Bohren unter hohen hydrostatischen Drücken", which translates as: the investigation of the efficiency of the drilling process with rotary percussion drilling at high hydrostatic pressures. This dissertation was completed at the Technical University Clausthal, in Clausthal, Germany on December 18, 1992.

The purpose of this research was to optimize deep-hole hammer drilling through understanding the effects of the many variables involved. The experiment matrix is shown in figure 1.

Five different cutters were used. The shapes and dimensions of these cutters are given in figure 2. Cutters 1 and 2 are diamond coated, round cutters, of $16 \mathrm{~mm}$ and 11 mm diameters, respectively. Cutters 3 and 4 are chisel and conical shaped cemented carbide cutters from Krupp-Widia $\mathrm{GmbH}$. Cutter 5 is a round tungsten carbide cutter from a Smith Tool Company F 57 roller bit. 


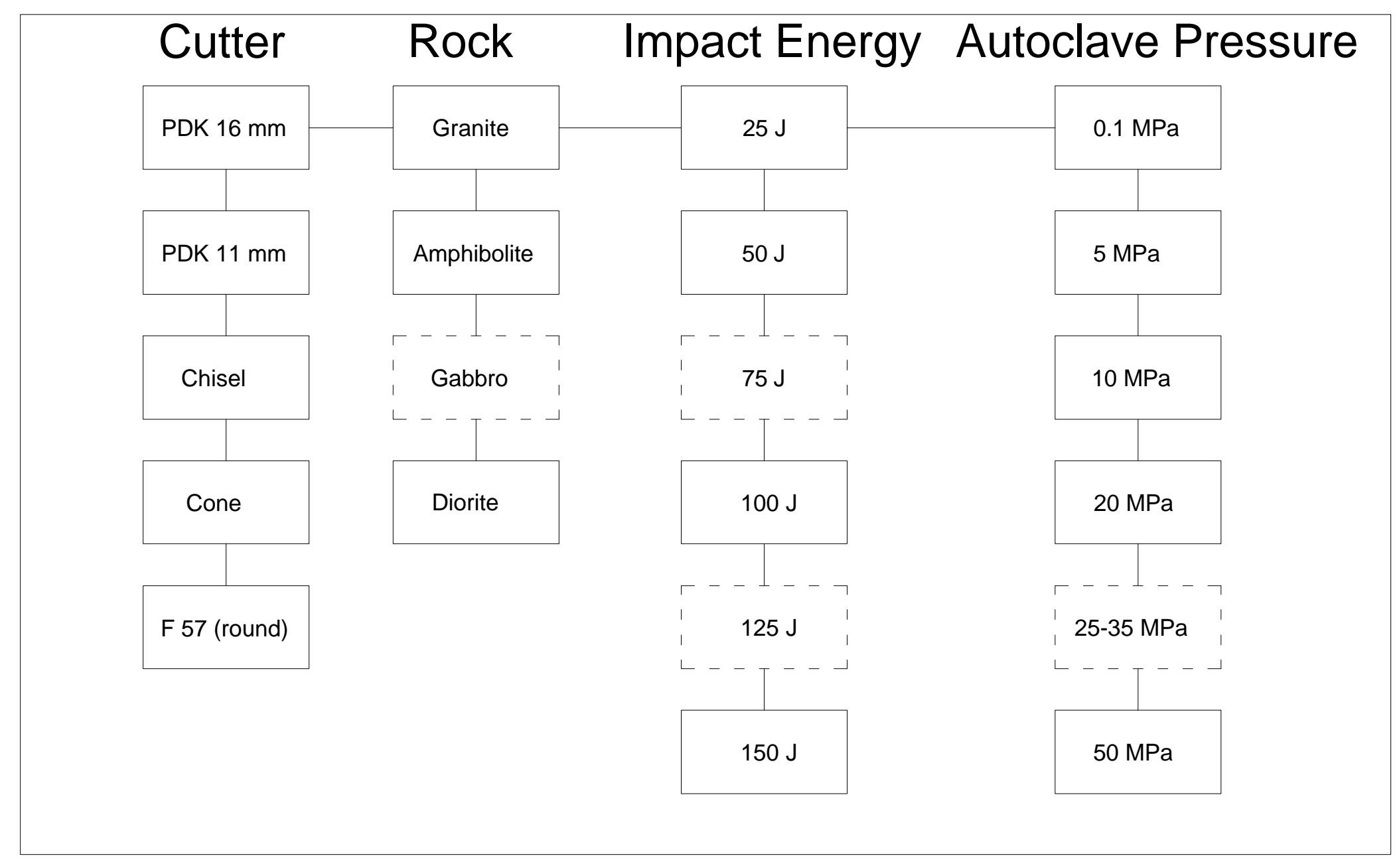

Figure 1. Test matrix for the Clausthal work. Dashed lines indicate options that were not fully tested. 

The rock types chosen for this research were selected based on the types of rock that would be encountered with deep continental drilling. The desired rock properties were:

- $\quad$ solid, crystalline structure

- high compressive strength

- high percentage of hard minerals

- homogeneity

- low permeability

- little pore space

- highly abrasive

Four rock types were selected for testing. They were granite, amphibolite, gabbro, and diorite. The compressive strengths and densities of the specimens are given in table 1 .

Table 1. Compressive strengths and densities of the rock specimens

\begin{tabular}{|c|c|c|}
\hline Rock Type & Compressive Strength, psi & Density, lbm/ft $^{\mathbf{3}}$ \\
\hline Granite & 24,200 & 162 \\
\hline Diorite & 26,100 & 185 \\
\hline Gabbro & 40,760 & 164 \\
\hline Amphibolite & 43,800 & 173 \\
\hline
\end{tabular}

Crater size was used as the measure of performance for the cutters. Crater volume was determined by capturing, drying, and weighing the cuttings. The crater size was calculated using the density of the rock, and the weight of the cuttings. The size distribution of the cuttings was also determined.

Some of the test results are given in figures 2 and 3. These figures show the volume of the rock liberated per blow in granite, at impact energies from $18.4 \mathrm{ft}-\mathrm{lb}(25 \mathrm{~J})$ to $110 \mathrm{ft}-\mathrm{lb}(150 \mathrm{~J})$. The data are grouped by hydrostatic pressure levels, which vary from atmospheric pressure to $7250 \mathrm{psi}(50 \mathrm{MPa})$. Figure 2 shows the results from tests using a chisel-shaped cutter, and figure 3 shows the results from a cone-shaped cutter test. The differences between these two charts are interesting, but the reasons for the differences are not explained. The crater volumes from the chisel-shaped cutter increase nearly linearly with impact energy, whereas, the crater volumes from the cone-shaped cutter appear to reach performance plateaus. Both charts show how quickly performance degrades with increasing borehole pressure. Figure 4 shows how different rock types respond to different cutters. All of these tests were at 7250 psi, with $100 \mathrm{~J}$ impact energy.

Dr. Luy concluded that even small hydrostatic pressures (700 - 1400 psi) degrade cutter performance, and under high hydrostatic pressures, cutter and rock type differences become unimportant. He also noted that increased impact energy could partially compensate for higher hydrostatic pressures. The specific energy was noted to be lower than rotary drilling, because rock breakage is thought to be more efficient with percussion drilling. Using the test result, he estimated that an 8 1/2" bit, with 26 cutters, a $2600 \mathrm{~J}$ hammer, and $52 \mathrm{~kW}$ of power could drill at a rate of 12.5 feet per hour. 
Volume Removed in Granite with Cutter 3

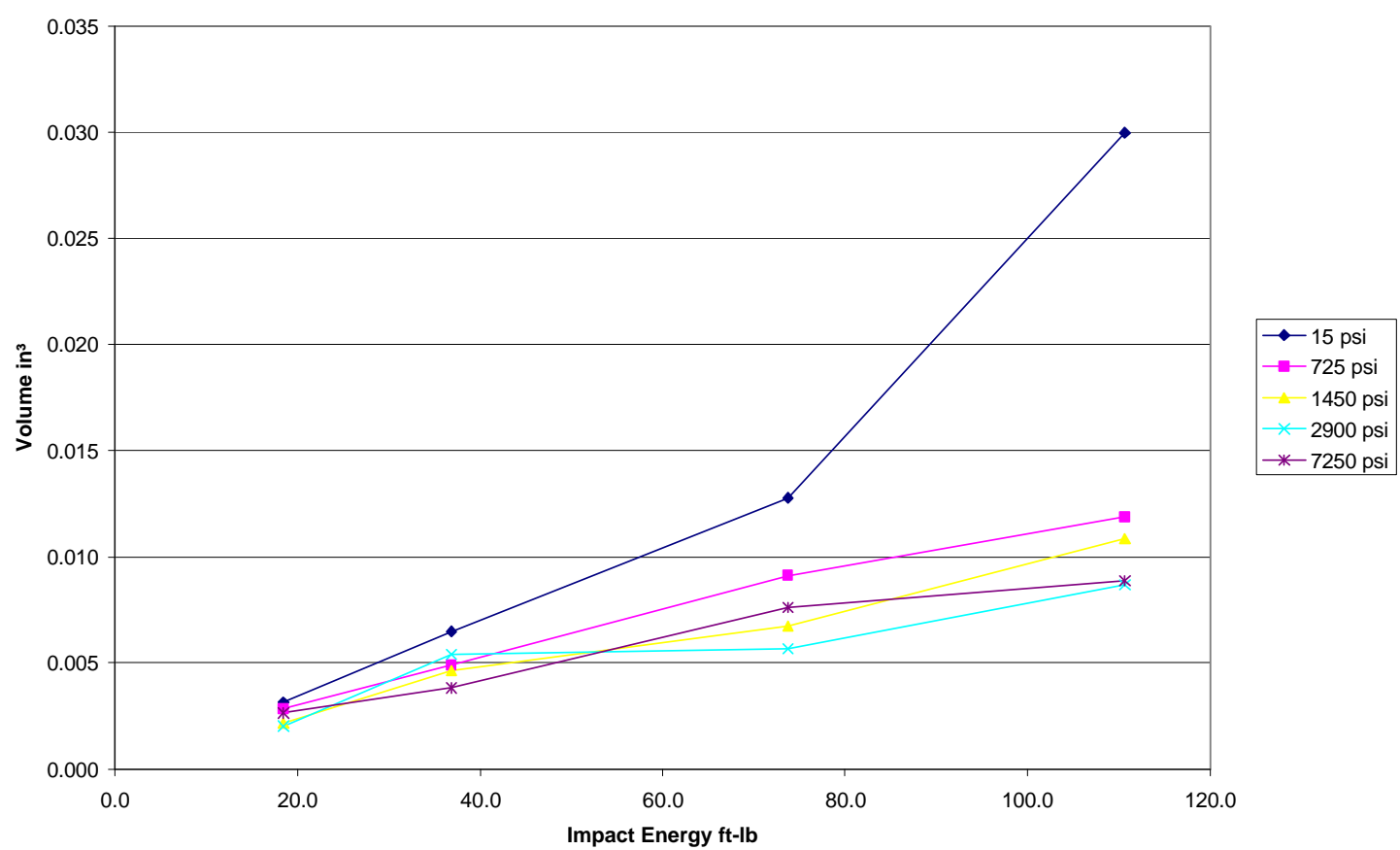

Figure 2. The volume of rock removed vs. impact energy at different hydrostatic pressure levels using a chisel-shaped cemented carbide cutter in granite.

Volume Removed in Granite with Cutter 4

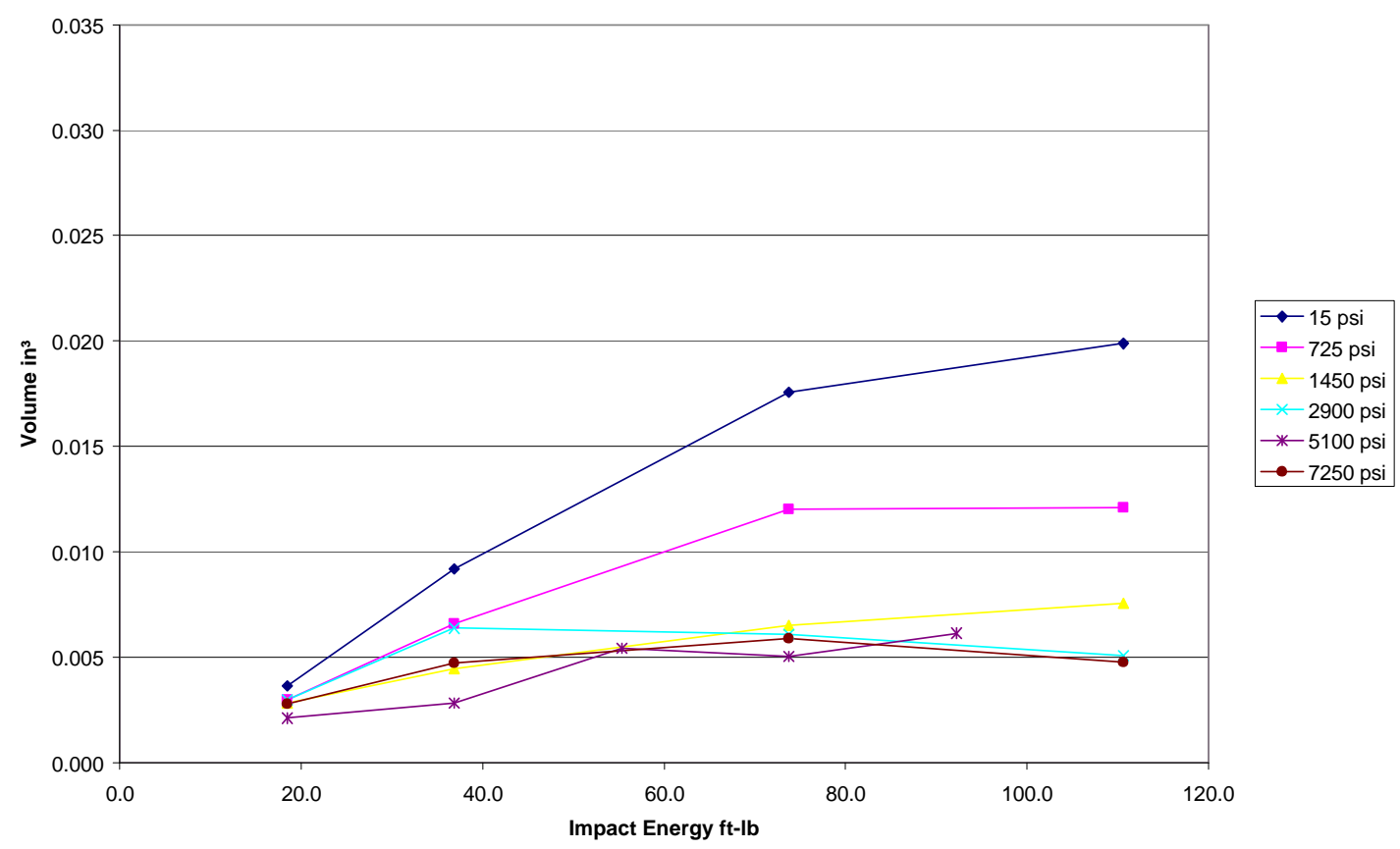

Figure 3. The volume of rock removed vs. impact energy at different hydrostatic pressure levels using a cone-shaped cemented carbide cutter in granite. 


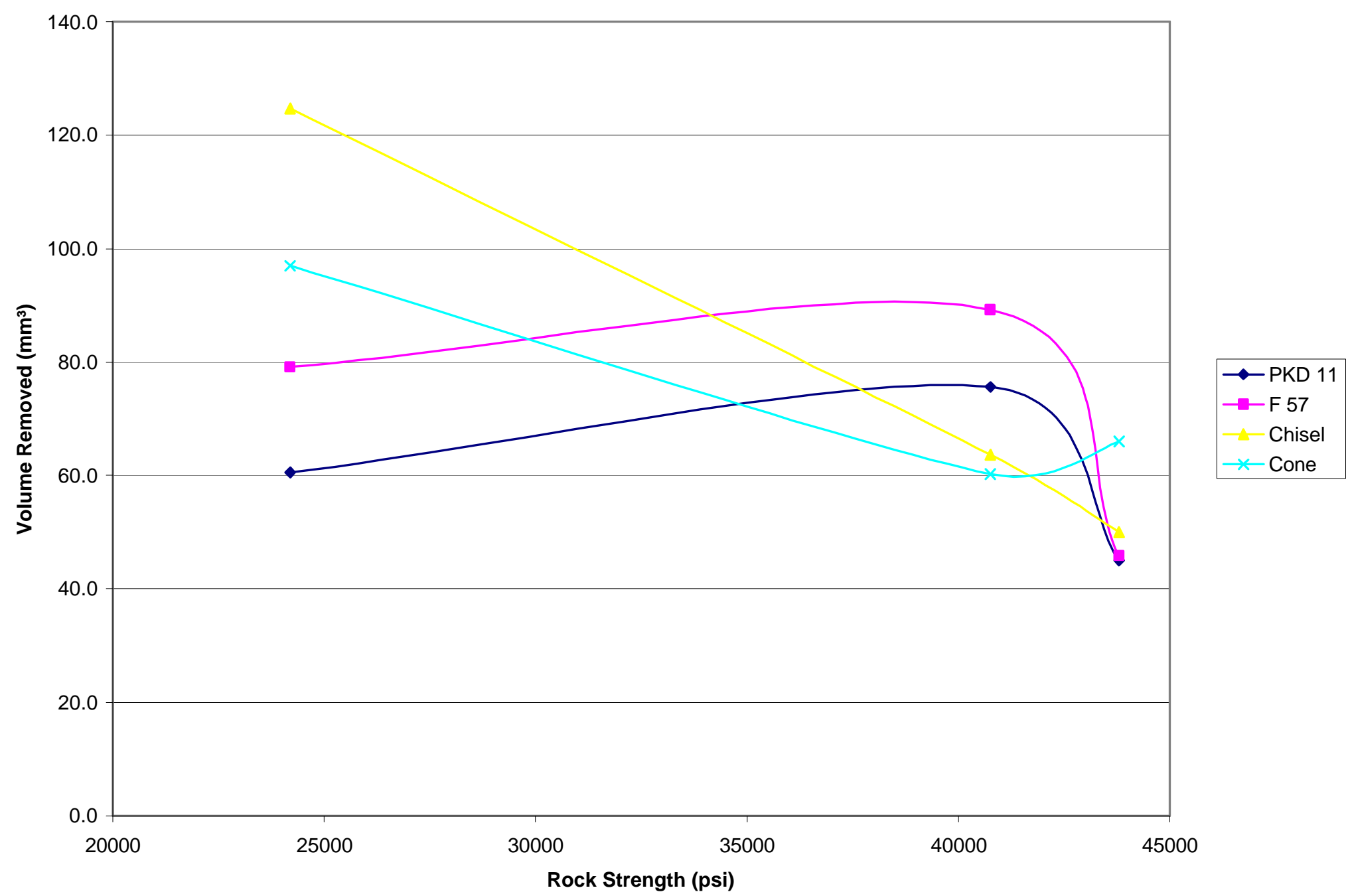

Figure 4. Volume of rock removed in three different rocks using four different cutters impacting with $100 \mathrm{~J}$ of energy and a hydrostatic pressure of $7250 \mathrm{psi}$. 


\section{TerraTek Work}

The objective of the work at TerraTek was to accurately document the behavior of mud hammers in deep-hole conditions. The work was directed by an advisory board with representatives from the Department of Energy (DOE)/ National Energy Technology Laboratory (NETL), ExxonMobil, BP, TerraTek, Novatek, SDS Digger Tools, Smith International and Pajarito Enterprises. The early results of these full-scale tests are given in SPE 74540, "World's First Benchmarking of Drilling Mud Hammer Performance at Depth Conditions", written by some members of the advisory board. Benchmarking tests on the Smith hammer were conducted later.

Mud hammers had been experimented with in various places around the world; however, their performance was not fully understood. They seemed to be less effective in deeper holes, and their performance in weighted mud was not accurately known. The tests conducted were designed to measure the ROP response of current mud hammers, and compare them to an $81 / 2$ " tricone bit (IADC Code 537). If the penetration rate of mud hammers could be made to exceed that of conventional tricone bits, more research would be justified, and significant cost savings could be realized.

\section{Future Work}

A new round of tests is being planned at TerraTek to further understand percussion drilling at depth. These tests will be a continuation of the work that was summarized above. The focus of this work will be on single cutter impact testing in pressurized mud, to better understand the cutter/rock interaction. This series of tests will include tests with elevated pore pressure in the samples and changes in the duration of the impact.

A preliminary test matrix is given in figure 5. These tests will use only one rock type, Crab Orchard or Nugget Sandstone, and one cutter type, round or chisel shaped. The borehole pressure will be varied up to 5000 psi. The pore pressure in the rock will be controlled to investigate over/under pressure situations. The impact energy will vary between $100 \mathrm{~J}$ and $200 \mathrm{~J}$. The duration of the impact will be changed while maintaining the same energy level, to evaluate the effect of the shape of the stress wave that enters the sample. This test matrix was designed for practicality and to gain a much better understanding of the physics of rock breaking that has been requested by the Department of Energy AND current Industry Sponsors.

The stress wave study will be unique to this project. The tests will use high amplitude, short wavelength stress waves, and compare them to low amplitude, long wavelength stress waves. The partitioning of energy could also be measured, i.e. how much energy actually causes rock damage, how much is reflected back into the tool, how much is absorbed by the rock without causing damage, and how much passes through the rock.

The performance of the cutter will be evaluated by measuring the crater volume, energy partitioning, and if possible, the extent of the damaged zone under the crater (perhaps with CT Scan). The results of these tests will be used to improve the state of mud hammer drilling at depth. Equipment engineering drawings are not in this report. 


\section{Test Matrix}

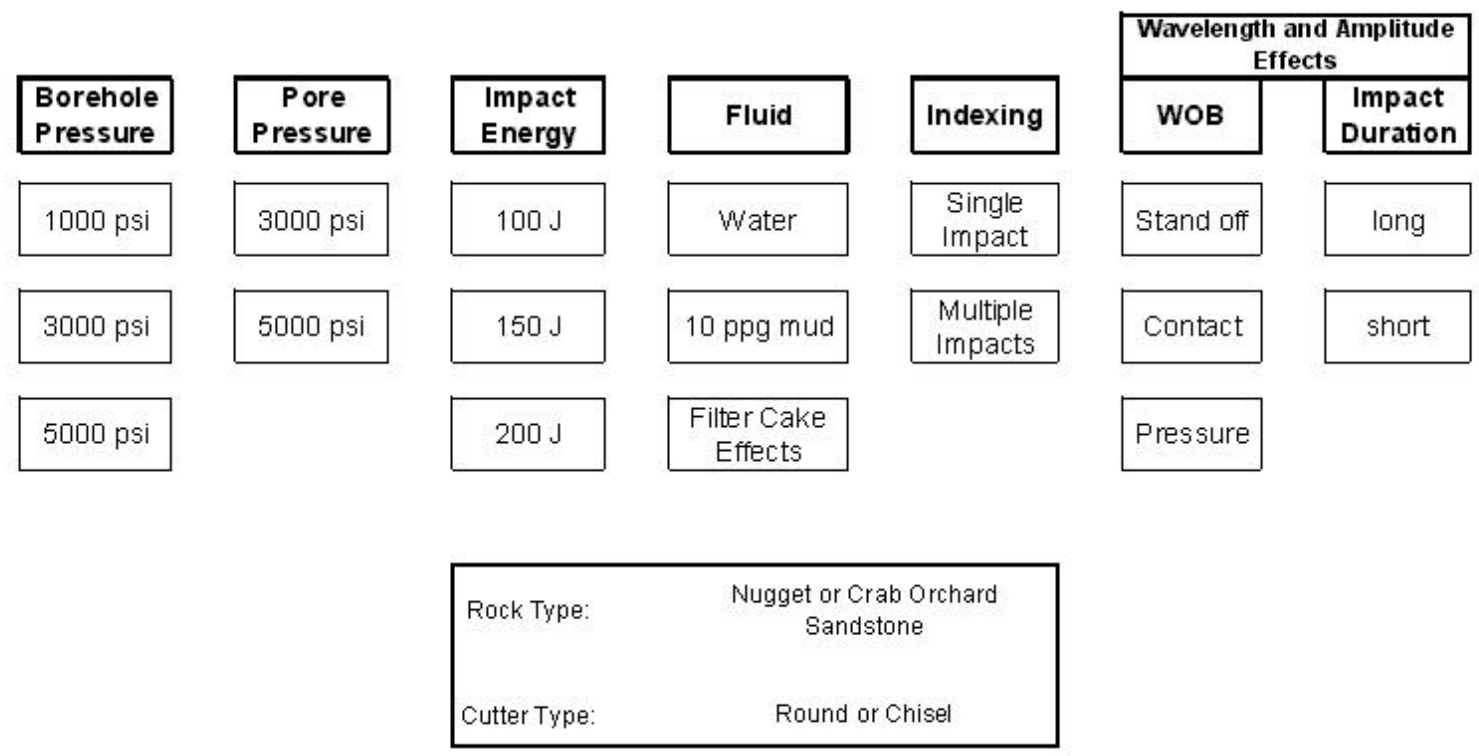

Figure 5. Proposed test matrix using one rock type and one cutter type.

Novatek Meeting at TerraTek 14 August 2003

Novatek's Terry Seyler and 3 others met at TerraTek to discuss testing schedules and layouts for the new mud hammer. Discussed were issues related to;

Frequency control

Working pressure drops approximately 1500 psi

Bits

Tool length, layout and collar chroming.

As additional information is acquired from Novatek, TerraTek will report it to the DOE.

$\underline{\text { Shell E\&P input into Task } 8}$

$* * * * *$

From: Cruz, Antonio A SIEP-EPT-AWO

Sent: Wednesday, September 03, 2003 9:56 AM

To: Tarr, Brian SIEP-EPT-DW

Cc: Pols, Albert AC SIEP-EPT-AWO

Subject: RE: Terratek Single Cutter Impact Projects 
Brian,

Thanks for the fax with the Terratek single cutter experimental program. Further to Albert's e-mail (28-8-2003), our interest in the proposed tests is primarily on the grounds of competitive intelligence on percussion drilling. We are therefore very interested in any progress reports etc that you may be able to provide.

A number of similar tests were done here in the '90's and the experience is that it can be difficult to interpret the results so as to predict actual bit performance in a drilling machine, let alone downhole.

Nevertheless, if you can influence the experimental programme in any way, our preferences would be as follows;

(1) Dome cutters are more interesting to us than chisel shapes since (a) domes are currently used in most air and liquid percussion bit designs, (b) domes have a greater impact resistance and hence a greater life.

(2) An investigation into the effects of an underbalance combination of borehole and pore pressure would be of interest. Otherwise 5000 psi (with a lower pore pressure) best corresponds to the scenarios where we tend to encounter hard rocks in E\&P.

(3) The proposed impact energies start at a rather high value for a single cutter. From the scanty published data I have seen so far (Anderhammer and Novatek) the range seems to be from around $250 \mathrm{~J}$ to $1500 \mathrm{~J}$ per blow, but one has to consider the number of cutters in the bit plus the fact that actual outputs are often substantially less than the theoretical values. Believe it or not, I would also do a test at 10 - $15 \mathrm{~J}$ impact with WOB.

(4) For some time there has been a belief that single cutter tests on a flat undamaged rock sample are too pessimistic in terms of volume removed/blow. An investigation into the effects of using a pre-damaged sample is therefore of interest. Indexing implies the relative positions of sequential blows are carefully controlled. A randomly impacted sample would probably give different results - which could be interesting.

(5) The higher the mud weight the better, 11 or $12 \mathrm{ppg}$ mud would be preferred (the tests already include water). The effects of OBM would be relevant, but I doubt they would/could consider using such fluids.

(6) If only one rock type is planned then we agree that a hard, abrasive sandstone is suitable. We are also interested in percussion drilling in other hard rocks such as limestones plus we need to be able to handle softer rocks such as shales (stringers in reservoirs).

Regards, Antonio

$* * * * *$ 


\section{Q4}

\section{TerraTek Meeting at Smith 18 November 2003}

\section{Modified Smith Hammer Drilling Test Plan}

Shantanu Swadi and Alan Black met in Houston on November 18, 2003 and from that planning meeting and further discussions the following test program is proposed:

3. Number of Tests: 5

4. Type Tests: $\quad 1$ hammer, 9 ppg NaCl brine, standard bit, Crab Orchard/Carthage composite 1 baseline, 10 ppg water-base, roller-cone, Crab Orchard/Carthage composite 1 hammer, 10 ppg water-base, standard bit, Crab Orchard/Carthage composite 1 hammer, 10 ppg water-base, standard bit, Crab Orchard ss with pore pressure $1 / 2$ hammer, 10 ppg water-base, aggressive bit, Carthage marble $1 / 2$ drilled $1 / 2$ hammer, 15 ppg water-base, aggressive bit, Carthage marble 1/2 drilled

3. Test Control:

TerraTek will attempt to set up the torque signal as feed back to the servocontroller and will check out this torque feed back mode prior to the DOE tests. If successful, torque feed back will be used to control the four hammer tests in the 500 to $1000 \mathrm{ft}$ lbs torque range.

4. Test 1 Hammer Test: Using Smith hammer with 8 1/2” standard bit, drill a composite sample of Crab Orchard ss/Carthage marble using 9 ppg $\mathrm{NaCl}$ brine in torque feed back between 500-1000 ft lbs with 500, 1000, 2000 and 3000 psi borehole pressures and flow rates 400 gpm or less as specified by Smith. RPM will be specified by Smith. Near the end of the test, drill a short distance at 0 psi borehole pressure by directly flowing back to the mud tank.

5. Test 2 Baseline Test: Using the standard 8 1/2" diameter Reed HPSM baseline bit, drill a composite sample of Crab Orchard ss/Carthage marble using a 10 ppg water-base mud and limit WOB 40,000 lbs and RPM $60 \mathrm{rpm}$. Run 10, 40 and 60 kips WOB, $60 \mathrm{rpm}$ and borehole pressures of 500, 2000 and 4000 psi.

6. Test 3 Hammer Test: Using Smith hammer with 8 1/2" standard bit, drill a composite sample of Crab Orchard ss/Carthage marble using 10 ppg water-base mud in torque feed back between 500-1000 ft lbs with 500, 1000, 2000 and 3000 psi borehole pressures and flow rates $400 \mathrm{gpm}$ or less as specified by Smith. RPM will be specified by Smith. Three times during the test (after 500 and 3000 psi borehole pressure in the Crab Orchard sandstone and 500 psi borehole in the Carthage marble) the test will be stopped and the cuttings screen emptied and the vessel opened up and sample removed to photograph the bottom hole pattern. After test, collect cuttings from 3000 psi in the Carthage marble and photograph bottom hole pattern. Near the end of the test, drill a short distance at 0 psi borehole pressure by directly flowing back to the mud tank.

7. Test 4 Hammer Test: Using Smith hammer with 8 1/2" standard bit, drill a full saturated sample of Crab Orchard ss using 10 ppg water-base mud in torque feed back between 500$1000 \mathrm{ft}$ lbs with differential pressure across the filter-cake from underbalanced to balanced to 3000 psi overbalanced. Initially pump fluid at a known rate into the bottom of the sample and through the borehole to create an underbalanced drilling condition. After drilling a short distance, stop pumping and with a borehole pressure and pore pressure equal at 3000 psi (0 psi differential) begin 
drilling and then open the pore pressure valve and begin bleeding off pore pressure at a reasonably controlled rate from 3000 to 0 psi. As differential pressure across the filter-cake increases, then ROP should decrease.

With flow rate 400 gpm or less as specified by Smith, RPM as specified by Smith, drill the entire sample. During the drilling test, continuously monitor borehole and pore pressure and the amount of pore fluid volume expelled versus time. Knowing the permeability of the Crab Orchard sandstone, back calculate the pressure drop across the rock and the resulting differential pressure across the filter-cake as (Borehole Pressure minus Pore Pressure) - (Calculated Pressure Drop Across the Rock).

8. Test 5 Hammer Test

9. Data Acquisition:

10. Make up/breakout:

11. Cuttings collection:

12. Bottomhole Photos: (at the same time the cuttings are recovered as noted above) and the mud from the bottomhole will be cleaned out and the bottom hole pattern photographed. It will be necessary to mount the camera on an extension rod and to provide lighting to get the camera close enough to the bottom hole to distinguish the bottom hole pattern clearly.

13. Test 4 Pore Pressure: Prior to Test 4, a 15.5" diameter by 35.5" long Crab Orchard sandstone sample will be evacuated and saturated with water. After placing the sample inside the pressure vessel and applying confining pressure, water will be pumped into the bottom of the sample via a flow distributor plate to flow through the sample. A 100 psi back pressure will be maintained on the water flowing out of the sample to help distribute the water throughout the sample and to absorb any residual gas into the pressurized water. Since the Crab Orchard sandstone has a relatively low permeability, this process will likely take at least 24 hours to complete the 
saturation. After the saturation is complete and just prior to the drilling test, the borehole pressure will be raised to 3000 psi and the pore pressure will be increased to 3000 psi by pumping water into the bottom of the sample to elevate the pore pressure to 3000 psi. As drilling commences, water will be pumped at a know rate to create an underbalanced drilling condition and then the pumping will be stopped and the pore pressure stabilized again at 3000 psi. At this balanced condition, drilling with the hammer at a fixed RPM and torque will again commence. A valve will then be opened on the pore pressure outlet to allow the pore pressure to be reduced (hopefully in a controlled manner) from 3000 psi to zero while the sample of Crab Orchard sandstone is being drilled up with the Smith hammer. The objective is to determine the effect of overbalance (borehole minus pore) on penetration rate. As noted, it will be necessary to measure the pore fluid volume with time to determine a filtration rate in order to calculate the pressure drop across the rock as the hole is deepened. The resulting differential pressure across the filter-cake as (Borehole Pressure minus Pore Pressure) - (Calculated Pressure Drop Across the Rock).

14. One Test Eliminated: Due to the added complexity and associated cost setting up and checking out torque control, to stop the test three times to collect cuttings and photograph bottom hole patterns during Tests 3 and 5 and the time and cost to saturate and control pore pressure during Test 4 , one drilling test has been eliminated from the originally planned 6 test program with the Smith hammer.

15. Test Schedule: The middle of February has been targeted to conduct the test program. This schedule could be modified depending on the results of Smith's internal check out tests and TerraTek's ability to implement the modifications i.e. torque control. Testing will likely take 7 to 8 days to complete.

Some changes to this program will be considered January 2004.

Notes pertaining to hammer collar length

Re: Revised Hammer Drilling Test Plan

Shantanu,

The layout looks good and the break point will work out very well.

We were planning to start preparing samples next week and wanted to confirm the way to stack the samples. In our test plan, we have three composite samples with Crab Orchard sandstone on top and Carthage marble on bottom, one Crab Orchard sample and one Carthage sample. We would make the top sample 17" long (2" for studding and 15" for drilling) and the bottom sample 19" (1" transition, 15" drilling and 3" left on the bottom). Do you have any objections to this way of stacking and the sample lengths. If not, we will proceed to prepare the samples next week. Thanks.

----- Original Message -----

From: Swadi, Shantanu

To: Alan Black

Subject: RE: Revised Hammer Drilling Test Plan

Alan, 
1.. Regarding the length issue, I have updated the hammer layout and the location of all connections are shown. We can break the assembly at the location shown in the drawing. Please review and let me know if there's any problem.

2.. I have located the crossover sub and it measures 6" (between shoulders) as indicated in the layout.

Regards,

Shantanu

-----Original Message------

From: Alan Black [mailto:ablack@terratek.com]

To: Swadi, Shantanu

Cc: Underwood, Lance; Arnis Judzis

Subject: Revised Hammer Drilling Test Plan

Shantanu,

We have looked at the layout with the longer hammer and there is an issue we overlooked before. There is enough length to connect the 16' long hammer to our drill shaft, however, it is to long to allow the bottom cross-beam on our rig frame to pass over the tool when the rig is moved into position for make-up. Therefore, it will be necessary to break a connection on the hammer (as illustrated on the lower drawing of the attached layout) and first connect the upper part of the hammer in our drill shaft. Then the rig can be moved into position and the hammer connection made up. First, could you send us a new layout or update the attached layout showing where the additional length has been added (15.25' to 16') and second, would you suggest which joint near the top portion of the hammer can practically be disconnected and connected before and after each test. Also, please check on the 8" long cross-over sub and make sure it exists and the length is correct. With this information, I will update our layout and send you a copy. Thanks.

\author{
Alan Black \\ TerraTek, Inc. \\ 400 Wakara Way \\ Salt Lake City, Utah 84108 \\ 801-584-2441 phone \\ 801-584-2406 fax \\ ablack@terratek.com e-mail
}




\title{
Manuscript for GTI Conference entitled "Mud Hammer Performance Optimization"
}

\author{
Mud Hammer Performance Optimization \\ Alan D. Black, General Manager Drilling and Completions \\ Arnis Judzis, Executive Vice President \\ TerraTek Inc. \\ 400 Wakara Way \\ Salt Lake City, UT 84108
}

Mud hammers have made relatively little impact to date on the economics of oil and gas well drilling. Improvements in the longevity of moving parts exposed to fluids containing solids have helped, though drilling performance at depth (higher borehole pressures) can be better. In a joint DOE and Industry Program, benchmark testing of three fluid hammers at severe conditions has demonstrated that this equipment will perform well under certain conditions and that optimization is possible. Energy of impact under pressure conditions, cutter rock breaking mechanisms, and treating bits and hammer section as a system have been identified as possible avenues of significant breakthroughs. This paper presents results of large-scale testing experiments performed under depthsimulated conditions and ongoing work to investigate rock-breaking mechanisms with cutter impacts. Some operators view this program as a way to reduce the risks of expensive field trials and they have identified applications for these tools, some actually requiring low fluid weights.

\section{Introduction}

Until recently mud hammer performance and endurance have not been adequately tested sufficiently for them to be viable in the marketplace. Hammer drilling, particularly in weighted fluids under high borehole pressure conditions, is prone to performance problems (both rate of penetration and longevity in muds containing solids) and can have variable degrees of success owing to low efficiencies, 'tuning problems', or modes of impact due to hydrodynamic conditions. Tool effectiveness is also dependent on wellbore pressures. Nonetheless, the markets for mud hammers, including directional mud hammers are sufficiently large to make compelling the development of a field usable device. If rate of penetration can be increased substantially, then 'deeper hard rock' basins in the United States would see more efficient operations and an increase in well construction activities resulting from enhanced economics; example basins include Anadarko, Appalachian, Arkoma, East Texas, Permian, and San Juan.

Large scale testing under simulated wellbore conditions offers an economical alternative to high day rates and can prove or disprove the viability of a particular mud hammer. The full scale testing facilities and the expertise in oilfield equipment at TerraTek offers a unique opportunity for the mud hammer to be demonstrated for subsequent commercialization. 
The program has the following goals:

1. Large-scale hammer drilling tests - To determine the viability of advanced mud hammer drilling through testing at reservoir conditions.

2. Benchmarking of hammer performance - To assess performance of mud hammer rates of penetration at high wellbore pressures relative to conventional drilling.

3. Optimization of hammer performance - To improve the performance of fluid hammers to a level acceptable to operators and develop best practices.

4. Commercialization and field deployment - To accelerate manufacture of field ready tools and ensure commercial availability in the marketplace.

To date benchmarking tests have been performed on three (3) fluid hammers, optimized fluid hammer testing programs are scheduled for Janaury 2004, and a 'cutter impact' fundamental testing program was kicked off 4Q 2003.

\section{Background and Context}

In January of 2001 the Mud Hammer Drilling Performance Testing Project was presented at a "kick off" meeting held at DOE's Morgantown, West Virginia offices. The original Industry Partners for this program were SDS Digger Tools, Novatek, BP Amoco, ExxonMobil and Pajarito Enterprises; i.e. the 'proposal team'.

TerraTek completed the first 13 drilling tests in 2001 in Carthage marble and hard Crab Orchard sandstone with the SDS Digger Tool, Novatek tool, and a conventional rock bit. Overall the hammers functioned properly at 'borehole' pressures up to 3,000 psi with weighted water based mud. Thus the Department of Energy goals to determine hammer benchmark rates of penetration and ability to function at depth were being met although ROPs diminish at higher wellbore pressures. SDS and Novatek gained considerable experience on the operation of their tools at simulated depth conditions. Optimization of the tools has already started and has been identified as a result of these first tests. Additionally, TerraTek, DOE, and BP America completed a publication (IADC/SPE 74540 "World's First Benchmarking of Drilling Mud Hammer Performance at Depth Conditions" authored by Gordon A. Tibbitts, formerly TerraTek; Roy C. Long, US Department of Energy, Brian E. Miller, formerly BP America, Inc.; Arnis Judzis, TerraTek; and Alan D. Black, TerraTek).

Subsequently PDVSA, Shell and ConocoPhillips joined the advisory team in light of their interest in percussion and hard rock drilling. And during 2002, Smith International joined and participated in the DOE Mud Hammer program through full scale benchmarking testing. The December 2002 issue of Journal of Petroleum Technology (Society of Petroleum Engineers) highlighted the DOE fluid hammer testing program and reviewed IADC/SPE Paper 74540 on the benchmark performance of the SDS Digger and Novatek hammers. An article by Wajid Rasheed in the March 2003 issue of Drilling further emphasized the potential impact of fluid hammers to the industry and also Smith International views on the technical challenges. 
During a progress meeting in 2002 with industry advisors present, three operators provided additional input with respect to their challenges;

\section{OPERATOR 1}

- Would like to see an "accounting" of hydraulic energy through the tool systems. How much energy is expended at each stage of the tool function and rock destruction? It would be helpful in establishing rig operating conditions.

- Would like to see an expansion of the project to include other mud hammers

OPERATOR 2

- Their applications require rock in the 25 to $30 \mathrm{ksi}$ strength range.

- Their applications to date are run with low weight mud systems.

- They have interest in the hammer/bit as a system.

OPERATOR 3

- Current and near future applications are aimed at near balanced or under balanced directional drilling conditions or low WOB slide applications in the reservoir sections of the hole

- They would like to see multi phase fluid tests to verify these tools can operate in such an environment; e.g. nitrogen / diesel

- Needs to establish the performance of these tools in shale sequences. Need to exhibit reasonable rates in shale as well as hard rock

- Would like to know the directional characteristics of mud hammers

\section{Technical Approach}

Full-scale drilling optimization tests were performed in TerraTek's Drilling and Completions Laboratory. In the wellbore simulator, confining and overburden stresses are applied to the rock samples and borehole pressure is established by choking the drilling fluid flow downstream of the bit. Weight on bit is applied with a servocontrolled system. Rotary speed is controlled with variable speed direct drive motors, 5speed transmission and standard oil-field rotary table.

The advantages in using TerraTek's rig and wellbore simulator include;

- Provides ability to benchmark a variety of tools and equipment

- Mud pumps offer full scale flow and pressure requirements

- Rig height 'daylight' offers easy access for long collars

- Drilling conditions are carefully controlled and monitored

- Data acquisition gives time based logs of weight-on-bit, rotary speed, flow rate, bit pressure drop, penetration rate, torque, etc. for each test.

After each test, time based data was reduced into concise records for each interval of steady drilling conditions. Typical data sets include distance drilled, penetration rate, penetration rate per revolution or cycle, torque, weight on bit, rotary speed, swivel (standpipe) pressure, borehole pressure, mechanical horsepower, bit pressure drop, bit hydraulic horsepower, and summaries of mud properties. For the mud hammer, power input estimates can be made knowing flow rates and nozzle sizes. 
The test program had the following features;

Equipment - 3 Hammers (Novatek 7 3/4", SDS Digger Tools Hydra 185, Smith 7”)

Bits $-8-1 / 2$ " rollercone and bits recommended by hammer supplier

Constant Conditions - Mud temperature, overburden stress on rock, rock size 151/2" by 36" long, confining pressure, and rotary speed.

Variables -

Rock types The rock samples for comparing the performance of the mud hammer with conventional drilling are Carthage marble and Crab Orchard sandstone. They have the following characteristics;

Carthage marble (Missouri) - light uniform gray, fine-grained compact limestone containing numerous fossil shell fragments, cemented, crystalline texture. Unconfined strength approximately 16,000 psi.

Crab Orchard sandstone (Tennessee) - Light gray, very fine grained, compact quartzose sandstone with tightly interlocking texture. Unconfined strength approximately 27,000 psi.

Hammer energy (flow rate and nozzles)

Weight on bit

Borehole pressure

Drilling fluid density (water based mud) - 2 water based muds $10 \& 15$ ppg, 9 ppg brine 


\section{Hammer with jacketed rock sample outside pressure vessel}

\section{Smith Hammer and Bit}
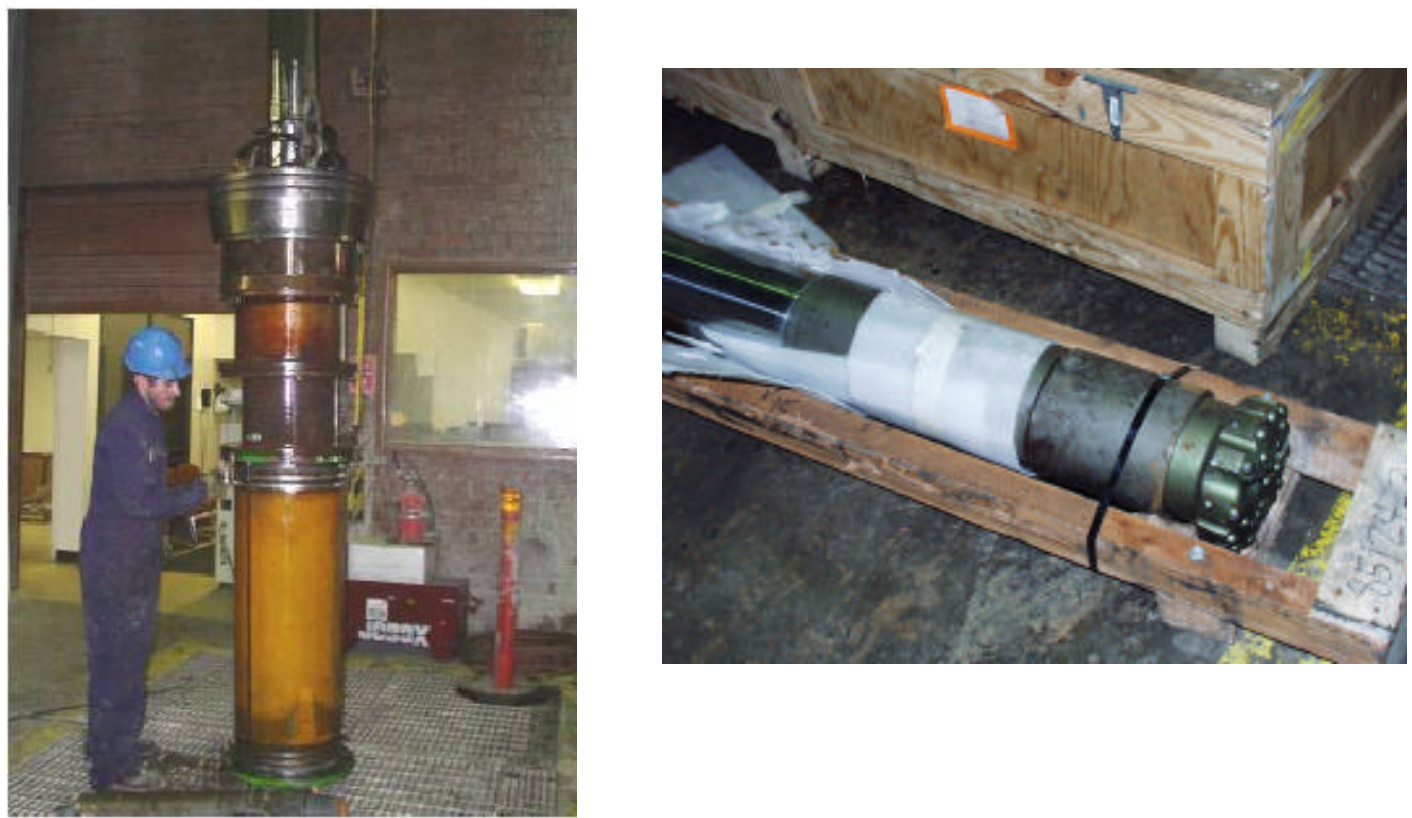

\section{SDS Impact Bit}

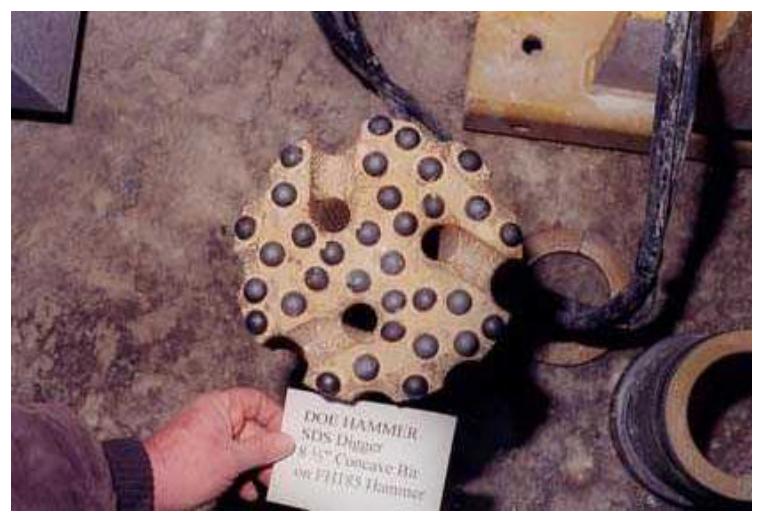

Novatek Bit (Patent Pending)

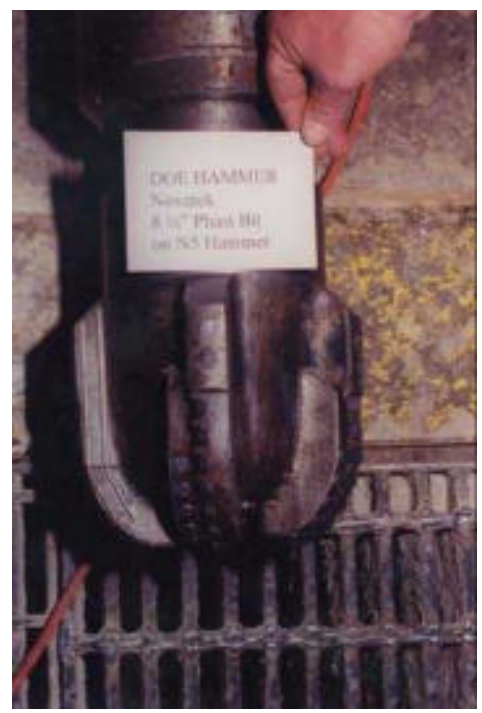




\section{Benchmarking Tests (18 total for first phase of work)}

\begin{tabular}{|c|c|c|c|}
\hline \multicolumn{4}{|c|}{ TEST SEQUENCE } \\
\hline TEST & HAMMER/BIT & ROCK & $\begin{array}{c}\text { MUD } \\
\text { nENCITv }\end{array}$ \\
\hline 1 & SDS/IMPACT & Carthage & 10 \\
\hline 2 & SDS/IMPACT & Crab Orchard & 10 \\
\hline 3 & Novatek PDC & Carthage & 10 \\
\hline $3 A^{*}$ & Novatek IADC & Carthage & 10 \\
\hline 4 & Rotary IADC 537 & Carthage & 15 \\
\hline 5 & Rotary IADC 537 & Crab Orchard & 15 \\
\hline 6 & SDS/IMPACT & Carthage & 15 \\
\hline 7 & SDS/IMPACT & Crab Orchard & 15 \\
\hline 8 & SDS/IMPACT & Carthage & 15 \\
\hline 9 & SDS/IMPACT & Crab Orchard & 15 \\
\hline 10 & Novatek PDC & Carthage & 15 \\
\hline 11 & Novatek PDC & Crab Orchard & 15 \\
\hline 12 & Novatek PDC & Carthage & 15 \\
\hline
\end{tabular}

* Test 3A is fourth test however numbered 3A due to bit change

\begin{tabular}{|r|c|c|c|}
\hline 13 & Rotary IADC 537 & Carthage & 9 (brine) \\
\hline 14 & Smith & Carthage & 9 (brine) \\
\hline 15 & Smith & Carthage & 10 \\
\hline 16 & Smith & Crab Orchard & 10 \\
\hline 17 & Smith & Carthage & 15 \\
\hline
\end{tabular}

The performance of an 8-1/2" roller cone bit (IADC Code 537) was previously documented in SPE Paper 15620. These tests were conducted using 10 and 15 ppg water based muds drilling into Carthage marble and Crab Orchard sandstone.

In a typical test a 15-1/2" diameter jacketed sample is connected to the wellbore simulator vessel's top plug. The assembly with the mud hammer and bit combination is then lowered into the vessel for sealing. Confining pressures and overburden loads were applied during the tests. 


\section{Sample readied for Fluid Hammer Testing}
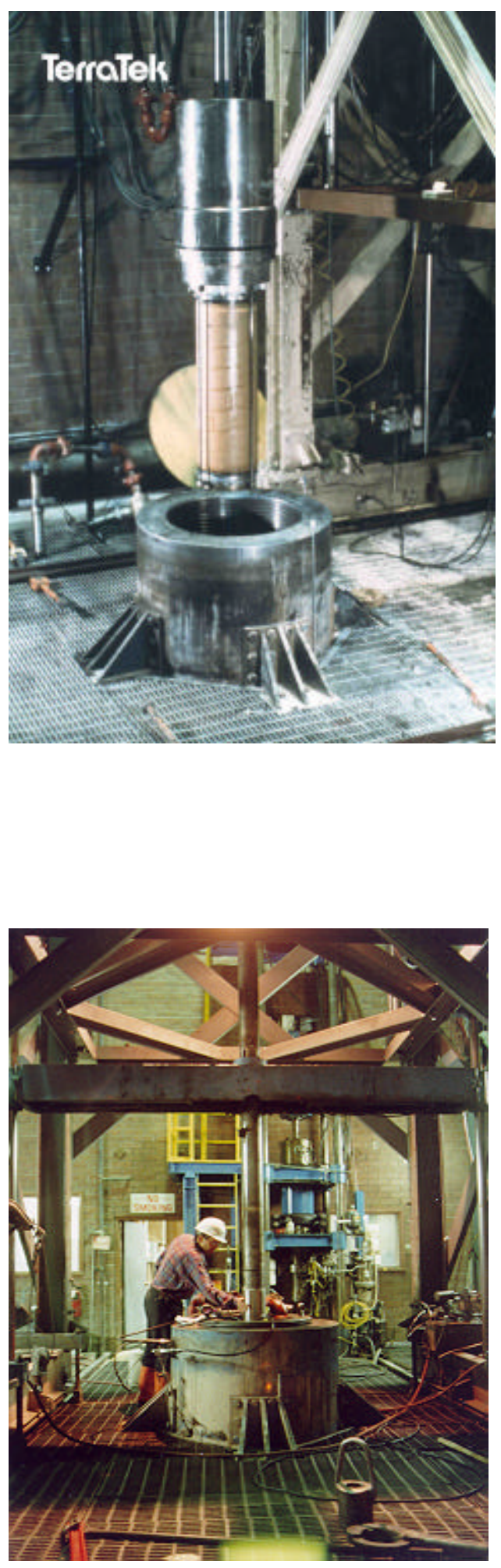


\section{Results of Benchmarking Tests}

\section{$\underline{\text { Baseline Tests }}$}

Baseline Data with 8 1/2" IADC 537 Bit with 10 ppg and 15 ppg Water-base Mud for Carthage Marble (reference IADC/SPE 74540)

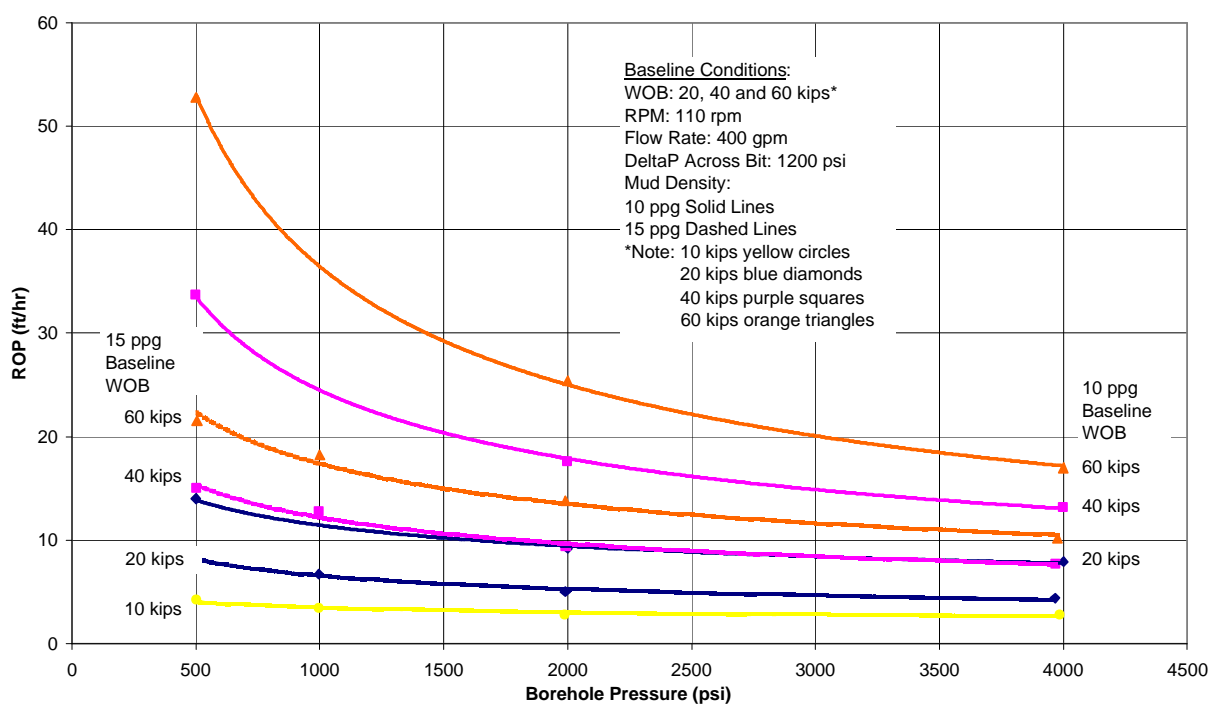

Baseline Data with $81 / 2$ " IADC 537 Bit with $10 \mathrm{ppg}$ and $15 \mathrm{ppg}$ Water-base Mud for Crab Orchard Sandstone (reference IADC/SPE 74540)

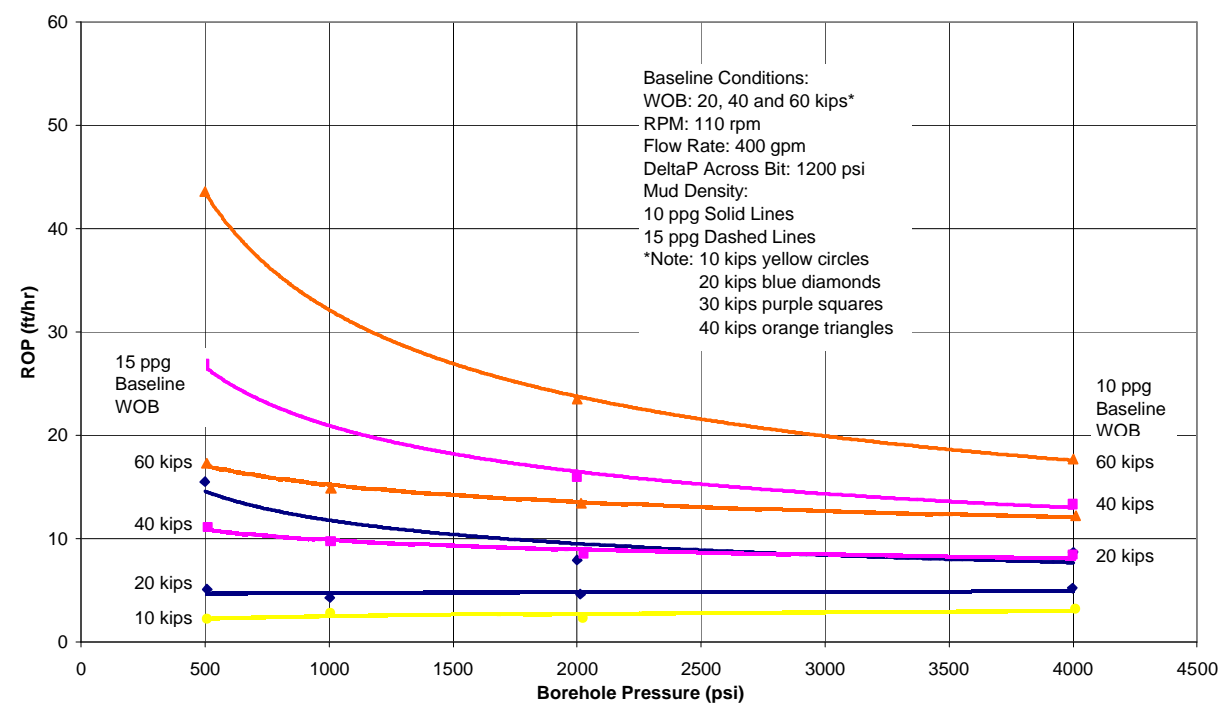




\section{0 ppg Crab Orchard Sandstone}

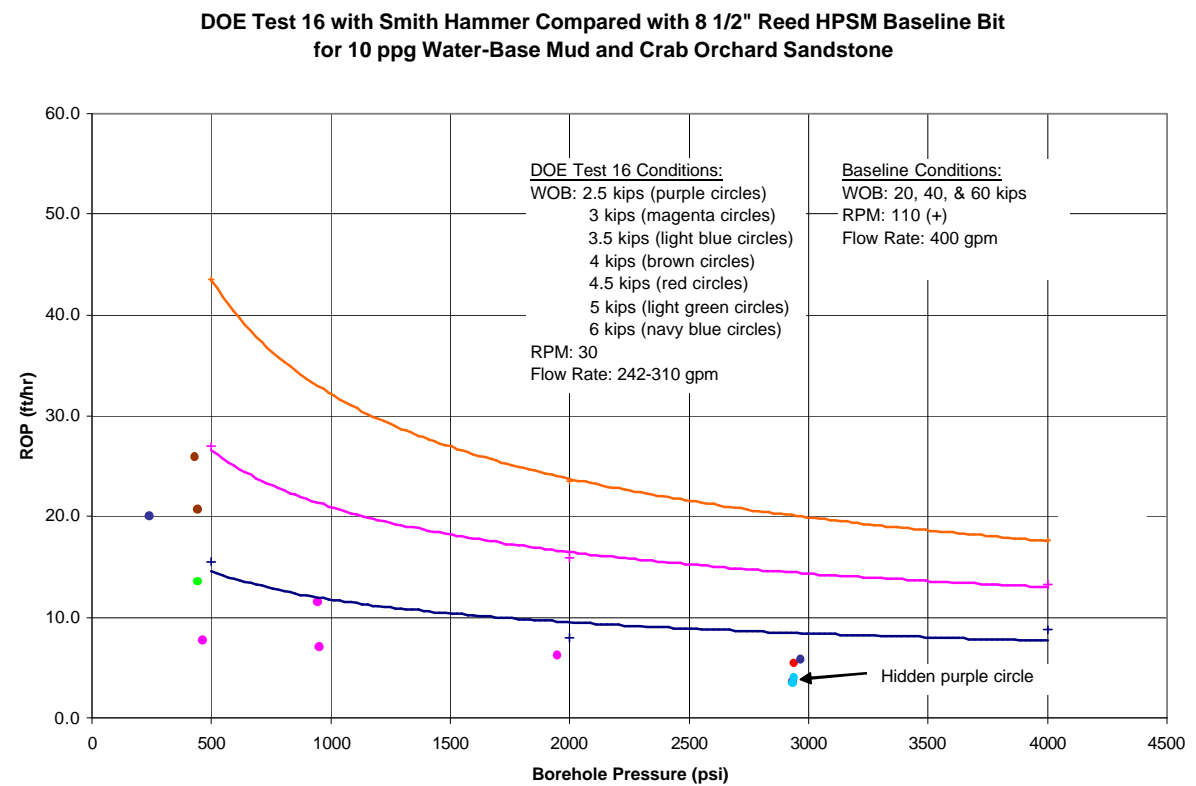

Comparison of DOE Test 2 SDS FH185 Hammer/Hard Formation Bit and 8 1/2" IADC 537 Bit Rotary Drilling for 10 ppg Water-base Mud and Crab Orchard Sandstone (reference IADC/SPE 74540)

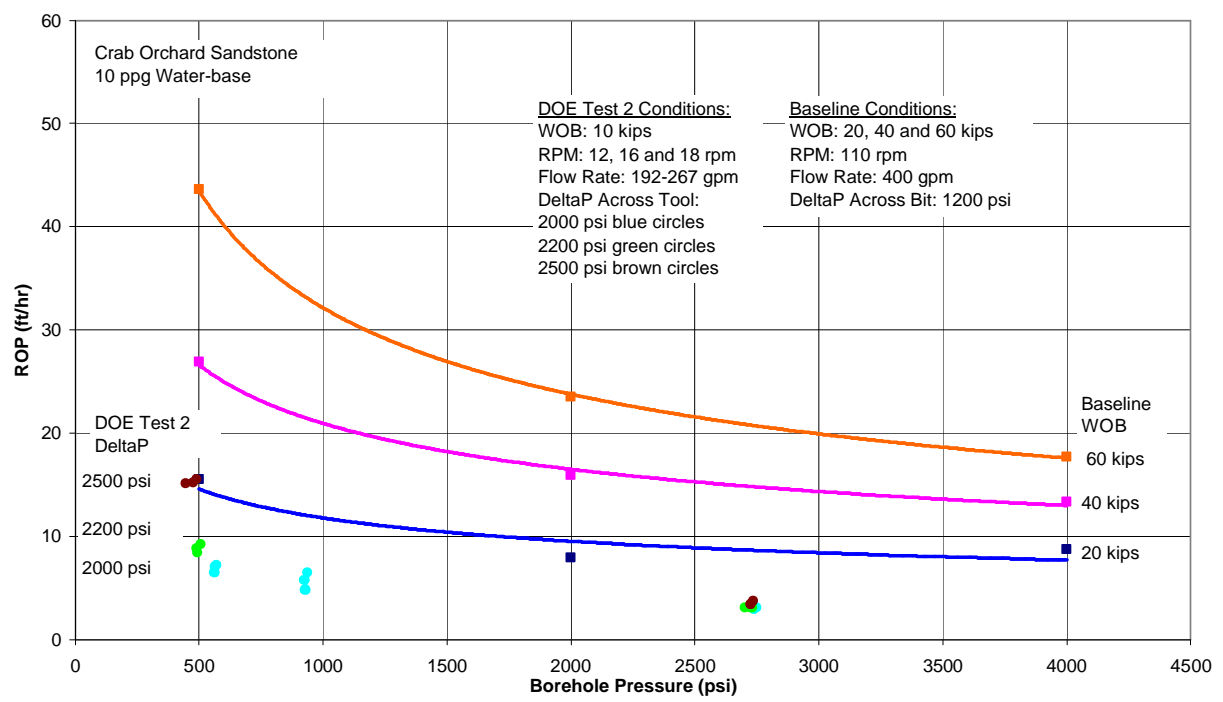




\section{5 ppg Carthage Marble}
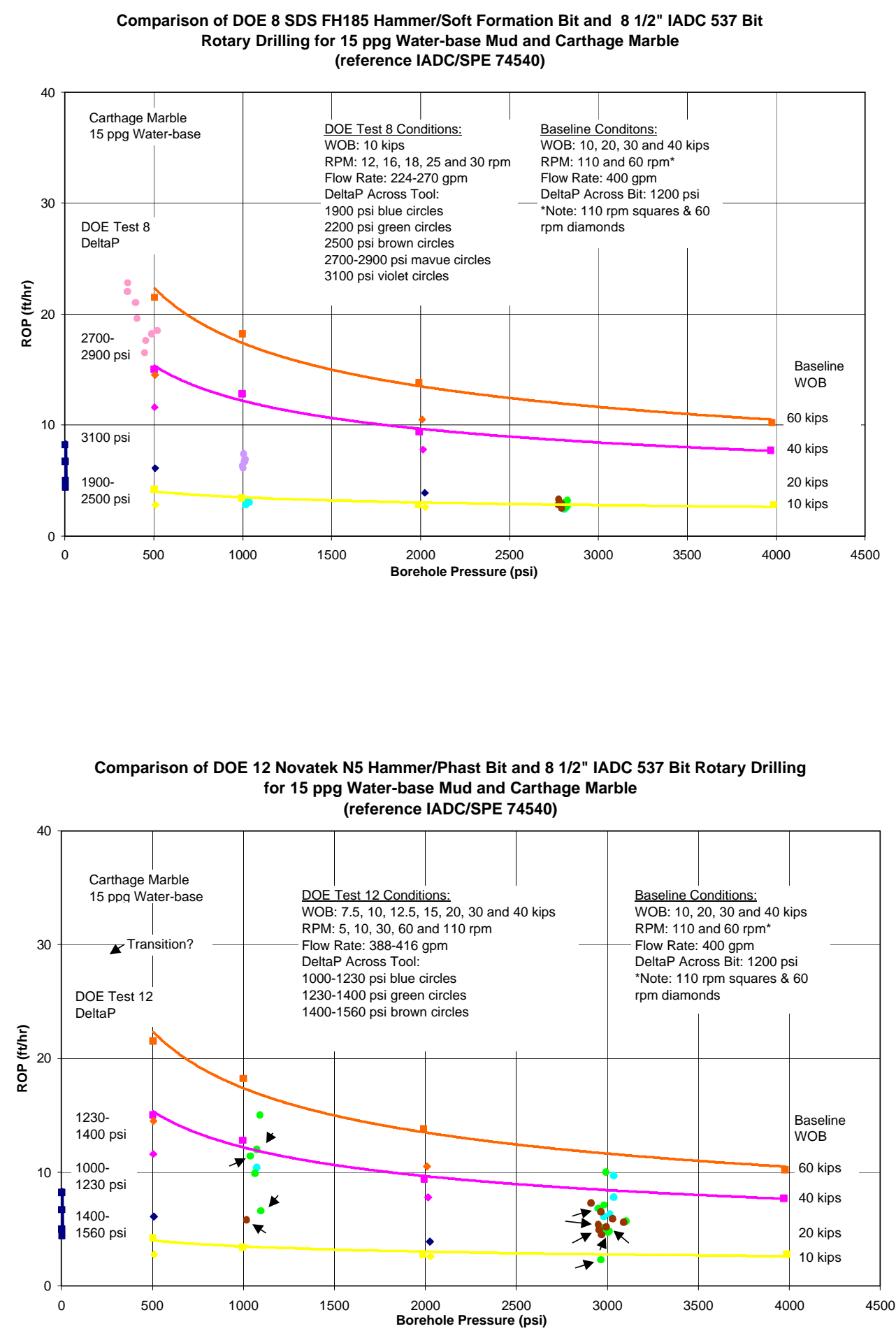
Example Bottomhole Pattern (Test \#8 SDS hammer drilling Carthage marble)

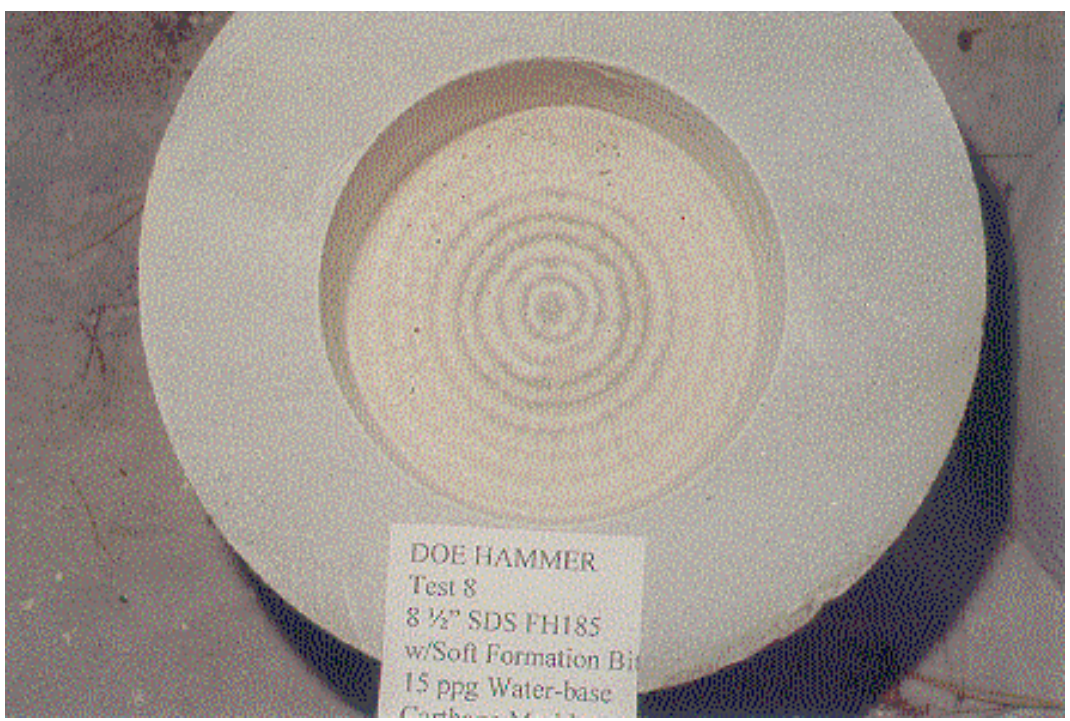

Example Bottomhole Pattern (Test \#16 Smith hammer drilling Crab Orchard SS)

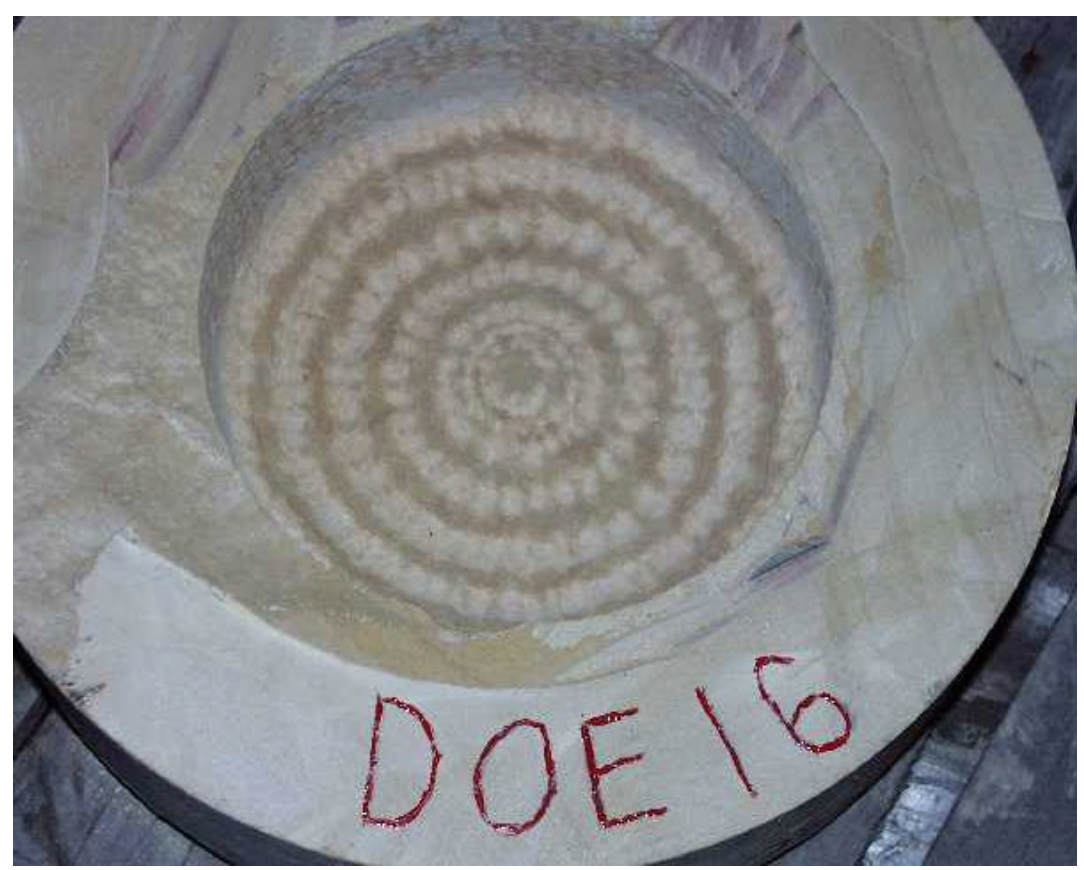




\section{Cutter Impact Testing}

Mud hammers had been experimented with in various places around the world; however, their performance was not fully understood. They seemed to be less effective in deeper holes, and their performance in weighted mud was not accurately known. The tests conducted at TerraTek were designed to measure the ROP response of current mud hammers, and compare them to an 8 1/2" tricone bit (IADC Code 537). Additionally, some excellent work conducted by Luy et al. at Claustal in Germany a number of years ago showed the challenges of rock removal via cutter impacts at pressure. Their work concentrated on rocks such as granite and a series of test results are summarized below.

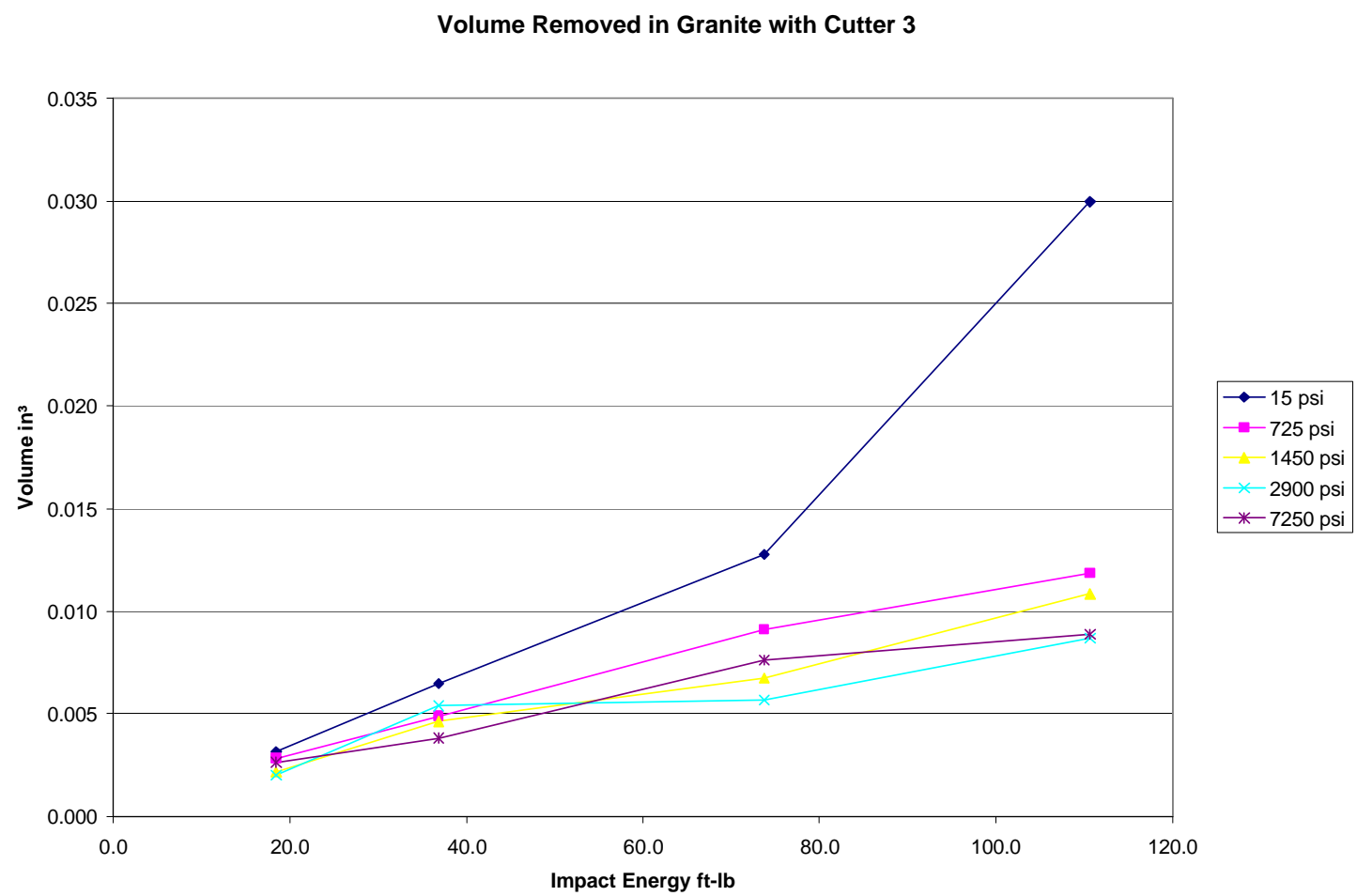

Figure above - The volume of rock removed vs. impact energy at different hydrostatic pressure levels using a chisel-shaped cemented carbide cutter in granite.

\section{Future Work}

A new round of tests are underway at TerraTek to further understand percussion drilling at depth. These tests will be a continuation of the work that was summarized above. The focus of this work will be on single cutter impact testing in pressurized mud, to better understand the cutter/rock interaction. This series of tests will include tests with elevated pore pressure in the samples and changes in the duration of the impact. 
These tests will use rock types such as Crab Orchard or Nugget Sandstone, and one cutter type, round or chisel shaped. The borehole pressure will be varied up to 5000 psi. The pore pressure in the rock will be controlled to investigate over/under pressure situations. The impact energy will vary between $100 \mathrm{~J}$ and $200 \mathrm{~J}$. The duration of the impact will be changed while maintaining the same energy level, to evaluate the effect of the shape of the stress wave that enters the sample. This test matrix was designed for practicality and to gain a much better understanding of the physics of rock breaking.

The performance of the cutter will be evaluated by measuring the crater volume, energy partitioning, and if possible, the extent of the damaged zone under the crater (perhaps with CT Scan). The results of these tests will be used to improve the state of mud hammer drilling at depth.

\section{Conclusions}

1. Benchmark testing on the three (3) fluid hammer systems has demonstrated the ability to operate under severe environments of high wellbore pressures and heavy mud weights. Rate of penetration performance does however decrease with increasing wellbore pressures.

2. Fluid drilling hammers can be optimized to provide better performance at pressure. This needs to be demonstrated quantitatively. Features such impact energy, frequency of strike, pressure drop across tool for energy input, hammer - bit 'system' approach and tool unload / rock breaking characteristics are avenues of research.

3. Some operators have harder rock applications using lower fluid weights, thus they are currently expected to attain reasonable drilling performance depending upon the application.

4. Much discussion has ensued by operators and suppliers on pressure drops that can be afforded by conventional land rigs vs. additional energy input at depth.

5. The 'cutter impact testing' program underway to examine rock removal under various confining and pore pressures could offer additional insights into fluid hammer performance optimization.

6. Development and optimization continues by the suppliers. This will accelerate as marketplace demands competition to conventional drilling techniques. 


\section{References}

1. Ramirez, J., Geraud, M., Salazar, V., and Algate, G., "Fluid Percussion Drilling in Deep Hard Rock in Eastern Venezuela", SPE Paper 69520 presented at the SPE Latin American and Caribbean Petroleum Engineering Conference held in Buenos Aires, Argentina, 25-28 March, 2001.

2. Walker, B.H., Black, A.D., Klauber, W.P., Little, T., and Khodaverdian, M., "RollerBit Penetration Rate Response as a Function of Rock Properties and Well Depth", SPE Paper 15620 presented at the $61^{\text {st }}$ Annual Technical Conference and Exhibition of the Society of Petroleum Engineers held in New Orleans, LA 5-8 October, 1986.

3. Santos, H., Placido, J., Oliveira, J., and Gamboa, L., "Overcoming Hard Rock Drilling Challenges", IADC/SPE Paper 59182 presented at the 2000 IADC/SPE Drilling Conference held in New Orleans, Louisiana, 23-25 February 2000.

4. Tibbitts, G.A., Long, R.C., Miller, B.E., Judzis, A. and Black, A. D., "World's First Benchmarking of Drilling Mud Hammer Performance at Depth Conditions" IADC/SPE 74540 to be presented at the 2002 IADC/SPE Drilling Conference in Dallas Texas, 25-28 February 2002. The co-authors affiliations are as follows Gordon A. Tibbitts, TerraTek; Roy C. Long, US Department of Energy, Brian E. Miller, BP America, Inc.; Arnis Judzis, TerraTek; and Alan D. Black, TerraTek.

5. Lagreca, A., De Santana, D., Suarez, G., Rodriguez, M. (PDVSA), McInnes, M. (SDS Digger Tools), "Fluid Percussion Hammer Filed Test in the Alocthonous Cretaceous Block Eastern Venezuela", presented at the Petroleum Society's Canadian International Petroleum Conference 2002, Calagary, Alberta, Canada, June 11-13, 2002.

6. 'Mud-Hammer Drilling Performance', Journal of Petroleum Technology, December, 2002, pg 38.

7. Rasheed, Wajid (Latin America Editor - Hart's E\&P) 'Mud Hammers Changing the Game', Drilling, American Association of Drilling Engineers, March, 2003, pp 1618.

8. Dr. Ralf Luy, dissertation entitled "Untersuchung zur Wirksamkeit des Bohrprozesses beim drehschlagenden Bohren unter hohen hydrostatischen Drücken”, which translates as: the investigation of the efficiency of the drilling process with rotary percussion drilling at high hydrostatic pressures. This dissertation was completed at the Technical University Clausthal, in Clausthal, Germany on December 18, 1992. 


\title{
Q1
}

\section{‘Cutter Impact Testing’ Industry / DOE meeting at TerraTek February 13, 2004}

\author{
'Cutter Impact Testing' Planning Meeting at TerraTek \\ Understanding Rock Breakage with Bits \\ February 13, 2004
}

\author{
Attendees; John Rogers, DOE/NETL \\ Roy Ledgerwood, Hughes Christensen \\ David Pixton, Novatek \\ Sidney Green, CEO TerraTek \\ Arnis Judzis, Executive Vice President TerraTek \\ Alan Black, General Manager Drilling and Completions TerraTek \\ Regrets; $\quad$ Brian Tarr, Shell \\ James Rigby and Tim Travis, ExxonMobil
}

Objective of Meeting - "To finalize testing plans within the sanctioned DOE program."

\section{Discussion -}

Arnis Judzis presented an overview and background of the program (presentation attached). Most pertinent to the discussion was input obtained from the Industry Advisors to date (slide 12 - information summarized from previous communications from Roy Ledgerwood, Hughes Christensen; Jesse Holster, ExxonMobil; Brian Tarr, Shell; and Shantanu Swadi, Smith International). David Pixton confirmed his interest in the program for high wellbore pressures and determination of 'rock damage'.

Alan Black presented (attached also) some details about the testing program and equipment status. A higher data acquisition system ( $\mathrm{PC}$ with a/d board, etc.) was implemented after the meeting allowing satisfactory measurement of load vs. time. Work continues to upgrade the velocity and/or displacement measurements.

Issues of interest;

1. Rock damage assessment - damage 'volume' may be derived from a routine method such as a casting. Additional work was proposed for some samples using thin sections / petrographic analysis, CT scan, etc.

2. Mike Bruno's DOE project with Terralog - John Rogers will work with the appropriate project manager to ensure there is connectivity of efforts with these projects. Terralog has already been in contact with Alan Black regarding the upcoming large-scale mud hammer tests with Smith International.

3. Test matrix -

Rock types $\quad$ Crab Orchard Sandstone, Carthage marble, and Mancos shale

Inserts 2 types; hemispherical and conical

Fluid types $\quad 10$ and 15 ppg WBM

Impact energies To be checked; however 75, 150, and 225 Joules were proposed (beyond Claustal work). Wellbore pressure would be maintained at 3000 psi, replicate testing would be included.

Specialty tests Vary impact duration, vary borehole pressure, limited tests of indexing, and aggressive PDC type cutter. Rock samples would be prepared with metal sleeves and a nominal total number of tests will exceed 50 (budgeted).

John Rogers added that this experimental work should help form the basis of subsequent analytical work and that the Industry Team see the testing program. Testing will commence in March after the equipment is fully operational. TerraTek will supply DOE with a schedule of activities after Novatek confirms their own schedule for their new tool. 
Arnis Judzis, Executive Vice President TerraTek, February 18, 2004

$* * * * *$ end of executive summary $* * * * *$
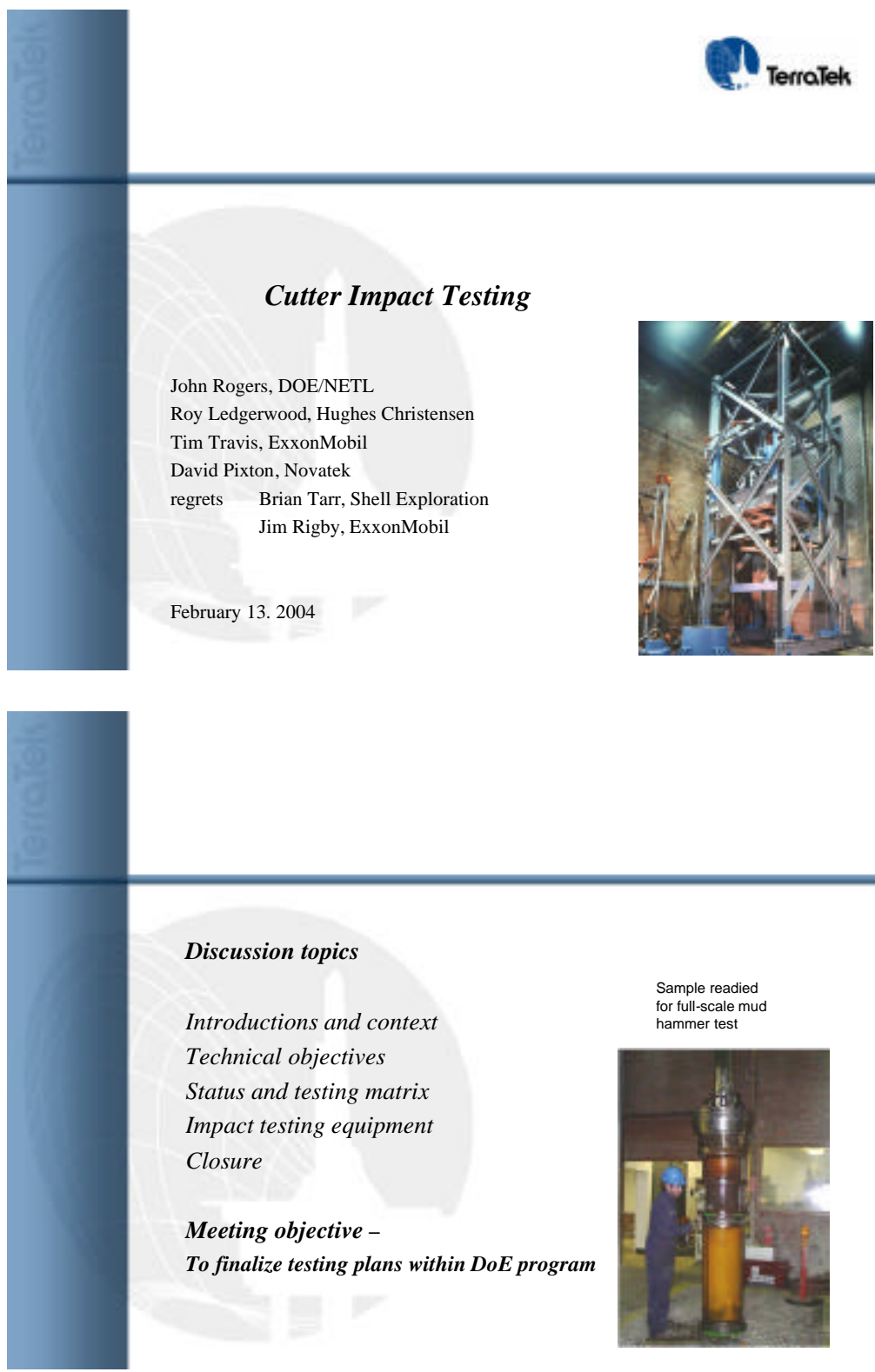


\section{Context}

- Benchmark testing on the 3 fluid hammer systems has demonstrated their ability to operate under severe environments of high wellbore pressures in weighted mud. ROP however decreases significantly with increasing wellbore pressures.

- Fluid hammers can be optimized to provide better performance at pressure. Impact energy, pressure drop, bit design and tool unload / rock breaking are valid avenues of research.

- Some operators have harder rock applications using lower fluid weights, thus could expect reasonable performance.

- 2 of these hammers will be re-tested during $1 Q$ and 2Q 2004.

- 'Cutter impact testing' will address the complex issue of understanding rock breaking mechanisms and challenges at pressure conditions.

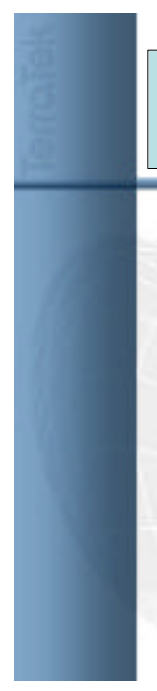

Impact Testing - "Understanding Rock Breakage" Obtain quantitative information with single cutter tests to better understand the effects of stress/borehole pressure in presence of fluid, impact energy, rock types, cutter geometry, and indexing.

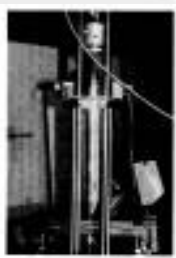

Claustal University Per Ralf Luy 1992

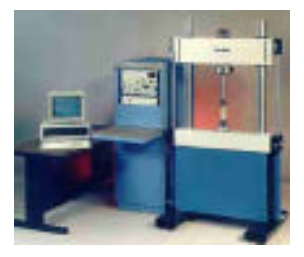

TerraTek

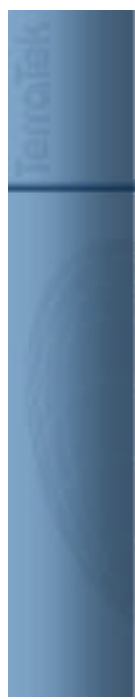

From Claustal University - Volume of rock removed vs. impact energy at various pressures $\mathrm{w} /$ chisel cutter

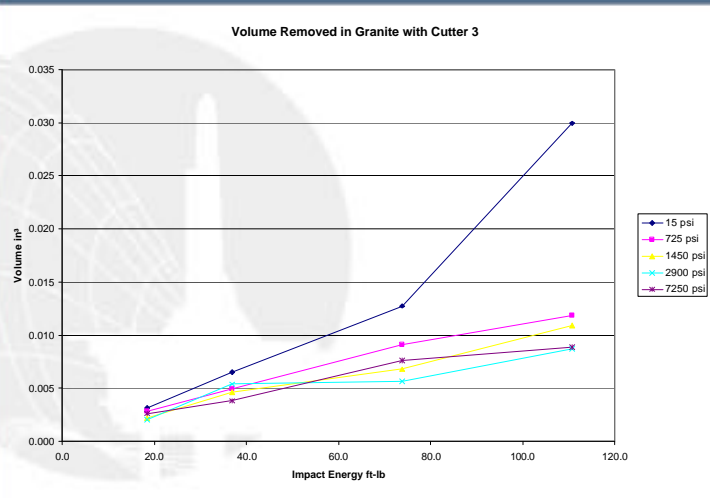




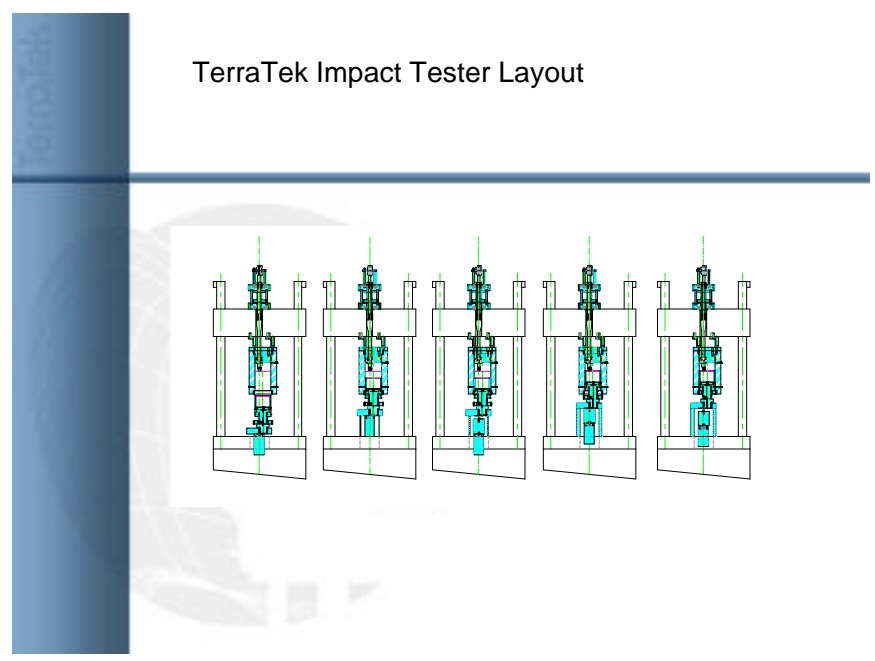

Industry Partner Team Input

- Hughes Christensen; energy partitioning, function of effective stress, impact type, rock types (sandstone and carbonate)

- ExxonMobil; at wellbore pressures, ductile or fracture [observations], rock types, pore pressure, impact loading/energy, indexing

- Shell Exploration; effect of wellbore pressure, pore pressure, range of impact energies, indexing, mud weight, hard sandstone

- Smith International; rock breakage as pressures increase, threshold impact energy for 'damage', impact type

Novatek; to be discussed at meeting

- Basis of test matrix discussion (common industry challenges) Pressure - elevated wellbore pressures, pore pressure Impact energy - low to high

Rock types - restrict to sandstone and carbonate Cutter type - limit to one or two type

Record damage - photos, etc.

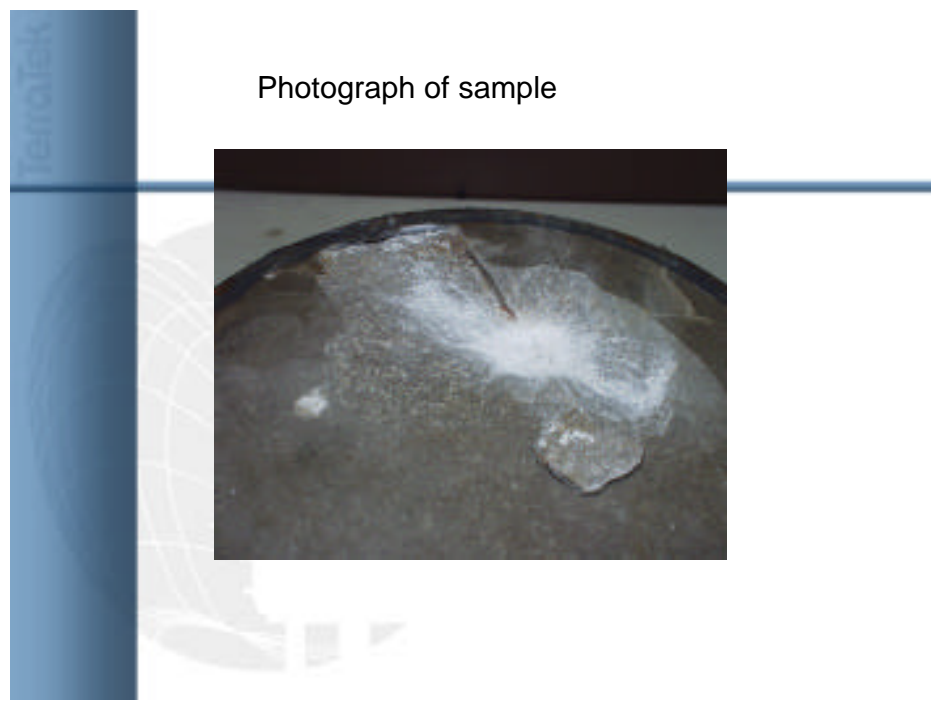




\section{Communication with Terralog to witness Smith Hammer testing at TerraTek March,} 2004

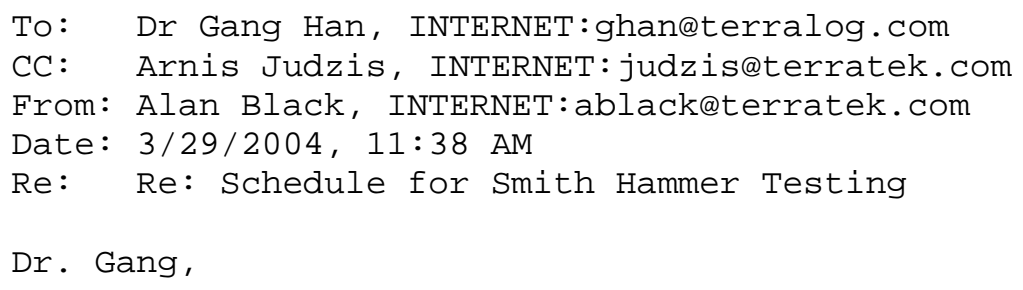

$\underline{\text { Novatek schedule }}$

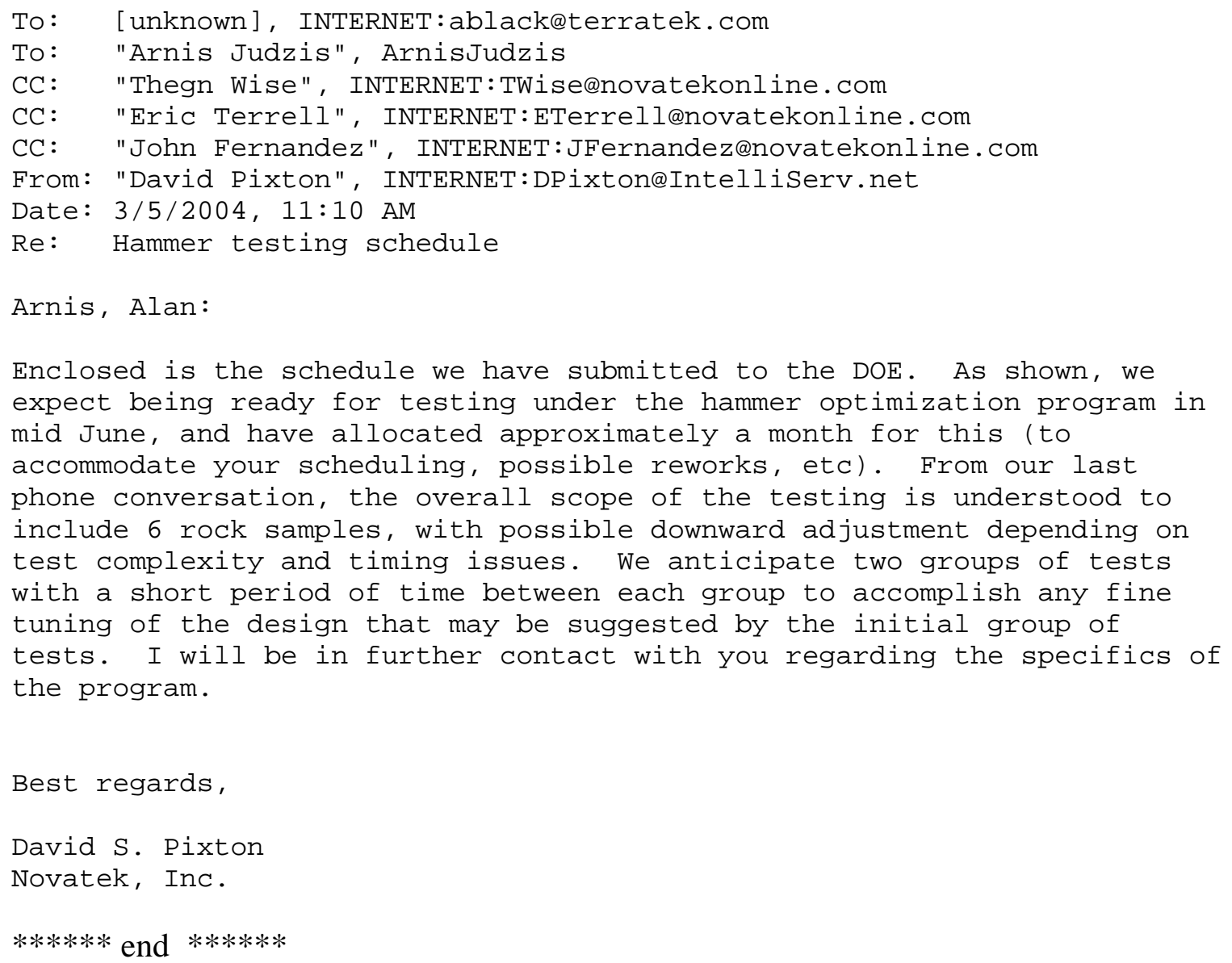


Q2

Optimization testing of Smith International Fluid Hammer

This section of the report presents performance results of the Smith Hammer during the three month time period.

DOE-Smith Hammer Comparison Between Old and New Hammer

Carthage Marble and $9.0 \mathrm{ppg}$ Brine

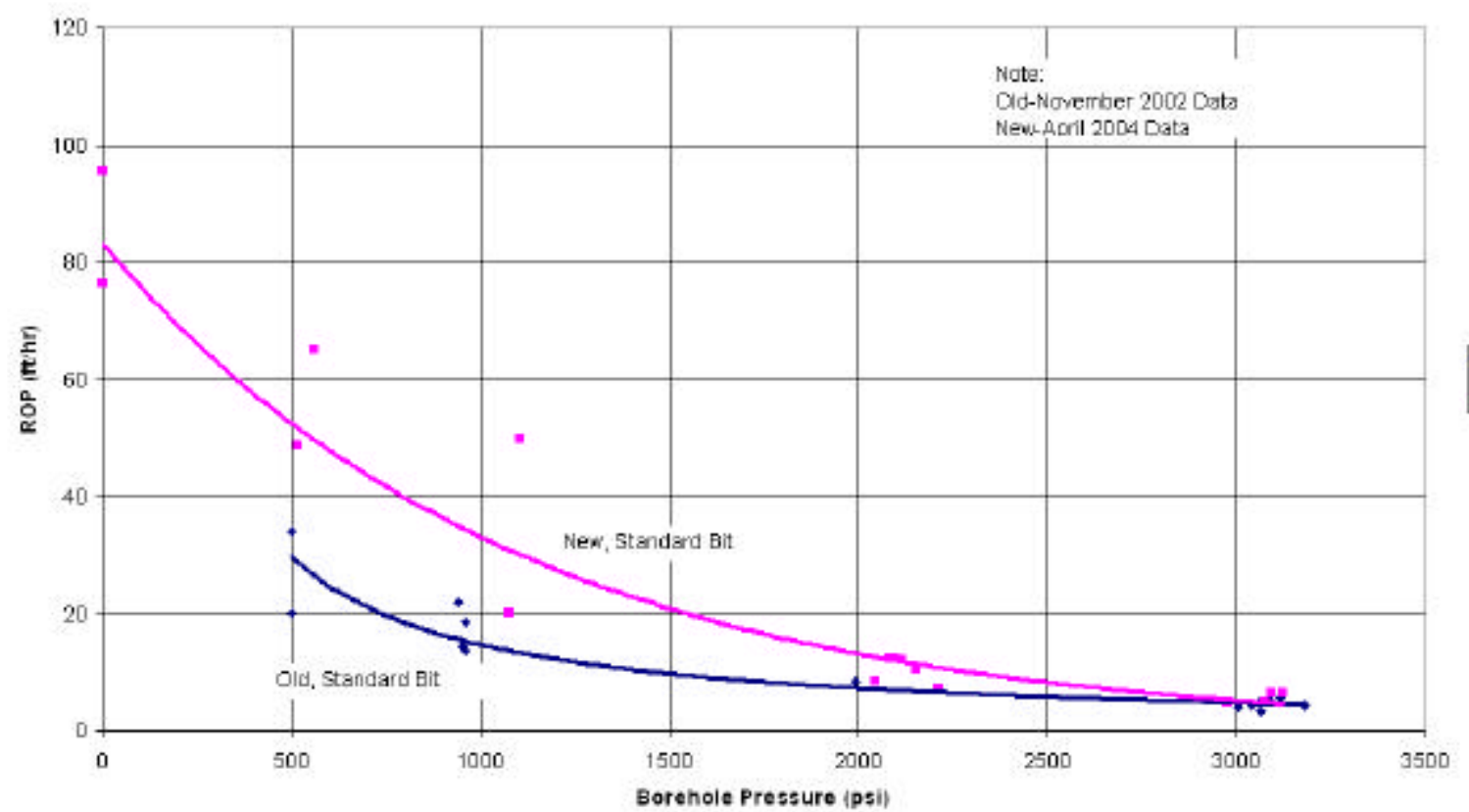

Figure 1 - Reference DOE Test 19

Figure 1 Carthage marble, 9.0 ppg brine with old hammer design and standard bit Carthage marble, 9.0 ppg brine with new hammer design and standard bit

As seen in Figure 1, the new hammer/standard bit ROP performance was significantly improved at borehole pressures lower than 2000 psi. At 2000 psi borehole pressure, there was a smaller improvement and at 3000 psi the performance was about the same. 
DOE-Smith Hammer Comparison Between Old and New Hammer Carthage Marble and $10 \mathrm{ppg}$ Water-base

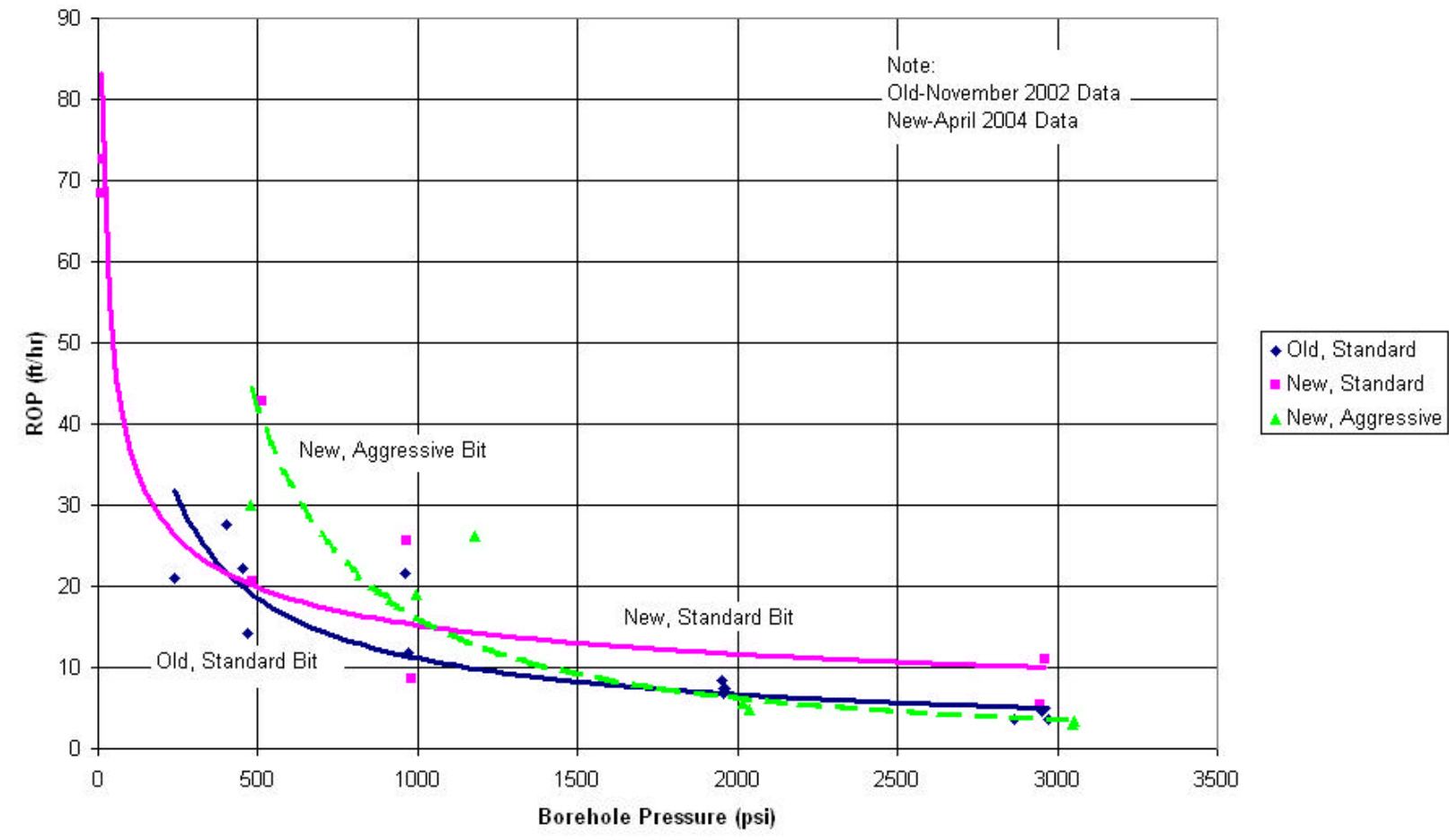

Figure 2 - Reference DOE Tests 20 and 22

Figure 2 Carthage marble, $10 \mathrm{ppg}$ WB with old hammer design and standard bit Carthage marble, 10 ppg WB with new hammer design and standard bit Carthage marble, 10 ppg WB with new hammer design and aggressive bit

As seen in Figure 2, the ROP performance of the new hammer/standard bit was in general greater than the old hammer/standard bit, however, the ROP performance was not consistent with the new hammer/standard bit. In some cases, the ROP performance was significantly greater, but then in other cases it was about the same. The new hammer / aggressive bit showed significant ROP improvement below 2000 psi borehole pressure, but at 2000 and 3000 psi borehole pressures, the performance was about the same as the old hammer/standard bit. 
DOE-Smith Hammer Comparison Between Old and New Hammer Crab Orchard Sandstone and $10 \mathrm{ppg}$ Water-base Mud

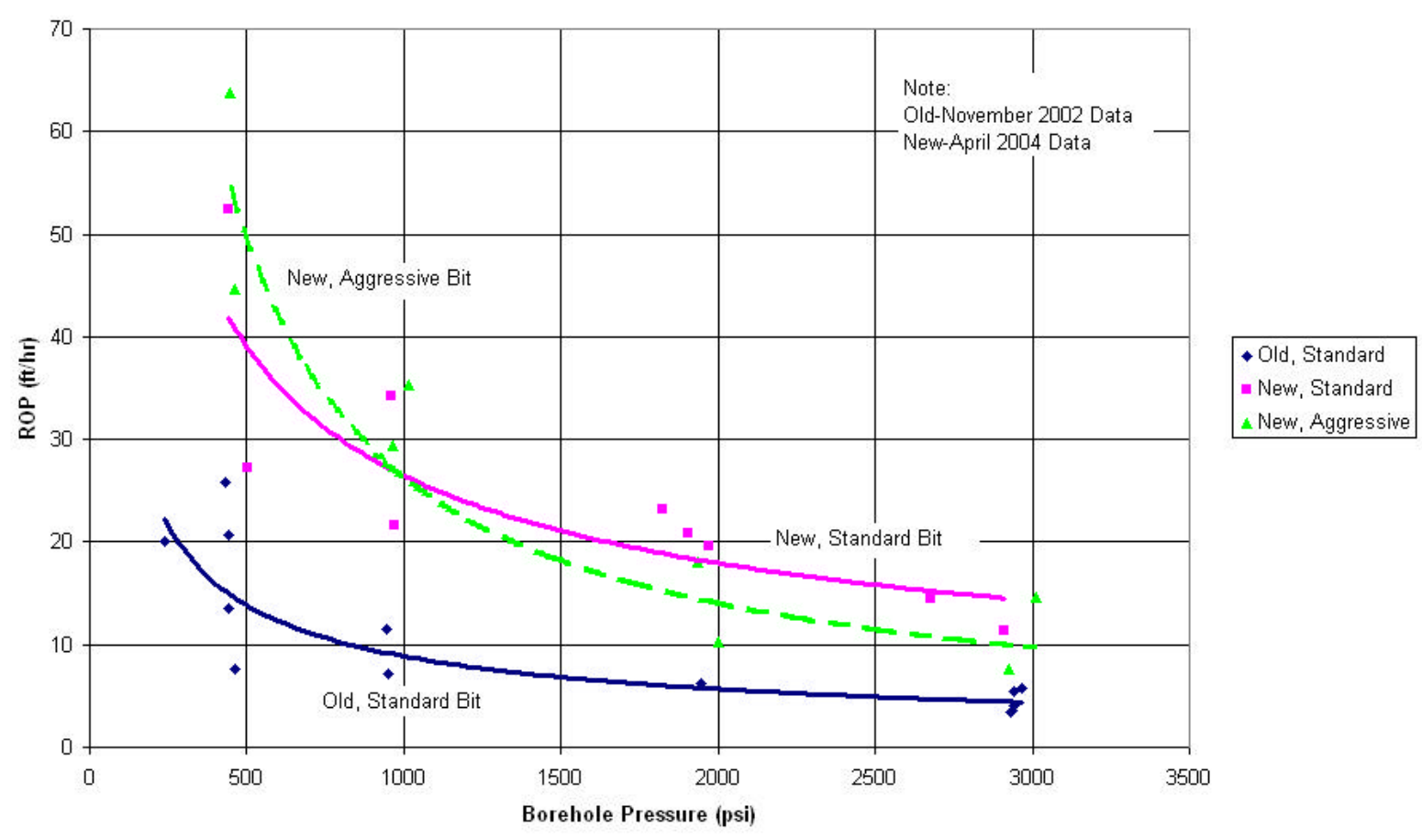

Figure 3 - Reference DOE Tests 20 and 22

Figure 3 Crab Orchard ss, 10 ppg WB with old hammer design and standard bit Crab Orchard ss, 10 ppg WB with new hammer design and standard bit Crab Orchard ss, 10 ppg WB with new hammer design and aggressive bit

As seen in Figure 3, in the Crab Orchard sandstone both the new hammer/standard bit and the new hammer/aggressive bit had very significant (2-3 times greater) ROP improvements over the old hammer/standard bit even at the higher borehole pressures. The ROP performance between the new hammer and standard and aggressive bit was similar.

The new hammer design failed during the end of the $10 \mathrm{ppg}$ water-base fluid testing. As a result, the testing of the Smith hammer was ended and no testing was performed with 15 ppg water-base fluid. The rock sample was saved and Smith indicated a desire to fix the problem and finish the testing around the same time the Novatek hammer is tested at TerraTek. This will be evaluated and considered depending upon budget constraints.

Analysis of Test 18 will be done for the next report as will Test 21. The Crab Orchard sandstone was rather tight making pore pressure control difficult. 
Representative photos of bottomhole patterns;

\section{Test 18}

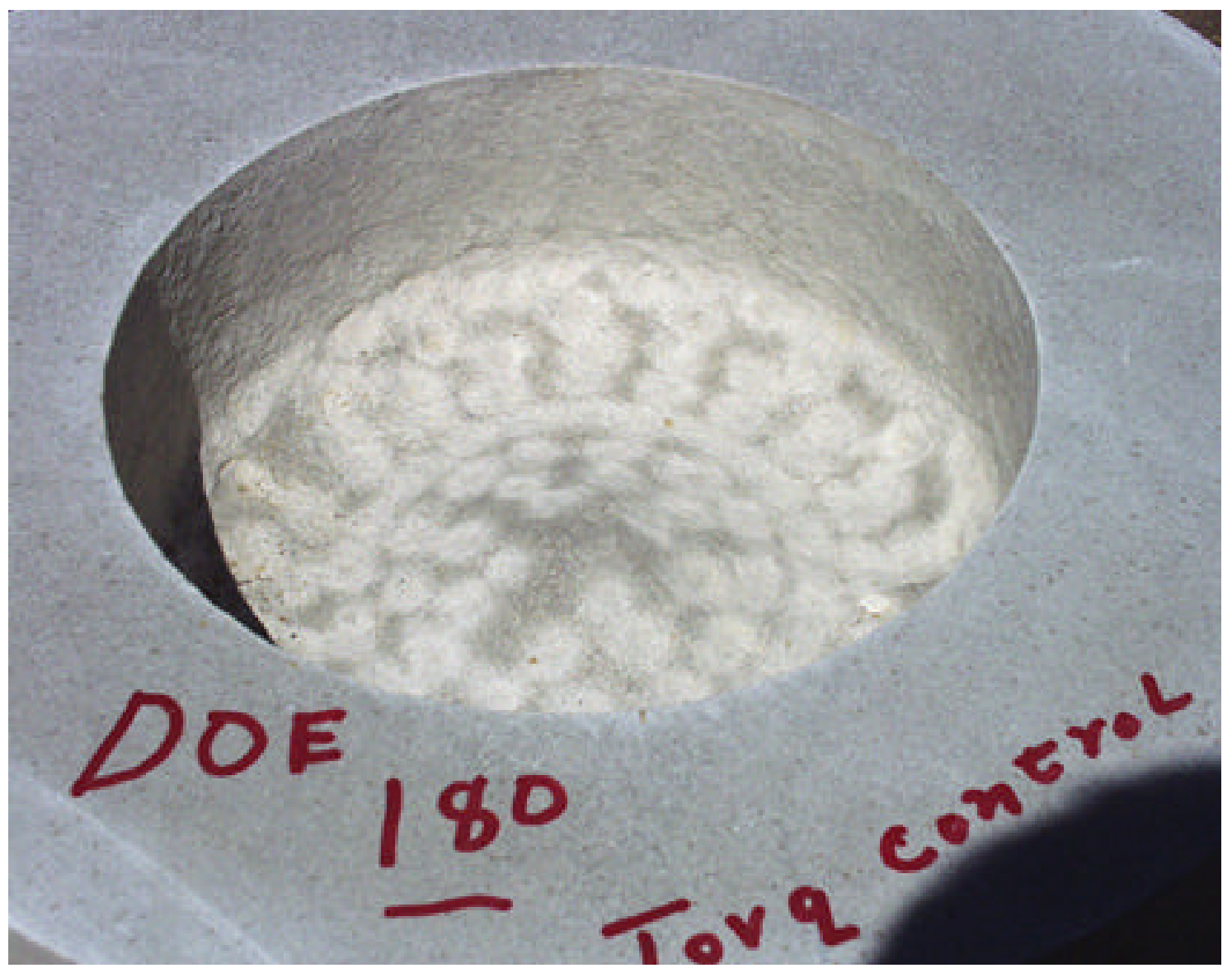




\section{Part of Test 20}

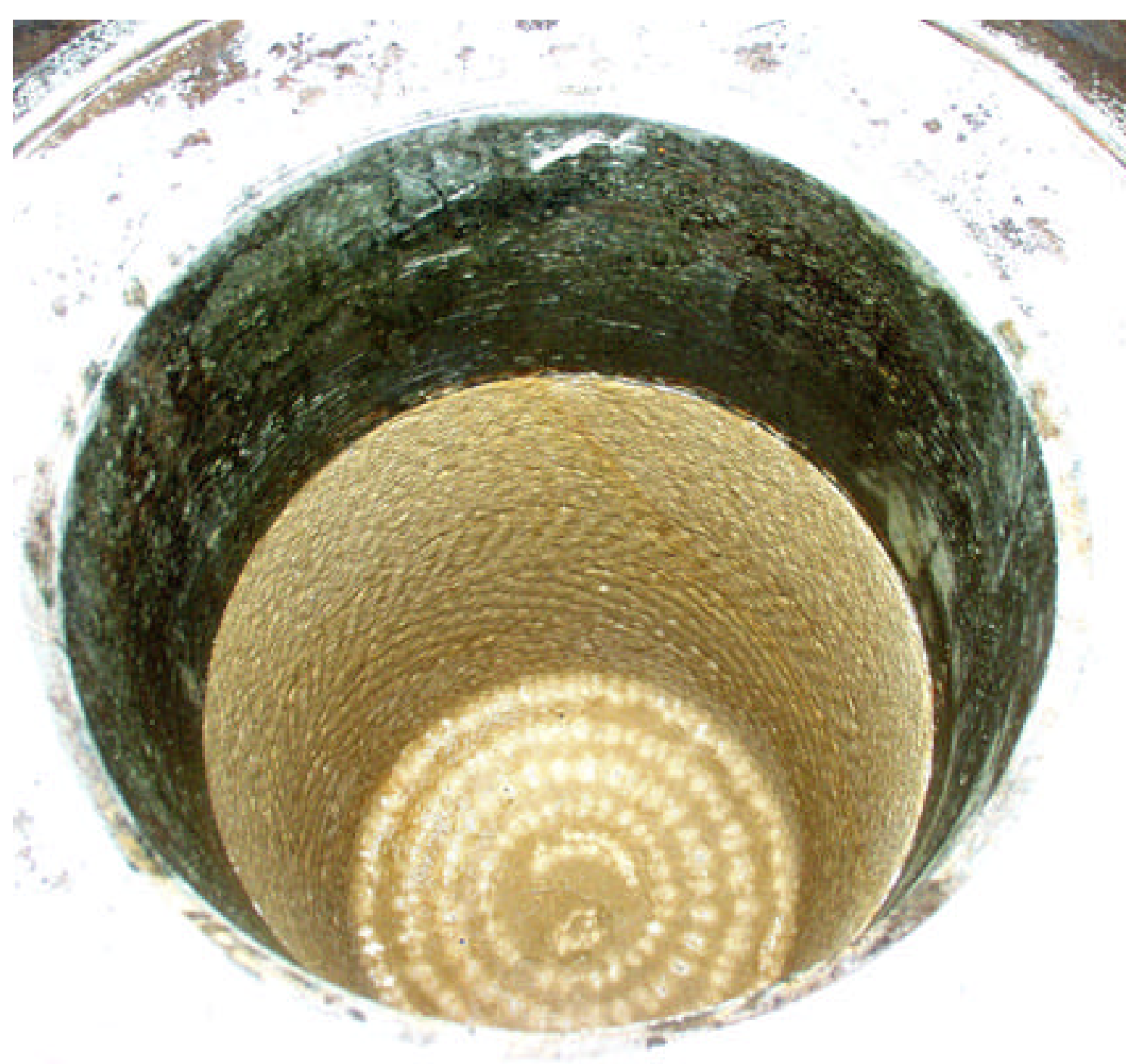


Part of Test 21

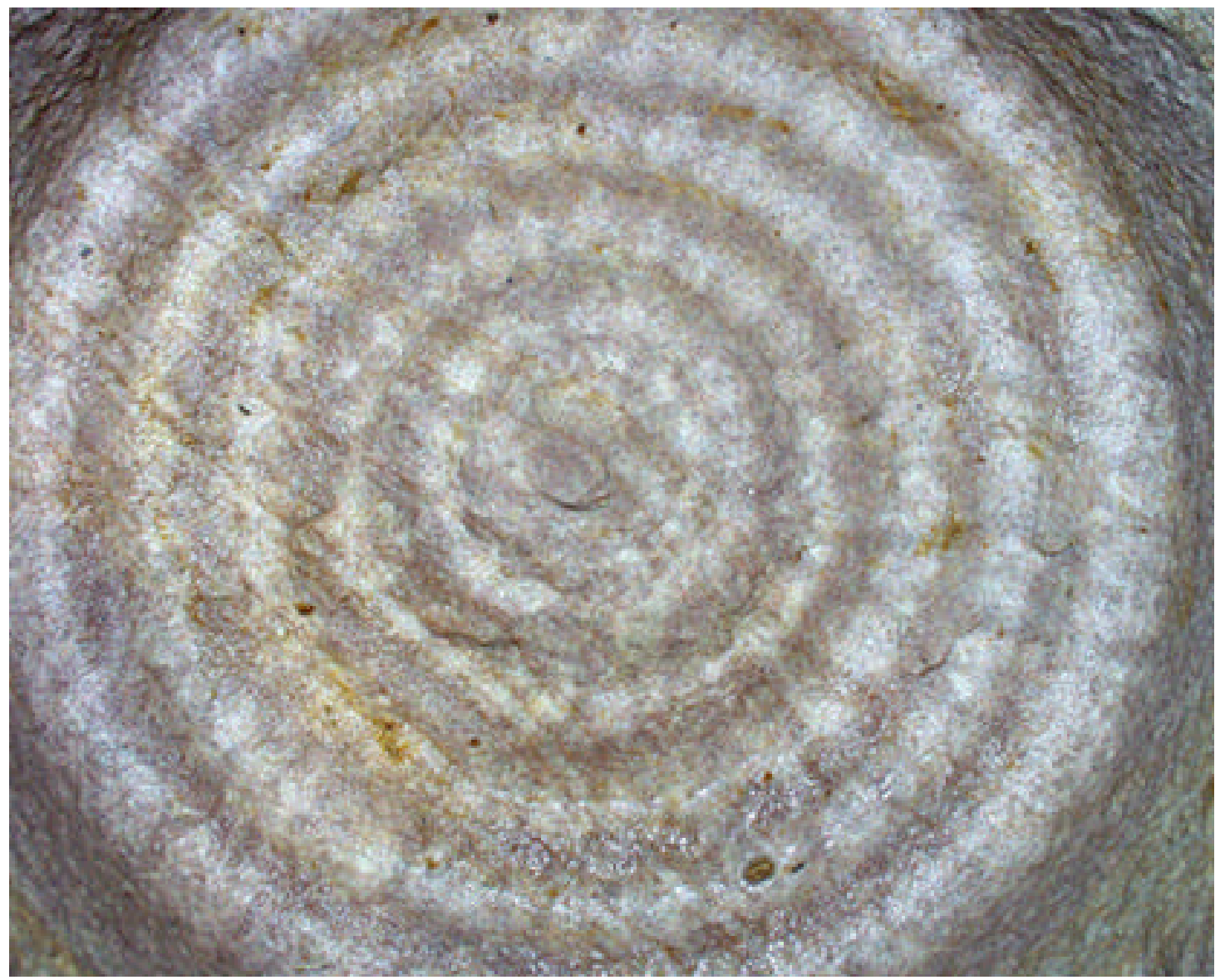




\section{Part of Test 22}

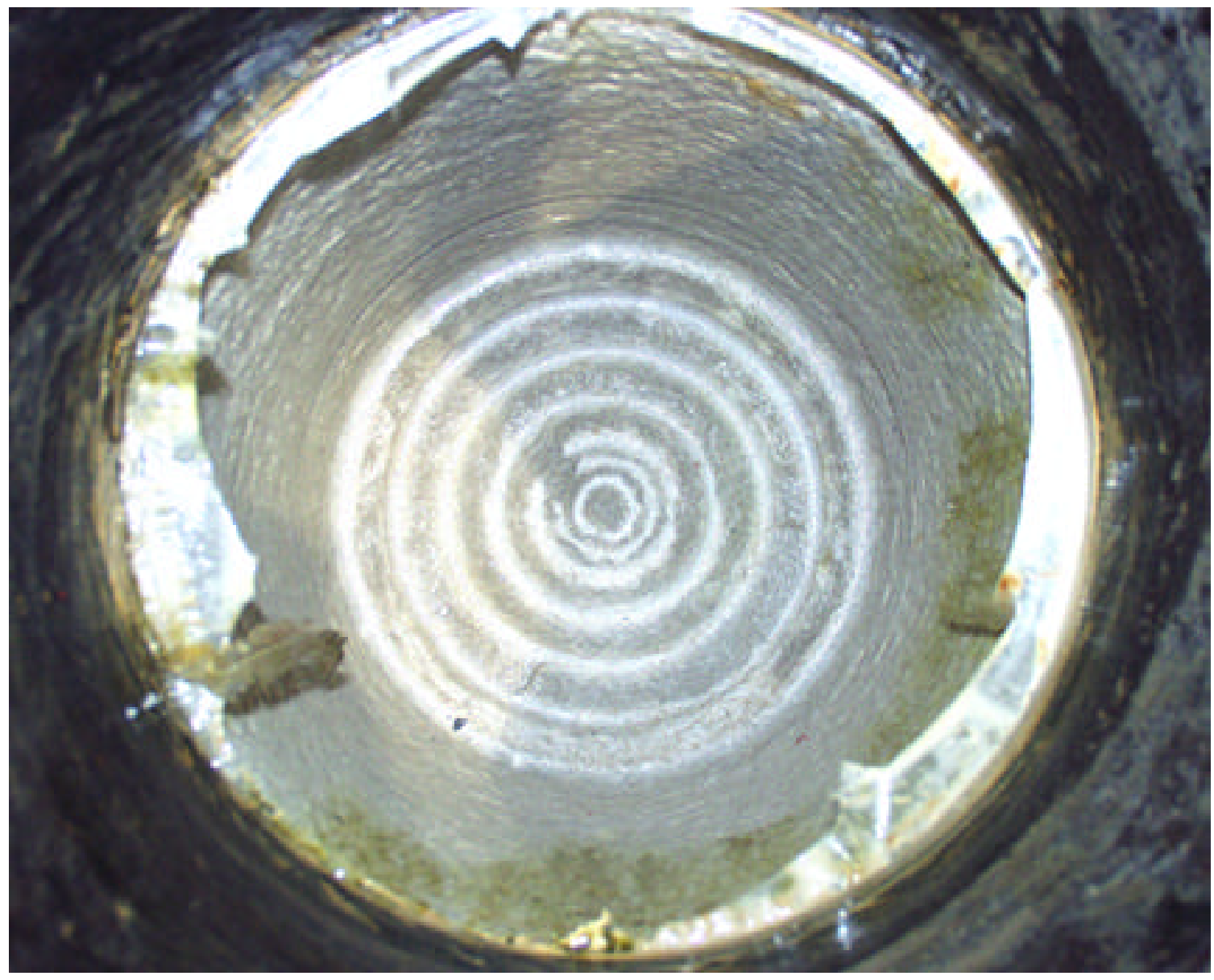




\section{Engineering for Novatek tool re-test}

$* * * * *$

To: John Fernandez, INTERNET:JFernandez@novatekonline.com

CC: Arnis Judzis, INTERNET:judzis@terratek.com

From: Alan Black, INTERNET:ablack@terratek.com

Date: 6/18/2004, 8:04 AM

Re: Re: Scissors Adaptor axial location

John,

I have been working on the layout for the Novatek hammer test and have attached an ACAD file and a Word file with a possible layout. Study it and then let's discuss. It looks like it will be feasible to have our stabilizer installed which will provide a place to mount the upper sealing device. The layout includes a concept for mounting the upper sealing unit. I believe it would need to be a split (two part) assembly to allow makeup of the API thread and then to bolt the two parts together after the thread is made up. This would require a way to support the upper sealing device prior to the make up. The slip ring would be mounted under the slip ring on a short (7") sub. As you can see, things are tight and getting the layout correct will be critical. Let's discuss after your review. $* * * * *$

To: John Fernandez, INTERNET:JFernandez@ novatekonline.com

CC: Arnis Judzis, INTERNET:judzis@terratek.com

From: Alan Black, INTERNET:ablack@terratek.com

Date: 6/23/2004, 11:40 AM

Re: Re: Scissors Adaptor axial location

John,

Concerning the gland dimensions for the seals. I believe the seals we use to seal the 7" diameter chrome shaft are probably larger than you would want to use for the leak seals, however, let me give you the information and then you can decide. The OD of the steel part that receives the seal is $8.750+.005 /-.000$ diameter. The seals we use are custom made by Economos 79 West 4500 South \#2 Murray, Utah 84107 281-3800 Brian is contact. They have both a concave and convex 90 degree V-grooves on opposite sides and the seal thickness and width are both about 0.8 " thick. The seals have some type of teflon fill and the material is identified at ECOFLON 2. We also have a bearing bronze ring on both sides of the seal with matching V-grooves. The OD and ID of the bearing bronze we have been using is $8.746 "$ and 7.127", respectively. It is critical to have the bearing bronze in contact with the chrome shaft and to keep any steel housing or support away from the chrome shaft. These seals typically have a very sharp sealing edge and so it is important to provide chamfers or other lead in's so the seals do not have to pass over sharp lips or edges that could cut into the sealing lip. The stack of bearing bronze ( 2 rings) and seal need to have some clearance in the mounting groove for thermal 
expansion. In other words, the seals are activated and seal by pressure and are not preloaded on the seal. We have an example of what the seal looks like we could loan you if that would help.

Concerning the mud outlet port and scissor arrangement, since the flow is small I now think we would be better off with a reinforced rubber hose and therefore suggest for now that we put a $3 / 4$ " or 1 " NPT female thread in your fixture for directing the flow out and then purchase a 5000 psi hose of the appropriate length to allow the rig movement. We should verify that we can get such a hose before committing to the tapped hole size. The ID of the hose should be large enough to avoid any possibility of erosion inside the hose. If there was such a thing as a urethane lined hose, we find urethane very good for minimizing erosion. The steel scissor idea would also work, but it is almost impossible to design in advance and would be more of a trial and error type arrangement. What do you think?

I will be here today and tomorrow, gone on Friday, in the office on Monday of next week and then will be gone until the Tuesday after the 4th holiday should you need to contact me before I leave. Thanks.

----- Original Message -----

From: John Fernandez

To: Alan Black

Sent: Monday, June 14, 2004 8:21 AM

Subject: Scissors Adaptor axial location

Alan,

I trust you had a good vacation at you son's graduation.

We are developing the adaptor for the upper exhaust at the moment. We would like to know the gland dimensions for the seal that is used at the bottom location to use it at the top adaptor. Additionally, what is the size of the scissors device connection?

We forgot to photocopy the drawing of the layout that was used in the previous test; could you fax it to 1-800-373-4707.

Thanks,

John Fernandez 

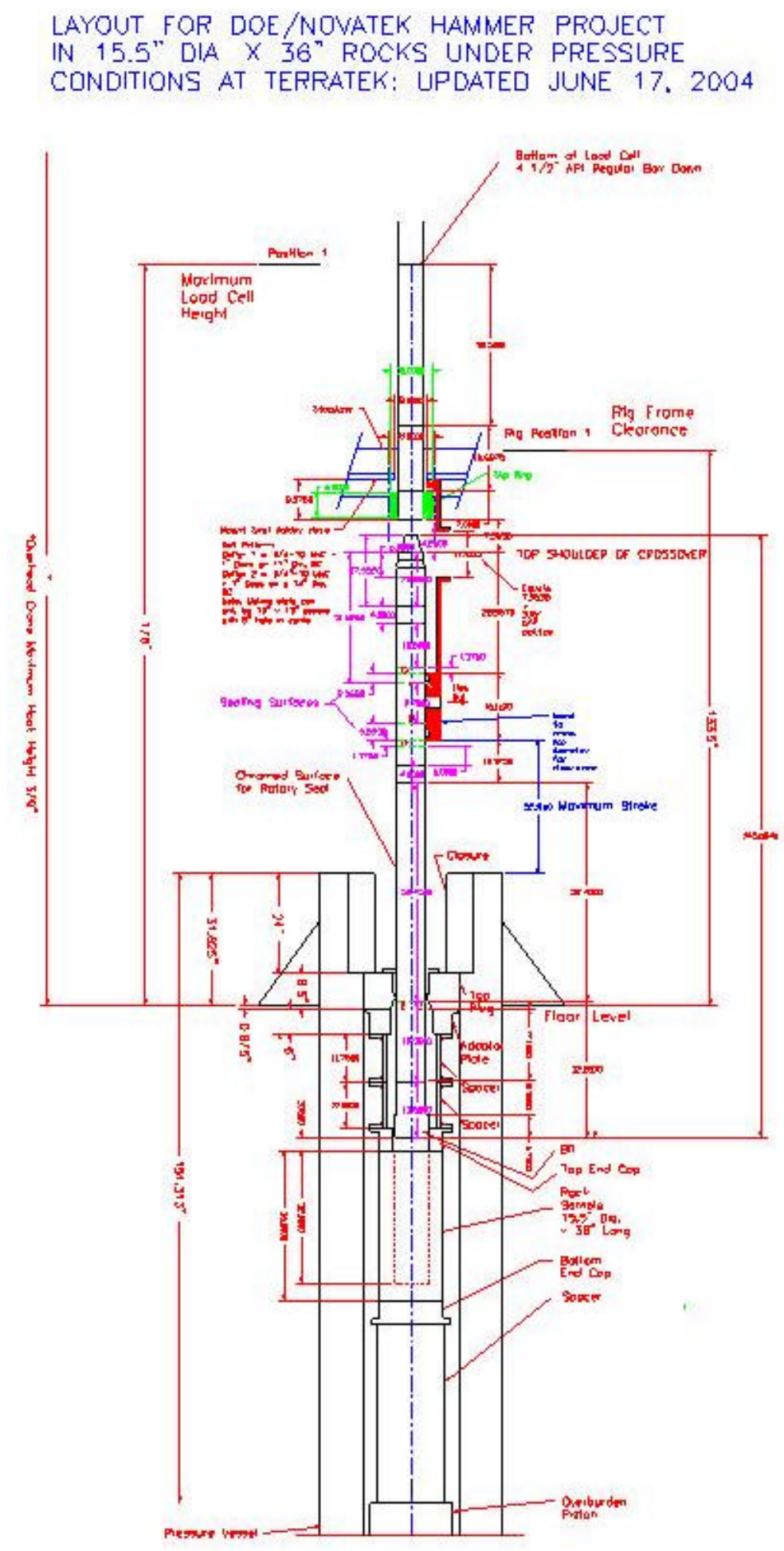


\section{$\underline{\text { Task } 8 \text { Impact Testing }}$}

After significant delays in instrumentation, the equipment was thoroughly tested with a number of trial checkout tests. The 3Q 2004 will report on the result of testing and analyses completed.

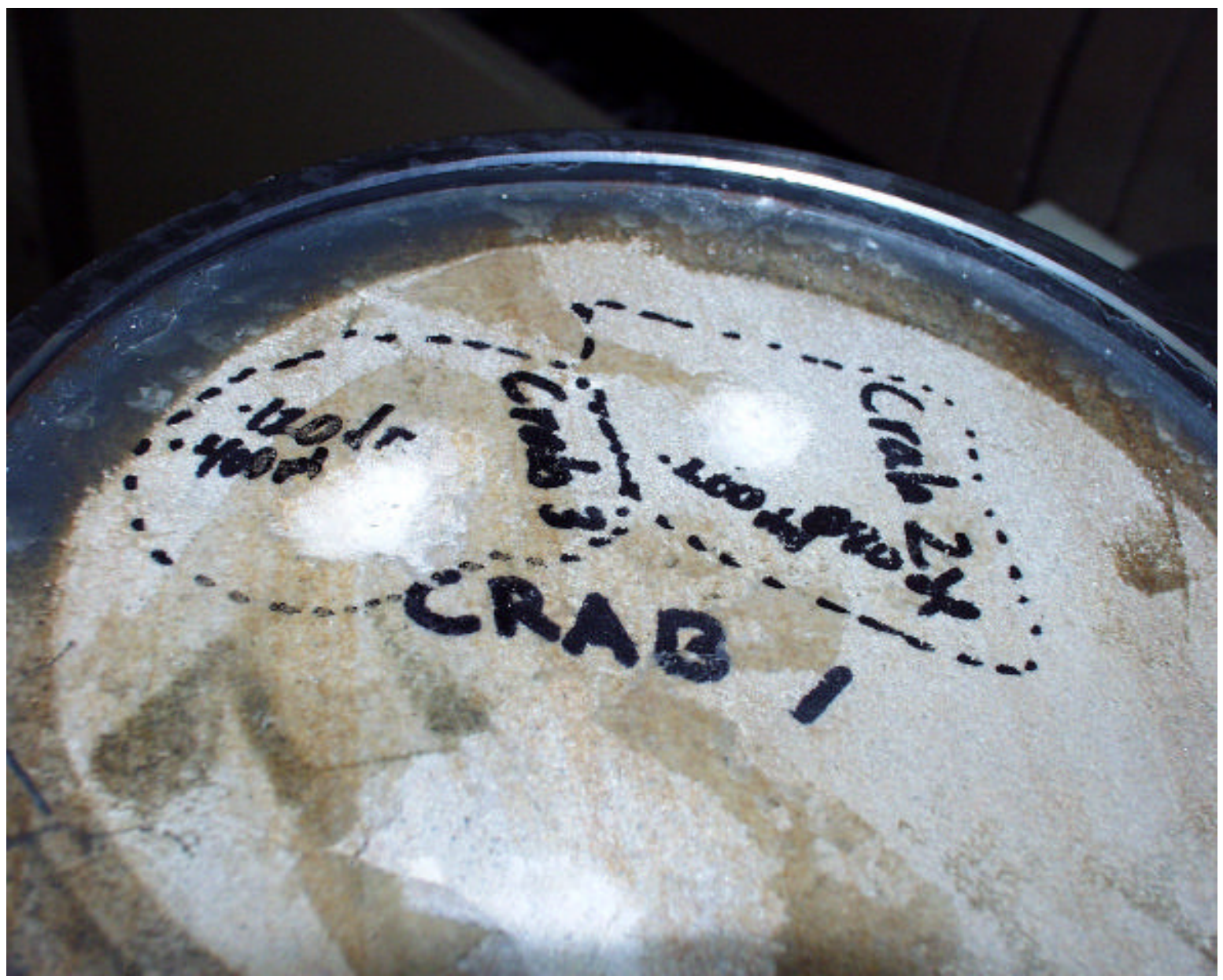




\section{Variables, Measurements and Calculations}

- Main Variables

- Rock Type

- Fluid Type

- Borehole Pressure

- Cutter Type

- Gas Pressure-Input Energy

- Piston Travel-Input Energy

- Gas Dump OrificeLoading Rate

- Others-Impact spacing, cutter contact vs gap
- Measurements

- Iload (strain gaged load cell on impact rod)

- Idispl (laser displacement transducer

- Borehole pressure, HGas, L-Gas

- Cutter indention

- Crater volume

- Calculations

- Energy (load vs displ)

- Specific energy 


\section{DOE Test Matrix}

- Rock Types

- Carthage marble

- Crab Orchard ss

- Mancos shale

- Fluid Density

- 10 ppg WB

- 15 ppg WB

- Borehole Pressure

- 3000 psi

- Cutters

- Conical

- Spherical
- Input Velocity and Travel of Gas Piston

- 350, 500, 500 (repeat) and $600 \mathrm{in} / \mathrm{sec}(0.25 "$ $0.5 ", 0 . .5$ " (repeat) and $0.75 ")$

- Number of Tests

- 3 rocks x 2 fluid densities $x 2$ cutters $x 3$ input energies +1 repeat $=48$ test 


\section{Checkout Test Results}

- Crab2, Crab Orchard, Conical Cutter, 3000 psi Borehole, 450 psi Gas Pressure, 0.75" Piston Travel and 0.03 " to Bottom Piston

- Results

- 0.08" Indention

$-0.0122 \mathrm{cu}$. in. Volume

- $40.5 \mathrm{ft}-\mathrm{lbs}$ ( 54.9

Joules) Energy

- 3318 ft-lb/cu. In. Spec. Energy
- Crab3, Crab Orchard, Conical Cutter, 0 psi Borehole, 450 psi Gas Pressure, 0.75" Piston Travel, 0.04" to Bottom Piston

- Results

- 0.12 Indention

- 0.0244 cu. In. Volume

- 57.8 ft-lbs (78.3 Joules Energy

- $2369 \mathrm{ft}-\mathrm{lb} / \mathrm{cu}$. in. Specific Energy 


\section{Q3}

\section{Performance Plots for Smith International's Optimized Fluid Hammer Tests}

DOE-Smith Hammer Comparison Between Old and New Hammer with Standard Bit and Rotary Baseline Bit with Carthage Marble and $9.0 \mathrm{ppg}$ Brine

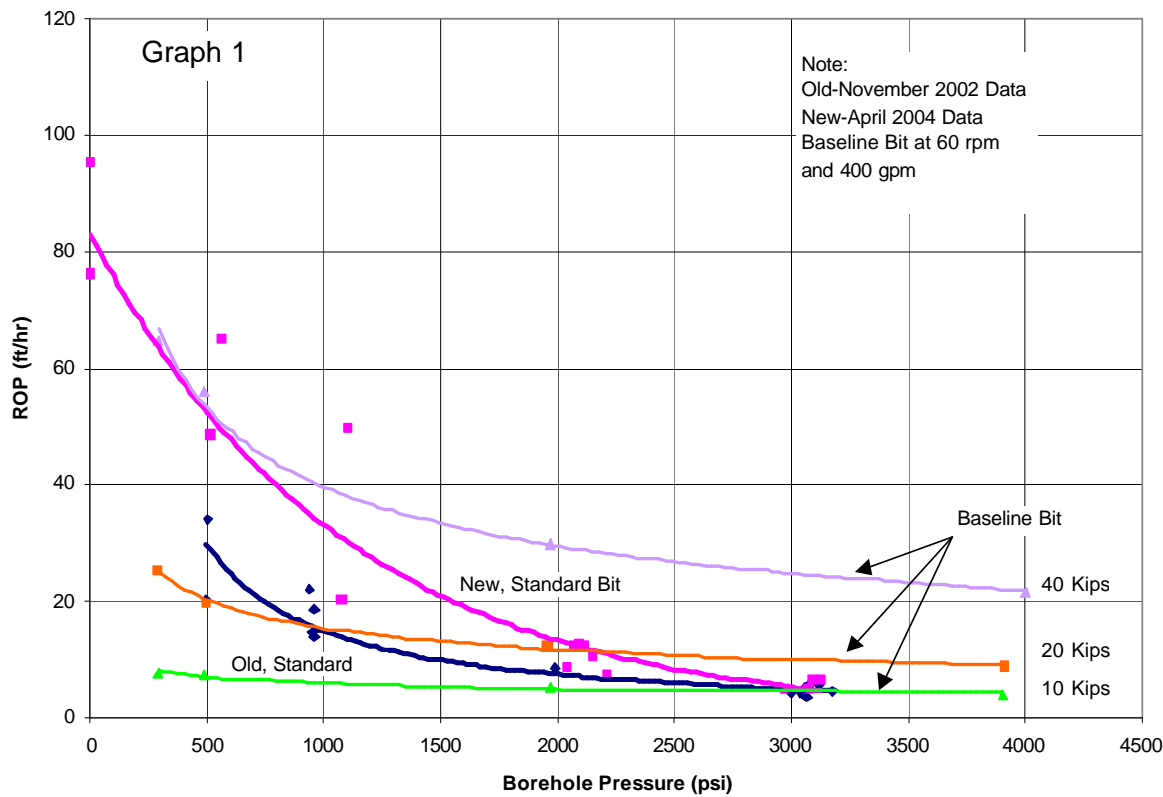

- Old, Standard

- New, Standard $\triangle$ Baseline, 10 Kips

- Baseline, $20 \mathrm{Kips}$ $\triangle$ Baseline, 40 Kips

DOE-Smith Hammer Comparison Between Old and New Hamme with Stanard and Aggressive Bit and Rotary Baseline Bit with Carthage Marble and 10 ppg Water-base

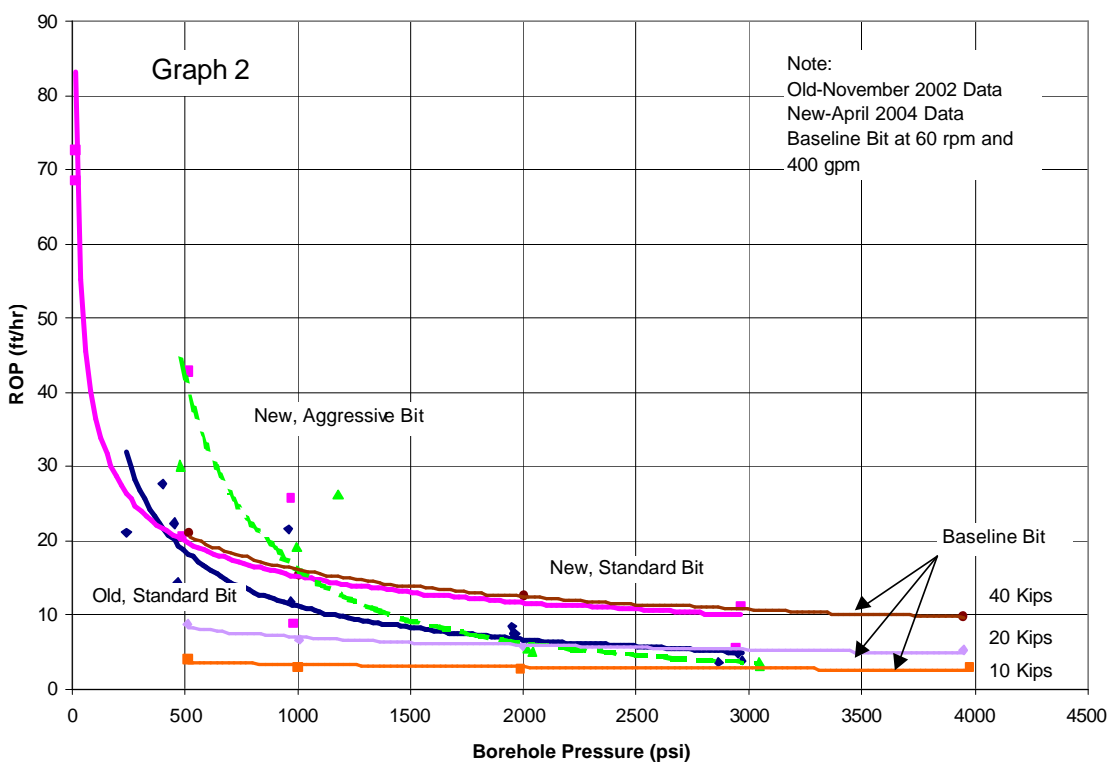


DOE-Smith Hammer Comparison Between Old and New Hammer with Standard and Aggressive Bit and Rotary Baseline Bit with Crab Orchard Sandstone and 10 ppg Water-base

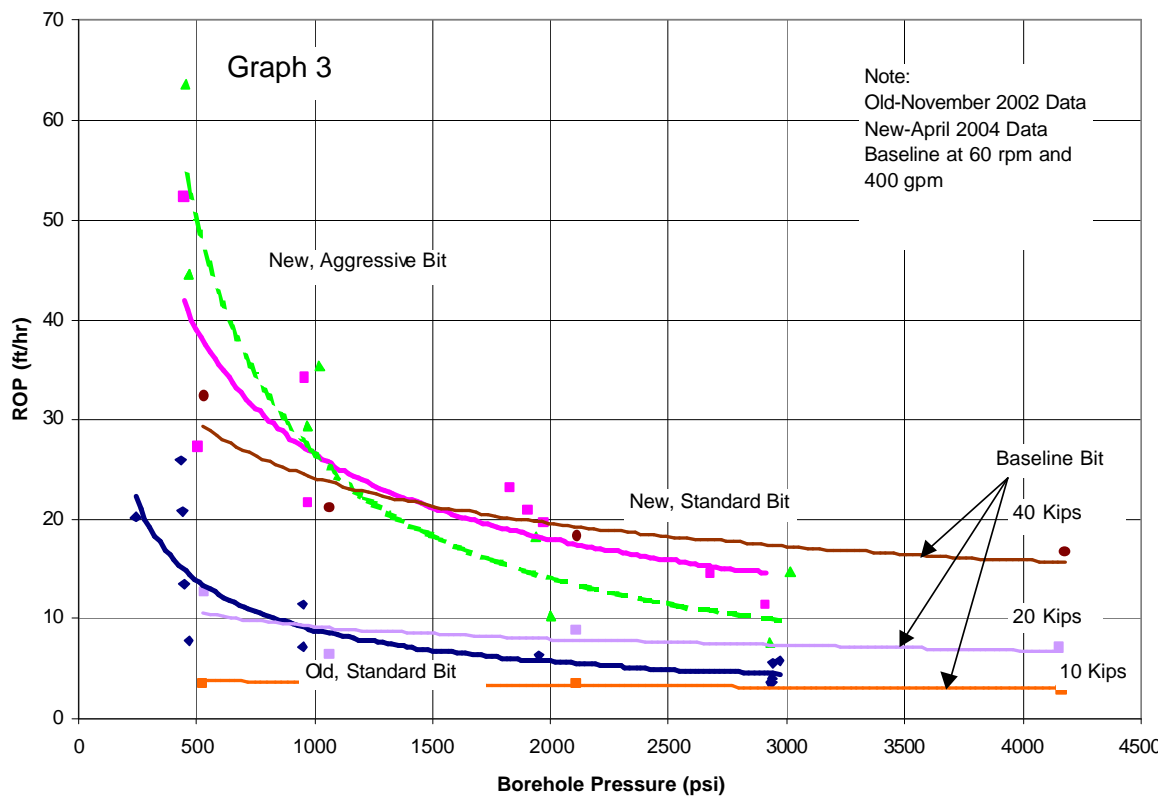

\section{Task 8 Impact Testing}

Example impacts in Crab Orchard sandstone appear below -

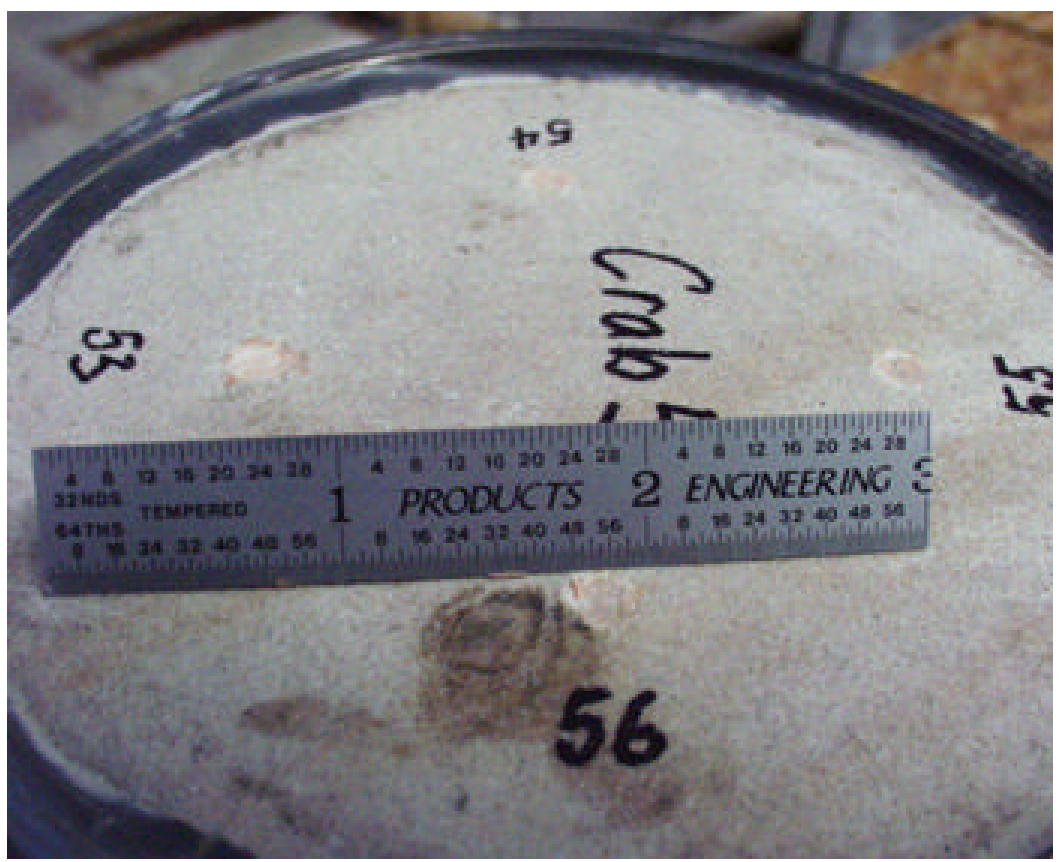


$\underline{\text { Review meeting for Industry Advisors (ReedHycalog, Hughes Christensen) }}$

\title{
TerraTek Cutter Impact Testing
}

\author{
Update \\ August 10, 2004
}

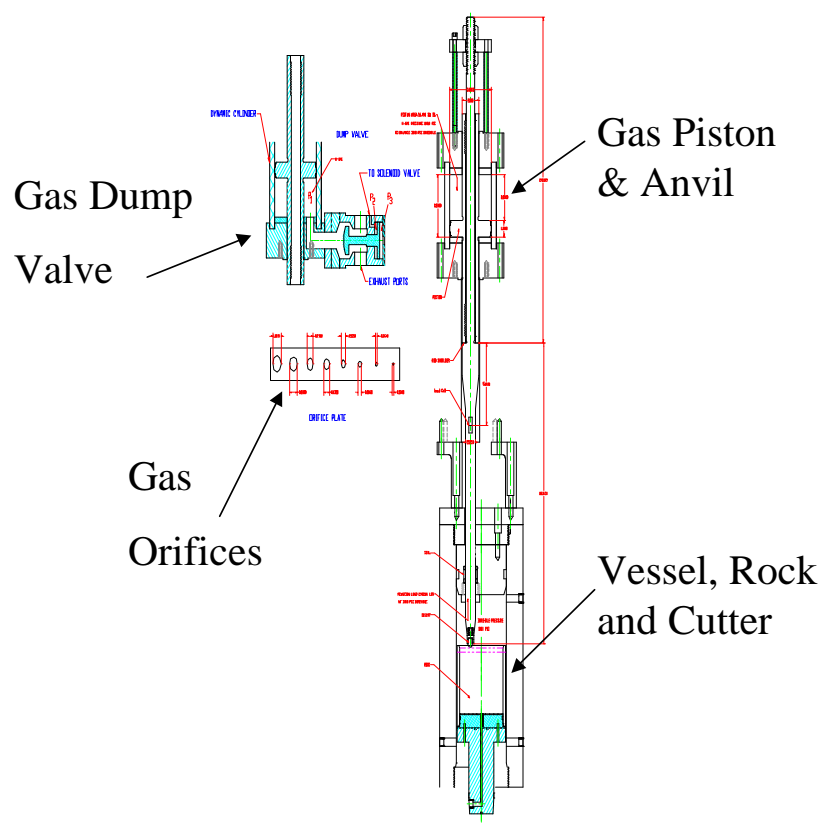




\section{Variables, Measurements and Calculations}

- Main Variables

- Rock Type

- Fluid Type

- Borehole Pressure

- Cutter Type

- Gas Pressure-Input Energy

- Piston Travel-Input Energy

- Gas Dump OrificeLoading Rate

- Others-Impact spacing, cutter contact vs gap
- Measurements

- Iload (strain gaged load cell on impact rod)

- Idispl (laser displacement transducer

- Borehole pressure, HGas, L-Gas

- Cutter indention

- Crater volume

- Calculations

- Energy (load vs displ)

- Specific energy

\section{DOE Test Matrix}

- Rock Types

- Carthage marble

- Crab Orchard ss

- Mancos shale

- Fluid Density

- 10 ppg WB

- 15 ppg WB

- Borehole Pressure

- 3000 psi

- Cutters

- Conical

- Spherical
- Input Velocity and Travel of Gas Piston

- 350, 500, 500 (repeat) and $600 \mathrm{in} / \mathrm{sec}(0.25 \%$, $0.5 ", 0 . .5$ " (repeat) and 0.75 ")

- Number of Tests

- 3 rocks x 2 fluid densities $\mathrm{x} 2$ cutters $\mathrm{x} 3$ input energies +1 repeat $=48$ test 


\section{Checkout Test Results}

- Crab2, Crab Orchard, Conical Cutter, 3000 psi Borehole, 450 psi Gas Pressure, 0.75" Piston Travel and 0.03" to Bottom Piston

- Results

- 0.08" Indention

- $0.0122 \mathrm{cu}$. in. Volume

- $40.5 \mathrm{ft}-\mathrm{lbs}$ ( 54.9 Joules) Energy

- $3318 \mathrm{ft}-\mathrm{lb} / \mathrm{cu}$. In. Spec. Energy
- Crab3, Crab Orchard, Conical Cutter, 0 psi

Borehole, 450 psi Gas

Pressure, 0.75" Piston

Travel, 0.04" to

Bottom Piston

- Results

- 0.12 Indention

- 0.0244 cu. In. Volume

- 57.8 ft-lbs (78.3 Joules Energy

- $2369 \mathrm{ft}-\mathrm{lb} / \mathrm{cu}$. in. Specific Energy

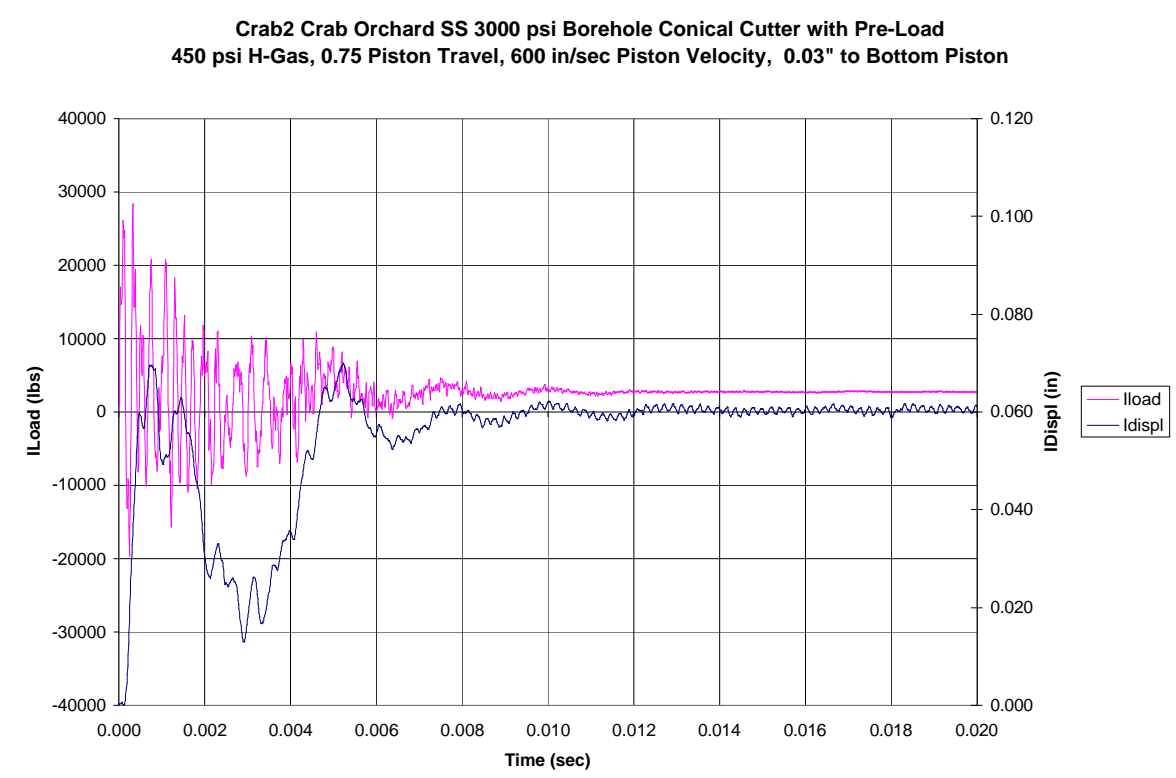


Crab2 Crab Orchard SS 3000 psi Borehole Conical Cutter with Pre-Load 450 psi H-Gas, 0.75 Piston Travel, 600 in/sec Piston Velocity, 0.03 " to Bottom Piston

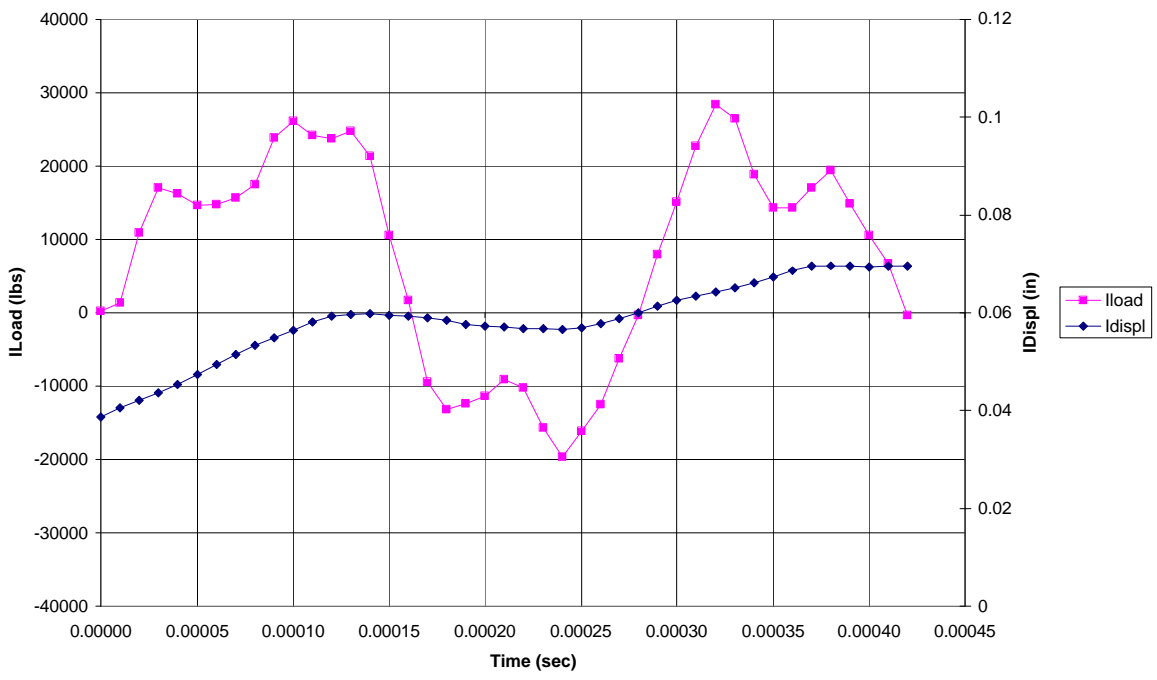

Crab2 Crab Orchard SS 3000 psi Borehole Conical Cutter with Pre-Load 450 psi H-Gas, 0.75 Piston Travel, 600 in/sec Piston Velocity, 0.03 " to Bottom Piston

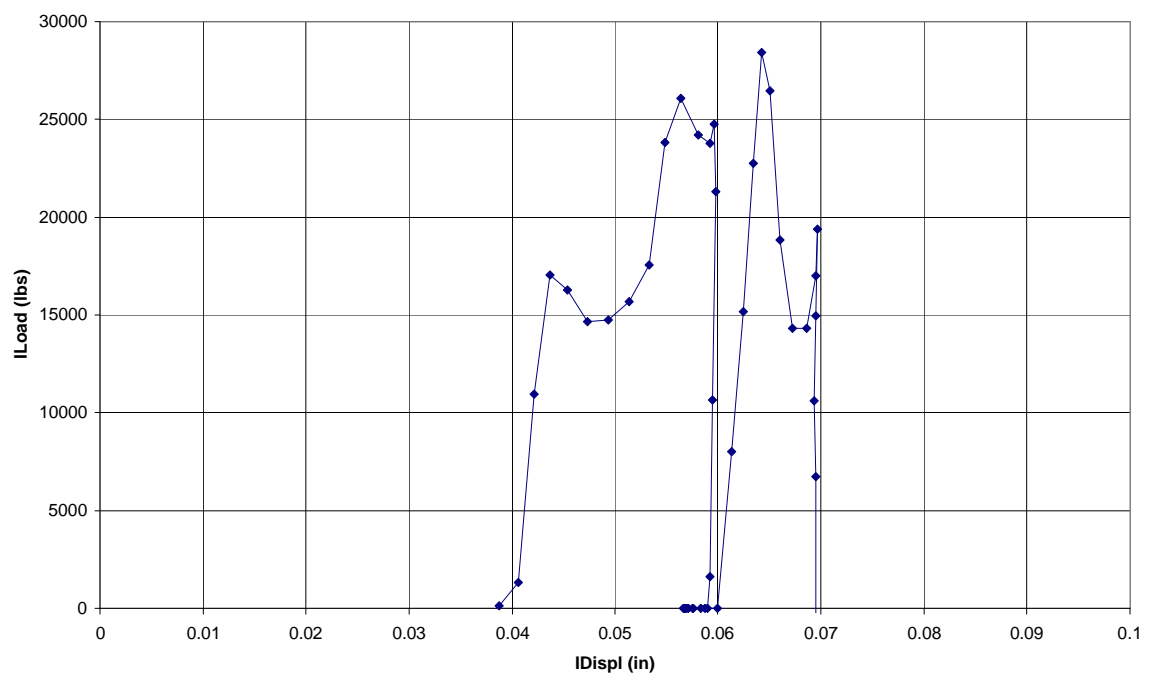


Crab3 Crab Orchard SS 0 psi Borehole Pressure Conical Cutter with Pre-Load 450 psi H-Gas, 0.75" Piston Gap, 600 in/sec Piston Velocity, 0.04" to Bottom Piston

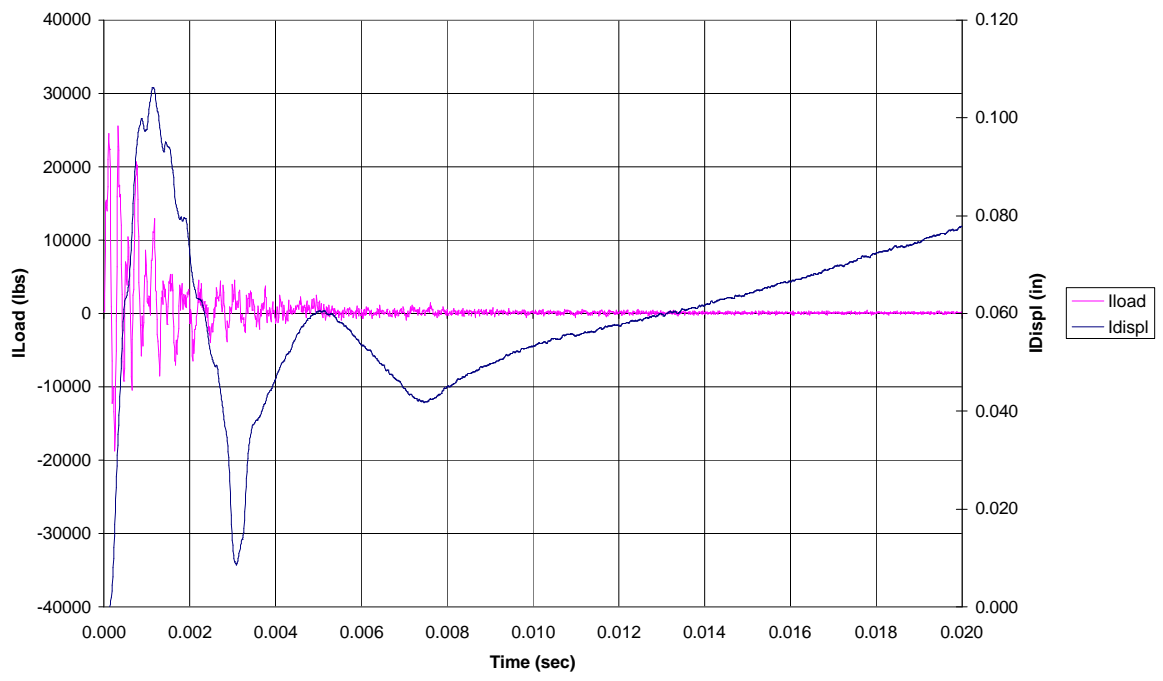

Crab3 Crab Orchard SS 0 psi Borehole Pressure Conical Cutter with Pre-Load 450 psi H-Gas, 0.75" Piston Gap, 600 in/sec Piston Velocity, 0.04" to Bottom Piston

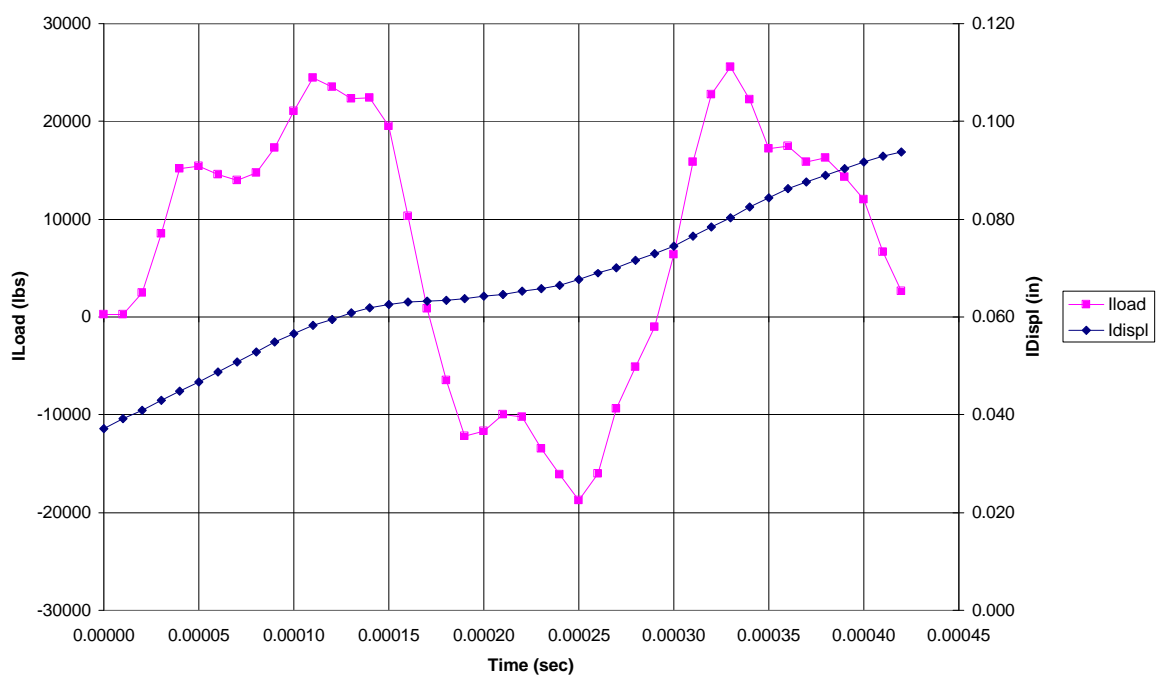


Crab3 Crab Orchard SS 0 psi Borehole Pressure Conical Cutter with Pre-Load 450 psi H-Gas, 0.75" Piston Gap, 600 in/sec Piston Velocity, 0.04" to Bottom Piston
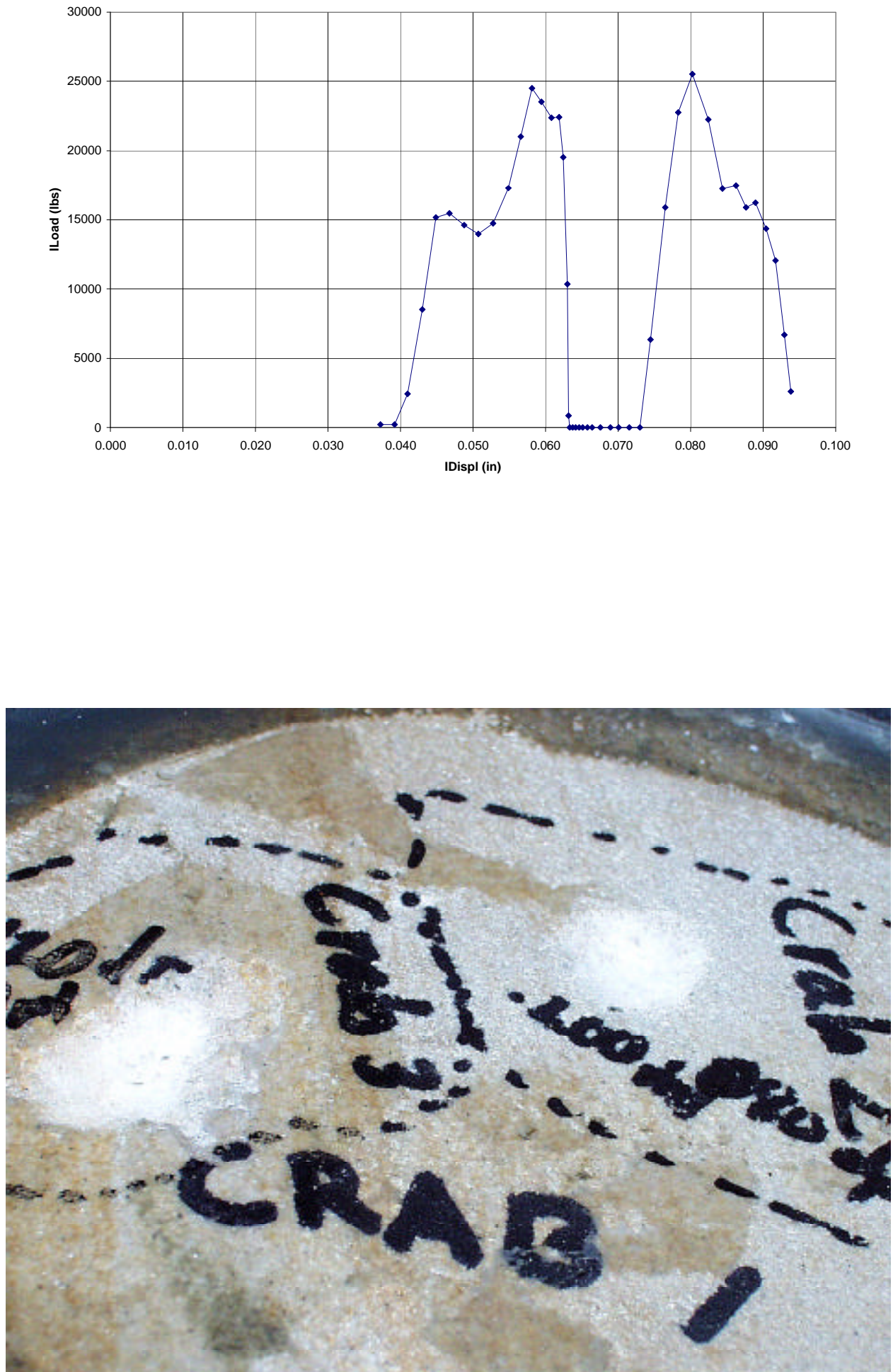
Carth3 Static Carthage Marble $\mathbf{3 0 0 0}$ psi Borehole Conical Cutter

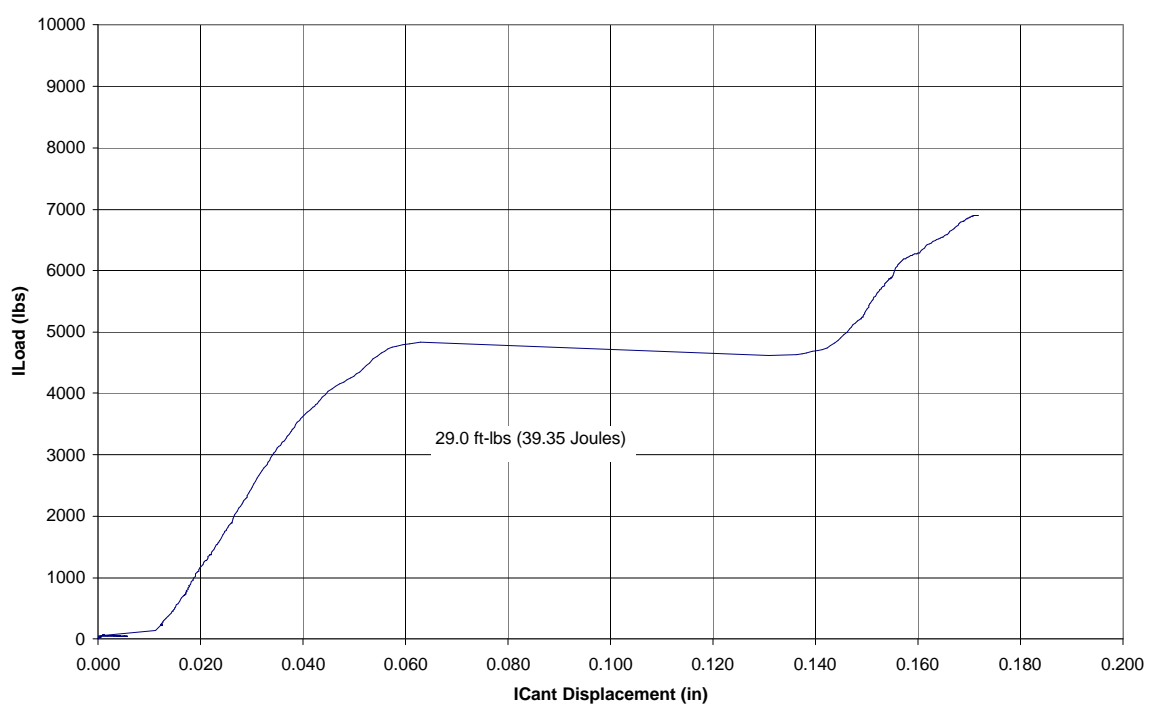

Crab1 Static Crab Orchard Sandstone 3000 psi Borehole Conical Cutter

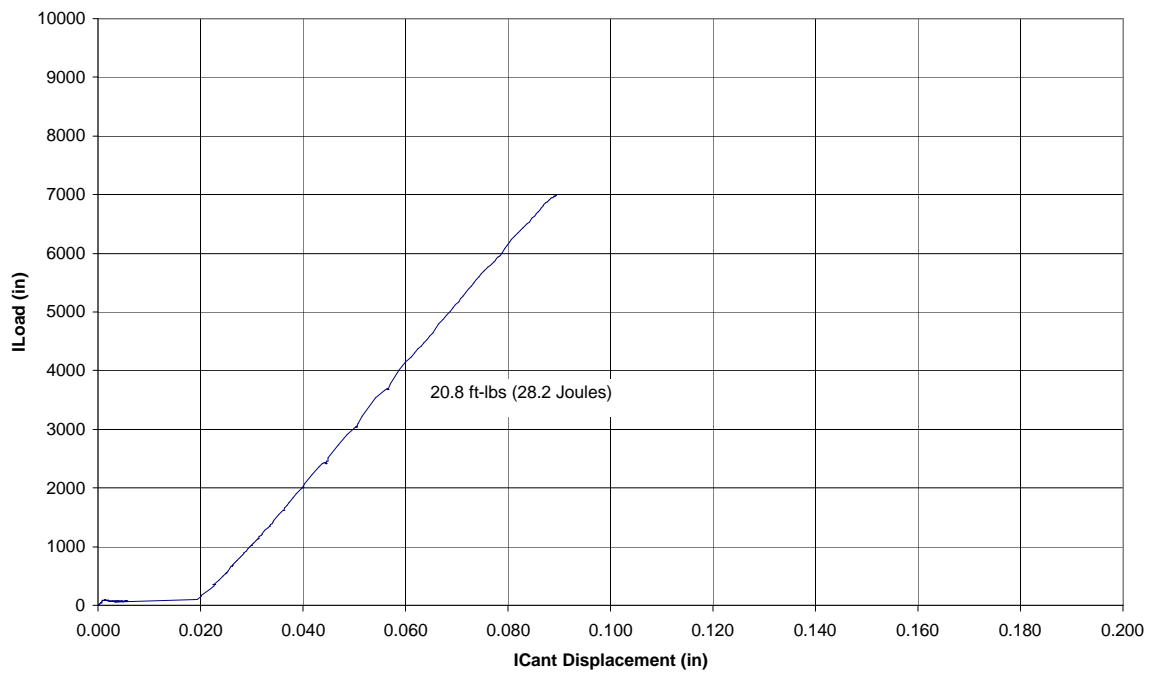




\title{
Q4
}

November 17, 2004 Review Meeting 'Fundamental Research on Percussion Drilling
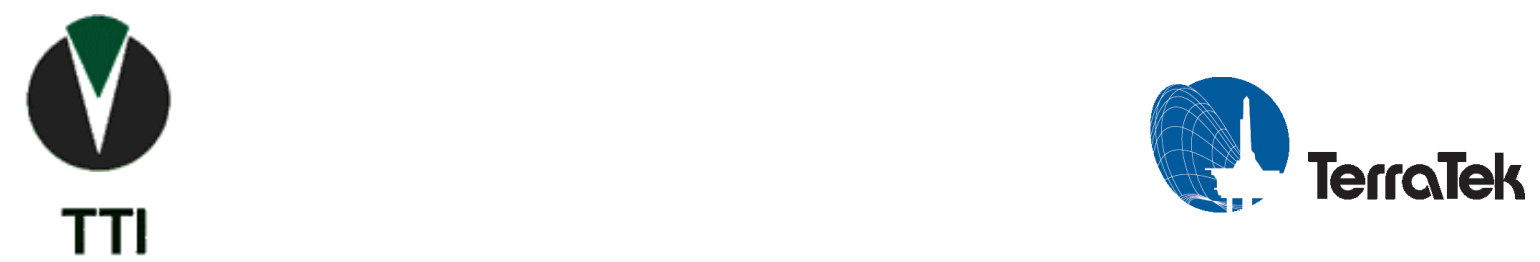

\section{Advanced Drilling Technology Project Workshop}

\author{
Wednesday, November 17, 2004 \\ Houston Marriott Greenspoint Hotel \\ 255 North Sam Houston Parkway East
}

Agenda

09.00 hrs Arrivals and Introductions

09.15 hrs Workshop Objectives and Context

Mike Bruno, Terralog

Arnis Judzis, TerraTek

Tim Grant \& John Rogers, Department of Energy

09.45 hrs Project Briefing 'Fundamental Research on Percussion Drilling', a cooperative research program funded in part by the DOE

(Mike Bruno, Terralog)

10.15 hrs $\quad$ Advanced Drilling Simulation (Dr. Gang Han, Terralog)

10.45 hrs Break

$11.00 \mathrm{hrs} \quad$ Full-scale performance and validation testing of fluid hammers - referencing 'Optimization of Mud Hammer Drilling Performance', a cooperative research program funded in part by the DOE

(Alan Black, TerraTek)

11.30 hrs Cutter Impact / High Rate Loading Testing - Advanced testing techniques to address fundamental issues of rock breakage in simulated downhole environments

(Sidney Green, TerraTek)

Working Lunch

Roundtable Discussion - Industry feedback and operational challenges requiring Advanced Drilling Simulation - Operators \& service companies

$13.00 \mathrm{hrs} \quad$ Industry perspective from a developer of fluid hammers - the need for performance testing and equipment optimization

(David Pixton, Novatek / IntelliServ) 
13.30 hrs Validation Testing Discussion - Large-scale fluid hammer testing, drilling performance evaluation under simulated downhole environments, and advanced impact testing techniques to validate drilling modeling.

14.30 hrs Closure and adjourn

\begin{tabular}{|c|c|c|c|c|c|}
\hline & Name & Company & Phoae Numaber & E.Mail & Comeients \\
\hline & Ron Bland & Baker Hughes INTEQ & (P13) E26-42EB & ren blandiginten.com & \\
\hline & Paul Luis & BP Exploration & 441932.730916 & paul.lurisghtp.com & Ponding \\
\hline & Gary Calins & Conocophilips & [281] $293-6969$ & 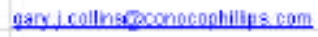 & \\
\hline & Eidk Sowb & DOE & & erick satbinetl doe ger & \\
\hline & Jamia Broun & DOE & & jamie.broun (a) netl doe gov & \\
\hline & Johm Rogers & DOE & (504) $208-4860$ & jahn, ragersoginat dae gay & \\
\hline & Tim Grant & DOE & (412] $38 E-5457$ & tim grartionell dee urr & \\
\hline & Stuen Kallser & Exxanktobil & D13) 431-7160 & tu kalievexuanmobi.cam & \\
\hline & Gary Weaner & HallountoriSecurty DES & {$[281] 505-2568$} & gag mesuarghalibuton com & \\
\hline 10 & Roff Pessier & Hughes Christensen & [R81] $363-5651$ & odf pessienethugheschris com & \\
\hline 11 & Bnan Ragers & M-I SWACO & (281) $561-1410$ & brogem Qmisweco com & \\
\hline 12 & Mario Zamora & MH SWACO & {$[281] 561-1331$} & mzamoragamisuacecoum & \\
\hline 13 & Sanjit Roy & MH SWACO & & scogemisuracog com & \\
\hline 14 & Ther Frotiand & M-I SWACO & & thoitendegmiewaco.com & \\
\hline 15 & David Pixtan or allernale & Novatek & {$[801] 374-2755$} & inixtorointellisen nes & Nowsrek will speak \\
\hline 16 & Adrian Snell & ReedHycalog & (281) 924-5684 & Adtisn SnellQRered Hyralog com & \\
\hline 17 & Marcel Boucher & ReadHycalog & (D13) 5245458 & \multicolumn{2}{|l|}{ 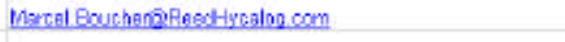 } \\
\hline 18 & Veronks Vajdova & Reeditycalog & & \multicolumn{2}{|l|}{ Veranika veldousarareadHucalon can } \\
\hline 19 & Chris Hakulin & Shell Rochy Moutain Praduction LLC. & (503) $306-7563$ & c.bakuingishellcan & \\
\hline 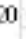 & Lance Underwaod & Smith Imemational & (281) $233-5892$ & lunderwoodsesmith com & \\
\hline 21 & Probhakarsn Centala. & Smith Intemational & & teartalingemith com & \\
\hline 22 & Shantanu Suradi & Srrith Iniemstional & [281] 2335220 & ssusdigsmithcam & \\
\hline 23 & Alan Black & TamaTak & (E01) $584-2441$ & atlacketerratek com & spester on hammer testing \\
\hline 24 & Amis Judzis & Tenstek & [B01] $684-2483$ & judziezcengtek,cain & Wransthop co-hasi \\
\hline 25 & Sidney Green & TerraTek & (1501) 584-2401 & sgreenetematek com & spesket on impact testing \\
\hline 26 & Gang Han & TII & & ghargiteraiog com & apestier \\
\hline 27 & Mike Buno & $\pi$ & [65) $306-8480$ & metaninopotarslog,com & spesker \\
\hline
\end{tabular}

Only some of the presentations are available as part of the report. 

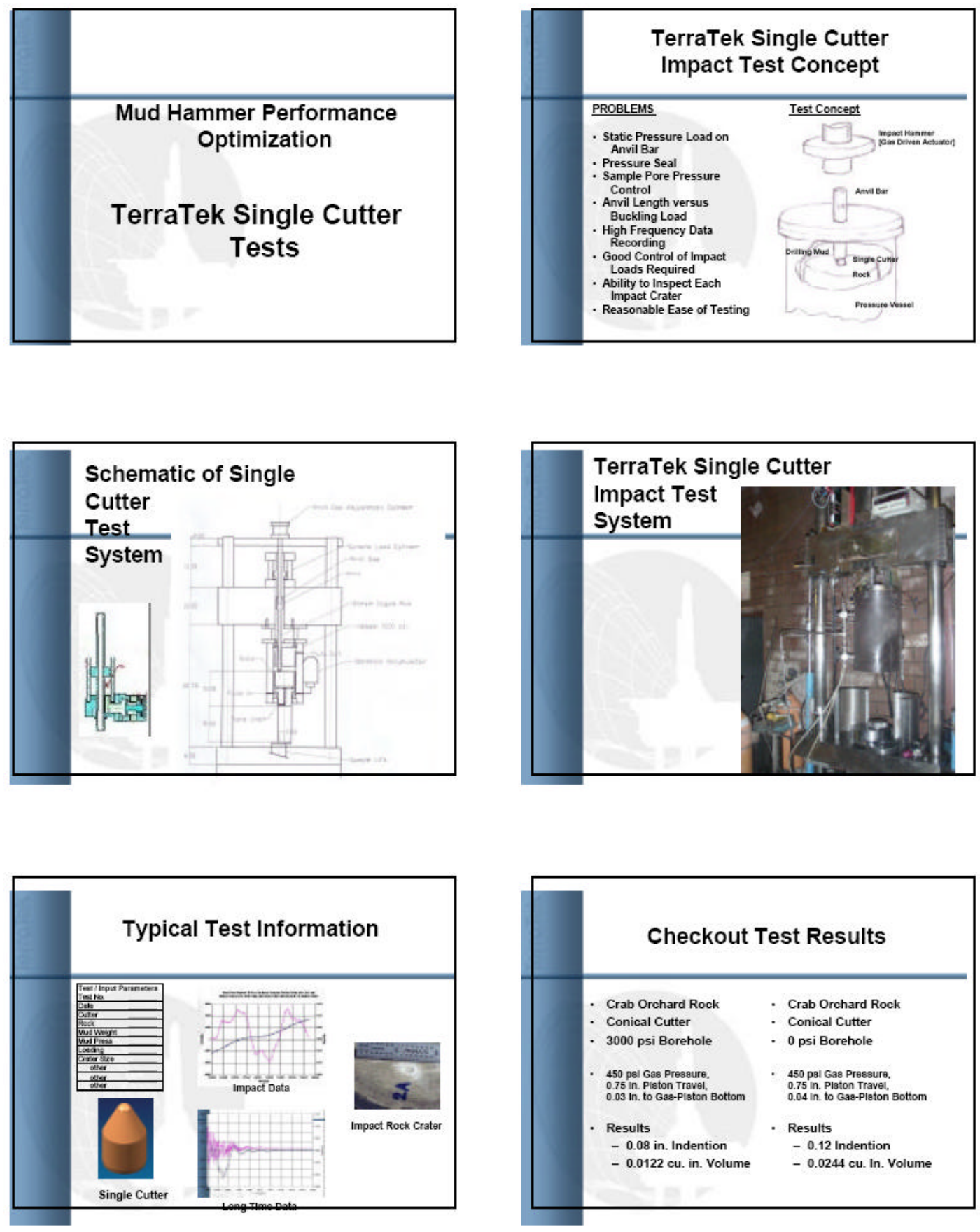

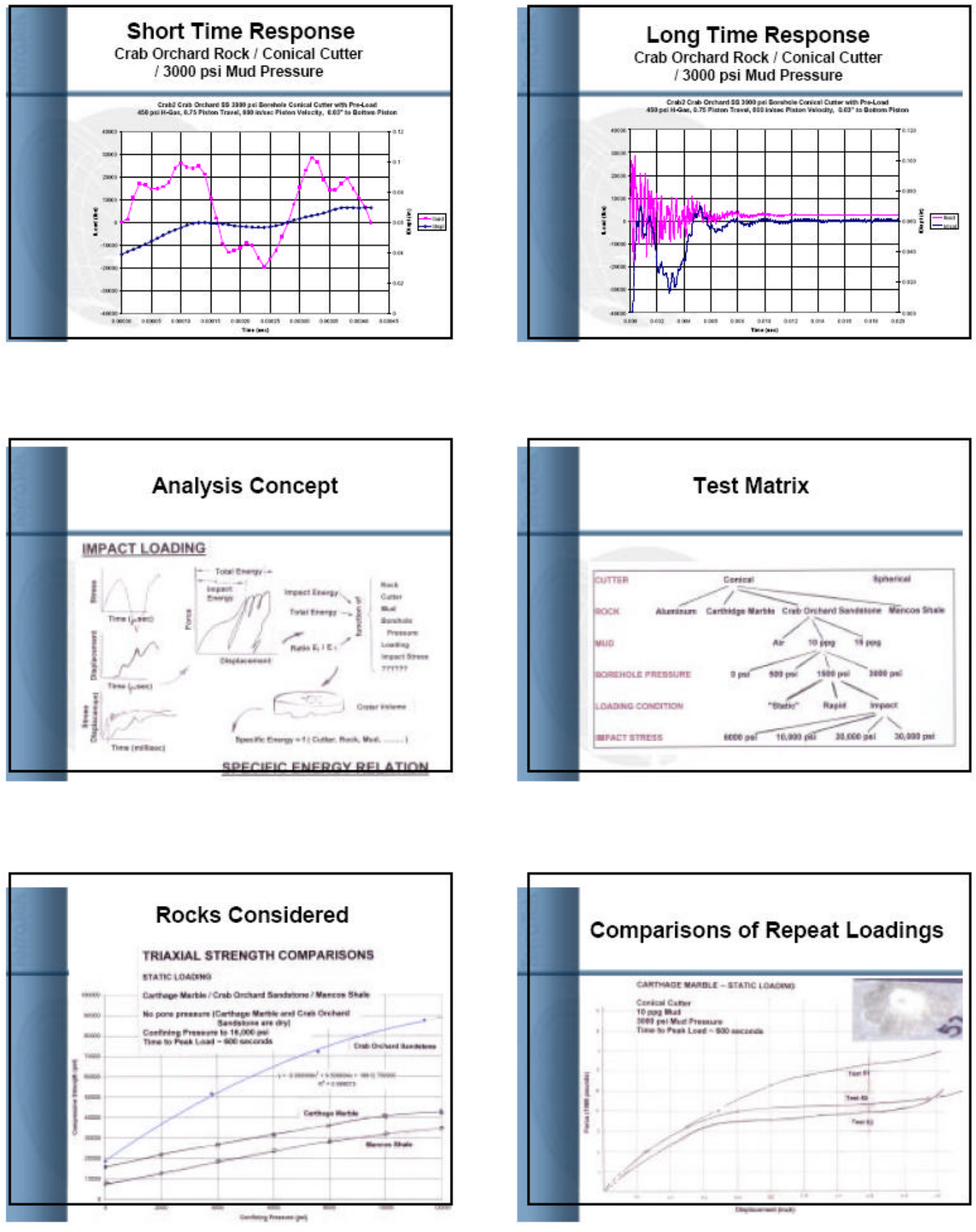

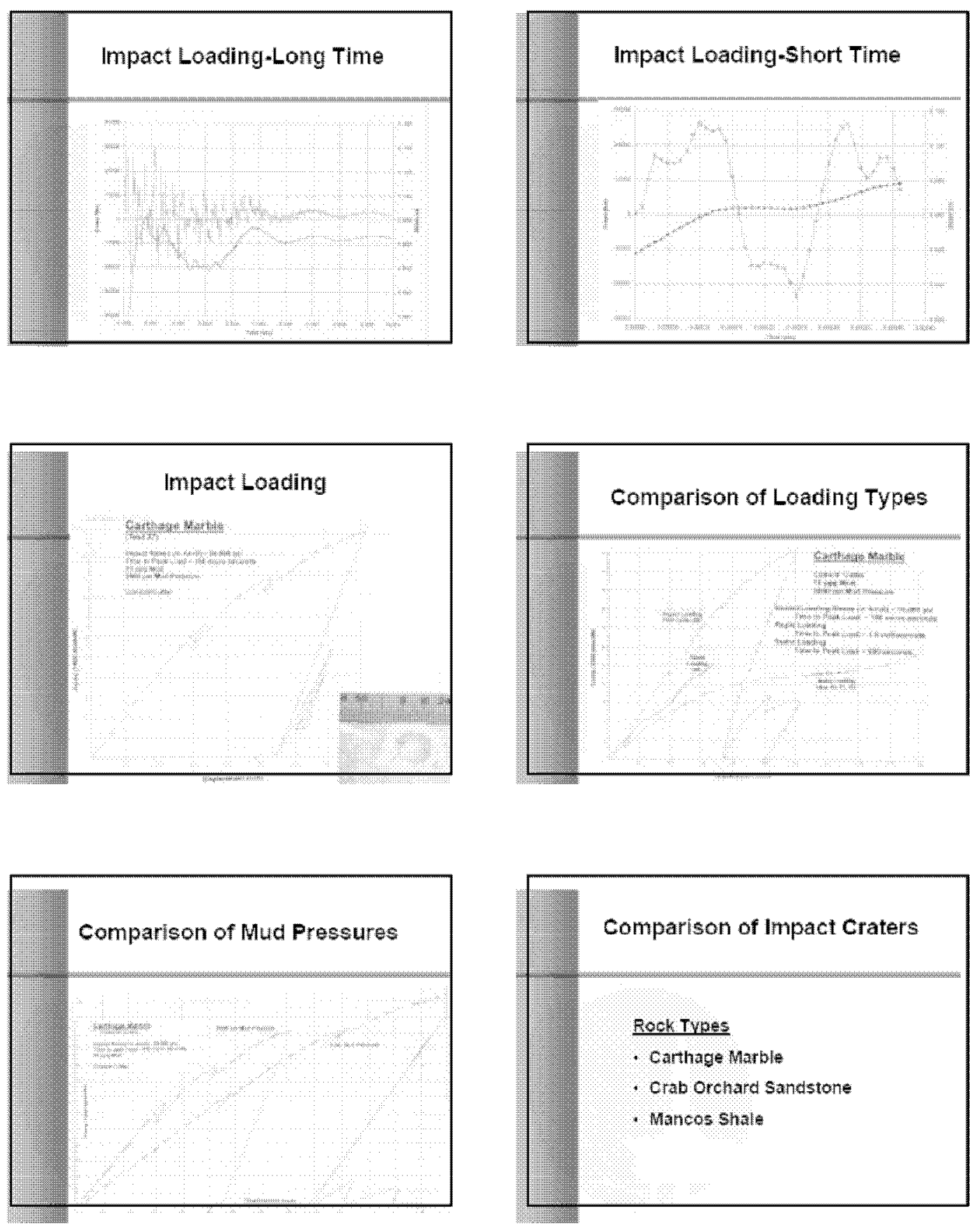

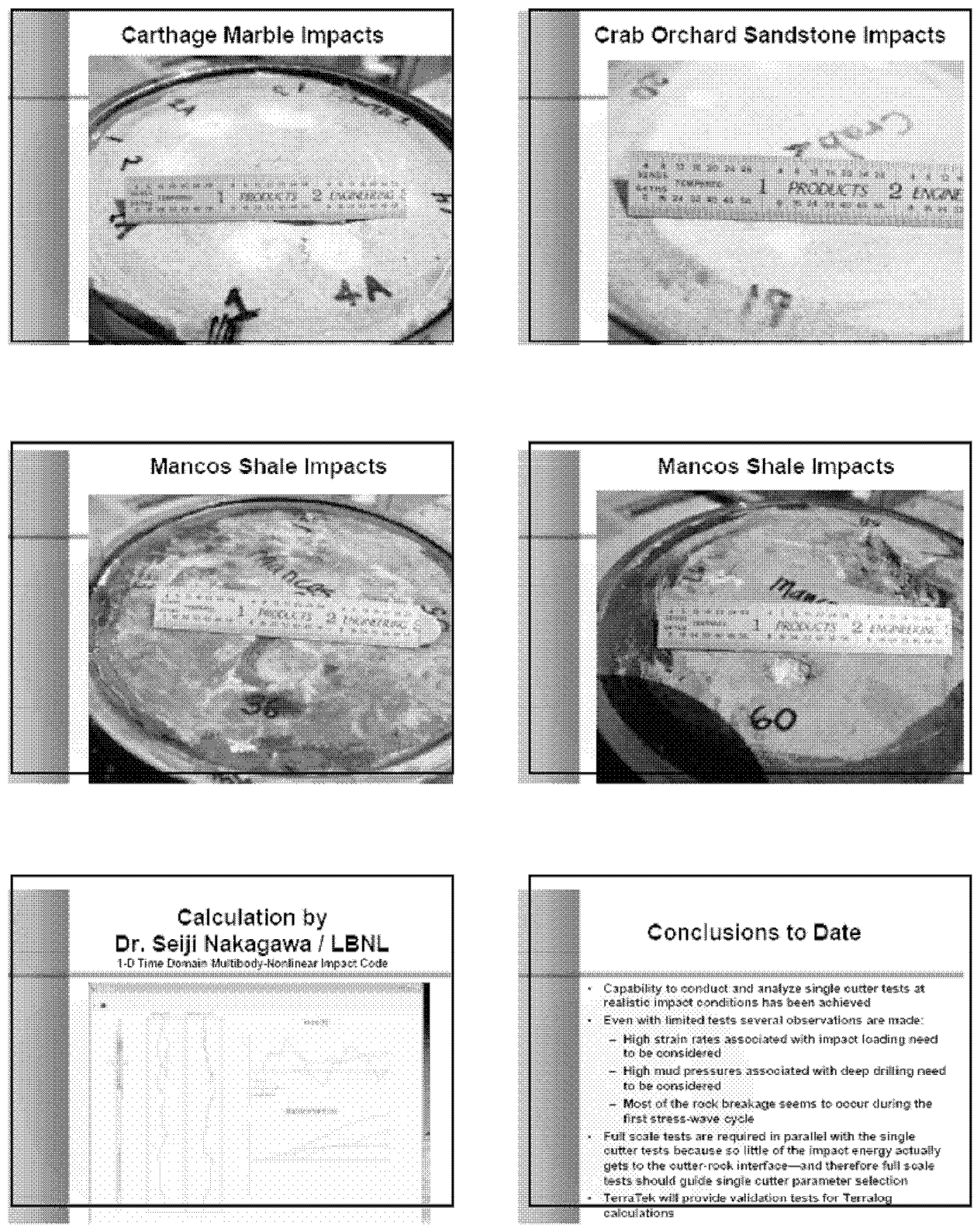


\section{Task 8 Impact Testing Summary Data}



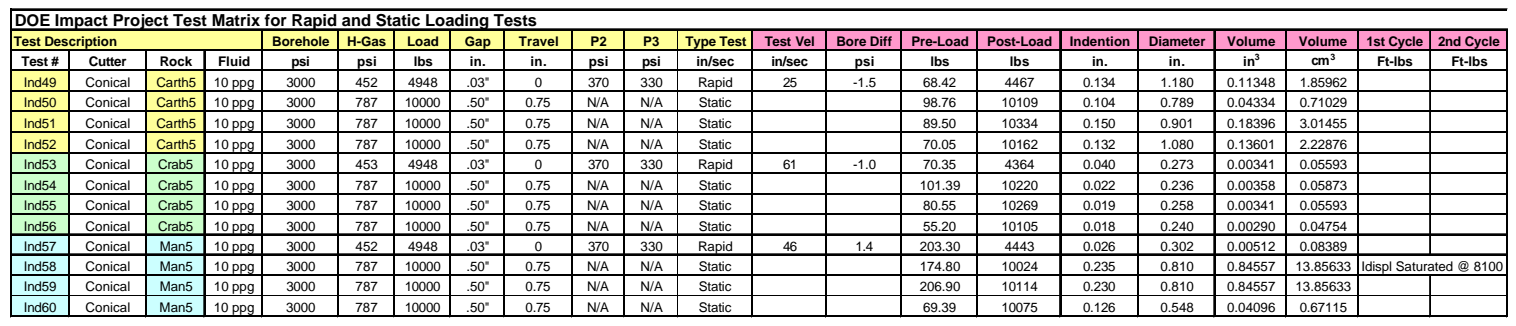

\section{5}


Publication Abstract Accepted by the Society of Petroleum Engineers

\section{Single Cutter Testing Improves Understanding of Deep-Well Hammer Drilling Performance}

Sid Green/Arnis Judzis/Alan Black (TerraTek), John Rogers (DOE-NETL), and David Curry/Umesh Prasad (Hughes Christensen).

The use of a percussion hammer can provide high penetration rates through hard rocks when air drilling. This paper describes work partly sponsored by the DOE to develop hammer drilling techniques for drilling deep hard rocks with liquid drilling fluids. Understanding rock breakage and cuttings removal under dynamic loading conditions of hammer drilling is difficult. Historically, empirical relations have been used to relate hammer blow energy and rate with drilling under atmospheric conditions. This paper presents results of carefully measured single cutter impact and high rate rock indentation tests under high borehole pressure conditions simulating deep-drilling, using real muds. The results include forcedisplacement, energy inputs and crater volumes for both first stress wave (impact) and long-time (quasi static) rock indentation.

Specific energy, the energy required to excavate unit volume of rock, indicates the efficiency of the drilling process. Specific energy values have been estimated for rock breakage under first stress wave and long time loading, and used to investigate the significance of various parameters on rock drilling by impact loading. Rock type, cutter configuration, wellbore pressure, and mud type are shown to be critical parameters. A key observation is that most of the rock breakage occurs during the first stress-wave, provided the initial impact stress exceeds the rock confined indentation strength. For higher impact stresses above this confined indentation strength, relatively little additional rock breakage occurs.

The specific energy values measured in these single cutter impact tests show the rock destruction efficiency that can be achieved by impact loading. They are compared with specific energies measured during full scale hammer and rotary drilling experiments under equivalent conditions to evaluate the potential for improving deep well drilling performance, which is significant for optimum design of bits. 


\section{Engineering for Novatek Test}

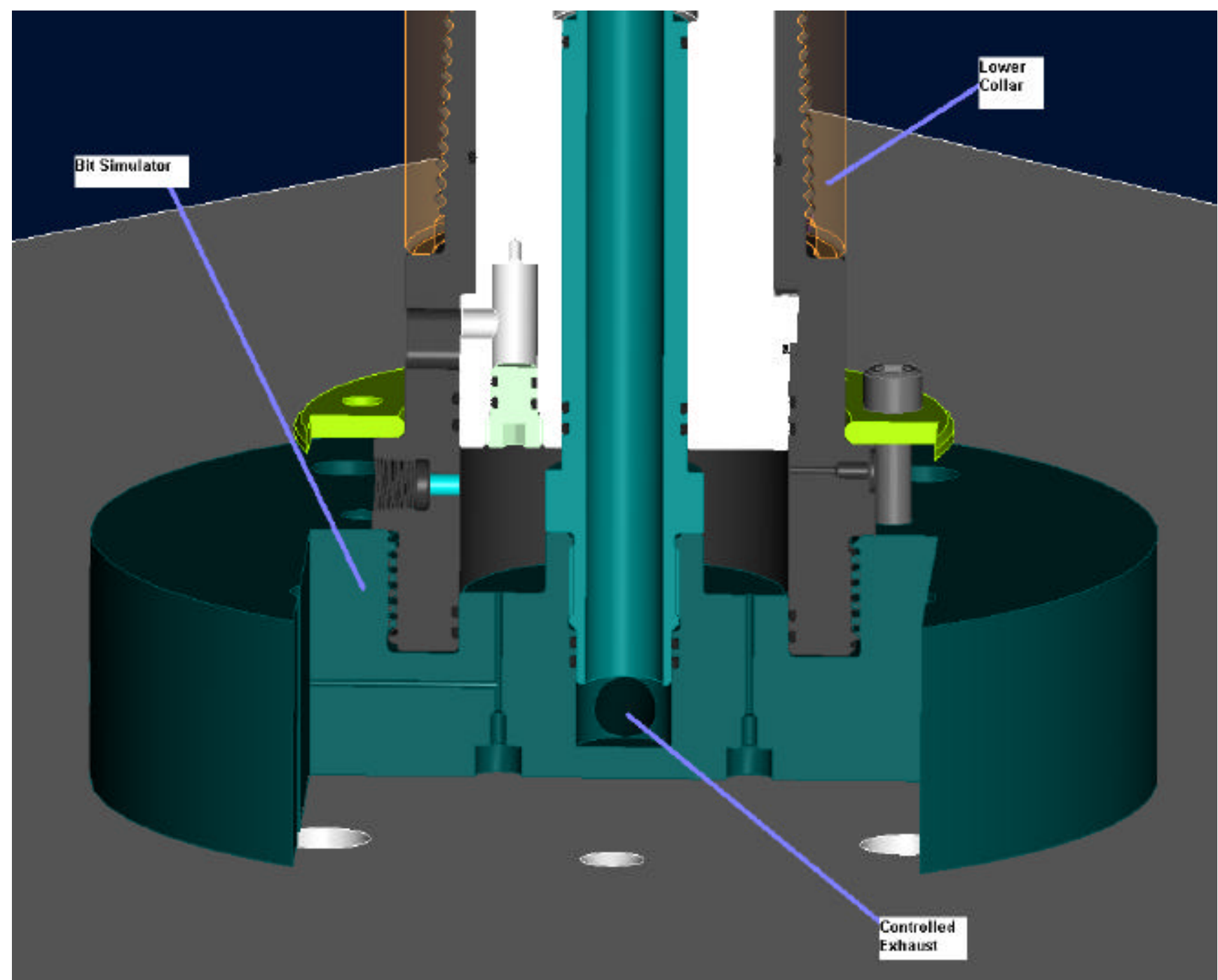




\section{$\underline{\text { Impact Testing Plans }}$}

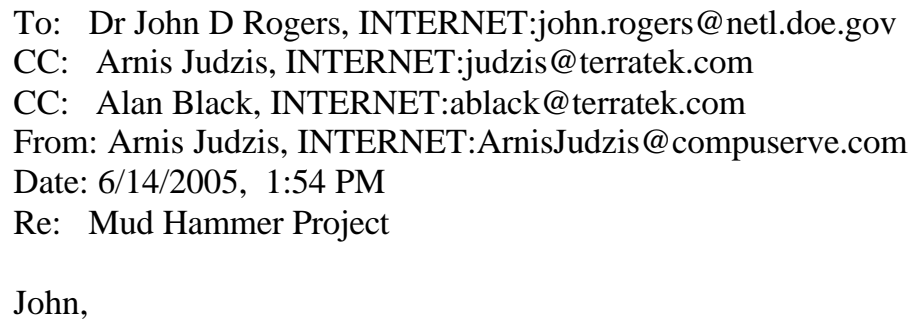

One item that you could help us with is to ensure that Novatek not construe this change as TerraTek not being patient in waiting for their tool. We have always maintained an excellent relationship with them and hope that we can test their tool later with monies budgeted in their own areas of responsibility.

Thank you for your help.

Arnis Judzis

TerraTek

judzis@terratek.com

(801) 584-2483 


\title{
Publication for the Society of Petroleum Engineers
}

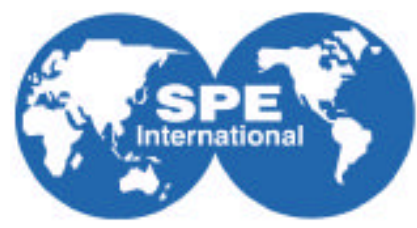

\section{SPE 97173}

\section{Single Cutter Impact Tests Investigate Deep-Well Hammer-Drilling Performance}

S. Green, SPE;TerraTek, A. Judzis, SPE; TerraTek, D. Curry, SPE, Hughes Christensen, A. Black, SPE; TerraTek, U. Prasad, SPE, Hughes Christensen, J. Rogers, SPE, U.S. Department of Energy

\begin{abstract}
The use of a percussion hammer can provide high penetration rates through hard rocks when air drilling. The work of this paper was partly sponsored by the US Department of Energy to develop hammer drilling techniques for drilling deep hard rocks, using real drilling muds. Unfortunately, development is complicated because understanding rock breakage and cuttings removal under the dynamic loading conditions of hammer drilling is difficult. Historically, empirical relations have been used to relate hammer blow energy and blow rate with drilling.

This paper presents results of carefully measured single cutter impact-as well as high rate and 'static' — rock indentation tests under high borehole pressure conditions, using real drilling muds. The results include cutter force-displacement and crater volumes for both first stress wave (initial impact) and long time (quasi static) rock indentations. From this, specific energy for rock breakage (i.e. the energy to excavate a unit volume of rock) can be calculated.

The specific energy values measured in these single cutter impact tests show the rock destruction efficiency that can be achieved by impact loading. They are compared with specific energies measured during full scale hammer and rotary drilling experiments, under relatively similar conditions.

For a given rock type, impact stress, cutter configuration, wellbore pressure, and mud type are shown to be critical parameters. A key observation is that most of the rock breakage occurs during the first stress-wave, and for higher impact stresses above the dynamic confined indentation strength, relatively little additional rock breakage seems to occur.
\end{abstract}

\section{Introduction}

Drilling is required for exploration and exploitation of oil, gas, and other energy resources. Furthermore, with the depletion of shallow energy resources, the cost of drilling is becoming increasingly greater as deeper and harder rock formations are penetrated. Under these conditions, the instantaneous rate of penetration often controls a significant portion of the total well cost; therefore increasing rate of penetration becomes highly desirable.

Various tools and techniques have been investigated in the past to drill efficiently in such conditions [for example Maurer, W.C., 1980; Rao, U.M., 1980, and Mishra, B, 1998]. Percussion or hammer drilling often gives efficient, high penetration rates under air drilling conditions. Consequently hammer drilling is one of the drilling tools being investigated for use in difficult drilling conditions, including deep and hard formations. Tibbitts et.at. (2002) has shown laboratory hammer drilling results under simulated deep drilling conditions, and Deutch et al. (1990) showed ultra deep drilling results $(15,000-30,000 \mathrm{ft})$ for crystalline igneous rocks.

Although air hammer (or percussion) drilling is used extensively in the mining industry, and much research has improved understanding and perfected the application, for deep oil and gas wells, high 
borehole mud pressure creates a different and complicated environment. As shown extensively by TerraTek and others, under high borehole pressures the rock strengthens and behaves in an apparent ductile manner (for exmple Robinson, L.H., 1958, Green, S.J., et. al. 1972, and Maurer, W.C., 1980). Also, rocks behave differently at high strain rates (Green, S.J. et. al. 1968, Green, S.J. et. al. 1974, Green, S.J. et. al. 1982) - although strain rate effects are very complicated due to pore fluid effects. Additionally, chip hold down occurs (Garnier and Van Lingen, 1959) and cuttings removal becomes more difficult (for example Van Lingen, 1962). Therefore, in order to optimize deep-well hammer drilling, quantifying rock deformation and breakage under high pressure impact loading is essential.

This work extends the understanding of hammer drilling by carefully measuring single-cutter impact rock breakage, under high borehole drilling mud pressures. Under these conditions the time of loading is 130-150 micro-seconds. Three rock types were considered.

\section{Background}

For hammer (or percussion) drilling, a piston (or anvil) is caused to accelerate (typically by a compressed fluid), and then impacts a drill rod, thereby transferring the piston energy into the drill rod. This energy travels as a stress wave thorough the drill rod, to the cutter attached at the end (typically conical, hemispherical, or wedge shaped), and ultimately into the rock. The stress in the piston, drill rod, and cutter must be lower than the fatigue limit for these materials but high enough to cause failure of the rock.

Although high energy levels are imparted to the drill rod and cutter, only a portion of this energy actually is imparted into the rock. Unfortunately for analysis, the energy level imparted into the drill rod is generally considered, rather than the actual load (or stress) that is applied to the rock. The actual load applied to the rock occurs as a stress wave (or a series of stress waves), over times of microsecondsdepending upon the geometry of the drill system or of the test system.

A complicating feature of hammer drilling analysis or of any impact testing is the transfer of energy across any change in mechanical impedance (sometimes called acoustic impedance, determined by the materials wave velocity, density; and geometry i.e. a change in geometry or change in material changes the mechanical impedance). Some portion of the energy transfers across the interface while some portion of the energy is reflected back. The proportions of energy transmitted and reflected are determined by the mechanical impedance change across the interface. The energy transfer occurs at very high strain rates, of the order of one thousand per second.

High strain rate rock properties measurements have been performed using a Hopkinson bar technique (for example Kolsky, 1949, Green, S.J. et.al. 1968, Grady and Kip, 1987, Birkimer, 1971, Christensen, R.J., et. al. 1972, Bohloli, B, 1997, Lipkin et.. al, 1977, Field et. al. 1994, Zhang, Z.X. et. al., 1999) or flat plate impact experiments (for example Green, S.J. et.al. 1968). From these tests strength increases (above 'static' tests) of thirty percent to two hundred percent are reported for strain rates of about one thousand per second; however, the effect of the pore fluid migration (for cases where pore fluids exist) is not well characterized.

Based on the high strain rate properties measurements and other observations, it has often been argued that the high efficiency of hammer drilling is due to a brittle mode of failure occurring in impact drilling. However, a brittle mode of failure has also been observed in many non-impact conditions-where quantitative measurements are more easily made.

For example, the failure of Indiana limestone and Carthage marble reported by Robinson (1958) (for confining pressure minus pore pressure up to 2,500 psi) and for Cliff and Berea sandstones (for confining pressure minus pore pressure up to 5,000 psi). Furthermore, almost all permeable rocks seem to fail in a brittle manner when pore pressure equals the confining pressure (i.e. when the effective confining pressure is zero). For example, Gnirk and Cheatham (1965) bit-tooth penetration tests to 5,000 psi and Maurer (1965) static and quasi-static bit-tooth (impact velocity of $9 \mathrm{ft} / \mathrm{sec}$ ) penetration tests into Indiana limestone and Berea sandstone. Podio and Gray (1965) and Yang and Gray (1967) conducted dynamic single tooth penetration tests (impact velocities of 4.5 to $7 \mathrm{ft} / \mathrm{sec}$ ) on Berea and Bandera sandstones up to 10,000 psi. Clark (1987) considered mining bits for deeper drilling, to understand penetration rates under deeper drilling conditions.

All the results confirm the behavior of permeable rocks as generally brittle at low effective stresses and generally [apparent] ductile at high effective stresses. However, the data do show that the crater formation is dependent not only on effective stress, but also upon the fluid type. For example, Pessier (1986) conducted single cutter tests on claystone under nitrogen and brine at confining pressures to 
5,000 psi, and found that the load-displacement curve seemed essentially brittle for unconfined and nitrogen conditions and more ductile under brine at 5000 psi confining pressure. And, Luy (1992) conducted single cutter impact tests on granite, diorite, and amphibolite under confining pressures to 7,250 psi, and concluded that even a small hydrostatic confining pressure (1,400 psi) showed less "brittle failure" as exhibited by a smaller impact crater.

Therefore, the conclusion must be made that any increased impact drilling efficiency cannot be based just on a more brittle rock failure under impact conditions.

\section{Impact Tests-Experimental Setup}

Impact tests were performed on the TerraTek Single Cutter Impact Tester as shown in (Figure 1). The rock sample is loaded inside the pressure vessel, and is exposed to drilling mud (for high pressure tests). The single cutter can be located tightly against the rock, at a given pre-load on the rock, or at various standoff distances from the rock. (For the tests here the cutter was in all cases tightly against the rock.)

A steel anvil-with a single cutter attached at the bottom-extends out of the pressure vessel and further extends upward through a hollow piston (Figure 2). A bracket at the upper end of the anvil "holds" the anvil to prevent the fluid pressure in the vessel from pushing the anvil out of the pressure vessel.

A gas driven piston (with a hole extending completely through the piston rod) is used to strike a shoulder on the anvil, at about the mid length of the anvil. This impact of the piston on the anvil shoulder sends a compressive stress wave down the anvil, through the cutter, and into the rock. The magnitude of the stress wave is determined by the velocity of the gas driven piston at the time it strikes the anvil shoulder. And, the time duration of the impact stress wave can be controlled by the travel of the gas driven piston before it "bottoms out" against the piston cylinder end plate-which terminates the stress wave.

By varying the stand off distance between the gas driven piston and the anvil shoulder, the gas used, the gas pressure, and the rate at which the gas is exhausted from the bottom of the piston cylinder, a controlled impact stress can be achieved-both the magnitude of the stress wave and the time duration of the stress wave before unloading occurs.

During the test the stress-time in the steel anvil is measured by strain gages located on the anvil outside the pressure vessel, and the displacement of the anvil is measured by a high frequency-high resolution displacement measuring device on the upper end of the anvil. Figure 3 shows a typical force time and displacement time recording for the early, first stress wave, part of the impact test.

Data was recorded at $100 \mathrm{~K} \mathrm{~Hz}$ frequency (i.e. a data point every ten microseconds) for about one second. Figure 4 shows the long time-complete test—for the test shown in Figure 3 above. The final crater indentation (this is after any rock "elastic rebound" has occurred) is measure after the test is complete. This is a key measurement for the analysis as will be noted later. Typical craters for the three rocks tested are shown in Figure 5.

\section{Impact Tests-Analysis Method}

Determination of the force-displacement at the cutter-rock interface is very difficult for early times. During the early time, a stress wave arrives at the cutter-rock interface; part of the stress wave energy is transmitted into the rock and part is reflected back into the cutter and travels up the anvil.

In an idealistic case, upon impact of the gas driven piston on the anvil shoulder, the compressive stress wave magnitude can be calculated as follows.

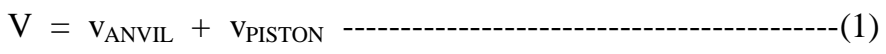

$\mathrm{V}_{\mathrm{ANVIL}}=\mathrm{V}_{\mathrm{PISOTN}}(\mathrm{a} / 1+\mathrm{a})$

Where $\mathrm{V}$ is the impact velocity, $\mathrm{v}_{\mathrm{ANVIL}}$ is the particle velocity of the anvil; $\mathrm{v}_{\text {PISTON }}$ is the particle velocity of the gas driven piston; and $\mathrm{a}$ is the ratio of the stress wave [mechanical] impedance of the piston to the anvil. Since both are of the same material (steel), the impedance is the ratio of the areas, which for the tests here are 2 square inches divided by 3.14 square inches, or 0.637 . It should be noted that if the impedances were equal (i.e. same materials and same areas of piston and anvil, then the particle velocities would be equal.

This gives a particle velocity in the anvil shoulder (note this is only in the anvil shoulder, and is not the average particle velocity that will propagate down the anvil) that is 0.389 times the particle velocity in the piston. 
The magnitude of the stress wave corresponding to these particle velocities is equal to:

$\mathrm{s}=(\mathrm{E} / \mathrm{c}) \mathrm{v}$

Where $\mathrm{s}$ is the plane strain stress [wave], $\mathrm{E}$ is the Young's modulus, $\mathrm{c}$ is the speed of sound, and $\mathrm{v}$ is the particle velocity of the piston and the anvil (both are the same material, steel) - for a given impact velocity.

From equation 1 and 2 above,

$\mathrm{v}_{\text {ANVIL }}=0.389 \mathrm{~V}$

and therefore,

$\mathrm{s}=(\mathrm{E} / \mathrm{c})(0.389 \mathrm{~V})$

Taking the Young's modulus to be 29 million $\mathrm{lb} / \mathrm{sq}$ in and the speed of sound of steel to be $230,000 \mathrm{in} / \mathrm{sec}$ (or about 4.5 micro-seconds per inch of travel in the steel), then:

$\mathrm{s}=4.905 \mathrm{~V}$

The stress in the uniform section of the anvil, through the strain gaged section and on to the cutter attached at the bottom, may be estimated by considering cross section geometry change-the area of the shoulder section impacted (which is about $2.0 \mathrm{sq}$ in cross section area), the total area of the shoulder on the anvil (which is about $3.14 \mathrm{sq}$ in), and the uniform section area (which is about $1.0 \mathrm{sq}$ in cross section area). Based on the cross section change, an estimate of zero amplification would seem reasonable. (This is only an estimate and does not accurately account for the wave reflections at the change in cross sections that occur in the anvil.)

Therefore the stress wave traveling down the anvil is approximately as given in equation (6); and, for the units here, $\mathrm{V}$ is in inches per second and the stress is in pounds per square inch.

The analysis is further complicated by the necessary changes in geometries of the test system. That is, upon impact of the gas driven piston on the anvil shoulder (see Figure 2) a compressive stress wave travels down the anvil and a tensile stress wave travels up the anvil. When the tensile stress wave reaches the upper end of the anvil, it reflects as an additional tensile wave traveling back down the anvil, and so forth. At the same time the gas driven piston strikes the anvil shoulder sending a compressive wave down the anvil, a compressive wave travels up the gas driven piston rod. When this wave reaches the enlarged piston, part of the wave energy reflects back down the gas piston rod as a compression wave, and so forth. Additionally, none of the waves are truly "step" stress changes-primarily due to impact alignment conditions and due to test system geometry changes; i.e. for example the shoulder on the anvil has gradual changes in dimensions to minimize stress concentrations, leading to continual wave reflections due to continual geometry (impedance) changes.

As assistance to visualize the loadings that occur-particularly at the cutter-rock interface, an idealized stress-wave ray tracing is helpful. Figure 6 shows such a wave ray tracing for the first stress wave cycle and some beyond. Any point on a line represents the location (ideally) of the stress wave front at that time.

Each line represents a new stress wave created by impact initially or a wave reflection that occurs at an impedance change. The ray tracing of course assumes a step stress change in all cases. (Again note, the ray tracing is only idealistic and the actual waves are not sharp fronted waves, but are created by continual wave reflections caused by geometry changes.)

From Figures 3 and 6, the time for the first stress wave loading is about 130-150 microseconds for the geometry of the test system here. From Figure 4 (and from a ray tracing estimation), after about 1000 microseconds, the anvil is traveling as a rigid body and is "vibrating" (or oscillating) up and down rapidly, but essentially "quasi-statically"; i.e. these vibrations load and unload the cutter, until the system comes to rest-some time at about 0.02 second as shown in Figure 4.

For each impact test, the determination of the force-displacement at the cutter-rock interface is required. The recorded stress (because the steel anvil is linear elastic, the stress is equivalent to the load or to the force) is at the strain gage location, about mid way between the cutter and the impacted shoulder on the anvil. And, the recorded displacement is at the upper end of the anvil. Because of the complicated geometry of the test system and since the corresponding stress wave reflections occur at any geometry 
(impedance) change, no easy and rigorous method exists to accurately determine the force-displacement at the cutter-rock interface. Therefore, an approximate method as described below is used.

For the analysis, several observations are known. The initial zero load-zero displacement is known; the final zero load-total displacement-neglecting the elastic rock rebound-is known. And, after about 1000 microseconds the anvil strain gage readings and the anvil displacement readings provide the force and displacement throughout the anvil (which is the force-displacement at the cutter-rock interface). That is, after a sufficient time the anvil is moving as a rigid body, and the load and the displacement are relatively uniform throughout the anvil-considering this rigid body motion.

Therefore, an approximate analysis method will begin at the end point- the final zero load and total displacement. And, from this end point the analysis will work backwards time wise, plotting the force-displacement. This works until a time of about 1000 microseconds, where the anvil is no longer moving as a rigid body. For earlier times, a stress wave analysis must be used-this is much more complicated.

For the early times - and following the ray tracing of Figure 6 as a guide - an estimate of the force-displacement at the cutter-rock interface can be made. First the force versus time at the cutter-rock interface is determined using an analysis similar to that used for a split Hopkinson bar test.

The force at the strain gage location is the sum of the loading stress wave traveling down the anvil and the reflected (from the cutter-rock interface) stress wave traveling up the anvil. (The force at the strain gage location is not directly equal to the force at the cutter-rock interface for early times.) An assumption is made that the stress wave loading down the anvil is constant and is selected by judgment from the straingage reading versus time (i.e. Figure 4). For example, Figure 7 shows such as estimate for Test 39-the solid line is the estimate of the constant stress wave that travels down the anvil. The stress wave reflected traveling up the anvil is not constant, but is changing due to the non-linear response of the rock. Therefore subtracting the constant stress wave traveling down the anvil (Figure 7 the solid line) from the strain gage reading will give the stress (or force) transmitted into the rock; i.e. the stress (or force) at the cutter-rock interface, but shifted timewise.

From the above, an estimate can be made of the force-time at the cutter-rock interface. Unfortunately, no such estimate can be made of the displacement-time at the interface. An estimate can be made, however, of the peak displacement that occurs during the first stress wave cycle. This is taken from the displacement measuring device on the upper end of the anvil. Knowing that the peak force and the peak displacement (for the first stress cycle) will occur at the same time, an estimate is therefore possible for the early time peak force-peak displacement at the cutter-rock interface. This is a very valuable data point.

To summarize, the analysis is an estimate of the force-displacement at the cutter-rock interface. The analysis proceeds backward from the final no force-total displacement, using the force and displacements measurements (Figure 4). This is adequate for the longer times-i.e. the quasi-static part of the test, back to about 1000 microseconds. For earlier times-specifically the first stress wave cycle, only an estimate of the peak force-peak displacement can be made; the force-displacement path cannot be accurately defined. However, from knowledge of rock behavior and from the measured static forcedisplacement curves, it is known that the path does not deviate substantially from a smooth curve.

\section{Impact Tests-Test Data}

Tests-Calibrations: Three rock types were considered-Carthage marble, Crab Orchard sandstone, and Mancos shale. Figure 8 shows the failure envelope for the three rocks; the Carthage marble and the Mancos shale are considerably weaker than the Crab Orchard sandstone. The Carthage marble and Crab Orchard sandstone are dry; i.e. no pore pressure, while the Mancos shale was tested as received and assumed at least partially saturated, and hence under the high stresses under the cutter indentation, some pore pressure would exist.

A conical $1 / 2$ inch diameter tungsten carbide conical cutter was used for all tests. Water based drilling mud of $10 \mathrm{ppg}$ weight was used, and for pressure tests, the mud pressure was up to $3000 \mathrm{psi}$.

For calibration, static loadings (time to peak load of about 600 seconds) were conducted. Figure 9 shows such repeat loadings for the three rocks considered. Additionally, for calibration a T6 aluminum alloy was tested in static, rapid loading, and impact modes. The aluminum is not strain rate sensitive at room temperature (Green, S.J. et.al. 1968) and hence the static, rapid, and impact force-displacement curves should all coincide-Figure 10 shows these tests. The excellent comparisons give much confidence to the approximate analysis used for the impact tests, first stress wave analysis. As a final calibration, 
Figure 11 shows a comparison of static loading (time to peak load of about 600 seconds), rapid loadings (time to peak load of about 1.5 milliseconds), and impact loading (time to peak loading of about 150 microseconds) for Carthage marble. The rapid loading shows somewhat higher force for a given displacement, and the impact loadings shows still higher force for a given displacement-all as expected, based on estimated strain rate sensitivity. The comparison, further gives confidence to the approximate analysis.

Test Data: The force-displacements of the cutter into the rock are shown for different impact conditions; i.e. 1) rock type, 2) borehole mud pressure, and 3) impact stress magnitude. The points marked on the displacement axis are the final crater indentation after the rock elastic rebound; the dashed lines on the curves are estimates from the approximate analysis as noted previously.

1) Rock Type: Figure 12 shows a comparison of impact loading under similar conditions for the three rocks considered. As expected considering the rock strengths, the Mancos shale shows the lowest and the Crab Orchard sandstone shows the highest force for a given displacement. The Mancos shale shows the greatest final impact indentation.

2) Borehole Mud Pressure: Figure 13 shows impact loadings peak stresses (for the first stress wave, which is the peak stress for the complete test) and final crater indentations (after the rock elastic rebound) for increasing borehole mud pressure for the rocks considered. Increasing the borehole pressure from zero to 3000 psi lowers the peak stress that occurs and significantly decreases the final crater indentation.

Additionally, the figure shows that the peak stress decreases with increasing borehole mud pressures-even though the impact stress (the stress in the anvil which is measured) is the same for all borehole pressures. This is believed due to the change in rock mechanical impedance with increasing pressures, thereby leading to a greater reflected wave (from the cutter-rock interface) and a reduced force into the rock; i.e. greater stress is reflected back up the anvil and less stress in transmitted into the rock. Therefore, the borehole mud pressure seems to have two effects; increasing pressure will increase the strength of the rock, and increasing pressure seems to reduce the stress wave magnitude that is transmitted into the rock.

3) Impact Stress Magnitude: Varying the impact stress (i.e. varying the impact velocity of the gas driven piston on the anvil shoulder) changes the stress magnitude of the stress wave traveling down the anvil. This has the direct effect of increasing or reducing the cutter force, and hence increasing or reducing the rock indentation. From the static tests (Figure 9) it is noted that force-displacement increases up to a point, and then a pronounced decrease in slope occurs (although this is not clear for the Crab Orchard sandstone, as the maximum force was just at the level to produce the first chip).

We refer to this cutter force as the "chip formation force" and for the impact loadings, the "dynamic chip formation force" (or DCF force). Further indentation leads to rapid force increase, followed by - in some cases - a second chip formation load point, and so forth. It appears that for stresses below the DCF force, the crater formed is small and considerable work is required to produce a small amount of rock destruction. And, above the DCF force, the load to produce additional indentation becomes very large; i.e. much work is required to produce additional rock destruction.

We conclude that the optimum impact should be to produce a stress just above the DCF force. And, it is noted (see Figure 13) that this required impact seems to increase with increasing borehole mud pressure (and although not considered here, likely will increase with increasing mud weights).

\section{Hammer Drilling}

For comparisons of specific energy, laboratory tests reported by Tibbitts et al. (2002) are shown. Hammer drilling penetration rate decreases rapidly with increasing borehole pressure. Figure 14 (TerraTek, 2005) shows drilling with 10 ppg oil based mud into Carthage marble, with both a flat-faced hammer spherical button bit and a roller cone button bit.

The figure shows penetration rates at noted weights on bit, different rotary speeds, different pressure drops across the bits (varying the flow rate provides different pressure drops), and borehole pressures.

Penetration rate for the hammer drill is highest at low borehole pressures, and as the borehole pressure increases to $3000 \mathrm{psi}$, penetration rate drops off significantly. Penetration rates do not improve noticeably with increasing pressure drops and increasing rotary speeds.

\section{Specific Energy}


An industry standard is to correlate drillability and drilling efficiency with specific energies. The specific energy generally is not a true specific energy to break the rock-as this is very difficult to obtain, but is the energy put into the mechanical action of the drill bit divided by the penetration for a unit time. This drill bit, rock destruction specific energy does not account for any benefit from erosion or cutting occurring from the drill mud, and it includes botomhole friction and other work required in the drilling action. This is often ploted as drilling specific energy versus rate of penetration (ROP).

Estimating specific energy for hammer or percussion drilling is likely more uncertain than for rotary drilling. Often the hammer piston energy is taken as the energy (i.e. the blow energy) and this is plotted versus penetration per blow (or piston energy times the number of blows versus the penetration for a unit time). It is generally not possible to determine how much of the piston energy actually gets into the rock to break the rock, and hence, this is really hammer blow specific energy as opposed to a true rock breakage specific energy.

Estimates of the specific energy for full scale drilling can be obtained from laboratory full-scale drilling, such as shown in Figure 14 (mud hammer and flat bottom bit [shown as dots] and an $81 / 2$ inch roller bit [shown as solid lines] drilling in Carthage marble with 10 ppg weight oil-base mud), or from field drilling (for example Dupriest and Koederitz 2005). For the full-scale drilling shown in Figure 14, the drilling specific energy as noted above versus rate of penetration is plotted in Figure 15 (ROP is calculated for $60 \mathrm{rpm}$ equivalent).

Figure 15 also shows specific energy for rock breakage from the single cutter tests conducted here. This specific energy is calculated by simply taking the area under the force-displacement curve divided by the volume of rock removed as noted by measuring the penetration crater volume. And, assuming a rate of penetration equal to the depth of penetration for a hammer drill at ten strokes per second with enough cutters (insert buttons) to impact the full bottom hole area every 8.8 blows. This latter specific energy would be closer to a true rock breakage specific energy, but may be considered optimistic because it does not take into account regrinding of cuttings and assumes that the same penetration would occur for each single cutter indentation for each blow.

Specific energies for the single cutter tests here are somewhat lower than for full-scale drilling, but correlate very well. The tests at high borehole mud pressures (3000 psi) show lower ROP for a given specific energy.

\section{Conclusions}

Deep-well laboratory full-scale drilling (and limited field tests) with mud hammers has shown that penetration rates seem to at best be only comparable to rates from roller or fixed cutter bits. Therefore, to make hammer drilling viable, improvements will be required. And, improvements require a better understanding of rock breakage and chip removal under impact loading with high borehole mud pressures. Unfortunately, understanding the impact phenomena in detail is very difficult; however, this work has addressed rock deformation and breakage in some detail for single cutter impacts. And, the approximations presented here provide much improved understanding, even though chip removal and overall hydraulic effects have not been considered.

Rock strain rate effects significantly increase the required impact load for rock deformation and breakage - what is referred to here as the dynamic chip formation (DCF) force, in line with the expected increase in strength with increased strain rate. The tests here did not consider pore pressure effects (except to the extent that the Mancos shale did contain pore fluid), and greater-maybe much greater-strain rate effects may occur under saturated, high pore pressure conditions. Drilling mud pressure has a significant effect to reduce the rock deformation and breakage for a given impact, even to borehole mud pressures of only 3000 psi. Increasing mud weight, although not considered here, is also likely to reduce rock breakage.

It appears that the first stress wave cycle contributes most of the rock breakage for the design of the test system here, and this is likely also true for real mud hammer designs. It also appears that impacts great enough to exceed the cutter DCF force are critical, but that greater impacts are less effective, since much less rock breakage occurs for greatly increasing loads. It is expected that once the DCF force is reached, better use of energy can be made by increasing the blows per minute.

Single cutter tests are very valuable to 1 ) better understand quantatitively how the specific energy to break rocks changes with different parameters and 2) to optimize the drill system to utilize as much of the drilling energy as possible to break the rock. Data here show that single cutter specific energy correlates well with full-scale drilling. 


\section{Acknowledgements}

The support of the US Department of Energy under contract DOE DE-FC26-00NT40918 for part of the work is greatly appreciated. Additionally, input from Mr. Ron Bland, Baker Hughes Drilling Fluids on the effects of muds and Mr. Matt Meiners, Hughes Christensen on the determination of specific energies was much appreciated. We would also like to acknowledge the work by Mike Sanderson and Jerry Pratt of TerraTek for making the laboratory tests successful.

\section{References}

B. Bohloli, 1997, "Effects of geological parameters on rock blasting using the Hopkinson Split Bar", International Journal of Rock Mechanics \& Mining Sciences Vol. 3/4, p. 630.

Birkimer, D.L., 1971; “A Possible Fracture Criterion for the Dynamic Tensile Strength of Rock.” 12 th US Symp. On Rock Mech. University of Missouri Rolla, Missouri. Clark, G.B. (editor): 573-590.

Christensen, R. 1972, "Hopkinson Bar Tests on Rocks Under Confining Pressure”, 12 $2^{\text {th }}$ US Rock Mechanics Symposium

Clark, G.B., 1987; “Principles of Rock Fragmentation”, John Wiley \& Sons, New York

Deutch, U., Marx, C., and Richmuller, H., 1990; "Evalaution of Hammerdrill Potential for KTB”, SuperDeep Continental Drilling and Deep Geophysical Sounding, Eds. Fuchs, K, Kozlovsky, Y.A., Krivtsov, A.I. and Zoback, M.D.

Dupriest, F.E. and Koederitz, W.L., "Maximizing Drill Rates with Real-Time Surveillance of Mechanical Specific Energy", SPE/IADC 92194

Field. J.E. et al., 1994; "Experimental Methods at High Rates of Strain.” Journal de Physique IV, Colloque C8, Suppl. au Journal de Phy., Vol 4: C8-3-C8-22

Garnier, A.J. and Van Lingen, N.H., "Phenomena Affecting Drilling Rates at Depth", Trans AIME 216 (1959) 232-239.

Gnirk, P.F., and Cheatham, J.B., 1965; “An Experimental Study of Single Bit-Tooth Penetration Into Dry Rock at Confining Pressures of 0 to 5,000 psi”, SPE-U. of Texas Conference on Drilling and Rock Mechanics, Austin, TX, Jan 20-21, 1965.

Grady, D.E. and Kipp, M.E., 1987; “Dynamic Rock Fragmentation.”, Fracture Mechanics of Rock, B.K. Atkinson (ed), Academic Press Ltd. London.: 429-472.

Green, S.J. et.al. 1972, “Strength of Shales Under Confining Pressures”, SPE 28763

Green, S.J. et. al. 1968, "Behavior of Rocks at High Strain Rates"; Journal of Geophysical Research; Green, S.J. et. al. 1976, "High Strain Rate Properties of Selected Rocks", US National Symposium on Rock Mechanics; Green, S.J. et. al., 1982, "Rock Properties at High Strain Rates”, NTS Annual Symposium, Sept 1982

Green, S.J. et. al. 1968, "Hopkinson Bar Tests on Several Rocks"; and Green, S.J. et. al. 1968, "Flat Plate Impact Experiments", Dept. of Defense, Symposium on Impact Dynamics, May 1968

Kolsky, H., 1949; "An Investigation of the Mechanical Properties of Materials at Very High Rates of Loading.", Proc. Roy. Soc., Vol B62: 676-700

Lipkin, J. et al., 1977, “Dynamic Flow and Fracture of Rock in Pure Shear”, Proc.18th US Symposimu on Rock Mech. Keystone, Colorado: 3B2-1. 
Luy. R., 1992, "The Investigation of the Efficiency of the Drilling Process with Rotary Percussion Drilling at High Hydrostatic Pressures", Ph.D. Dissertion, Technical University Clausthal, Germany.

Maurer, W.C., 1965, "Bit-Tooth Penetration Under Simulated Borehole Conditions", SPE Annual Fall Meeting, Denver Colo, Oct. 3-6, 1965

Maurer, W. C., 1980, “Advanced Drilling Techniques”, Pennwell Corp.

Pessier, R.C., 1986, “Hughes Christensen Internal Product Research”, Report \#46-09-17.

Podio, A.L., and Gray, K.E., 1965, "Single-Blow Bit-Tooth Impact Tests on Saturated Rocks under Confining Pressure at Zero Pore Pressure”, Soc. Pet. Eng. J., pp 211-224.

Rao, U. M. and Mishra, B., 1998; "Principles of Rock Drilling", A. A. Balkema Publishers

Rasheed, Wajid, "Mud Hammers Changing the Game in Drilling”, Mar 2003 Supplement to Hart's E\&P, pages 16-18.

Robinson, L.H., 1958, "Effects of Pore and Confining Pressures on Failure Characteristics of Sedimentary Rocks", SPE Annual Fall Meeting, Houston, TX, Oct 5-8

TerraTek, 2005, "Full-Scale Laboratory Drilling Experiments", Partly Funded by US Department of Energy, Report 2005

Tibbitts, G.A. et al., 2002, "World's First Benchmarking of Drilling Mud Hammer Performance at Depth Conditions", SPE/IADC paper 74540

Van Lingen, N.H., 1962, "Bottom Scavenging-a Major Factor Governing Penetration Rates at Depth", JPT pp 187-196

Walker, B.H., Black, A.D., Klauber, W.P., Little, T., Khodaverdian, M. "Roller-Bit Penetration Rate Response As a Function of rock Properties and Well Depth", SPE 15620 presented at the SPE Annual Conference in New Orleans, October 5-8, 1986

Yang, J. H., and Gray, K.E., 1967, "Single-Blow Bit-Tooth Impact Tests on Saturated Rocks under Confining Pressure: II. Elevated Pore Pressure”, SPE 1702

Zhang, Z.X. et. al., 1999, "Effects of Loading Rate on Rock Fracture", Int. J. of Rock Mechanics and Mining Sc. Vol 36, pp 597-611 


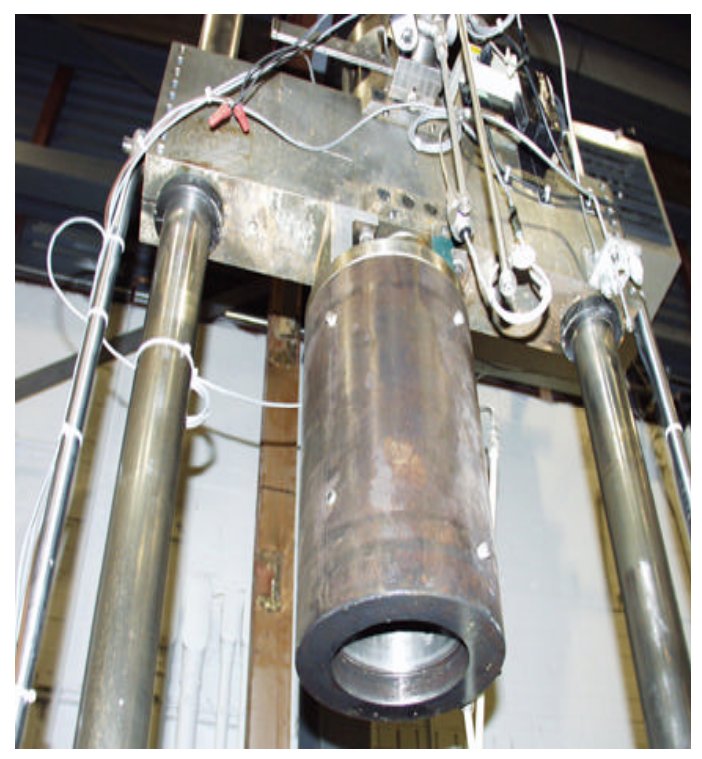

Figure 1. TerraTek Single Cutter Impact Tester

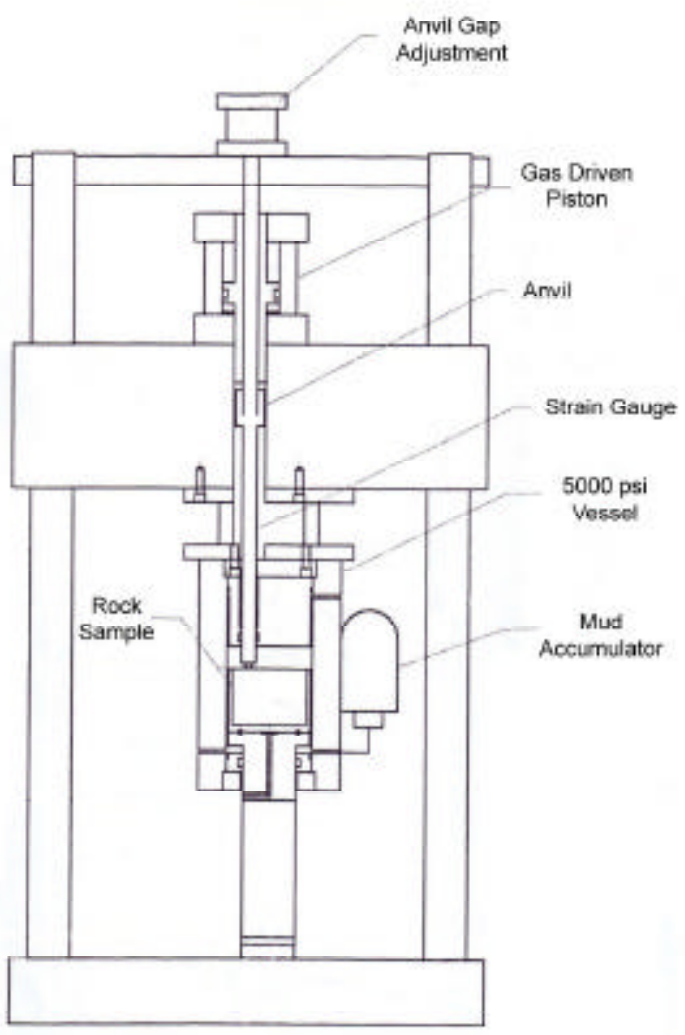

Figure 2. Schematic of Impact Tester 


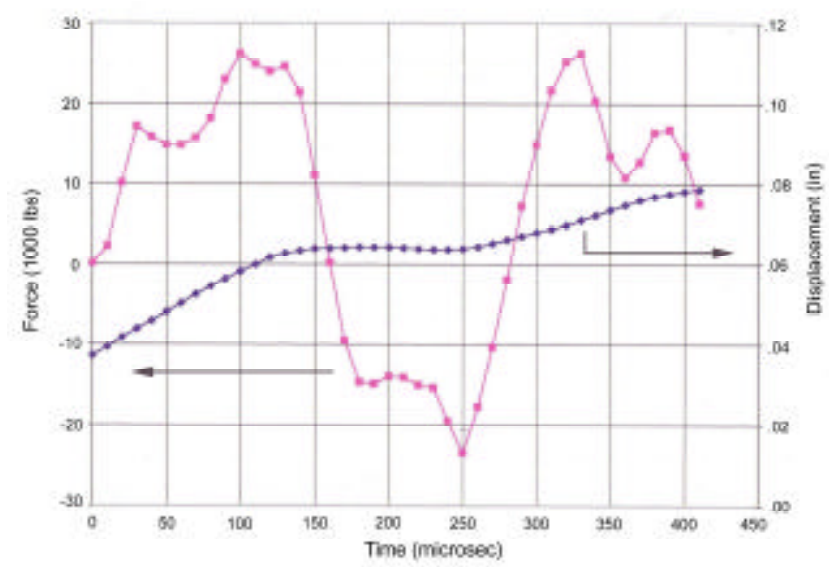

Figure 3. Early Time Force and Displacement Recordings

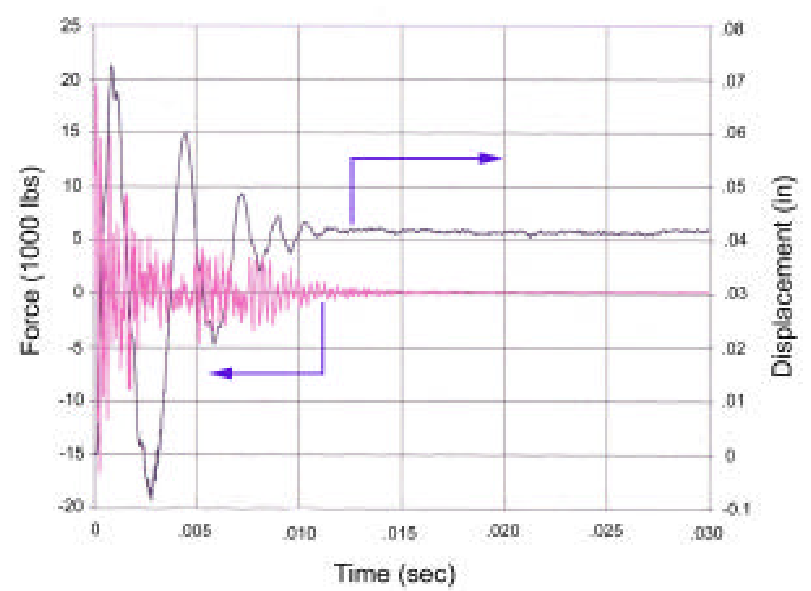

Figure 4. Force and Displacement Recorded for a Complete Test 


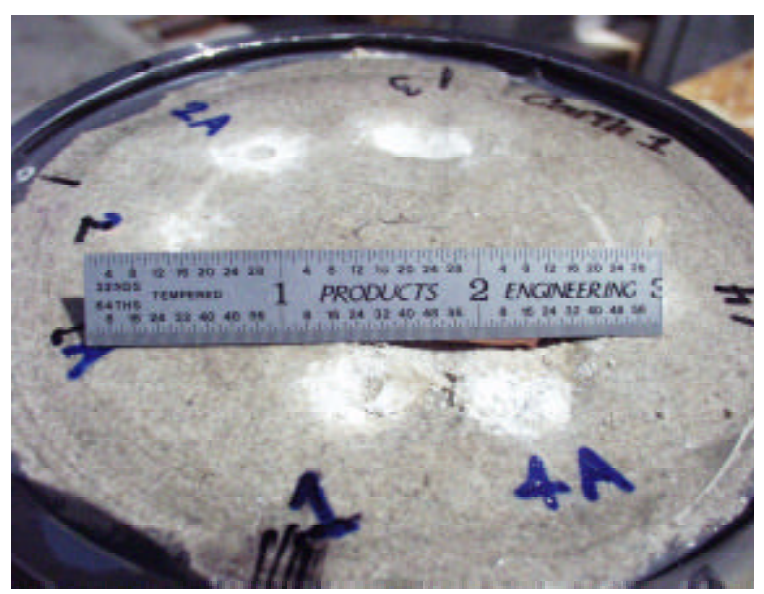

Figure 5. Typical Impact Craters (Carthage Marble)

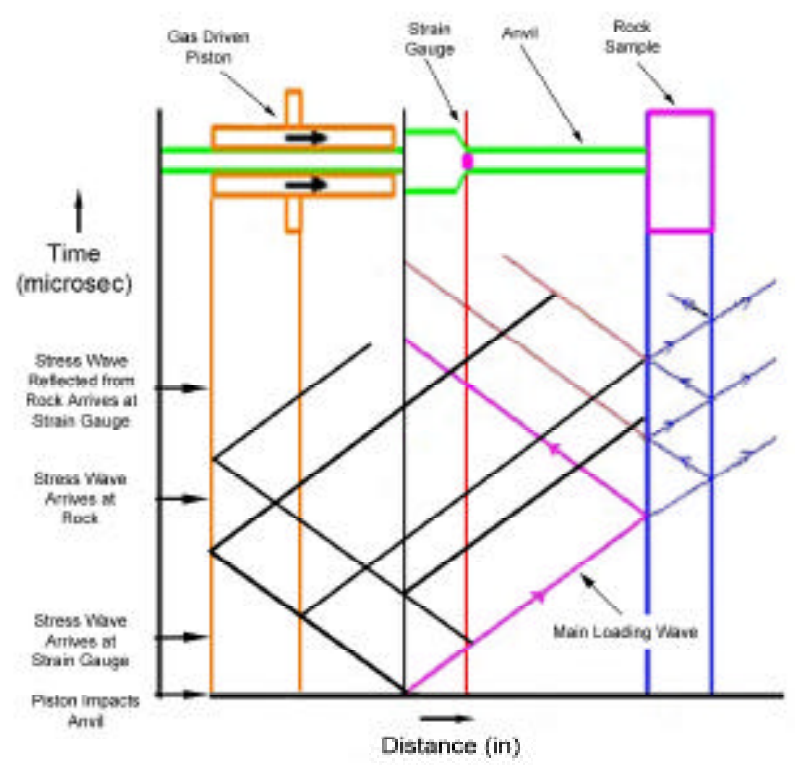

Figure 6. Approximate Stress Wave Ray Tracing 


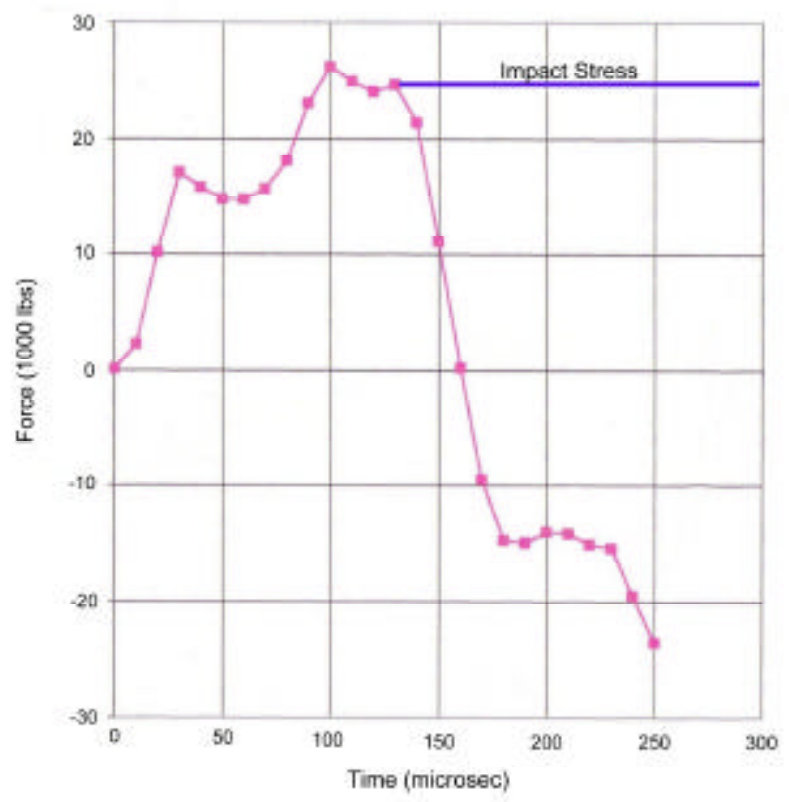

Figure 7. Estimate of Impact Stress Wave

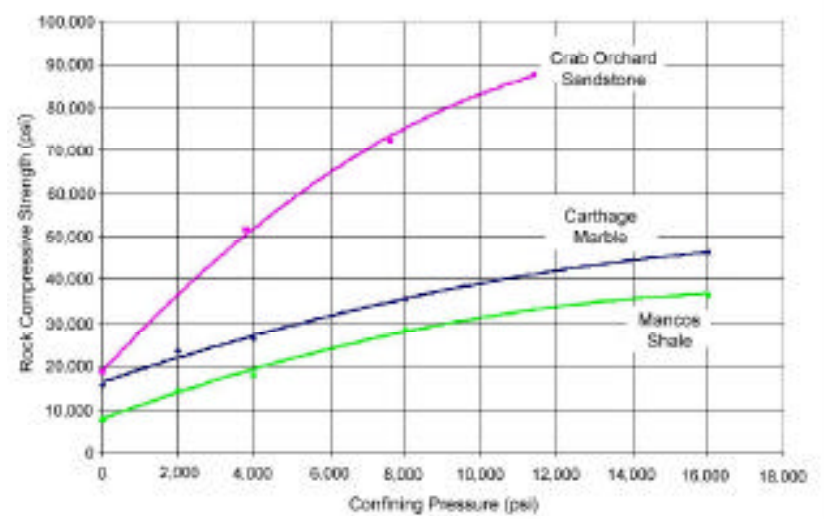

Figure 8. Effect of Confining Pressure on Rock Strength 


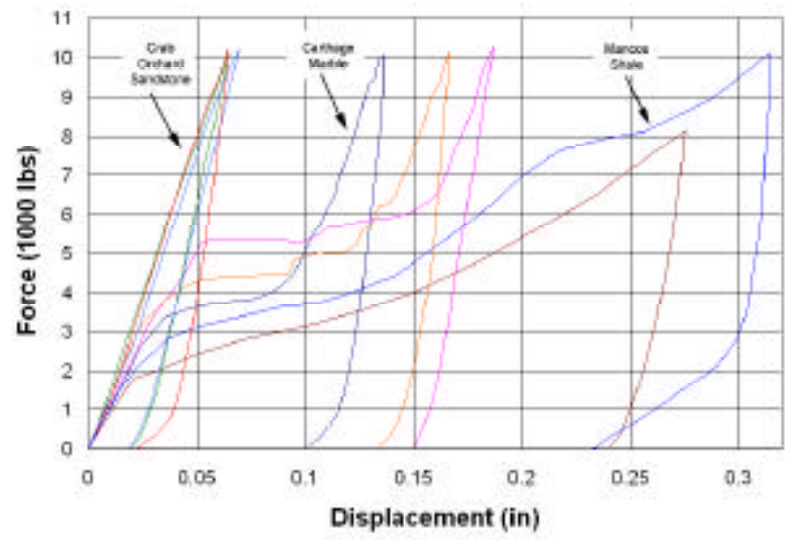

Figure 9. Repeat Static Loadings on Rocks Considered

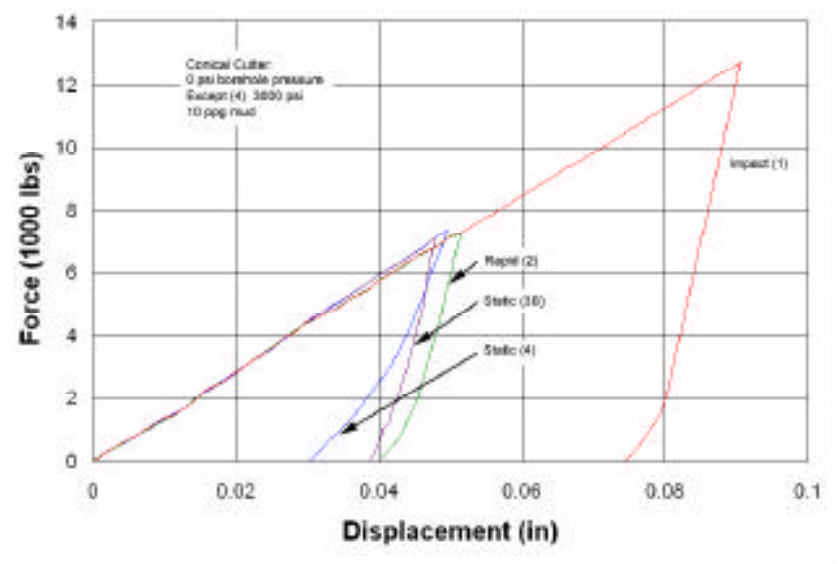

Figure 10. Calibration Tests on Aluminum Alloy 


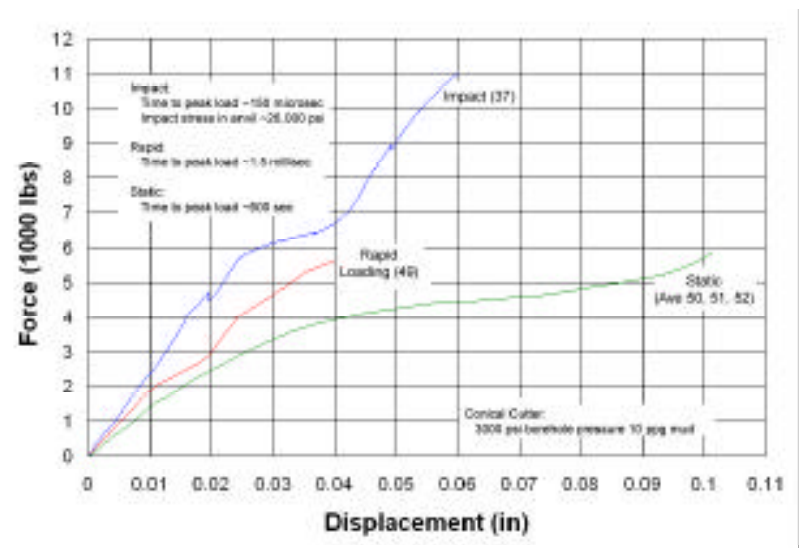

Figure 11. Type of Loadings Comparison (Carthage Marble)

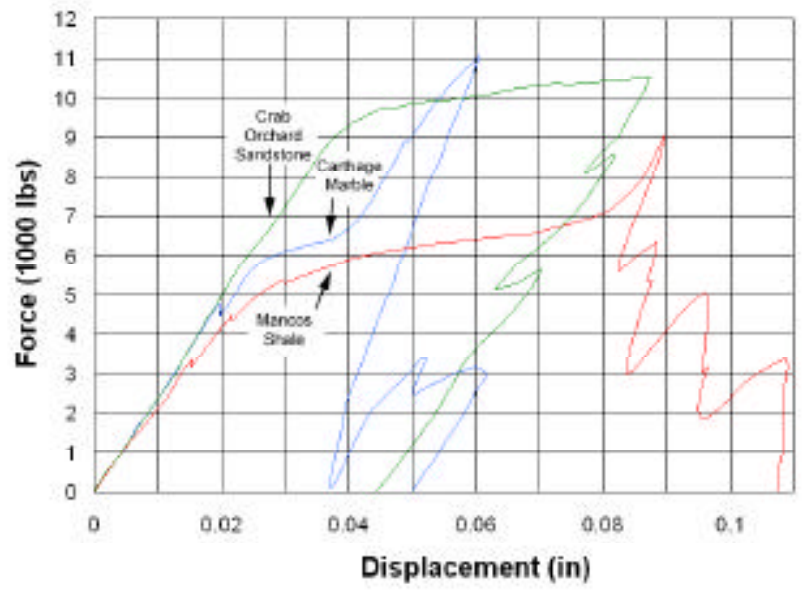

Figure 12. Comparison of Impact Loadings for Different Rocks Considered 


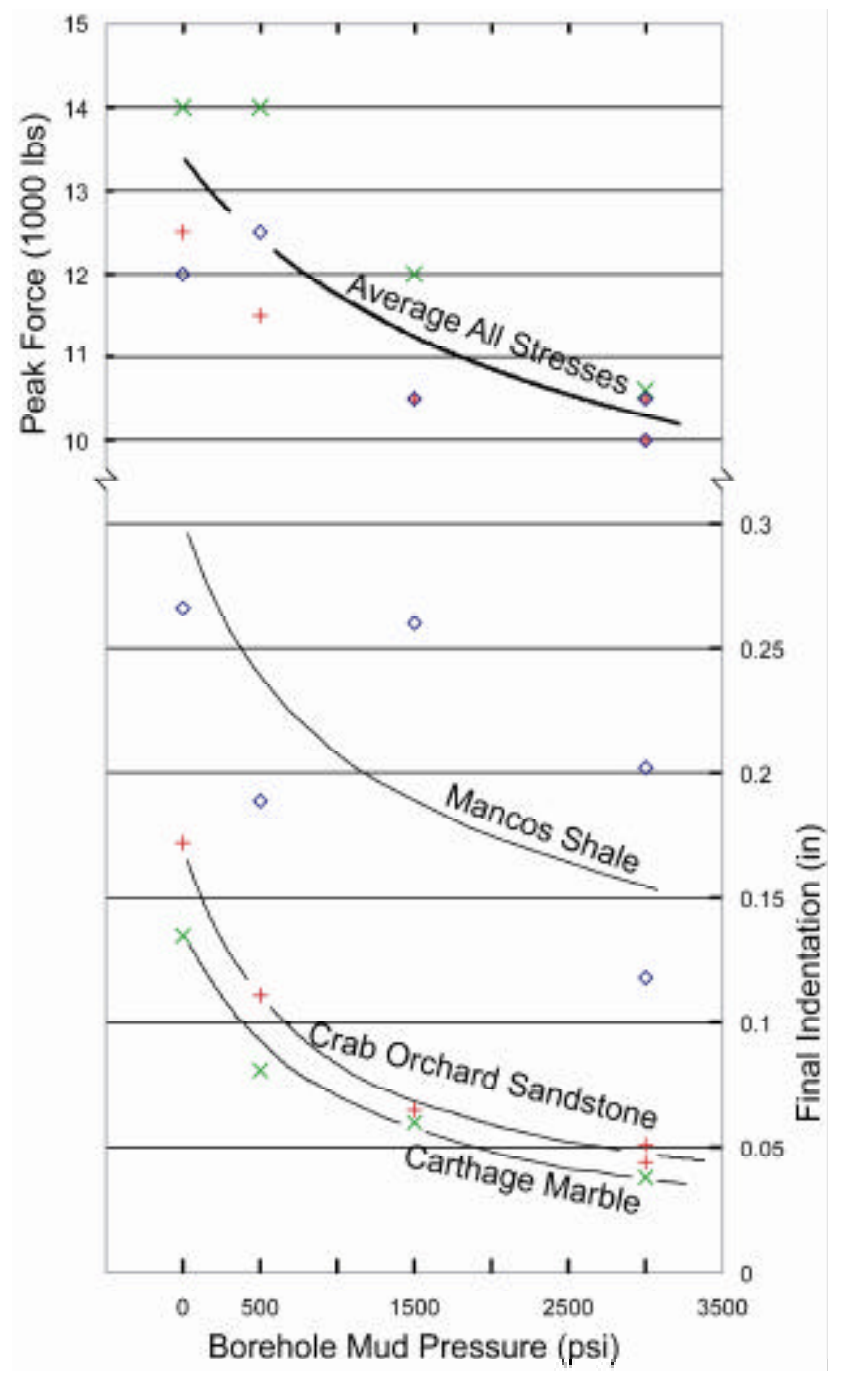

Figure 13. Effect of Increasing Borehole Mud Pressure

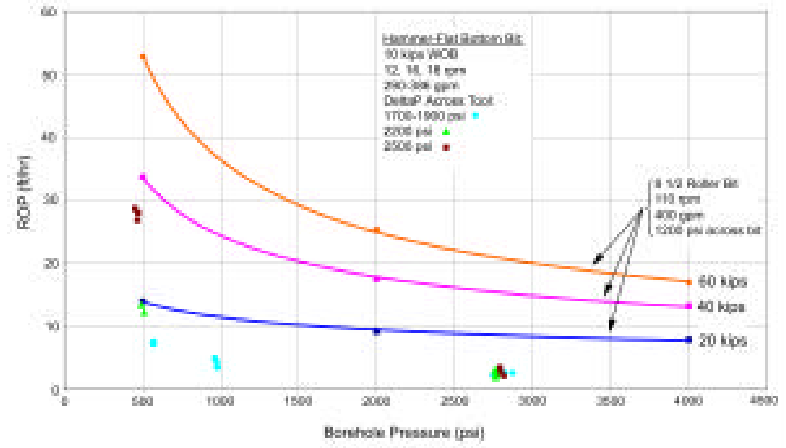

Figure 14. Full Scale Rotary and Hammer Drilling on Carthage Marble 


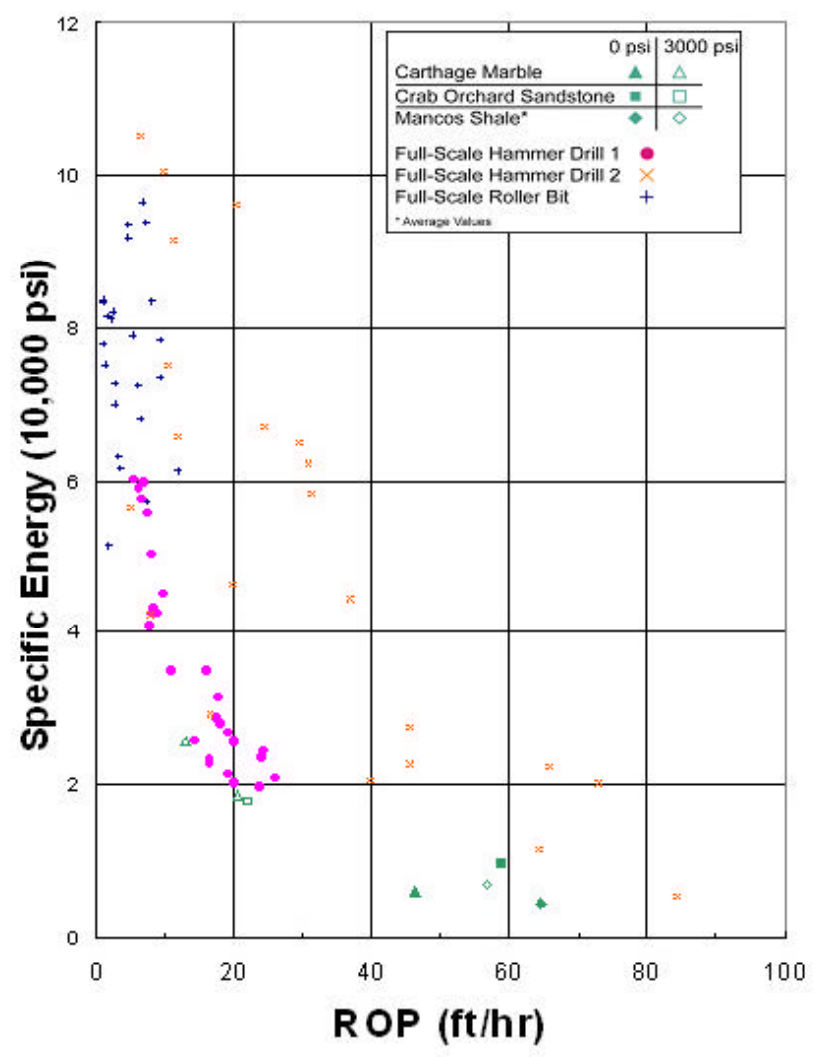

Figure 15. Specific Energy for Full Scale Laboratory Drilling and Single Cutter Impact Tests 


\section{CONCLUSIONS}

- Tasks $1,2,3,4$, and 5 are completed in the original format, now complete also with respect to Task 3 Smith tool benchmarking during 4Q 2002.

- Task 6 is complete having conducted a Planning Meeting and testing of Smith International's optimized tool. Novatek plans are still pending with the DOE in another program.

- Task 7 D2 completed with formal presentation / paper as encouraged by DOE/NETL at the SPE/IAD Drilling Conference. A couple additional publications in Drilling and Hart's E\&P (latter an editorial) further emphasized the results to date for the oil and gas industry. A recent publication at the request of DOE for a GTI Gas Technologies Conference was presented February 10, 2004. Also the submittal of the SPE manuscript for the 2005 Annual Meeting (SPE \# 97173) was completed in 2005.

- Task 8 work has been completed. Most experimental work was conducted during $3 \mathrm{Q}$ 2004. The expanded testing program was reported in 2005 and published in SPE 97173

- TerraTek was instrumented in organizing for DOE an Industry Review of the project entitled 'Fundamental Research on Percussion Drilling'. This was a task added in to the TerraTek program and partially paid through a sub-contract from Terralog.

- Large-scale testing of the optimized and redesigned Smith International fluid hammer at simulated downhole conditions was conducted during April 2004.

- Rates of penetration were much improved from Phase 1 benchmarking, in some cases significant improvements compared to baseline roller cone bits and ROPs noted above $10 \mathrm{ft} / \mathrm{hr}$. Industry Advisors had always hoped to exceed the $10 \mathrm{ft} / \mathrm{hr}$ drilling rate at high wellbore pressures - in some cases the Smith tool achieved that goal.

- The optimization process that Smith International used included a near doubling of blow energy (increased tool efficiency, more horsepower, and various internal component changes). There were some operational differences including the use of higher flow rates, a successful demonstration of an aggressive bit with chisel shaped cutters, and the use of a servo-control on the torque signal at TerraTek's drilling facility to better operate the hammer. 


\section{REFERENCES}

1. Ramirez, J., Geraud, M., Salazar, V., and Algate, G., "Fluid Percussion Drilling in Deep Hard Rock in Eastern Venezuela", SPE Paper 69520 presented at the SPE Latin American and Caribbean Petroleum Engineering Conference held in Buenos Aires, Argentina, 25-28 March, 2001.

2. Walker, B.H., Black, A.D., Klauber, W.P., Little, T., and Khodaverdian, M., "Roller-Bit Penetration Rate Response as a Function of Rock Properties and Well Depth", SPE Paper 15620 presented at the $61^{\text {st }}$ Annual Technical Conference and Exhibition of the Society of Petroleum Engineers held in New Orleans, LA 5-8 October, 1986.

3. Santos, H., Placido, J., Oliveira, J., and Gamboa, L., "Overcoming Hard Rock Drilling Challenges", IADC/SPE Paper 59182 presented at the 2000 IADC/SPE Drilling Conference held in New Orleans, Louisiana, 23-25 February 2000.

4. Tibbitts, G.A., Long, R.C., Miller, B.E., Judzis, A. and Black, A. D., "World's First Benchmarking of Drilling Mud Hammer Performance at Depth Conditions" IADC/SPE 74540 presented at the 2002 IADC/SPE Drilling Conference in Dallas Texas, 25-28 February 2002.

5. Lagreca, A., De Santana, D., Suarez, G., Rodriguez, M. (PDVSA), McInnes, M. (SDS Digger Tools), "Fluid Percussion Hammer Filed Test in the Alocthonous Cretaceous Block Eastern Venezuela", presented at the Petroleum Society's Canadian International Petroleum Conference 2002, Calagary, Alberta, Canada, June 11-13, 2002.

6. 'Mud-Hammer Drilling Performance', Journal of Petroleum Technology, December, 2002, pg 38.

7. Pixton, D., Sianguang, Y., Fryer, B., Payne, S., Hall, D., "A New Generation Mud Driven Rotary Percussion Tool:, Third Edition, February 15, 1995, Novatek, Provo, Utah.

8. Melamed, Y., Kiselev, A., Gelfgat, M., Dreesen, D., Blacic, J., "Hydraulic Hammer Drilling Technology: Development and Capabilities", Presented at Energy Week Conference \& Exhibition, ASME, January 28-30, 1997, Houston, Texas.

9. Deutsch, U., Marx, C., Rischmuller, "Evaluation of Hammerdrill - Potential for KTB in Super-Deep Continental Drilling and Deep Geophysical Sounding," K. Fuchs, Ed. Springer-Verlad, Berlin, pp. 310-321.

10. Rasheed, Wajid (Latin America Editor - Hart's E\&P) 'Mud Hammers Changing the Game', Drilling, American Association of Drilling Engineers, March, 2003, pp 16-18.

11. Ralf Luy, "Untersuchung zur Wirksamkeit des Bohrprozesses beim drehschlagenden Bohren unter hohen hydrostatischen Drucken", Dissertation Doktor-Ingeneurs, Technischen Universitat Clausthal (Germany), December 18, 1992.

12. Prasad, U., Mohanty, B., and Nemes, J., "Dynamic Strength and Fragmentation of Selected Rocks under Impact Loading”, Pacific Rocks 2000 'Rock around the 
Rim', Proceedings of the $4^{\text {th }}$ North American Rock Mechanics Symposium NARMS 2000, Seattle, 31 July - 3 August 2000, pgs. 577-581.

13. B. Bohloli, 1997, "Effects of geological parameters on rock blasting using the Hopkinson Split Bar", International Journal of Rock Mechanics \& Mining Sciences Vol. 3/4, p. 630.

14. Birkimer, D.L., 1971; “A Possible Fracture Criterion for the Dynamic Tensile Strength of Rock." 12 th US Symp. On Rock Mech. University of Missouri Rolla, Missouri. Clark, G.B. (editor): 573-590.

15. Christensen, R. 1972, "Hopkinson Bar Tests on Rocks Under Confining Pressure", $12^{\text {th }}$ US Rock Mechanics Symposium

16. Clark, G.B., 1987; "Principles of Rock Fragmentation”, John Wiley \& Sons, New York

17. Dupriest, F.E. and Koederitz, W.L., "Maximizing Drill Rates with Real-Time Surveillance of Mechanical Specific Energy", SPE/IADC 92194

18. Field. J.E. et al., 1994; "Experimental Methods at High Rates of Strain.” Journal de Physique IV, Colloque C8, Suppl. au Journal de Phy., Vol 4: C8-3-C8-22

19. Garnier, A.J. and Van Lingen, N.H., "Phenomena Affecting Drilling Rates at Depth", Trans AIME 216 (1959) 232-239.

20. Gnirk, P.F., and Cheatham, J.B., 1965; “An Experimental Study of Single BitTooth Penetration Into Dry Rock at Confining Pressures of 0 to 5,000 psi”, SPEU. of Texas Conference on Drilling and Rock Mechanics, Austin, TX, Jan 20-21, 1965.

21. Grady, D.E. and Kipp, M.E., 1987; “Dynamic Rock Fragmentation.”, Fracture Mechanics of Rock, B.K. Atkinson (ed), Academic Press Ltd. London.: 429-472.

22. Green, S.J. et.al. 1972, "Strength of Shales Under Confining Pressures", SPE 28763

23. Green, S.J. et. al. 1968, "Behavior of Rocks at High Strain Rates"; Journal of Geophysical Research

24. Green, S.J. et. al. 1976, "High Strain Rate Properties of Selected Rocks", US National Symposium on Rock Mechanics

25. Green, S.J. et. al., 1982, "Rock Properties at High Strain Rates”, NTS Annual Symposium, Sept 1982

26. Green, S.J. et. al. 1968, "Hopkinson Bar Tests on Several Rocks"; and Green, S.J. et. al. 1968, "Flat Plate Impact Experiments", Dept. of Defense, Symposium on Impact Dynamics, May 1968

27. Kolsky, H., 1949; "An Investigation of the Mechanical Properties of Materials at Very High Rates of Loading.", Proc. Roy. Soc., Vol B62: 676-700

28. Lipkin, J. et al., 1977, "Dynamic Flow and Fracture of Rock in Pure Shear", Proc.18th US Symposimu on Rock Mech. Keystone, Colorado: 3B2-1.

29. Maurer, W.C., 1965, "Bit-Tooth Penetration Under Simulated Borehole Conditions", SPE Annual Fall Meeting, Denver Colo, Oct. 3-6, 1965

30. Maurer, W. C., 1980, “Advanced Drilling Techniques”, Pennwell Corp.

31. Pessier, R.C., 1986, "Hughes Christensen Internal Product Research", Report \#46-09-17. 
32. Podio, A.L., and Gray, K.E., 1965, "Single-Blow Bit-Tooth Impact Tests on Saturated Rocks under Confining Pressure at Zero Pore Pressure", Soc. Pet. Eng. J., pp 211-224.

33. Rao, U. M. and Mishra, B., 1998; "Principles of Rock Drilling", A. A. Balkema Publishers

34. Robinson, L.H., 1958, "Effects of Pore and Confining Pressures on Failure Characteristics of Sedimentary Rocks", SPE Annual Fall Meeting, Houston, TX, Oct 5-8

35. Van Lingen, N.H., 1962, "Bottom Scavenging-a Major Factor Governing Penetration Rates at Depth", JPT pp 187-196

36. Yang, J. H., and Gray, K.E., 1967, "Single-Blow Bit-Tooth Impact Tests on Saturated Rocks under Confining Pressure: II. Elevated Pore Pressure", SPE 1702

37. Zhang, Z.X. et. al., 1999, "Effects of Loading Rate on Rock Fracture", Int. J. of Rock Mechanics and Mining Sc. Vol 36, pp 597-611 